\title{
Zur Struktur und Funktion regulatorischer Elemente des $c b b$-Regulons in Ralstonia eutropha
}

\author{
Dissertation \\ zur Erlangung des Doktorgrades \\ der Mathematisch-Naturwissenschaftlichen Fakultäten \\ der Georg-August-Universität zu Göttingen
}

vorgelegt von

Thomas Jeffke

aus Bremen

Göttingen 2000 
Die vorliegende Arbeit wurde am Institut für Mikrobiologie und Genetik der Georg-AugustUniversität zu Göttingen angefertigt.

Die Untersuchungen wurden durch Mittel der Deutschen Forschungsgemeinschaft im Rahmen des DFG-Schwerpunktprogramms „Molekulare Analyse von Regulationsnetzwerken in Bakterien“ und des Graduiertenkollegs „Chemische Aktivitäten von Mikroorganismen“ gefördert.

Ergebnisse dieser Arbeit wurden bereits veröffentlicht:

Jeffke T., Gropp N.-H., Kaiser C., Grzeszik C., Kusian B., Bowien B. (1999). Mutational analysis of the $c b b$ operon $\left(\mathrm{CO}_{2}\right.$ assimilation) promoter of Ralstonia eutropha. J. Bacteriol. 181, 4374-4380.

Grzeszik C., Jeffke T., Schäferjohann J., Kusian B., Bowien B. (2000). Phosphoenolpyruvate is a signal metabolite in transcriptional control of the $c b b \mathrm{CO}_{2}$ fixation operons in Ralstonia eutropha. J. Mol. Microbiol. Biotechnol. 2, 311-320.

D7

Referent: $\quad$ Prof. Dr. B. Bowien

Korreferent: $\quad$ Prof. Dr. G. H. Braus

Tag der mündlichen Prüfung: $\quad 31.01 .2001$ 
Meiner Mutter gewidmet 
Inhaltsverzeichnis $\quad$ I

$\begin{array}{lll}\text { Abkürzungen } & \text { VII }\end{array}$

1 EINLEITUNG 1

2 MATERIAL UND METHODEN

$\begin{array}{lll}\text { 2.1 } & \text { Organismen und Plasmide } & 7\end{array}$

$\begin{array}{lll}2.2 & \text { Nährmedien und Zellanzucht } & 11\end{array}$

2.2.1 Nährmedien für R. eutropha 11

2.2.2 Nährmedien für E. coli 12

$\begin{array}{ll}2.2 .3 \text { Antibiotika } & 13\end{array}$

$\begin{array}{ll}\text { 2.2.4 Anzuchtbedingungen } & 14\end{array}$

2.2.5 Bestimmung der Zelldichte 14

2.2.6 Stammhaltung und Reinheitskontrolle $\quad 15$

$\begin{array}{ll}\text { 2.2.7 Zellernte } & 15\end{array}$

$\begin{array}{lll}2.3 & \text { Zellaufschluß und Herstellung von Rohextrakten } & 15\end{array}$

2.4 Bestimmung von Enzymaktivitäten 16

2.4.1 B-Galactosidase 16

$\begin{array}{lll}2.5 & \text { Elektrophorese von Proteinen } & 17\end{array}$

$\begin{array}{ll}\text { 2.5.1 SDS-Polyacrylamid-Gelelektrophorese } & 17\end{array}$

$\begin{array}{ll}\text { 2.5.2 Coomassie Blue-Färbung } & 19\end{array}$

$\begin{array}{ll}2.5 .3 \text { Silberfärbung } & 19\end{array}$

$\begin{array}{llr}2.6 & \text { Western-Blot } & 20\end{array}$

2.7 Heterologe Genexpression in $E$. coli 21

2.7.1 Expression mit pUC18/19 oder pBBR1MCS2 21

2.7.2 Expression mit dem Impact-CN-System $\quad 21$

2.7.2.1 Unter Kontrolle des tac-Promotors in pCYB2 22 
2.7.2.2 Mit Hilfe des T7-RNA-Polymerase/Promotor-System in pTYB12 22

2.7.3 Expression mit dem T7-RNA-Polymerase/Promotor-System in pT7-7 22

2.8 Anreicherung der Proteine P1 und P2 aus R. eutropha 22

2.8.1 Herstellung der löslichen Proteinfraktion 22

2.8.2 Fraktionierte Ammoniumsulfat-Fällung 23

2.8.3 Hydrophobe Interaktionschromatographie 23

2.8.4 Kationenaustauschchromatographie $\quad 24$

2.8.5 Affinitätschromatographie an Streptavidin-Sepharose 24

2.9 Bestimmung einer N-terminalen Proteinsequenz 26

$\begin{array}{ll}2.10 & \text { Isolierung von Nucleinsäuren }\end{array}$

2.10.1 Vorbehandlung von Geräten und Lösungen 26

2.10.2 Phenolextraktion und Fällung von DNA 27

$\begin{array}{ll}2.10 .3 & \text { Isolierung von Gesamt-DNA } \\ \end{array}$

2.10.4 Isolierung von Plasmid-DNA 28

2.10.4.1 Analytische Präparation durch schnelles Kochen 28

2.10.4.2 Analytische Präparation durch alkalische Lyse 29

2.10.4.3 Präparative Isolierung mit dem ‘QIAprep Miniprep’ 30

2.10.4.4 Präparative Isolierung durch alkalische Lyse $\quad 30$

2.10.5 Isolierung von DNA-Fragmenten aus Agarosegelen 31

2.10.5.1 Mit dem 'QIAquick Gel Extraction Kit' 31

2.10.5.2 Aus niedrigschmelzender Agarose $\quad 31$

$\begin{array}{ll}\text { 2.11 Konzentrationsbestimmung von Nucleinsäuren } & 31\end{array}$

2.12 Enzymatische Modifikation von DNA 32

2.12.1 Restriktionsspaltung 32

2.12.2 Dephosphorylierung 32

2.12.3 Auffüllen überstehender 5' -Enden 32

2.12.4 Ligation von DNA-Fragmenten 33

2.12.5 Radioaktive Markierung durch PCR 33

2.12.6 Radioaktive Markierung von Oligonucleotiden 34 
2.13 Selektion rekombinanter Klone von $E$. coli

2.13.1 Herstellung kompetenter Zellen für die Transformation 35

2.13.2 Transformation 35

2.13.3 Selektion rekombinanter Klone 36

2.14 Konjugative Plasmidübertragung 36

2.15 Gelelektrophoretische Auftrennung von Nucleinsäuren $\quad 37$

2.15.1 Agarose-Gelelektrophorese 37

2.15.2 LMP-Agarose-Gelelektrophorese 38

2.15.3 Polyacrylamid-Harnstoff-Gelelektrophorese 38

2.16 Gelretardation von DNA-Protein-Komplexen 39

2.16.1 In der nicht-denaturierenden PAGE $\quad 40$

2.16.2 In Agarosegelen $\quad 41$

2.17 Sequenzierung von DNA $\quad 42$

2.17.1 Radioaktive Sequenzierung durch 'cycle sequencing' 42

$\begin{array}{lll}2.18 & \text { DNA-DNA-Hybridisierung } & 43\end{array}$

2.18.1 Southern-Blotting 43

2.18.2 Radioaktive Hybridisierung 44

$\begin{array}{lll}2.19 & \text { Autoradiographie } & 45\end{array}$

$\begin{array}{lll}\text { 2.20 PCR-Methoden } & 45\end{array}$

2.20.1 Standard-PCR 45

$\begin{array}{ll}2.20 .2 \text { Touchdown-PCR } & 47\end{array}$

2.20.3 Ortspezifischer Mutagenese durch asymmetrische PCR 47

$\begin{array}{ll}\text { 2.21 Chemikalien und Materialien } & 49\end{array}$

3 EXPERIMENTE UND ERGEBNISSE

$\begin{array}{lll}3.1 & \text { Stand der Vorarbeiten } & 51\end{array}$

3.2 Bindung von Proteinen an die $c b b$-Kontrollregion von $R$. eutropha H16 52 
3.3 Anreicherungen von P1 und P2 aus R. eutropha HB14 56

3.3.1 Fraktionierte Ammoniumsulfatfällung $\quad 57$

3.3.2 Hydrophobe Interaktionschromatographie $\quad 57$

3.3.3 Kationenaustauschchromatographie $\quad 59$

3.3.4 DNA-Affinitätschromatographie $\quad 61$

3.3.5 Ergebnis der Anreicherung von P1 und P2 62

3.3.6 N-terminale Aminosäuresequenz von P1 64

$\begin{array}{lll}\text { 3.3.6.1 Ableitung degenerierter Oligonucleotide } & 65\end{array}$

3.4 Untersuchungen zur Identität von P2 66

3.4.1 Deletion von phcA in R. eutropha $\quad 67$

$\begin{array}{lll}\text { 3.4.1.1 Konstruktion des Suizidvektors pNHG } \Delta p h c A & 67\end{array}$

3.4.1.2 Isolierung von Homogenoten $\quad 69$

3.4.1.3 Verifikation der phcA-Deletion durch PCR 70

3.4.2 'Mobility shifts' mit Rohextrakten der Deletionsmutanten 72

3.4.3 Phänotypische Charakterisierung der phcA-Deletionsmutanten 72

3.5 DNA-Bindungsstudien mit PhcA (P2), PhcA*, CbbR und P1 75

3.5.1 Heterologe Expression von $p h c A / p h c A *$ und $c b b R$ in E. coli 76

$\begin{array}{lll}\text { 3.5.1.1 Expressionsanalyse im 'mobility shift' } & 77\end{array}$

3.5.2 Expression in E. coli mit dem Impact-CN-System 78

3.5.2.1 Konstruktion und Expression $\operatorname{der} p h c A / p h c A$ *-Intein-Fusionsgene $\quad 78$

$\begin{array}{lll}\text { 3.5.2.2 Expressionsanalyse im 'mobility shift' } & 80\end{array}$

3.5.3 Identifikation der Bindungsregion von P1 und PhcA 80

3.5.3.1 Amplifikation von Subfragmenten der $c b b$-Kontrollregion durch PCR 81

3.5.3.2 Identifikation der Bindungsregion von P1 83

3.5.3.3 Identifikation der PhcA*-Bindungsregion 86

3.5.4 Bindungsstudien mit P1, PhcA (P2) und PhcA* 88

3.5.5 Bindungsstudien mit CbbR und P1 89

3.6 Analyse der durch P1, PhcA* und CbbR induzierten DNA-Krümmungen 91

3.6.1 Amplifikation von Fragmenten der $c b b$-Kontrollregion 91 
3.6.2 P1-induzierte DNA-Krümmung 93

3.6.3 CbbR- und PhcA*- induzierte DNA-Krümmungen 95

3.6.4 P1-CbbR- und P1-PhcA*-induzierte DNA-Krümmungen 98

3.7 Effekte potentieller Signalmetaboliten des $c b b$-Systems 99

3.7.1 Beeinflussung der Bindungsaffinität von CbbR durch PEP 100

3.7.2 Einfluß des intrazellulären PEP-Spiegels auf die heterologe Aktivität des cbb-Operonpromotors in E. coli 102

3.7.3 Suche nach potentiellen Effektoren von P1 103

3.8 Strukturelle und funktionelle Analyse der $c b b$-Promotoren $\quad 104$

3.8.1 Erzeugung von Promotormutationen durch gerichtete Mutagenese 104

3.8.2 Aktivitäten der mutierten $c b b$-Operonpromotoren in R. eutropha 107

3.8.3 Aktivitäten der mutierten $c b b$-Operonpromotoren in E. coli 109

3.8.4 Aktivitäten der $c b b$-Promotoren in Subfragmenten der $c b b$-Kontrollregion $\quad 110$

$\begin{array}{lll}3.8 .4 .1 & c b b \text {-Operonpromotor } & 110\end{array}$

$\begin{array}{lll}3.8 .4 .2 & c b b R \text {-Promotor } & 112\end{array}$

4 DISKUSSION 115

$\begin{array}{lll}\text { 4.1 Regulation von } c b b \text {-Operonen durch CbbR } & 115\end{array}$

4.2 Identifikation eines PhcA-Homologs in R. eutropha 116

4.2.1 Funktion von PhcA und PhcA* in R. eutropha H16 und HB14R 119

4.2.1.1 PhcA in R. solanacearum und R. eutropha 119

$\begin{array}{lll}\text { 4.2.1.2 PhcA* ersetzt CbbR in der Mutante HB14R } & 123\end{array}$

4.3 Struktur und Funktion der $c b b$-Promotoren $\quad 124$

4.3.1 Strukturelle Analyse des $c b b$-Operonpromotors $p_{c b b L} \quad 124$

$\begin{array}{ll}\text { 4.3.2 Aktivität des } c b b R \text {-Promotors } p_{c b b R} & 127\end{array}$

4.4 Phosphoenolpyruvat als negativer Effektor von CbbR 129

4.4.1 Einfluß von PEP auf die DNA-Bindung von CbbR 130

4.4.2 PEP-abhängige Regulation von $p_{c b b L}$ in E. coli 131

4.5 P1 als potentieller Modulator des $c b b$-Systems 132 
4.5.1 Zur Identität von P1 132

4.5.2 Funktionen von P1 und CbbR bei der Aktivierung von $p_{c b b L}$

4.5.3 Vergleich mit anderen LTTR-regulierten Systemen 137

4.5.4 Modell für die $c b b$-Regulation $\quad 139$

$\begin{array}{lll}4.6 & \text { Ausblick } & 141\end{array}$

5 ZUSAMMENFASSUNG

6 LITERATURVERZEICHNIS 145 


\section{Abkürzungen}

A

$\mathrm{Ap}^{\mathrm{r}}$

ATP

bidest.

Bis

$b(p)$

$\mathrm{C}$

$\mathrm{Ci}$

cos

CTAB

d

D

$\mathrm{Da}$

dATP

dCTP

dGTP

dTTP

dNTP

DMF

DMSO

DNA

DNase

DTT

$\varepsilon$

$\mathrm{E}$

EC

EDTA

et al.

$\mathrm{F}$

G

h

$\mathrm{H}$

HIC

I

IVTS

IPTG

$\mathrm{K}$

KAC

$\mathrm{kb}$

$\mathrm{Km}^{\mathrm{r}}$

$\mathrm{L}$

LB

LMP

LTTR

$\mathrm{M}$
Adenin, Alanin

Ampicillinresistenz

Adenosin-5'-triphosphat

zweimal destilliert

N,N-Methylen-bis-Acrylamid

Basenpaare (DNA)/Basen (RNA)

Cystein, Cytosin

Curie

Kosinus

Hexadecyltrimethylammoniumbromid

Desoxy-, Küvettenschichtdicke, Tag

Asparaginsäure

Dalton

Desoxyadenosin-5'-triphosphat

Desoxycytosin-5'-triphosphat

Desoxyguanosin-5'-triphosphat

Desoxythymidin-5'-triphosphat

Desoxynucleosid-5'-triphosphat

N,N'-Dimethylformamid

Dimethylsulfoxid

Desoxyribonukleinsäure

Desoxyribonuclease

Dithiothreit

Extinktionskoeffizient

Glutamat

Enzymkommission (Enzyme Commission)

Ethylendiamintetraessigsäure

et alteri (und andere)

Phenylalanin

Glycin, Guanin

Stunde

Histidin

Hydrophobe Interaktionschromatographie

Isoleucin

In vitro-Transkriptionssystem

Isopropyl- $\beta$-thiogalactopyranosid

Lysin

Kationenaustauschchromatographie

Kilobasen(paare)

Kanamycinresistenz

Leucin

Luria Bertani

niedriger Schmelzpunkt (low melting point)

LysR-Typ-Transkriptionsregulatoren

Methionin, molar 


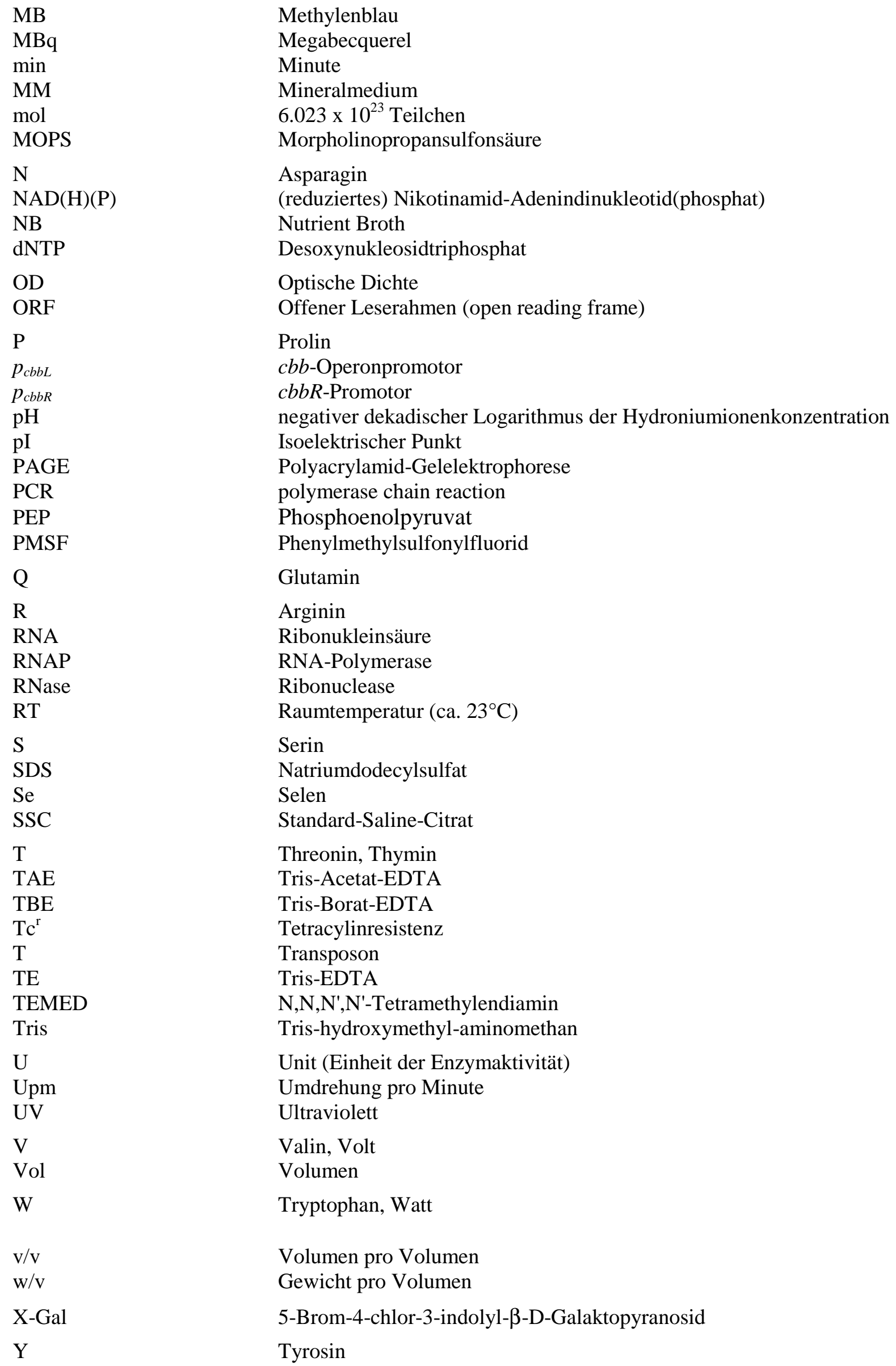




\section{EINLEITUNG}

Prokaryonten sind aufgrund ihrer metabolischen und strukturellen Diversität in der Lage, nahezu alle ökologischen Nischen zu besiedeln. Da sie im direkten Kontakt mit dem sie umgebenden Milieu stehen, sind schnelle Anpassungsmechanismen erforderlich, die es ihnen ermöglichen, auf oft drastische Umweltveränderungen effizient $\mathrm{zu}$ reagieren. Diese Adaptation läuft auf zwei unterschiedlichen Ebenen ab. Während eine sofortige metabolische Reaktion auf enzymatischem Niveau stattfindet, erfolgt eine verzögerte, aber längerfristige Veränderung über die Kontrolle der Genexpression. Für eine effiziente Anpassung und ökonomische Verwendung der Zellresourcen ist eine entsprechende Regulation der Genexpression essentiell. Die Regulationsmechanismen sind hierbei hierarchisch organisiert. An erster Stelle stehen globale Regulationsnetzwerke, wie z.B. das CRP-Modulon im Rahmen der Katabolitrepression (Busby \& Kolb, 1996), das in Interaktion mit dem PTS-System (Postma et al., 1993), einem Signaltransduktionssystem, steht, wobei die Signalvermittlung über einen Signalmetaboliten, den 'second messenger' cAMP (Botsford \& Harman, 1992) erfolgt. Die übergeordnete Regulation besteht in der Aktivierung oder auch Repression untergeordneter Einheiten, die in Form von Regulonen, Operonen oder Einzelgenen vorliegen. Diese können ihrerseits ebenfalls regulatorische Funktionen auf weiter untergeordnete Systeme ausüben oder tragen bereits zur direkten Umsetzung der adaptiven Antwort bei. Der eigentliche Regulationsmechansimus bei der Transkription beruht im wesentlichen auf der Aktivität DNA-bindender Proteine, die im komplexen Zusammenspiel mit weiteren regulatorischen Elementen wie Effektoren oder auch spezifischen Promotorstrukturen als Aktivatoren, Modulatoren oder auch Repressoren in Interaktion mit der RNA-Polymerase fungieren.

Ralstonia eutropha ist ein aerobes, fakultativ chemolithoautotrophes Bakterium, das zur Gruppe der B-Proteobakterien gehört (Stackebrandt, 1988; Yabuuchi et al., 1995). Während des autotrophen Wachstums fixiert $R$. eutropha $\mathrm{CO}_{2}$ über den Calvin-BensonBassham(CBB)-Cyclus (Bassham et al., 1954), dem qualitativ wichtigsten Stoffwechselweg zur Assimilation von $\mathrm{CO}_{2}$ (Ellis, 1979). Im Gegensatz zu den Eukaryonten sind bei den Prokaryonten noch drei weitere Wege der $\mathrm{CO}_{2}$-Assimilation bekannt, der reduktive Tricarbonsäurecyclus (Fuchs et al., 1980), der reduktive Acetyl-CoA-Weg (Wood et al., 1986; Fuchs et al., 1989) und der 3-Hydroxypropionat-Cyclus (Holo, 1989; Eisenreich et al., 1989; Straus \& Fuchs, 1993). 
Unter autotrophen Wachstumsbedingungen gewinnt $R$. eutropha die für die Assimilation von $\mathrm{CO}_{2}$ benötigte Energie aus der Oxidation von Wasserstoff oder Formiat, sein Stoffwechselmodus ist demnach litho- bzw. organoautotroph. Die Oxidation von Wasserstoff wird durch zwei unterschiedliche Hydrogenasen katalysiert, von denen eine membrangebunden vorliegt (Schink und Schlegel, 1979), während die zweite ein NAD ${ }^{+}$-reduzierendes Enzym ist (Schneider und Schlegel, 1976), das in gelöster Form im Cytoplasma lokalisiert ist. In ähnlicher Weise findet die Oxidation von Formiat durch eine lösliche NAD ${ }^{+}$-abhängige und eine membrangebundene Formiat-Dehydrogenase statt (Friedrich et al., 1979; Friedebold \& Bowien 1993). Heterotroph verwendet $R$. eutropha eine große Vielfalt organischer Substrate, hauptsächlich organische Säuren aber auch Aromaten. Zucker sind dagegen keine bevorzugten Substrate, lediglich die Hexosen Fructose und - nicht bei allen Stämmen Glucose sowie die Zuckersäure Gluconat werden über den Entner-Doudoroff-Weg abgebaut (Bowien \& Schlegel, 1981).

Beim Wechsel zwischen der energetisch sehr aufwendigen Autotrophie und der Heterotrophie ist es für fakultativ autotrophe Organsimen geboten, die benötigten Stoffwechselwege, sowohl direkt auf metabolischer als auch auf genetischer Ebene zu regulieren. Das wird am hohen Bedarf an Energie und Reduktionskraft bei der Synthese eines Moleküls Glycerinaldehyd-3phosphat aus $3 \mathrm{CO}_{2}$ deutlich, der 6 ATP und 9 NADH beträgt (Shively et al., 1998). Während auf enzymatischer Ebene vor allem die Schlüsselenzyme des Calvin-Cyclus, Ribulose-1,5bisphosphat-Carboxylase/Oxygenase (RubisCO) und Phosphoribulokinase (PRK) die Hauptangriffspunkte der Regulation in R. eutropha H16 darstellen (Bowien, 1989), unterliegen die Gene der Enyzme des Calvin-Cyclus, die $c b b$-Gene, einer strikter Regulation auf transkriptioneller Ebene (Friedrich et al., 1981; Kusian \& Bowien, 1997). Dabei erlaubt die Anordnung der $c b b$-Gene innerhalb zweier hochgradig homologer $c b b$-Operone eine koordinierte Regulation (Bowien, 1996; Abb. 1A). Bis auf die Triosephosphat-Isomerase und die Ribose-5-phosphat-Isomerase sind alle Enzyme des Cyclus innerhalb dieser beiden $c b b$ Operone codiert, von denen sich eines auf einem der beiden Chromosome befindet, während das zweite auf dem Megaplasmid pHG1 von Stamm H16 lokalisiert ist (Kossmann et al., 1989; Windhövel \& Bowien, 1990a; Bednarski, 1992; Kusian et al., 1992; Schäferjohann et al., 1993, 1995; Yoo \& Bowien, 1995; Bömmer et al., 1996) und sich dort in umittelbarer Nähe der Gene des Hydrogenasesystems (hox) befindet (Friedrich \& Schwartz, 1993). Die Funktionen der Gene $c b b X$ und $c b b Y$ konnten bisher noch nicht aufgeklärt werden. Gleiches gilt für $c b b B$, das als einziges Strukturgen in nicht duplizierter Form nur im chromosomalen 
A

\section{Plasmid pHG1}
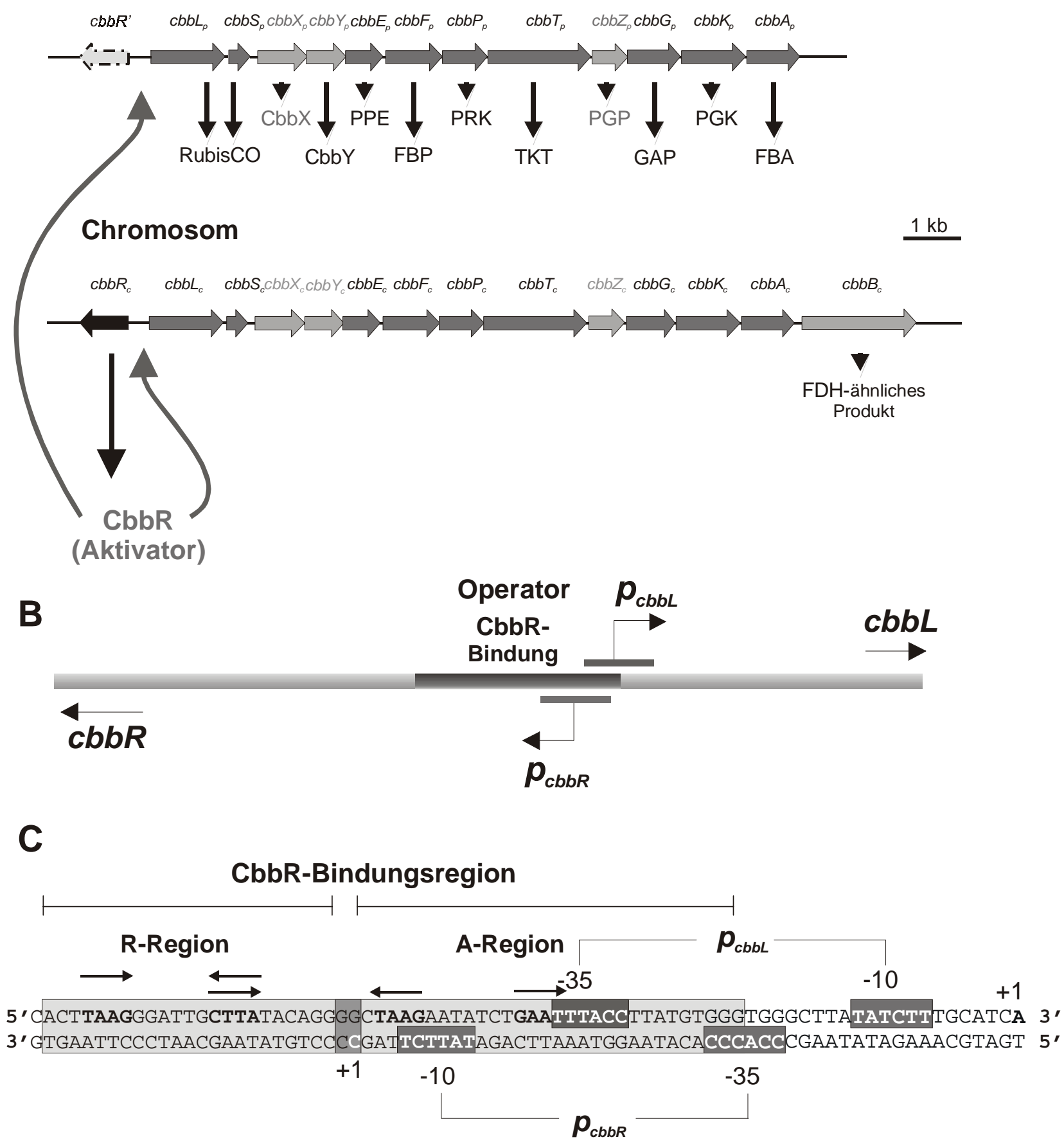

Abb. 1. Organisation der $c b b$-Gene (A), schematische Darstellung der intergenen $c b b$ Kontrollregionen (B) und Sequenz der überlappenden Operator-PromotorRegion innerhalb der chromsomalen $\boldsymbol{c} b \boldsymbol{b}$-Kontrollregion (nach Bowien et al., 1993; Kusian \& Bowien, 1995; Schäferjohann et al. 1996). A: Gen- und Proteinbezeichnungen mit ensprechenden Abkürzungen; $c b b L$, große Untereinheit der Ribulose-1,5-bisphosphat-Carboxylase/Oxygenase (RubisCO); $c b b S$, kleine Untereinheit der RubisCO; $c b b X$ und $c b b Y$, Produkte mit unbekannter Funktion; $c b b E$, Pentose-5-phosphat-3-Epimerase (PPE); $c b b F$, Fructose-1,6-bisphosphatase /Sedoheptulose-1,7-bisphosphatase (FBP); 
$c b b P$, Phosphoribulokinase (PRK); $c b b T$, Transketolase (TKT); cbbZ, 2Phosphoglycolat-Phosphatase (PGP); $c b b G$, Glycerinaldehyd-3-phosphat-Dehydrogenase (GAP); $c b b K$, Phosphoglycerat-Kinase (PGK); $c b b A$, Fructose-1,6bisphosphat-/Sedoheptulose-1,7-bisphosphat-Aldolase (FBA); $c b b B$, Produkt mit unbekannter Funktion, ähnelt Formiat-Dehydrogenase); $c b b R$, Aktivator (CbbR), $c b b R$ ', defekte Kopie von $c b b R$. B: Die Positionen der CbbR-Bindungsregion (Operator, dunkel unterlegt) sowie des $c b b$-Operonpromotors $p_{c b b L}$ und des $c b b R$ Promotors $p_{c b b R}$ (Balken) sind dargestellt. Die relative Lage und Orientierung der Gene $c b b L$ und $c b b R$ sind durch Pfeile angezeigt. C: CbbR-Bindungsregion (hell unterlegt) mit der R-Region und der A-Region. Die Pfeile zeigen die Struktur der unvollständigen Palindrome des Bindungsmotivs von CbbR an. Dunkel unterlegt sind die ' -35 '- und '-10'-Regionen von $p_{c b b L}$ und $p_{c b b R}$.

Operon vorliegt und ein dem Formiat-Dehydrogenasen ähnliches Protein mit unbekannter Funktion codiert.

Die strikte Regulation der $c b b$-Operone von $R$. eutropha beruht auf einer direkten Abhängigkeit von den zur Verfügung stehenden Kohlstoff- und Energiequellen (Friedrich et al., 1981; Kusian \& Bowien, 1997). Eine starke Expression der $c b b$-Operone erfolgt unter litho- und organoautotrophen Wachstumsbedingungen mit Wasserstoff bzw. Formiat als Energiequelle. Ein zusätzlicher Anstieg der Expression ist unter $\mathrm{CO}_{2}$-limitierenden Bedingungen zu beobachten (Friedrich, 1982; Kusian \& Bowien, 1997). Im Gegensatz dazu verursacht heterotrophes Wachstum mit z.B. Pyruvat oder Succinat eine vollständige Repression der $c b b$-Operone. Einige Substrate, wie Fructose oder Gluconat, bewirken hingegen eine teilweise Derepression, die bis zu zwei Drittel des unter autotrophen Bedingungen beobachteten Expressionsniveaus betragen kann. Das Phänomen der heterotrophen Derepression tritt so ausgeprägt nur bei Stämmen von $R$. eutropha auf, die das Megaplasmid pHG1 beherbergen und wurde bei Wildtypstämmen bisher nur bei $R$. eutropha H16 beobachtet. (Bowien et al., 1984; Windhövel \& Bowien 1990b). Mixotrophes Wachstum ist bei $R$. eutropha unter anderem durch gleichzeitige Verwertung von Fructose und Formiat möglich, wobei eine Induktion des $c b b$-Operons unabhängig von der Gegenwart des Megaplasmids pHG1 auf annähernd autotrophem Niveau stattfindet (Im \& Friedrich, 1983; Kusian \& Bowien, 1997).

Die koordinierte Expression der beiden $c b b$-Operone von $R$. eutropha H16 in Form eines Regulons wird primär durch den chromosomal codierten Aktivator CbbR gesteuert (Windhövel \& Bowien, 1991; Kusian \& Bowien, 1995), dessen Strukturgen 167 bp 
stromaufwärts vom ersten Strukturgen des $c b b$-Operons, $c b b L$, in divergenter Orientierung lokalisiert ist. In dem entsprechenden Bereich befindet sich auf dem Megaplasmid pHG1 ein defektes Gen (cbbR', Abb. 1A; Windhövel \& Bowien, 1991). CbbR gehört zur Familie der bakeriellen Transkriptionsregulatoren vom LysR-Typ (LTTR; Henikoff et al., 1988; Schell, 1993) und ist für die Aktivierung der $c b b$-Operone essentiell, was anhand einer Inaktivierung von $c b b R$ durch Tn5-Mob-Insertion (Windhövel \& Bowien, 1991) und durch direkte Deletion des Gens (Jeffke et al., 1999) gezeigt wurde.

Die jeweilige Kontrollregion der $c b b$-Operone befindet sich in dem 167 bp langen, intergenen Bereich zwischen $c b b L_{c} / c b b L_{p}$ und $c b b R / c b b R^{\prime}$ (Kusian \& Bowien, 1995). Sie ist bei beiden Operonen nahezu identisch und beinhaltet neben dem $c b b$-Operonpromotor $p_{c b b L}$ den Promotor $p_{c b b R}$ des Aktivatorgens sowie den Operator (CbbR-Bindungsregion; Abb. 1B). Die CbbR-Bindungsregion überlappt mit der '-35'-Region von $p_{c b b L}(\mathrm{Abb} .1 \mathrm{C})$, eine generelle Konfiguration wie sie häufig bei LTTR-regulierten Systemen zu beobachten ist. Innerhalb der CbbR-Bindungsregion liegen zwei voneinander getrennte CbbR-Bindungsstellen vor, die aufgrund ihrer relativen Position $\mathrm{zu} p_{c b b L}$ und ihrer vermutlichen Funktion als R-Region ('recognition region'; $c b b R$-seitig) und A-Region ('activation region'; $c b b L$-seitig) bezeichnet werden. Eine Analyse der differentiellen Genexpression einzelner Gene innerhalb des $c b b$ Operons ergab, daß die relativ erhöhte Expression der $c b b L S$-Gene auf einer vorzeitigen Transkriptionstermination durch eine unmittelbar stromabwärts von $c b b L S$ lokalisierte Haarnadelstruktur zurückzuführen ist (Schäferjohann et al., 1996). Subpromotoren innerhalb der $c b b$-Operone wurden nicht gefunden.

$\mathrm{Zu}$ den Charakteristika der LTTR, wie CbbR, gehört ein im N-terminalen Bereich der Proteine lokalisiertes, stark konserviertes Helix-Turn-Helix-DNA-Bindemotiv (Harrison, 1991). Als Aktivatoren der von ihnen regulierten Gene stehen die LTTR meist in direkter Interaktion mit Effektoren aus ihrem umittelbaren metabolischen Umfeld, die intrazellulären oder externen Ursprungs sein können (Schell, 1993). Für die durch CbbR vermittelte Regulation ist (sind) im Sinne einer physiologisch sinnvollen Aktivierung der $c b b$-Operone (ein) intrazelluläre(r) Signalmetabolit(e) aus dem Energiestoffwechsel und/oder dem zentralen Kohlenstoffmetabolismus denkbar. Tatsächlich wurde Phosphoenolpyruvat (PEP) als negativer Effektor von CbbR bereits identifiziert (Grzeszik et al., 2000). Nach wie vor zu klären bleibt jedoch die Frage, ob die Regulation der $c b b$-Operone allein durch CbbR erfolgt, oder dazu ein weiterer Regulator/Modulator benötigt wird. Auf letztere Möglichkeit deuten verschiedene Befunde hin. So zeigten Studien, die im CbbR-freien Hintergrund einer $c b b R$ - 
Deletionsmutante und Promotormutanten von $p_{c b b L}$ durchgeführt worden waren, daß das generelle Regulationsmuster des $c b b$-Systems auch in Abwesenheit von CbbR prinzipiell, wenn auch auf sehr niedrigem Niveau, erhalten blieb (Jeffke et al., 1999).

Ziel der vorliegenden Arbeit war es daher, die bereits identifizierten regulatorischen Komponenten des $c b b$-Systems von $R$. eutropha H16 in ihrer Funktionsweise näher zu charakterisieren und weitere potentielle Regulatoren/Modulatoren $\mathrm{zu}$ identifizieren, die zusammen mit CbbR an der Kontrolle der cbb-Operone beteiligt sein könnten. Durch ortspezifische Mutagenese innerhalb von $p_{c b b L}$ sollte eine eingehende Verifizierung der zuvor nur abgeleiteten Position, sowie eine strukturelle und funktionelle Analyse des Promotors erfolgen. Im Hinblick auf die Funktionsweise des negativen CbbR-Effektors PEP wurden Bindungsstudien mit dem Aktivator und der $c b b$-Kontrollregion durchgeführt. Diese Untersuchungen wurden durch In vivo-Studien im heterologen System von E. coli abgesichert, wobei die Aktivitäten von $p_{c b b L}$ bei unterschiedlichen intrazellulären PEPKonzentrationen überprüft wurden. Im Zentrum des Interesses stand jedoch die Anreicherung, Identifikation und Charakterisierung zweier Proteine, P1 und P2, die wie CbbR spezifisch an die $c b b$-Kontrollregion binden und als zusätzliche Regulatoren des $c b b$-Systems in Betracht kamen. 


\section{MATERIAL UND METHODEN}

\subsection{Organismen und Plasmide}

Im Rahmen dieser Arbeit verwendete Stämme von Ralstonia eutropha und Escherichia coli, sowie bereits vorhandene und neukonstruierte Plasmide sind mit ihren entsprechenden phänobzw. genotypischen Eigenschaften und ihrer Herkunft nach in den Tabellen 1-3 aufgeführt.

Tab. 1. Stämme von Ralstonia eutropha

\begin{tabular}{|c|c|c|}
\hline Stamm & Relevanter Phäno- und Genotyp & Referenz \\
\hline H16 & $\mathrm{Cfx}^{+}, \mathrm{Hox}^{+} ; \mathrm{pHG}^{+}$ & DSM 428, ATCC 17699 \\
\hline HF210 & $\mathrm{Sm}^{\mathrm{r}}, \mathrm{Cfx}^{+}, \mathrm{Hox}^{-}, \mathrm{pHG}^{-}$ & $\begin{array}{l}\text { Kortlüke \& Friedrich } \\
\text { (1992) }\end{array}$ \\
\hline HB14 & $\begin{array}{l}\mathrm{Cfx}^{-}, \mathrm{Hox}^{+} ; \mathrm{pHG}^{+} ; \Delta c b b R \\
\text { Mutante von } \mathrm{H} 16\end{array}$ & $\begin{array}{l}\text { Jeffke et al. (1997) \& } \\
\text { B. Bowien }\end{array}$ \\
\hline HB14R & $\begin{array}{l}\mathrm{Cfx}^{+}, \mathrm{Hox}^{+} ; \mathrm{pHG}^{+} ; \Delta ; c b b R p h c A^{*} \\
\text { Phänotypische Revertante von HB14 }\end{array}$ & D. Oed \& B. Bowien \\
\hline HB15 & $\begin{array}{l}\mathrm{Sm}^{\mathrm{r}}, \mathrm{Cfx}^{-}, \mathrm{Hox}^{-}, \mathrm{pHG}^{-} ; \text {cbbR } \\
\text { Mutante von HF210 }\end{array}$ & G. Stahlhut \& B. Bowien \\
\hline HB16 & $\begin{array}{l}\mathrm{Cfx}^{+}, \mathrm{Hox}^{+} ; \mathrm{pHG}^{+} ; \Delta p h c A \\
\text { Mutante von } \mathrm{H} 16\end{array}$ & Diese Arbeit \\
\hline HB17 & $\begin{array}{l}\mathrm{Cfx}^{-}, \mathrm{Hox}^{+} ; \mathrm{pHG}^{+} ; \Delta p h c A \\
\text { Doppelmutante von } \mathrm{H} 16\end{array}$ & Diese Arbeit \\
\hline
\end{tabular}

Phänotypbezeichnung: Cfx, $\mathrm{CO}_{2}$-Fixierung; Hox, Wasserstoffoxidation; $\mathrm{Sm}^{\mathrm{r}}$, Streptomycinresistenz; pHG1, Megaplasmid; $p h c A^{*}$ (mutiertes $p h c A$ ).

Tab. 2. Stämme von Escherichia coli

\begin{tabular}{|c|c|c|}
\hline Stamm & Relevanter Phäno- und Genotyp & Referenz \\
\hline JW1 & $\begin{array}{l}\text { ara, } \Delta(\text { lac-proAB), rpsL, thi, } \Phi 80 \text {, } \\
\text { F'lac }^{\mathrm{q}}, \operatorname{lac} Z \Delta M 15, \operatorname{proA}^{+} B^{+}\end{array}$ & Kolmar et al. (1990) \\
\hline XL1-Blue & $\begin{array}{l}\mathrm{Tc}^{\mathrm{r}} ; \operatorname{rec} A^{-}, \text {thi, hsdR1, supE44, relA1, } \\
\operatorname{lac}\left[\mathrm{F}^{\prime}, \operatorname{pro} \mathrm{r} B, \operatorname{lac} I^{\mathrm{q}}, \operatorname{lac} Z \Delta M 15, \mathrm{Tn} 10\right]\end{array}$ & Bullock et al. (1987) \\
\hline S17-1 & $\begin{array}{l}\mathrm{Sm}^{\mathrm{r}}, \mathrm{Tp}^{\mathrm{r}}, \mathrm{Mod}^{+}, \mathrm{Res}^{-}, \text {thi, pro, recA; } \\
\text { integriertes Plasmid RP4-Tc::Mu- } \\
\mathrm{Km}:: \operatorname{Tn} 7\end{array}$ & Simon et al. (1983) \\
\hline BL21-DE3 & $\mathrm{F}^{-}, o m p T, h s d S B(r B-m B-), g a l, d c m(D E 3)$ & Calbiochem-Novabiochem \\
\hline
\end{tabular}

Bezeichnung der Phänotypen: $\mathrm{Sm}^{\mathrm{r}}$, Streptomycinresistenz; Tp ${ }^{\mathrm{r}}$, Trimethoprimresistenz; Genotypenbezeichnungen gemäß Berlyn et al. (1996). 
Tab. 3. Plasmide

\begin{tabular}{|c|c|c|}
\hline Plasmid & Relevanter Phäno- oder Genotyp & Referenz \\
\hline pUC18/19 & $\mathrm{Ap}^{\mathrm{r}} ;$ lacPOZ' & $\begin{array}{l}\text { Yanisch-Perron et al. } \\
\text { (1985) }\end{array}$ \\
\hline pBluescriptSK $\mathrm{KSS}^{-}$ & $\mathrm{Ap}^{\mathrm{r}} ;$ lacPOZ & Stratagene \\
\hline pBH2241 & pUC19::224 bp-EcoRI-HindIII & $\begin{array}{l}\text { Kusian \& Bowien } \\
\text { (1995) }\end{array}$ \\
\hline $\mathrm{pBK}$ & $\begin{array}{l}\mathrm{Tc}^{\mathrm{r}}, \mathrm{pMP} 220:: 1.87 \mathrm{~kb} \text { EcoRI-XbaI mit gusA } \\
\text { aus pUIDA }\end{array}$ & $\begin{array}{l}\text { Kusian \& Bowien } \\
\text { (1995) }\end{array}$ \\
\hline pBK2240 & $\mathrm{pBK}:: 236 \mathrm{bp}-X b a \mathrm{I} / P s t \mathrm{I}$ aus $\mathrm{pBH} 2240$ & $\begin{array}{l}\text { Kusian \& Bowien } \\
\text { (1995) }\end{array}$ \\
\hline pBK2241 & pBK::236 bp-XbaI/PstI aus pBH2241 & $\begin{array}{l}\text { Kusian \& Bowien } \\
\text { (1995) }\end{array}$ \\
\hline pNHG1 & $\mathrm{Km}^{\mathrm{r}}, \mathrm{Tc}^{\mathrm{r}}, s a c B, \mathrm{RP} 4$ oriT, ColE1 ori, & Jeffke et al. (1999) \\
\hline pCYB2 & $A p^{r} ; P_{\text {tac }}-$ Promotor; Intein-CBD & New England Biolabs \\
\hline pTYB12 & $\mathrm{Ap}^{\mathrm{r}}, \mathrm{P}_{\mathrm{T} 7}$-Promotor; Intein-CBD & New England Biolabs \\
\hline pBBR1MCS2 & $\mathrm{Km}^{\mathrm{r}}, \mathrm{Mob}^{+}$, lacPOZ & Kovach et al. (1995) \\
\hline pAECR5 & $\begin{array}{l}\text { Ap }^{\mathrm{r}}, \mathrm{pT} 7-7:: 958 \text { bp Fragment mit artifiziel- } \\
\text { ler RBS, } \mathrm{P}_{\mathrm{T} 7} \text {-Promotor }\end{array}$ & $\begin{array}{l}\text { Windhövel \& Bowien } \\
\text { (1991) }\end{array}$ \\
\hline pAECR6 & $\begin{array}{l}\text { pTYB12::843 bp-NdeI/NdeI + } 129 \text { bp- } \\
\text { NdeI/HindIII aus pAECR5 }\end{array}$ & Diese Arbeit \\
\hline pAECR7 & $\begin{array}{l}\text { pUC18::1015 bp-XbaI/HindIII aus } \\
\text { pAECR5 }\end{array}$ & Diese Arbeit \\
\hline pCG3 & pBBR1MCS2::1.3 kb-MunI ( $\left.p h c A^{*}\right)$ & C. Grzeszik \\
\hline pCG4 & pBBR1MCS2::1.3 kb-MunI (phcA) & $\begin{array}{l}\text { S. Walburg \& } \\
\text { Bowien }\end{array}$ \\
\hline pCG12 & pBBR1MCS2::2.15 kb-SalI $\left(p h c A^{*}\right)$ & C. Grzeszik \\
\hline pCG12 $\Delta$ StuI & pBBR1MCS2::1.35 kb-SalI $(p h c A \Delta)$ & C. Grzeszik \\
\hline pCG7 & $\begin{array}{l}\text { pUC19::1037 bp-BamH1/SalI aus pCG3 } \\
\left(p h c A^{*}\right)\end{array}$ & Diese Arbeit \\
\hline pCG8 & $\begin{array}{l}\text { pUC19 }(E c o \mathrm{RI}):: 1310 \mathrm{bp}-M u n \mathrm{I} \text { in } E c o \mathrm{R} 1 \\
\text { aus pCG3 }(p h c A)\end{array}$ & $\begin{array}{l}\text { S. Walburg \& B. } \\
\text { Bowien }\end{array}$ \\
\hline $\mathrm{pJPh} 14 \mathrm{R}^{\mathrm{a}}$ & $\begin{array}{l}\text { pCYB2::906 bp-NdeI/SmaI + } 98 \text { bp Nde/ } \\
\text { Nde; nach PCR mit pCG3 (phcA mut) }\end{array}$ & Diese Arbeit \\
\hline
\end{tabular}


Tab. 3. Plasmide (Fortsetzung)

\begin{tabular}{|c|c|c|}
\hline Plasmid & Relevanter Phäno- oder Genotyp & Referenz \\
\hline pJPh16 & $\begin{array}{l}\text { pCYB2::906 bp-NdeI/SmaI- + } 98 \text { bp Nde/Nde, } \\
\text { nach PCR mit pCG4 (phcA mut) }\end{array}$ & Diese Arbeit \\
\hline $\mathrm{pNHG} \Delta p h c A$ & $\begin{array}{l}\text { pNHG:: } 2.1 \mathrm{~kb}-S a l \mathrm{I}(\Delta S t u \mathrm{I}) \text { mit HincII aus pCG12 } \\
\text { in PmeI von pNHG }\end{array}$ & Diese Arbeit \\
\hline $\mathrm{pKCR} 2150^{\mathrm{a}}$ & $\mathrm{pKS}^{-}:: 227$ bp-XbaI /PstI nach PCR mit pBH2241 & Diese Arbeit \\
\hline pKCR1670 & $\mathrm{pKS}^{-}:: 119$ bp-XbaI /PstI nach PCR mit pBH2241 & Diese Arbeit \\
\hline pKCR1450 & $\mathrm{pKS}^{-}:: 157 \mathrm{bp}-X b a \mathrm{I} / P s t \mathrm{I}$ nach PCR mit pBH2241 & Diese Arbeit \\
\hline pKCR1200 & $\mathrm{pKS}^{-}:: 132$ bp-XbaI /PstI nach PCR mit pBH2241 & Diese Arbeit \\
\hline pKCR0910 & $\mathrm{pKS}^{-}:: 103$ bp-XbaI /PstI nach PCR mit pBH2241 & Diese Arbeit \\
\hline pKCR0430 & $\mathrm{pKS}^{-}:: 55$ bp-XbaI /PstI nach PCR mit pBH2241 & Diese Arbeit \\
\hline pKCR1200- $\Delta 24$ & $\mathrm{pKS}^{-}:: 108$ bp-XbaI /PstI nach PCR mit pBH2241 & Diese Arbeit \\
\hline pKCR1200- $\Delta 43$ & pKS $:: 89$ bp-XbaI /PstI nach PCR mit pBH2241 & Diese Arbeit \\
\hline pKCR2151 & $\mathrm{pKS}^{-}:: 227 \mathrm{bp}-X b a \mathrm{I} / P s t \mathrm{I}$ nach PCR mit pBH2241 & Diese Arbeit \\
\hline pKCR1671 & $\mathrm{pKS}^{-}:: 119 \mathrm{bp}-X b a \mathrm{I} / P s t \mathrm{I}$ nach PCR mit pBH2241 & Diese Arbeit \\
\hline pKCR1451 & $\mathrm{pKS}^{-}:: 157 \mathrm{bp}-X b a \mathrm{I} / P s t \mathrm{I}$ nach PCR mit pBH2241 & Diese Arbeit \\
\hline pKCR1201 & $\mathrm{pKS}^{-}:: 132$ bp-XbaI /PstI nach PCR mit pBH2241 & Diese Arbeit \\
\hline pKCR1141 & $\mathrm{pKS}^{-}:: 132$ bp-XbaI /PstI nach PCR mit pBH2241 & Diese Arbeit \\
\hline pKCR0911 & $\mathrm{pKS}^{-}:: 103$ bp-XbaI /PstI nach PCR mit pBH2241 & Diese Arbeit \\
\hline pKCR0431 & $\mathrm{pKS}^{-}:: 55$ bp-XbaI /PstI nach PCR mit pBH2241 & Diese Arbeit \\
\hline $\mathrm{pKCR} 1201-\Delta 24$ & $\mathrm{pKS}^{-}:: 108$ bp-XbaI /PstI nach PCR mit pBH2241 & Diese Arbeit \\
\hline $\mathrm{pKCR} 1201-\Delta 43$ & $\mathrm{pKS}^{-}:: 89$ bp-XbaI /PstI nach PCR mit pBH2241 & Diese Arbeit \\
\hline $\mathrm{pBK} 2150^{\mathrm{a}}$ & $\mathrm{pBK}:: 227 \mathrm{bp}-X b a \mathrm{I} / P s t \mathrm{I}$ aus pKCR2150 & Diese Arbeit \\
\hline pBK1670 & pBK::179 bp-XbaI/PstI aus pKCR1670 & Diese Arbeit \\
\hline pBK1450 & pBK::157 bp-XbaI/PstI aus pKCR1450 & Diese Arbeit \\
\hline pBK1200a & pBK::132 bp-XbaI/PstI aus pKCR1200 & Diese Arbeit \\
\hline pBK0910 & pBK::130 bp-XbaI/PstI aus pKCR0910 & Diese Arbeit \\
\hline
\end{tabular}


Tab. 3. Plasmide (Fortsetzung)

\begin{tabular}{lll}
\hline Plasmid & Relevanter Phäno- oder Genotyp & Referenz \\
\hline pBK0430 ${ }^{a}$ & pBK::55 bp-XbaI/PstI aus pKCR0430 & Diese Arbeit \\
pBK1200- 424 & pBK::108 bp-XbaI/PstI aus pKCR1200- 24 & Diese Arbeit \\
pBK1200- 443 & pBK::89 bp-XbaI/PstI aus pKCR1200- 443 & Diese Arbeit \\
pBK2151 & pBK::227 bp-XbaI/PstI aus pKCR2151 & Diese Arbeit \\
pBK1671 & pBK::179 bp-XbaI/PstI aus pKCR1671 & Diese Arbeit \\
pBK1451 & pBK::157 bp-XbaI/PstI aus pKCR1451 & Diese Arbeit \\
pBK1201 & pBK::132 bp-XbaI/PstI aus pKCR1201 & Diese Arbeit \\
pBK0911 & pBK::130 bp-XbaI/PstI aus pKCR0911 & Diese Arbeit \\
pBK1201- $\Delta 24$ & pBK::108 bp-XbaI/PstI aus pKCR1201-24 & Diese Arbeit \\
\hline
\end{tabular}

Phänotypenbezeichnungen: $\mathrm{Ap}^{\mathrm{r}}$, Ampicillinresistenz; $\mathrm{Km}^{\mathrm{r}}$, Kanamycinresistenz; $\mathrm{Tc}^{\mathrm{r}}$, Tetracyclinresistenz; Genotypenbezeichnungen gemäß Berlyn (1996).

aPlasmidnomenklatur:

pKCR-, pBK und pCYB2-Derivate:

pKCR und pBK enthalten ausgehend vom Beginn des cbbL-Gens (stromaufwärts) unterschiedliche große Subfragmente. Fragmentorientierung: 0 als letzte Zahl der Bezeichnung: $p_{c b b R}$ ist in pBK colinear zu lacZ bzw. colinear zu PstI in pKS; 1 als letzte Zahl der Bezeichnung: $p_{c b b L}$ ist in pBK colinear zu lacZ bzw. colinear zu PstI in $\mathrm{pKS}^{-} ; \Delta 243 / \Delta 43$, Anzahl der Basen die am $c b b L$-seitigen-Ende der $c b b$-Kontrollregion ausgehend vom 120 bp-Fragment (pKCR120 bzw. pBK120) deletiert sind.

Tab. 4. In pBK und pKS (pKCR) klonierte Fragmente der $c b b$-Kontrollregion

Fragment (Größe in bp)

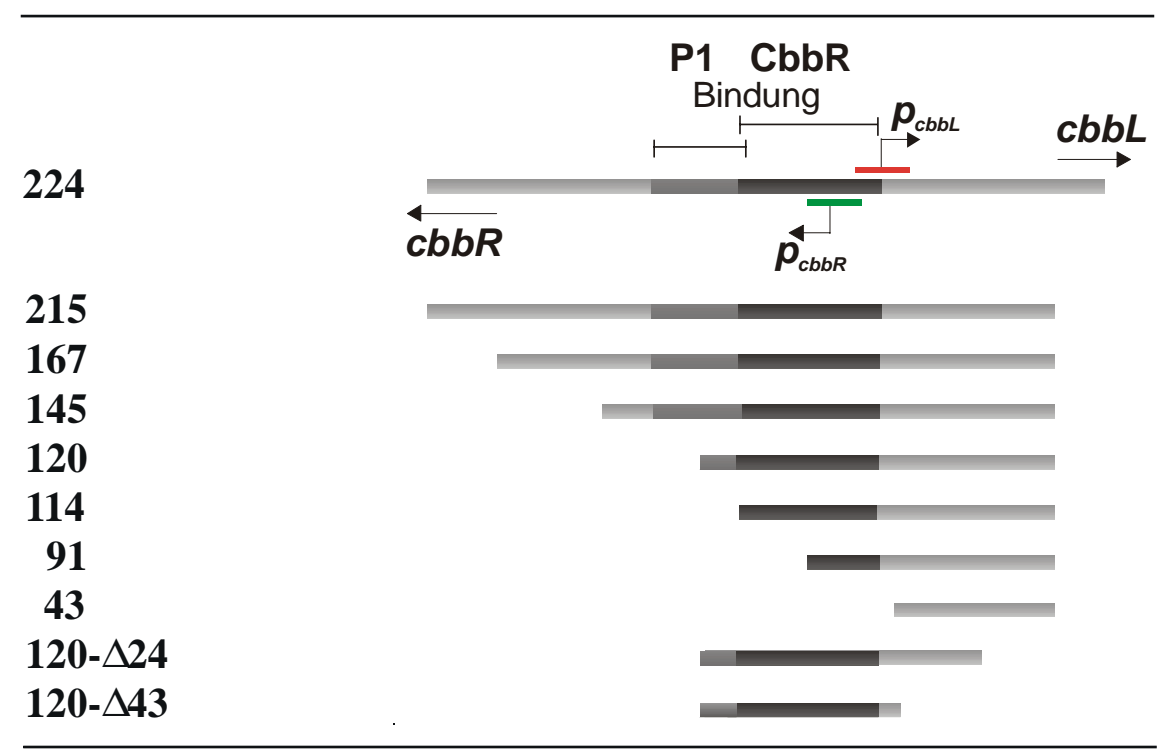




\subsection{Nährmedien und Zellanzucht}

\subsubsection{Nährmedien für $R$. eutropha}

Stämme von $R$. eutropha wurden entweder in Mineralmedium mit unterschiedlichen organischen und anorganischen Zusätzen oder in Komplexmedien angezogen. Zur Herstellung fester Nährböden wurde den Medien vor dem Autoklavieren Agar in einer Konzentration von $1.5 \%$ (w/v) zugesetzt.

Mineralmedium (Schlegel et al., 1961)

Lösung A (30x):

$$
\begin{array}{lc}
\mathrm{Na}_{2} \mathrm{HPO}_{4} \times 12 \mathrm{H}_{2} \mathrm{O} & 270 \mathrm{~g} \\
\mathrm{KH}_{2} \mathrm{PO}_{4} & 45 \mathrm{~g} \\
\mathrm{H}_{2} \mathrm{O} \text { bidest. } & \text { ad } 1,000 \mathrm{ml}
\end{array}
$$

Lösung B (30x):

$$
\begin{array}{lc}
\mathrm{MgSO}_{4} \times 7 \mathrm{H}_{2} \mathrm{O} & 6 \mathrm{~g} \\
\mathrm{NH}_{4} \mathrm{Cl} & 60 \mathrm{~g} \\
\mathrm{SL} 7 & 30 \mathrm{ml} \\
\mathrm{H}_{2} \mathrm{O} \text { bidest. } & \text { ad } 1,000 \mathrm{ml} \\
\mathrm{Fe}(\mathrm{III}) \mathrm{NH}_{4} \text {-Citrat } & 125 \mathrm{mg}
\end{array}
$$

Lösung C (100x):

$$
\begin{array}{lr}
\mathrm{CaCl}_{2} \text { × } 2 \mathrm{H}_{2} \mathrm{O} & 250 \mathrm{mg} \\
\mathrm{H}_{2} \mathrm{O} \text { bidest. } & \text { ad } 250 \mathrm{ml}
\end{array}
$$

Spurenelementelösung SL7 (Pfennig \& Trüper, 1981; modifiziert)

$$
\begin{array}{lc}
25 \%(\text { w/v }) \mathrm{HCl} & 1.3 \mathrm{ml} \\
\mathrm{H}_{3} \mathrm{BO}_{3} & 62 \mathrm{mg} \\
\mathrm{CoCl}_{2} \times 6 \mathrm{H}_{2} \mathrm{O} & 190 \mathrm{mg} \\
\mathrm{CuCl}_{2} \times 2 \mathrm{H}_{2} \mathrm{O} & 17 \mathrm{mg} \\
\mathrm{MnCl}_{2} \times 4 \mathrm{H}_{2} \mathrm{O} & 100 \mathrm{mg} \\
\mathrm{Na}_{2} \mathrm{MoO}_{4} \times 2 \mathrm{H}_{2} \mathrm{O} & 36 \mathrm{mg} \\
\mathrm{NiCl}_{2} \times 6 \mathrm{H}_{2} \mathrm{O} & 24 \mathrm{mg} \\
\mathrm{ZnCl}_{2} & 70 \mathrm{mg} \\
\mathrm{H}_{2} \mathrm{O} \text { bidest. } & \text { ad } 1,000 \mathrm{ml} ; \mathrm{pH} 6.5
\end{array}
$$


Die Lösungen A und B wurden im Verhältnis 1:1:28 mit $\mathrm{H}_{2} \mathrm{O}$ bidest. gemischt. Der pH-Wert wurde vor dem Autoklavieren mit verdünnter Phosphorsäure auf pH 7.0 eingestellt. Nach dem Autoklavieren erfolgte die Zugabe von 0.01 Volumen Lösung C.

\section{Komplexmedium}

Nutrient Broth (NB)

$\mathrm{H}_{2} \mathrm{O}$ bidest.

$$
\begin{array}{r}
8 \mathrm{~g} \\
\text { ad } 1,000 \mathrm{ml}
\end{array}
$$

\section{Anzuchten in Mineralmedium}

Die jeweiligen Substrate wurden als 100-fach konzentrierte Stammlösungen (5-40 \% [w/v]) angesetzt und sterilfiltriert.

Lithoautotrophe Anzuchten erfolgten nach Zusatz von $0.05 \%$ (w/v) $\mathrm{NaHCO}_{3}$ und wurden unter einer Atmosphäre aus $80 \% \mathrm{H}_{2}, 10 \% \mathrm{CO}_{2}$ und $10 \% \mathrm{O}_{2}(\mathrm{v} / \mathrm{v})$ durchgeführt.

Bei organoautotropher Anzucht mit $0.2 \%$ (w/v) Formiat wurde der pH-Wert des Mediums auf pH 6.7 eingestellt. Aufgrund der zunehmenden Alkalisierung des Mediums mußte der pHWert der wachsenden Kultur durch Titration mit $20 \%$ (w/v) Ameisensäure auf ca. 7.0 gehalten werden.

Bei Anzuchten unter mixotrophen Bedingungen wurde zunächst für $24 \mathrm{~h}$ mit $0.1 \%(\mathrm{w} / \mathrm{v})$ Fructose inkubiert und dann mit $0.2 \%(\mathrm{w} / \mathrm{v})$ Formiat für weitere $9 \mathrm{~h}$ induziert. Auch bei diesen Anzuchten mußte der pH-Wert auf ca. 7.0 zurücktitriert werden.

Für heterotrophe Anzuchten wurde das Standard-Mineralmedium mit 0.2 oder $0.4 \%$ (w/v) Fructose oder $0.2 \%$ (w/v) Pyruvat supplementiert.

\subsubsection{Nährmedien für $E$. coli}

Als Komplexmedium für E. coli wurde LB-Medium (Sambrook et al., 1989; modifiziert) verwendet.

\section{Luria-Bertani Broth (LB)}

Bacto-Trypton $10 \mathrm{~g}$

Hefeextrakt $5 \mathrm{~g}$

$\mathrm{NaCl} \quad 5 \mathrm{~g}$

$\mathrm{H}_{2} \mathrm{O}$ bidest. $\quad \mathrm{ad} 1,000 \mathrm{ml}$ 
Zur Herstellung fester Nährmedien wurde dem Medium vor dem Autoklavieren Agar in einer Endkonzentration von $1.5 \%(\mathrm{w} / \mathrm{v})$ zugesetzt. Indikatorplatten zur Selektion rekombinanter Klone (s. 2.13.3 enthielten zusätzlich $0.1 \mathrm{mM}$ IPTG und $0.002 \%$ (w/v) X-Gal.

Als Mineralmedium für E. coli diente M9-Mineralmedium (Sambrook et al., 1989; modifiziert).

\section{0x M9-Mineralmedium}

$\begin{array}{lrl}\mathrm{Na}_{2} \mathrm{HPO}_{4} \times 12 \mathrm{H}_{2} \mathrm{O} & 89.5 \mathrm{~g} \\ \mathrm{KH}_{2} \mathrm{PO}_{4} & 30 & \mathrm{~g} \\ \mathrm{NaCl} & 5 & \mathrm{~g} \\ \mathrm{NH}_{4} \mathrm{Cl} & 10 & \mathrm{~g} \\ \mathrm{H}_{2} \mathrm{O} \text { bidest. } & \text { ad } 1,000 & \mathrm{ml}\end{array}$

Vor dem Autoklavieren wurde der $\mathrm{pH}-\mathrm{Wert}$ mit $\mathrm{NaOH}$ auf $\mathrm{pH} 7.0$ eingestellt. Nach dem Autoklavieren wurden pro Liter Medium folgende Lösungen steril zugesetzt:

\begin{tabular}{lr} 
Lösung C (s.2.2.1) & $10 \mathrm{ml}$ \\
$10 \mathrm{mM}$ Thiamin & $5 \mathrm{ml}$ \\
SL7-Spurenelementlösung & $1 \mathrm{ml}$ \\
\multicolumn{1}{c}{ (s. 2.2.1) } & \\
$1 \mathrm{M} \mathrm{MgSO}_{4}+1 \mathrm{M} \mathrm{MgCl}_{2}$ & $1 \mathrm{ml}$ \\
$0,1 \mathrm{M} \mathrm{CaCl}_{2}$ & $1 \mathrm{ml}$
\end{tabular}

Als C-Quelle wurde dem M9-Medium entweder Glucose oder Succinat in Endkonzentration von 0.4 bzw. $0.3 \%(\mathrm{w} / \mathrm{v})$ zugesetzt.

\subsubsection{Antibiotika}

Für die Selektion von Klonen mit Hilfe von Resistenzmarkern erfolgten die Anzuchten unter Zusatz folgender Antibiotika nach den Angaben von Sambrook et al. (1989): 


$\begin{array}{lll}\text { E. coli: } & \text { Ampicillin } & 50 \mu \mathrm{g} / \mathrm{ml} \\ & \text { Kanamycin } & 50 \mu \mathrm{g} / \mathrm{ml} \\ & \text { Tetracyclin } & 15 \mu \mathrm{g} / \mathrm{ml}\end{array}$

$\begin{array}{ll}\text { R. eutropha: } \quad \text { Kanamycin } & 120 \mu \mathrm{g} / \mathrm{ml} \text { (NB-Medium) } \\ & 350-500 \mu \mathrm{g} / \mathrm{ml} \text { (Mineralmedium) }\end{array}$

Tetracyclin $\quad 20 \mu \mathrm{g} / \mathrm{ml}$

\subsubsection{Anzuchtbedingungen}

Die Anzucht von Flüssigkulturen erfolgte in Erlenmeyerkolben oder Reagenzgläsern mit 0.1-1.0\% Kulturvolumen. Kulturen von R. eutropha wurden bei $30{ }^{\circ} \mathrm{C}$, diejenigen von E. coli bei $37^{\circ} \mathrm{C}$ unter Schütteln angezogen. Vorkulturen wurden mit Einzelkolonien, Hauptkulturen mit 1-2 \% (v/v) einer gut gewachsenen Vorkultur beimpft. Für lithoautotrophe Anzuchten von R. eutropha wurden die Kolben mit Begasungsaufsätzen versehen und kontinuierlich begast. Kleinere Kulturen und Agarplatten für lithoautotrophe Anzuchten wurden im Witt'schen Topf unter entsprechenden Gasgemisch inkubiert.

\section{Anzucht im 3 l-Maßstab}

Für die Gewinnung größerer Zellmassen von $R$. eutropha (s. 2.8) wurden 3 1-Kulturen in Rundkolben bei $30^{\circ} \mathrm{C}$ angezogen. Die Begasung erfolgte durch sterilfiltrierte Druckluft unter permanenter magnetischer Rührung. Die Kultur wurde bis zu einer $\mathrm{OD}_{436}$ von etwa 3.0 angezogen und durch Zentrifugation abgeerntet (Sorvall RC5C mit GSA oder GS3 Rotor, 20 min, 7,000 Upm; oder Milchzentrifuge). Anschließend wurden die Zellen mit AufschlußPuffer gewaschen.

\subsubsection{Bestimmung der Zelldichte}

Das Wachstum der Kulturen wurde anhand der optischen Dichte (OD) bestimmt. Die Messung erfolgte in einem Spektralphotometer (Shimadzu UV 120 02; Shimadzu, Duisburg) bei einer Wellenlänge von $436 \mathrm{~nm}$ für $R$. eutropha sowie, je nach Vorschrift, bei 550 oder $600 \mathrm{~nm}$ für E. coli. Die Zellsuspensionen wurden dabei so verdünnt, daß eine gemessene OD von 0.3 nicht überschritten wurde.

Wachstumsversuche mit $R$. eutropha wurden in Klett-Photometerkolben durchgeführt. Die Trübungsmessung erfolgte direkt im Seitenarm der Kolben in einem Klett-Summerson- 
Photometer (Klett, New York, NY, USA; Filter No. 54: 520-580 nm). Anhand einer Eichkurve wurden die gemessenen Werte (Klett-Einheiten) in $\mathrm{OD}_{436}$-Werte umgerechnet.

\subsubsection{Stammhaltung und Reinheitskontrolle}

Für Zeiträume bis max. 8 Wochen wurden häufig benötigte Stämme von $R$. eutropha und $E$. coli auf Agarplatten oder in 10 ml-Flüssigkulturen kultiviert und bei $4{ }^{\circ} \mathrm{C}$ gelagert. Eine Langzeitlagerung erfolgte in Glycerin-Suspensionen nach Yanisch-Perron et al. (1985). Dazu wurden sterile 2 ml-Schraubdeckelröhrchen mit $750 \mu 187 \%$ (w/v) Glycerin angesetzt, mit $1 \mathrm{ml}$ einer frisch gewachsenen Kultur gemischt und bei $-70{ }^{\circ} \mathrm{C}$ gelagert. $R$. eutropha wurde in Mineral-, E. coli in LB-Medium angezogen.

Eine Reinheitsüberprüfung der Kulturen erfolgte durch mikroskopische Kontrolle (Zellform), Ausstrich auf Komplexnährböden (Koloniemorphologie) unter entsprechendem Selektionsdruck in Gegenwart von Antibiotika oder durch Anzucht unter spezifischen Bedingungen (autotrophe Kultivierung von R. eutropha).

\subsubsection{Zellernte}

Die Aberntung größerer Kulturvolumina erfolgte durch Zentrifugation in 10 oder $50 \mathrm{ml}$ Pyrexröhrchen (Sigma 3K-1; Sigma, Osterode; $20 \mathrm{~min}$, 4,000 Upm, $4{ }^{\circ} \mathrm{C}$ ) oder in $40 \mathrm{ml}$ Polyallomerröhrchen (SS 34-Rotor, Sorvall RC5C, DuPont de Nemours, Bad Homburg; 10 min, 10,000 Upm, $4{ }^{\circ} \mathrm{C}$ ).

Bei kleineren Kulturvolumina von bis $\mathrm{zu} 4 \mathrm{ml}$ wurden die Zellen in EppendorfReaktionsgefäßen in einer Mikrozentrifuge (Eppendorf-Zentrifuge 5415C; Nebeler und Hinz, Hamburg) bei RT und 13,000 Upm für 1 min sedimentiert.

\subsection{Zellaufschluß und Herstellung von Rohextrakten}

Der Aufschluß kleinerer Zellmengen erfolgte durch Ultraschallbehandlung. Hierzu wurden die Zellen in geeigneten Aufschlußpuffer resuspendiert, so daß eine $\mathrm{OD}_{436}$ von 100 - 200 eingestellt war. Zum Aufschluß wurde die Suspension für 5 min in Cyclen von $0.5 \mathrm{~s} \mathrm{Be-}$ schallung und $0.5 \mathrm{~s}$ Kühlpause bei einer Amplitude von $30 \%$ behandelt (Ultraschallgerät UP 200s, Dr. Hielscher). Die Kühlung erfolgte durch eine Eis/NaCl-Mischung. Zelltrümmer und nicht aufgeschlossene Zellen wurden anschließend abzentrifugiert (13,000 Upm, $4^{\circ} \mathrm{C}, 20 \mathrm{~min}$; Mikrozentrifuge). Der zellfreie Überstand wurde als Rohextrakt bezeichnet und bis zur 
Verwendung auf Eis gelagert. Die Messung von Enzymaktivitäten erfolgte ausschließlich mit frischen Rohextrakten.

Der Aufschluß größerer Zellmengen erfolgte durch dreimalige Passage der Suspension durch eine French-Presse (SLM Instruments, Urbana, Il., USA) bei einem Druck von ca. 125 MPa. Aus dem Homogenat wurden Zelltrümmer und nicht aufgeschlossene Zellen durch Zentrifugation abgetrennt (20 $\mathrm{min}, 18,000 \mathrm{Upm}, 4^{\circ} \mathrm{C}$; SM24-Rotor, Sorvall RC5C-Zentrifuge).

Die Bestimmung von Proteinkonzentrationen erfolgte nach Bradford (1976; modifiziert) unter Verwendung von Rinderserumalbumin als Referenzprotein. Von der entsprechenden Proteinlösung wurden $10 \mu \mathrm{l}$ einer geeigneten Verdünnung mit $1 \mathrm{ml}$ Bradford-Reagenz gemischt. Nach 5 min Inkubation bei RT wurde die Extinktion bei $578 \mathrm{~nm}$ innerhalb eines linearen Bereiches $(\leq 0.3)$ gegen den Reagentienleerwert gemessen (Shimadzu UV 120 02; Shimadzu, Duisburg).

\section{Bradford-Reagenz}

$\begin{array}{lr}\text { Serva Blau G-250 } & 70 \mathrm{mg} \\ 96 \%(\text { w/v) Ethanol } & 50 \mathrm{ml} \\ 85 \%\left(\text { w/v) } \mathrm{H}_{3} \mathrm{PO}_{4}\right. & 100 \mathrm{ml} \\ \mathrm{H}_{2} \mathrm{O} \text { bidest. } & \text { ad } 1,000 \mathrm{ml}\end{array}$

Nach Ansetzen der Lösung wurde diese zunächst $24 \mathrm{~h}$ stehen gelassen und anschließend filtriert. Die Lösung konnte lichtgeschützt in einer Braunglasflasche gelagert werden.

\subsection{Bestimmung von Enzymaktivitäten}

\subsubsection{B-Galaktosidase}

Zur Bestimmung der Aktivität von $\beta$-Galaktosidase (EC 3.2.1.23) wurde das Substratanalogon ortho-Nitrophenylgalactopyranosid (o-NPG) verwendet (Miller, 1972; modifiziert). Die Zellen wurden zur Herstellung des Rohextrakts in $\beta$-Galaktosidase-Puffer aufgenommen und durch Ultraschallbehandlung aufgeschlossen (s. 2.3

$\begin{array}{rll}\boldsymbol{\beta} \text { - Galaktosidase Puffer } & 50 \mathrm{mM} & \mathrm{Na}_{4} \mathrm{PO}_{4}, \mathrm{pH} 7.0 \\ 10 \mathrm{mM} & \mathrm{KCl} \\ 1 \mathrm{mM} & \mathrm{MgSO}_{4} \\ 10 \mathrm{mM} & 2-\mathrm{Mercaptoethanol}\end{array}$


Die Umsetzung von $o$-NPG zu $o$-Nitrophenol wurde durch Messung der Extinktion bei 420 nm bestimmt. Hierzu wurden zunächst $10 \mu \mathrm{l}$ Rohextrakt mit $990 \mu 1 \beta$-Galaktosidase-Puffer gemischt. Anschließend erfolgte eine Vorinkubation des Ansatzes für 2 min bei $37^{\circ} \mathrm{C}$. Durch Zugabe von $200 \mu 10.2 \%$ (w/v) $o$-NPG wurde die Reaktion gestartet und nach max. 20 min oder nach Erreichen einer deutlichen Gelbfärbung durch Zugabe von $500 \mu 11 \mathrm{M} \mathrm{Na}_{2} \mathrm{CO}_{3}$ abgestoppt. Die Bestimmung der Extinktion (Shimadzu UV-120-02) erfolgte bei $420 \mathrm{~nm}$ gegen einen Blindwert (sofort nach Substratzugabe abgestoppter Ansatz). Anhand des linearen molaren Extinktionskoeffizienten $\varepsilon_{420}=21300 \mathrm{ml} \mathrm{x} \mathrm{mmol}^{-1} \mathrm{x} \mathrm{cm}^{-1}$ für $o$-Nitrophenol (Dawson et al., 1986) konnte daraus die spezifische $\beta$ - Galaktosidase-Aktivität (nmol x min ${ }^{-1}$ $\mathrm{x} \mathrm{mg}^{-1}$ ) berechnet werden:

$$
\frac{\Delta \mathrm{E}_{420} \cdot 1.7[\mathrm{ml}]}{2.13 \cdot 10^{-2}\left[\frac{\mathrm{ml}}{\mathrm{nmol} \cdot \mathrm{cm}}\right] \cdot \mathrm{t}[\mathrm{min}] \cdot 0.01[\mathrm{ml}] \cdot \operatorname{Protein}\left[\frac{\mathrm{mg}}{\mathrm{ml}}\right] \cdot 1[\mathrm{~cm}]}\left[\frac{\mathrm{nmol}}{\mathrm{min} \cdot \mathrm{mg}}\right]
$$

$\Delta \mathrm{E}_{420}$ : Extinktionsänderung im Testansatz bei $420 \mathrm{~nm}$

$\mathrm{t} \quad$ : Reaktionszeit [min]

\subsection{Elektrophorese von Proteinen}

\subsubsection{SDS-Polyacrylamid-Gelelektrophorese}

Die gelelektrophoretische Auftrennung von Proteinen erfolgte in eindimensionalen, diskontinuierlichen Polyacrylamidgelen unter denaturierenden Bedingungen (SDS-PAGE, Laemmli, 1970; modifiziert). Die Elektrophorese wurde in vertikalen Minigelen $(6$ x 8 x $0.1 \mathrm{~cm})$ in entsprechenden Gelkammern (Biometra, Göttingen) durchgeführt. Sammel- und Trenngele wurden nach folgender Zusammensetzung hergestellt: 


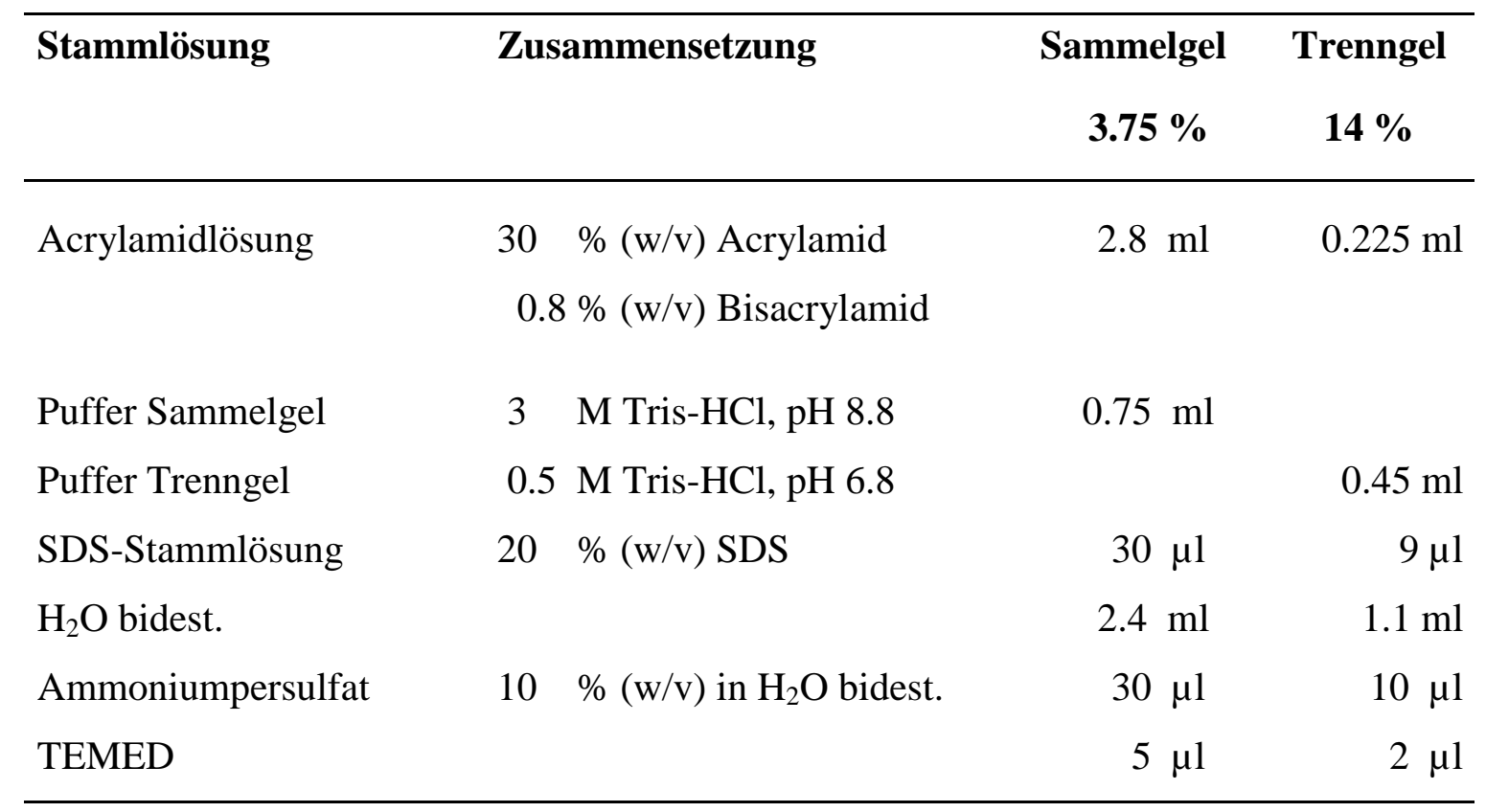

Die Gellösungen wurden jeweils frisch angesetzt. Der Polymerisationsstart erfolgte durch Zugabe von Ammoniumpersulfat und TEMED. Nach dem blasenfreien Eingießen der Trenngellösung wurde diese sofort mit Wasser überschichtet, um einen glatten Abschluß des Geles zu gewährleisten. Nach 30 min Polymerisation des Trenngels wurde die Sammelgellösung aufgetragen und der Kamm eingesetzt. Pro Geltasche konnten bei Verwendung eines zehnzähnigen Kamms maximal $15 \mu$ l aufgetragen werden.

\section{Probenvorbereitung und Elektrophorese}

Die aufzutrennende Probe wurde mit 0.3 Volumen Probenpuffer versetzt und $10 \mathrm{~min}$ im kochenden Wasserbad denaturiert. Nach dem Abkühlen auf RT wurden die Proben kurz anzentrifugiert und aufgetragen. Als Proteingrößenstandard diente eine $10 \mathrm{kDa}$-Proteinleiter (Life Technologies, Eggenstein). Die Menge der aufgetragenen Proteine hing von der sich anschließenden Färbemethode ab (10 $\mu \mathrm{g}$ bei Coomassiefärbung, s. 2.5.2 oder 0.1-1 $\mu \mathrm{g}$ bei Silberfärbung, s. 2.5.3. Die Elektrophorese erfolgte bei RT und einer Stromstärke von $25 \mathrm{~mA}$ bis die Farbmarkerbande den unteren Rand der Kammer erreicht hatte. Proben- und Elektrophoresepuffer setzten sich folgendermaßen zusammen:

Probenpuffer

$$
\begin{aligned}
60 \mathrm{mM} & \text { Tris-HCl, } \mathrm{pH} 7.0 \\
10 \%(\mathrm{w} / \mathrm{v}) & \text { Glycerin } \\
1 \%(\mathrm{w} / \mathrm{v}) & \text { SDS } \\
0.01 \%(\mathrm{w} / \mathrm{v}) & \text { Bromphenolblau } \\
1 \%(\mathrm{w} / \mathrm{v}) & \beta-M e r c a p t o e t h a n o l(\text { frisch) }
\end{aligned}
$$




\section{Elektrophoresepuffer $\quad 25 \mathrm{mM}$ Tris \\ $192 \mathrm{mM}$ Glycin \\ $0.1 \%(\mathrm{w} / \mathrm{v})$ SDS \\ $\mathrm{pH} 8,3$}

\subsubsection{Coomassie Blue-Färbung}

Für die Färbung von Polyacrylamidgelen mit Coomassie Blue wurden diese für 20-30 min in Färbelösung (Weber \& Osborn, 1969) geschwenkt und anschließend solange mit Entfärbelösung behandelt, bis der Hintergrund vollständig entfärbt war. Die Entfärbelösung wurde dabei 1-2-mal gewechselt. Die gefärbten Gele wurden mit Azidlösung $\left(0.02 \%\right.$ [w/v] $\left.\mathrm{NaN}_{3}\right)$ in Folie eingeschweißt und konnten so im Dunkeln bei $4{ }^{\circ} \mathrm{C}$ über längere Zeiträume gelagert werden.

$\begin{array}{llrr}\text { Färbelösung } & \text { Serva Blau G-250 } & 1.65 & \mathrm{~g} \\ \text { Methanol } & 330 & \mathrm{ml} \\ & \text { Essigsäure } & 100 & \mathrm{ml} \\ & \mathrm{H}_{2} \mathrm{O} \text { bidest. } & \text { ad } 1,000 & \mathrm{ml}\end{array}$

$\begin{array}{rlrr}\text { Entfärbelösung } & \text { Methanol } & 330 & \mathrm{ml} \\ & \text { Essigsäure } & 100 & \mathrm{ml} \\ & \mathrm{H}_{2} \mathrm{O} \text { bidest. } & \text { ad } 1,000 & \mathrm{ml}\end{array}$

\subsubsection{Silberfärbung}

Bei geringen Proteinmengen $(<1 \mu \mathrm{g})$ wurde eine Silberfärbung (Blum et al., 1987) eingesetzt. Sie zeichnet sich gegenüber der Färbung mit Coomassie-Blue durch eine um etwa drei Größenordnungen höhere Sensitivität aus. Die Nachweisgrenze für die Silberfärbung liegt bei 2 - 5 ng, die für Coomassie-Blau bei 0.3 - $1 \mu$ g (Ausubel et al., 1988). Alle Schritte wurden in Plastikschalen bei RT unter Schwenken durchgeführt. 


\begin{tabular}{llrr}
\hline Schritt & Lösungen & & \multicolumn{1}{c}{ Dauer } \\
\hline Fixieren & Methanol & $500 \mathrm{ml}$ 1h oder länger \\
& Essigsäure & $120 \mathrm{ml}$ & \\
& $37 \%(w / v)$ Formaldehyd & $0.5 \mathrm{ml}$ & \\
Waschen & $\mathrm{H}_{2} \mathrm{O}$ bidest. & ad $1,000 \mathrm{ml}$ & \\
& Ethanol & $500 \mathrm{ml}$ & $3 \times 20 \mathrm{~min}$ \\
Vorbehandlung & $\mathrm{H}_{2} \mathrm{O}$ bidest. & ad $1,000 \mathrm{ml}$ & \\
& $\mathrm{Na}_{2} \mathrm{~S}_{2} \mathrm{O}_{3} \times 5 \mathrm{H}_{2} \mathrm{O}$ & $0.2 \mathrm{~g}$ & $30 \mathrm{~s}$ \\
Waschen & $\mathrm{H}_{2} \mathrm{O}$ bidest. & ad $1,000 \mathrm{ml}$ & \\
Imprägnieren & $\mathrm{H}_{2} \mathrm{O}$ bidest. & & $3 \times 20 \mathrm{~s}$ \\
& $\mathrm{AgNO}_{3}$ & $2 \mathrm{~g}$ & $20 \mathrm{~min}$ \\
& $37 \%($ w/v) Formaldehyd & $0.5 \mathrm{ml}$ & \\
Waschen & $\mathrm{H}_{2} \mathrm{O}$ bidest. & ad $1,000 \mathrm{ml}$ & \\
Entwickeln & $\mathrm{H}_{2} \mathrm{O}$ bidest. & & $2 \times 20 \mathrm{~s}$ \\
& $\mathrm{Na}_{2} \mathrm{CO}_{3}$ & $60 \mathrm{~g}$ & $2-8 \mathrm{~min}$ \\
& $37 \%($ w/v) Formaldehyd & $0.5 \mathrm{ml}$ & \\
& $\mathrm{Na}_{2} \mathrm{~S}_{2} \mathrm{O}_{3} \times 5 \mathrm{H}_{2} \mathrm{O}$ & $4 \mathrm{mg}$ & \\
Stop & $\mathrm{H}_{2} \mathrm{O}$ bidest. & ad 1,000 ml & \\
& $\mathrm{EDTA}$ & $18.6 \mathrm{~g}$ & $15 \mathrm{~min}$ \\
& $\mathrm{H}_{2} \mathrm{O}$ bidest. & ad 1,000 ml &
\end{tabular}

\subsection{Western-Blot}

Nach Auftrennung in der SDS-PAGE (s. 2.5.1) wurden Proteine elektrophoretisch auf eine PVDF-Membran (Immobilon-P; Millipore, Eschborn) übertragen (Towbin et al., 1979; modifiziert). Hierzu wurden auf die Kathodenplatte eines Elektrotransfergerätes (Semi-Dry Fast Blot; Biometra) drei Lagen auf Gelgröße zurechtgeschnittenes 3MM Filterpapier (Whatman, Maidstone, GB) luftblasenfrei aufgelegt, das zuvor $10 \mathrm{~min}$ in Transferpuffer getränkt worden war. Im Anschluß daran wurde das Gel darüber gelegt, gefolgt von der zuvor mit Methanol benetzten und dann in Transferpuffer äquilibrierten Membran. Den Abschluß bildeten fünf in Transferpuffer getränkte Lagen Filterpapier und der Anodendeckel. Der Deckel wurde zusätzlich mit einer Masse von ca. $1 \mathrm{~kg}$ beschwert. Der Transfer der Proteine erfolgte bei einer Stromstärke von 400 mA für 1 h unter Wasserkühlung.

$\begin{array}{llr}\text { Transferpuffer } & \text { Tris } & 3 \mathrm{~g} \\ & \text { Glycin } & 14.4 \mathrm{~g} \\ & \text { Methanol } & 100 \mathrm{ml} \\ & \mathrm{H}_{2} \mathrm{O} \text { bidest. } & \text { ad } 1,000 \mathrm{ml}\end{array}$


Die Übertragung der Proteine auf die Membran wurde anschließend durch eine Färbung mit Coomassie Blue (s. 2.5.2 überprüft. Zur Kontrolle des Proteintransfers erfolgte ebenfalls eine Coomassie Blue- oder auch Silberfärbung (s. 2.5.3) des Gels.

\subsection{Heterologe Genexpression in $E$. coli}

Die heterologe Expression von Genen aus R. eutropha in E.coli erfolgte nach Klonierung in Plasmiden mit induzierbaren lac- bzw. tac-Promotoren oder in Vektoren mit einem T7-RNAPolymerase/Promotor System. Allen Expressionsstrategien gemeinsam war die durch IPTG bewirkte Induktion der Promotoren.

Die Anzucht der Kulturen erfolgte bei $37^{\circ} \mathrm{C}$ unter Zugabe der entsprechenden Antibiotika bis $\mathrm{zu}$ einer $\mathrm{OD}_{550}$ von 0.5, wonach die Expression durch Zugabe von 0.5 mM IPTG induziert und die Kultur für weitere $5 \mathrm{~h}$ inkubiert wurde.

\subsubsection{Expression mit pUC18/19 oder pBBR1MCS2}

Für diese Expressionen wurden die entsprechenden Gene in die multiple Klonierungsstelle colinear zum lacZ'-Gen in pUC18/19 oder pBBR1MCS2 kloniert. Als Wirtsstamm diente für der zur $\alpha$-Komplementation (s. 2.13.3 befähigte E. coli JW1.

Die Expression der klonierten Gene mit den pUC bzw. pBBR- Konstrukten erfolgte zwar auf einem relativ geringen Niveau, das aber für Aktivitätsstudien der entsprechenden Gene zumeist ausreichte.

\subsubsection{Expression mit dem Impact-CN-System}

Die Expressionsstrategie dieses Systems liegt in der Konstruktion sowohl N- wie auch Cterminaler Fusionen der Proteinprodukte der $\mathrm{zu}$ klonierenden Gene mit einem Chitinbindenen Affinitäts-TAG, der eine selbstspleißendes Proteinelement enthält. Der TAG ermöglichte nach einer Expression des Fusionsgens in E. coli eine schnelle Anreicherung des resultierenden Fusionsproteins über eine Chitin-Affinitätssäule, an der während des Waschens alle übrigen Proteine entfernt werden. Im Anschluß läßt sich der TAG über die selbstspaltende Aktivität des Inteins unter reduzierenden Bedingungen vom Zielprotein abtrennen. 


\subsubsection{Unter Kontrolle des tac-Promotors in pCYB2}

Unter Verwendung des Plasmids pCYB2 wurden C-terminale Fusionsproteine konstruiert, deren Synthese unter der Kontrolle des tac-Promotors stand und durch IPTG induziert werden konnte. Die multiple Klonierungsstelle erlaubte eine Klonierung des zu exprimierenden Gens mit überlappenden Start-Codon im Leseraster bei Verwendung der NdeI-Schnittstelle.

\subsubsection{Mit Hilfe des T7-RNA-Polymerase/Promotor-System in pTYB12}

Das Plasmid pTYB12 diente zur Konstruktion N-terminaler Fusionsproteine. Die Expression der korrespondierenden Fusionsgene erfolgte unter Kontrolle des T7-Promotors in E. coli BL21 (DE3), in dessen Chromosom eine Kopie des T7-RNA-Polymerase-Gens inseriert ist. Durch IPTG wurde die Expression eingeleitet, wobei eine gleichzeitige Induktion des T7RNA-Polymerase-Gens (unter Kontrolle des lac-Promotors/Operators) und des T7-Promotors (mit stromabwärts gelegenem lac-Operator) erfolgte. Die pTY-Konstrukte stellen vor allem bei eventuell für den Wirtsstamm problematischen Genprodukten ein sehr stringentes Expressionskontrollsystem mit einem sehr niedrigen Hintergrund der Transkription dar. Die Expression in pTYB12 wird zusätzlich durch eine optimierte Ribosomenbindungsstelle unterstützt.

\subsubsection{Expression mit dem T7-RNA-Polymerase/Promotor-System in pT7-7}

Die Induktion der Expression von Genen, die in pT7-7 kloniert waren, erfolgte wie im Fall von pTYB12 in E. coli BL21 (DE3). Im Gegensatz zu pTYB12 liegt der T7-Promotor nicht zusätzlich unter der Kontrolle des lac-Operators, was eine weniger stringente Kontrolle der Expression zur Folge hat. Ähnlich wie pTYB12 besitzt auch pT7-7 eine optimierte Ribosomenbindungsstelle.

\subsection{Anreicherung der Proteine P1 und P2 aus R. eutropha}

Die Anreicherung von P1 und P2 erfolgte über insgesamt 4 Schritte wobei von einem bereits für CbbR etablierten Anreicherungsverfahren ausgegangen wurde. Sie wurde bei $0-4^{\circ} \mathrm{C}$ durchgeführt.

\subsubsection{Herstellung der löslichen Proteinfraktion}

Für eine Standardanreicherung wurden $4 \mathrm{~g}$ Zellen von $R$. eutropha HB14 in 8 ml Aufschlußpuffer resuspendiert. Der Zellaufschluß erfolgte in einer French-Presse. Zelltrümmer und 
nicht aufgeschlossene Zellen wurden aus dem Homogenat durch Zentrifugation für 20 min bei $4^{\circ} \mathrm{C}$ und 18,000 Upm abgetrennt (SM24-Rotor, Sorvall RC5C). Der erhaltene Überstand wurde als Rohextrakt bezeichnet.

\subsubsection{Fraktionierte Ammoniumsulfat-Fällung}

Eine Vortrennung der Proteine im Rohextrakt wurde über eine fraktionierte Ammoniumsulfat-Fällung bei einer Sättigung von 20-45 \% erreicht. Dazu wurde dem Extrakt 0.25 Volumen einer gesättigten Ammoniumsulfat-Lösung $\left(4^{\circ} \mathrm{C}\right.$ oder auf Eis) tropfenweise unter Rühren zugesetzt (ad 20 \% Sättigung) und nach 30 min unter Rühren auf Eis das ausgefällte Protein durch Zentrifugation (20 min, 18,000 Upm, $4^{\circ} \mathrm{C}$; SM24-Rotor; Sorvall RC5C-Zentrifuge) entfernt. Dem Überstand wurde dann in einem zweiten Schritt 0.47 Volumen gesättigte Ammoniumsulfat-Lösung zugesetzt (ad 45 \% Sättigung) und nach weiteren 30 min Inkubation das präzipitierte Protein abzentrifugiert, das anschließend in $8 \mathrm{ml} \mathrm{HIC-Bindungspuffer}$ aufgenommen wurde.

$\begin{array}{rrl}\text { Aufschlußpuffer } & 50 \mathrm{mM} & \text { Tris-HCl, pH } 7.4 \\ 10 \mathrm{mM} & \mathrm{KCl} \\ 1 \mathrm{mM} & \text { EDTA } \\ 1 \mathrm{mM} & \text { DTT } \\ 1 \mathrm{mM} & \text { Phenylmethylsulfonylflourid } \\ 1 \%(\mathrm{w} / \mathrm{v}) & \text { Glycerin }\end{array}$

\section{Gesättigte Ammoniumsulfat-Lösung}

$800 \mathrm{~g}$ Ammoniumsulfat in 11 Aufschlußpuffer, $\mathrm{pH} 7.4\left(4^{\circ} \mathrm{C}\right)$

\subsubsection{Hydrophobe Interaktionschromatographie}

Die nächsten zwei Anreicherungsschritte erfolgten säulenchromatographisch an einer FPLC(HPLC)-Anlage (Pumpe L6210) mit angeschlossenem Detektor (UV-VIS-Detektor L4200), Chromatointegrator (D2500) und Fraktionssammler (L5200; Merck-Hitachi, Darmstadt). Die Elution des Proteins von den Säulen wurde durch Messung der Extinktion bei $280 \mathrm{~nm}$ verfolgt.

Zunächst wurde eine hydrophobe Interaktionschromatographie (HIC) an Fractogel-TSK Butyl 650 (S) (Säule: 150 x 10 mm; Merck, Darmstadt) durchgeführt. Dazu wurde der Ansatz für zwei Läufe geteilt. Das Protein wurde bei hoher Ionenstärke (HIC-Bindungspuffer) an die 
Säulenmatrix gebunden und anschließend über einen linear abnehmenden Salzgradienten in HIC-Elutionspuffer eluiert (0-10 min: Waschen mit Bindungspuffer; 10-40 min: Elution; 4060 min: nachwaschen mit Elutionspuffer).

$\begin{array}{crl}\text { HIC-Bindungspuffer/ } & 50 \mathrm{mM} & \text { Tris/HCl, pH 7.4 } \\ \text { Elutionspuffer } & 10 \mathrm{mM} & \mathrm{KCl} \\ 1 \mathrm{mM} & \text { EDTA } \\ \pm 1 \mathrm{M} & \left(\mathrm{NH}_{4}\right)_{2} \mathrm{SO}_{4} \\ & 1 \%(\mathrm{w} / \mathrm{v}) & \text { Glycerin }\end{array}$

\subsubsection{Kationenaustauschchromatographie}

Die weitere Aufreinigung erfolgte durch Kationenaustauschchromatographie an Fractogel $\mathrm{EMD} \mathrm{SO}_{3}{ }^{-} 650$ (S) (Säule: 150 x $10 \mathrm{~mm}$; Merck). Aufgrund der späten Elution von P1 und P2 in der HIC war eine nachträgliche Dialyse zum Entfernen der Salze nicht notwendig. Um die Bindung an die Säulenmatrix zu ermöglichen, wurden die nach der HIC erhaltenen P1und P2-haltigen Spitzenfraktionen mit 2 Volumen $\mathrm{SO}_{3}{ }^{-}$-Bindungspuffer gemischt. Die Elution erfolgte über einen linear ansteigenden Salzgradienten mit $\mathrm{SO}_{3}{ }^{-}$-Elutionspuffer (010 min: Waschen mit Bindungspuffer; 10-40 min: Elution; 40-60 min: Nachspülen mit Elutionspuffer).

$\begin{array}{rll}\text { SO}_{3} \text {-Bindungspuffer/ } & 40 \mathrm{mM} & \mathrm{K}^{-P_{4}}, \mathrm{pH} 6.5 \\ \text { Elutionspuffer } & 50 \mathrm{mM} / 1 \mathrm{M} & \mathrm{KCl} \\ 1 \mathrm{mM} & \text { EDTA } \\ 1 \%(\mathrm{w} / \mathrm{v}) & \text { Glycerin }\end{array}$

\subsubsection{Affinitätschromatographie an Streptavidin-Sepharose}

Die abschließende Aufreinigung von P1 erfolgte anhand einer DNA-Affinitätschromatographie an einer Streptavidin-Agarosematrix. Durch PCR amplifizierte (s. 2.20.1), biotinylierte DNA-Fragmente der $c b b$-Kontrollregion dienten dabei als hochspezifische Liganden für die Bindung von P1. Die Bindung der biotinylierten Fragmente an die Agarosematrix erfolgte über deren angekoppelte Liganden (1,5 ml-Säulen; IBA Bioanalytik, Göttingen). Der Biotin-Streptavidin-Komplex hat mit $10^{15} \mathrm{~mol}^{-1}$ eine der höchsten natürlichen 
Bindungskonstanten und war unter den gegebenen Bedingungen äußerst stabil. Die Biotinbindungskapazität der Streptavidin-Sepharosesäule lag bei $60 \mathrm{nmol} / \mathrm{ml}$. Pro ml StreptavidinSepharose dienten 200-400 $\mu \mathrm{g}(12-24 \mathrm{nmol} / \mathrm{ml})$ mit Biotin modifizierte $236 \mathrm{bp}$-Fragmente der $c b b$-Kontrollregion als spezifische Liganden, die durch einfaches Auftragen in Sepharose-Bindungspuffer an die Säule gebunden wurden.

Zur Amplifikation der $c b b$-Ligandenfragmente wurde jeweils nur ein biotinylierter Primer (Tab. 5 eingesetzt, da die gleichzeitige Biotinylierung beider Enden der Fragmente möglicherweise $\mathrm{zu}$ ungünstigen Kopplungseigenschaften mit dem Streptavidin bezüglich der Bindung der anzureichernden Proteine geführt hätte. Der jeweils eingesetzte Primer war am 5'-Ende mit Biotin modifiziert.

Wegen der hohen Salzkonzentration der P1-und P2-Spitzenfraktionen nach dem $\mathrm{SO}_{3}{ }^{-}-$ Säulenlauf wurden die Proben 1:4 bis 1:5 mit HIC-Elutionspuffer verdünnt und in Anwesenheit von 1 mM DTT und Kompetitor-DNA (Lachsspermien-DNA) auf die Säule aufgetragen. Die Menge an eingesetzter Kompetitor-DNA stand in einem Verhältnis von 4:1 zu den bereits an die Säule gekoppelten, biotinylierten Fragmenten der $c b b$-Kontrollregion. Pro Anreicherung wurden maximal 1-2 ml Spitzenfraktion aufgetragen, um eine Überladung der Säule und einen damit verbundenen Verlust angereicherten Proteins zu vermeiden. Nach dreimaligem Waschen mit 3 Bettvolumen $(4.5 \mathrm{ml})$ Sepharose-Waschpuffer erfolgte die Elution durch langsame Zugabe des Elutionspuffers. Direkt nach Auftrag des Elutionspuffers wurde nach dem Durchlauf eines Bettvolumen der weitere Durchlauf für 45 min gestoppt, so daß die Säule mit Elutionspuffer äquilibriert und eine weitgehend vollständige Elution des gebundenen Protein mit Fortsetzung des Durchlaufs gewährleistet war. Die einzelnen Fraktionen wurden in Volumina von 200-500 $\mu$ l in Eppendorfgefäßen aufgefangen und abschließend in der 14\% SDS-PAGE (s.2.5.1) und durch Gelretardationen (s. 2.16) auf Reinheit und relative Aktivitätsausbeute analysiert.

Sepharose-Wasch-Puffer

$50 \mathrm{mM} \quad$ Tris- $\mathrm{HCl}, \mathrm{pH} 7.4$

/Elutionspuffer

$$
\begin{array}{rl}
200 \mathrm{mM} / 2 \mathrm{M} & \mathrm{KCl} \\
1 \mathrm{mM} & \text { EDTA } \\
1 \%(\mathrm{w} / \mathrm{v}) & \text { Glycerin }
\end{array}
$$

Die Lagerung von angereichertem $\mathrm{P} 1$ erfolgte in $\mathrm{SO}_{3}{ }^{-}$-Elutionspuffer oder SepharoseElutionspuffer bei $-20^{\circ} \mathrm{C}$. 
Tab. 5. Primer zur Amplifikation der biotinylierten 234 bp DNA-Fragmente 1 und 2, die jeweils die $c b b$-Kontrollregion enthielten

\begin{tabular}{cll}
\hline Fragment & Forward Primer: 5' $\rightarrow \mathbf{3}$, & Reverse Primer: 5' $\rightarrow$ 3' \\
\hline 1 & F1-Biot (an 5' mit Biotin modifiziert) & R1 \\
& GTC GAT CTG CAA CTG GCG AA & GTG ATT CAG GTG CGT TCA TGC \\
2 & F1 & R1-Biot (an 5' mit Biotin modifiziert) \\
& GTC GAT CTG CAA CTG GCG AA & GTG ATT CAG GTG CGT TCA TGC \\
\hline
\end{tabular}

\subsection{Bestimmung einer N-terminalen Proteinsequenz}

Die Sequenzanalyse erfolgte durch Edman-Abbau in einem Proteinsequenzierautomaten (Applied Biosystems, Weiterstadt) und anschließender chromatographischer Identifikation der Produkte in einem HPLC-Mikrogradientensystem (Applied Biosystems 140C mit angeschlossenem Detektor 785A; Säule: C18 CP-51; Vydac; MI, Niederlande).

Beim Edman-Abbau (Lottspeich \& Sorbas, 1998) handelt es sich um einen zyklischen Prozeß, bei dem in jedem Reaktionscyclus die N-terminale Aminosäure abgespalten wird. Die Reaktion besteht aus drei gut voneinander abgrenzbaren Schritten: Kupplung, Spaltung und Konvertierung.

Bei der Kupplung reagiert die ungeladene Aminogruppe am N-Terminus des Peptids mit Phenylisothiocyanat. Es bildet sich ein Phenylthiocarbamoyl-Derivat, das zusammen mit der aminoterminalen Aminosäure unter sauren Bedingungen abgespalten wird. In einem weiteren Schritt, der Konvertierung, wird die chemisch instabile Verbindung in ein Phenylthiohydantoin (PTH)-derivat umgewandelt, das anschließend chromatographisch identifiziert werden kann. Da das restliche Peptid während der Prozedur nicht zerstört worden ist, kann innerhalb des cyclischen Prozesses wiederholt die Abspaltung einer Aminosäure vom N-Terminus her erfolgen.

\subsection{Isolierung von Nucleinsäuren}

\subsubsection{Vorbehandlung von Geräten und Lösungen}

Alle hitzebeständigen Lösungen und Geräte wurden zur Inaktivierung von Nucleasen für 20 min bei $121{ }^{\circ} \mathrm{C}$ autoklaviert. Nicht-autoklavierbare Geräte wurden mit $70 \%$ Ethanol behandelt und anschließend mit sterilem $\mathrm{H}_{2} \mathrm{O}$ bidest. gespült. Bei nicht-autoklavierbaren Lösungen erfolgte eine Sterilfiltration. 


\subsubsection{Phenolextraktion und Fällung von DNA}

Zur Entfernung von Proteinen aus wässrigen DNA-Lösungen erfolgte eine Extraktion mit Phenol-Chloroform. Dazu wurde die Lösung mit 1 Vol. des Lösungsmittelgemisches versetzt und bis zur Bildung einer homogenen Emulsion geschwenkt. Die Phasen wurden durch Zentrifugation getrennt (5 min, 13,000 Upm, RT; Mikrozentrifuge). Die wässrige Oberphase wurde in ein neues Reaktionsgefäß überführt und die Extraktion so oft wiederholt, bis kein Präzipitat mehr in der Interphase sichtbar war.

$\begin{array}{ccll}\text { Phenol-Chloroform } & 25 & \text { Vol. } & \text { Phenol (äquilibriert mit TE-Puffer, } \mathrm{pH} \text { 8.0) } \\ 24 & \text { Vol. } & \text { Chloroform } \\ 1 & \text { Vol. } & \text { Isoamylalkohol } \\ 0.1 \%(w / v) & \text { Hydroxychinolin }\end{array}$

Die DNA-Fällung aus wässrigen Lösungen mit hoher Ionenstärke erfolgte durch Zugabe organischer Lösungsmittel. Dazu wurde die Lösung zunächst mit 0.1 Vol. $3 \mathrm{M} \mathrm{Na-Acetat,} \mathrm{pH}$ 5.2, oder mit 0.4 Vol. $5 \mathrm{M} \mathrm{NH}_{4}$-Acetat, $\mathrm{pH} 7.5$, versetzt. Anschließend erfolgte die Fällung durch Zugabe von 2 Vol. 96 \% (w/v) Ethanol oder 0.7 Vol. Isopropanol. Nach gründlichem Durchmischen wurde, je nach Art und Menge der DNA, unterschiedlich lange inkubiert $\left(4{ }^{\circ} \mathrm{C}\right.$ oder RT; 1 min bis über Nacht) und abzentrifugiert (15 min, 13,000 Upm, RT; Mikrozentrifuge oder $30 \mathrm{~min}, 14,000 \mathrm{Upm}, 4{ }^{\circ} \mathrm{C}$; Sorvall RC5C, Rotor SS-34).

Zum Waschen wurde das DNA-Pellet in $1 \mathrm{ml} 70 \%(\mathrm{w} / \mathrm{v})$ Ethanol resuspendiert. Nach anschließender Zentrifugation (5 min, 13,000 Upm, RT; Mikrozentrifuge) wurde der Überstand entfernt und die DNA für $3 \mathrm{~min}$ in der Vakuumzentrifuge (Univapo $150 \mathrm{H}$; Zirbus, Osterode) oder an der Luft für 5-10 min bei $37^{\circ} \mathrm{C}$ getrocknet. Schließlich wurde die DNA in einem angemessenem Volumen $\mathrm{H}_{2} \mathrm{O}$ bidest., TE- oder Tris-HCl-Puffer gelöst.

\subsubsection{Isolierung von Gesamt-DNA}

Die Isolierung von Gesamt-DNA aus $R$. eutropha-Stämmen erfolgte nach AUSUBEL et al. (1988). Die Zellen wurden über Nacht in $40 \mathrm{ml}$ NB-Medium bei $30^{\circ} \mathrm{C}$ angezogen, geerntet (s. 2.2.7 und in $9.5 \mathrm{ml}$ TE-Puffer resuspendiert. Nach Zugabe von $0.5 \mathrm{ml} 10 \%$ (w/v) SDSLösung und $50 \mu \mathrm{l}$ Proteinase K-Lösung $\left(20 \mathrm{mg} / \mathrm{ml} \mathrm{H}_{2} \mathrm{O}\right)$ wurde der Ansatz $1 \mathrm{~h}$ bei $37^{\circ} \mathrm{C}$ inkubiert. Danach wurden zunächst $1,8 \mathrm{ml} 5 \mathrm{M} \mathrm{NaCl-Lösung} \mathrm{und} \mathrm{anschließend} \mathrm{1,5} \mathrm{ml}$ CTAB-NaCl-Lösung (10\% [w/v] CTAB in 0,7 M NaCl) eingemischt und es wurde $20 \mathrm{~min}$ 
bei $65{ }^{\circ} \mathrm{C}$ weiter inkubiert. Zur anschließenden Extraktion der CTAB-Protein-PolysaccharidKomplexe wurden $14 \mathrm{ml}$ Chloroform-Isoamylalkohol eingemischt. Die anschließende Phasentrennung erfolgte durch Zentrifugation für 10 min bei 13,000 Upm (Sorvall RC5C, Rotor SS-34). Der wässrige Überstand wurde mit 1 Vol. Phenol-Chloroform extrahiert (s. 2.10.2 und erneut abzentrifugiert. Die Nucleinsäuren aus dem Überstand der Extraktion wurden nach Zugabe von 0.1 Vol. 3 M Na-Acetat-Lösung, pH 5.2, mit 0.7 Vol. Isopropanol gefällt und für 60 min bei 13,000 Upm und $4^{\circ} \mathrm{C}$ abzentrifugiert. Das DNA-Pellet wurde mit $70 \%$ (w/v) Ethanol gewaschen, 2 ml-Eppendorfgefäße überführt, anschließend luftgetrocknet und in $500 \mu \mathrm{l}$ TE-Puffer aufgenommen. Die so präparierte Gesamt-DNA konnte direkt zur Restriktionsspaltung eingesetzt werden.

\subsubsection{Isolierung von Plasmid-DNA}

Zur Plasmidisolierung standen je nach Organismus und Mengenbedarf verschiedene Methoden zur Verfügung. Isolierungen im analytischen Maßstab aus E. coli erfolgten entweder nach der Methode des 'rapid boiling' (Holmes \& Quigley, 1981; modifiziert nach Riggs \& McLachlan, 1986) oder durch alkalische Lysis (Birnboim \& Doly, 1979; modifiziert). Plasmid-DNA aus $R$. eutropha konnte nur durch alkalische Lysis isoliert werden. Größere Plasmidmengen wurden sowohl aus $E$. coli als auch aus $R$. eutropha nach alkalischer Lyse der Zellen isoliert.

\subsubsection{Analytische Präparation durch schnelles Kochen}

Die analytische Plasmidisolierung aus E. coli wurde nach der Methode des schnellen Kochens ('rapid boiling') durchgeführt. Die Anzucht der zu testenden Klone erfolgte über Nacht auf LB-Selektivagar. Eine Impföse Zellmaterial wurde in $150 \mu 1$ Lysispuffer resuspendiert. Anschließend wurden $150 \mu \mathrm{l}$ Lysispuffer (mit $2 \mathrm{mg}$ Lysozym/ml, frisch angesetzt) eingemischt und die Proben $60 \mathrm{~s}$ im Wasserbad gekocht. Zur Abkühlung wurden die Ansätze für mindestens $3 \mathrm{~min}$ auf Eis gestellt. Im Anschluß erfolgte eine Pelletierung der denaturierten Proteine durch Zentrifugation für $10 \mathrm{~min}$ bei RT und 13,000 Upm. Das Sediment wurde anschließend mit Hilfe eines sterilen Zahnstochers entfernt. Durch Zugabe von 0.4 Vol. 5M $\mathrm{NH}_{4}$-Acetat, $\mathrm{pH} 7.5$, und 0.7 Vol. Isopropanol wurde dann die DNA gefällt (s. 2.10.2 und nach 10 min Trocknung bei $37^{\circ} \mathrm{C}$ in $20 \mu \mathrm{TE}$-Puffer aufgenommen. 


$\begin{aligned} & \text { Lysispuffer: } 10 \mathrm{mM} \text { Tris-HCl, } \mathrm{pH} 8.0 \\ & 50 \mathrm{mM} \text { EDTA, } \mathrm{pH} 8.0 \\ & 8 \%(\mathrm{w} / \mathrm{v}) \text { Saccharose } \\ & 0.5 \%(\mathrm{w} / \mathrm{v}) \text { Triton X-100 }\end{aligned}$

\subsubsection{Analytische Präparation durch alkalische Lyse}

Für die alkalische Lyse von $R$. eutropha wurde ein modifiziertes Protokoll der präparativen Plasmidisolierung (s. 2.10.4.4 verwendet. Um aus E. coli im analytischen Maßstab PlasmidDNA zu erhalten, wurde diese Methode alternativ zur Qiagen-Plasmidisolierung (s .2.10.4.3 verwendet.

Zur Isolierung aus E. coli wurde bei Plasmiden hoher Kopienzahl $2 \mathrm{ml}$, bei Plasmiden mit niedriger Kopienzahl 4-6 ml einer in LB-Medium angezogenen Bakterienkultur verwendet. Bei R. eutropha wurden 2-4 ml einer NB- oder Fructose-MM-Kultur eingesetzt. Nach Ernte der Zellen (s.2.2.7 wurden diese in $300 \mu$ l Lösung 1 resuspendiert. Nach Zugabe von $300 \mu 1$ frisch angesetzter Lösung 2 erfolgte ein Durchmischen des Reaktionsansatzes durch mehrfaches Schwenken des Eppendorfgefäßes. Die Lyse der Zellen war nach maximal 5 min Inkubation bei RT abgeschlossen. Nach Zugabe von $300 \mu$ l Lösung 3 wurde wiederum gründlich durchmischt und für $10 \mathrm{~min}$ auf Eis inkubiert. Die präzipitierten SDSProteinkomplexe wurden dann durch Zentrifugation (15 min, 13,000 Upm, RT) pelletiert. Zur Entfernung der restlichen Proteine aus dem Überstand erfolgte eine Phenol-ChloroformExtraktion. Die DNA wurde anschließend gefällt, gewaschen, getrocknet und in TE-Puffer aufgenommen (s. 2.10.2.

Eine Überprüfung von Qualität und Ausbeute der isolierten DNA wurde durch Restriktionsverdau (s. 2.12.1 und anschließende elektrophoretische Auftrennung im Agarosegel (s. 2.15 vorgenommen.

Lösung 1

$50 \mathrm{mM}$ Tris-HCl, $\mathrm{pH} 8.0$

$10 \mathrm{mM}$ EDTA

Lösung 2

$0.2 \mathrm{~N} \mathrm{NaOH}$ (vor Gebrauch frisch angesetzt)

$1 \%(\mathrm{w} / \mathrm{v}) \mathrm{SDS}$

Lösung 3

$3 \mathrm{M} \quad$ K-Acetat, $\mathrm{pH} 5.5$ 


\subsubsection{Präparative Isolierung mit dem 'QIAprep Miniprep'}

Um qualitativ besonders hochwertige Plasmid-DNA, u.a. für Sequenzierungen, zu gewinnen, wurden Plasmide mit hoher Kopienzahl mit Hilfe des 'QIAprep Miniprep Kit' (Qiagen, Hilden) isoliert. Dieses Verfahren beruht auf der Methode der alkalischen Lyse nach Birnboim \& Doly, 1979 (s. 2.10.4.2, mit einer sich anschließenden Adsorption der DNA an die Silikagelmembran einer Minisäule unter Hochsalzbedingungen und einer abschließenden Elution unter Niedrigsalsbedingungen.

Für eine Standardplasmidisolierung wurden von $10 \mathrm{ml}$ einer bei $37^{\circ} \mathrm{C}$ über Nacht gewachsenen Kultur von E. coli 2x 1.5ml abgenommen und für 1 min bei 13,000 Upm abzentrifugiert. Die anschließende Plasmidisolierung erfolgte nach Angaben des Herstellers.

\subsubsection{Präparative Isolierung durch alkalische Lyse}

Zur Isolierung präparativer Mengen Plasmid-DNA wurden bei Plasmiden hoher Kopienzahl $50 \mathrm{ml}$, bei Plasmiden niedriger Kopienzahl $100 \mathrm{ml}$ einer über Nacht in LB-Medium angezogenen Kultur von E. coli eingesetzt. Nach Ernte der Zellen (s. 2.2.7) erfolgte eine Resuspension in $4 \mathrm{ml}$ Lösung 1 mit $40 \mu \mathrm{l}$ RNase-Lösung (10 mg/ml). Anschließend wurden $4 \mathrm{ml}$ frisch angesetzter Lösung 2 zugegeben und durch Schwenken eingemischt. Nach maximal 5 min Inkubation bei RT wurde das klare Lysat mit $4 \mathrm{ml}$ eiskalter Lösung 3 versetzt, gründlich durchmischt und 10 min auf Eis inkubiert. Die ausgefällten Proteine wurden durch Zentrifugation abgetrennt (15 min, 14,000 Upm, $4{ }^{\circ}$ C; Sorvall RC5C, Rotor SS-34). Danach wurde die DNA aus dem wässrigen Überstand durch Zugabe von 0.7 Vol. Isopropanol gefällt. Nach der Zentrifugation (30 min, 14,000 Upm, $4{ }^{\circ} \mathrm{C}$; Sorvall RC5C, Rotor SS-34) wurde das DNAPellet mit $70 \%$ (w/v) Ethanol gewaschen und dabei in Eppendorf-Reaktionsgefäße überführt. Die DNA wurde getrocknet und in $500 \mu 1$ TE-Puffer resuspendiert. Proteinreste wurden durch Phenolextraktion (s. 2.10.2 entfernt. Die DNA wurde erneut gefällt, gewaschen, getrocknet (s. 2.10.2 und je nach Ausbeute in 50-200 $\mu$ 1 TE-Puffer gelöst. Qualität und Ausbeute der isolierten DNA wurden durch Restriktionsverdau (s. 2.12.1] und anschließender elektrophoretischer Auftrennung im Agarosegel (s. 2.15 überprüft. 


\subsubsection{Isolierung von DNA-Fragmenten aus Agarosegelen}

\subsubsection{Mit dem 'QIAquick Gel Extraction Kit'}

Mit dem 'QIAquick Gel Extraction Kit' (Qiagen) wurden DNA-Fragmente für Klonierungen und Gelretardationsexperimente isoliert. Nach der elektrophoretischen Auftrennung des zu isolierenden Fragmentes in einem TAE-Agarosegel (s. 2.15.1) wurde die entsprechende DNA-Bande mit einem Skalpell unter UV-Licht (366 nm) aus dem Gel ausgeschnitten, in ein Eppendorf-Reaktionsgefäß überführt und gewogen. Aufgrund der Volumenbegrenzung der Präparation mußte das Gelstück möglichst genau ausgeschnitten werden. Anschließend wurde die Isolierung des Fragmentes nach den Angaben des Herstellers durchgeführt.

\subsubsection{Aus niedrigschmelzender Agarose}

Alternativ zum 'QIAquick Gel extraction Kit' wurden DNA-Fragmente im Größenbereich von 0.1-10 kb aus LMP-Agarosegelen (s.2.15.2 isoliert. Es wurde Sea-Plaque-GTG Agarose (Biozym, Hessisch Oldendorf) verwendet. Nach der elektrophoretischen Auftrennung wurde das zu isolierende Fragment unter UV-Licht (366 nm) mit einem Skalpell ausgeschnitten und in ein Eppendorf-Reaktionsgefäß überführt. Es folgte eine Inkubation für 10 min bei $65^{\circ} \mathrm{C}$, um DNasen zu inaktivieren. Die so isolierte DNA konnte ohne weitere Aufreinigung direkt zur Ligation (s. 2.12.4 eingesetzt und bei $4{ }^{\circ} \mathrm{C}$ gelagert werden.

\subsection{Konzentrationsbestimmung von Nucleinsäuren}

Die Konzentration von DNA-Lösungen wurde entweder photometrisch durch Messung der Absorption bei $260 \mathrm{~nm}$ gegen $\mathrm{H}_{2} \mathrm{O}$ bidest. bestimmt oder im Rahmen einer AgaroseGelelektrophorese bei parallelem Auftrag eines definierten Standards (z.B. mit HindIII verdauter $\lambda$-DNA) abgeschätzt. Bei der photometrischen Bestimmung wurden bei einer $A_{260}$ von 1 nach Sambrook et al. (1989) folgende Konzentrationen zugrunde gelegt:

doppelsträngige DNA $\quad 50 \mu \mathrm{g} / \mathrm{ml}$

einzelsträngige DNA $\quad 40 \mu \mathrm{g} / \mathrm{ml}$

Oligonucleotide $\quad 31 \mu \mathrm{g} / \mathrm{ml}$

Alternativ dazu wurde die Konzentration geringer Nucleinsäuremengen nach elektrophoretischer Auftrennung im Agarosegel (s. 2.15.1) und Anfärbung mit Ethidiumbromid abge- 
schätzt, und zwar durch Vergleich der Fluoreszenzintensitäten mit einem mitgeführten Standard bekannter Konzentration.

\subsection{Enzymatische Modifikation von DNA}

\subsubsection{Restriktionsspaltung}

Isolierte DNA wurde mit 2-10 U Restriktionsenzym/ $\mu \mathrm{g}$ DNA im geeigneten Puffersystem des jeweiligen Herstellers zwischen $30 \mathrm{~min}$ und $5 \mathrm{~h}$ bei empfohlener Temperatur vollständig verdaut. Zur Entfernung von RNA wurde RNase in einer Endkonzentration von $20 \mu \mathrm{g} / \mathrm{ml}$ zugesetzt. Doppelverdaue mit Restriktionsenzymen, die unterschiedliche Puffer benötigten, wurden in 'One-for-all Buffer' (Pharmacia) durchgeführt. In speziellen Fällen erfolgten Doppelverdaue in zwei Schritten, wobei nach dem ersten Verdau eine Fällung mit Ethanol durchgeführt wurde (s. 2.10.2. Nach Resuspension der DNA konnte dann der zweite Verdau erfolgen. Die Restriktionsverdaue konnten durch Hitzeinaktivierung (nach Angaben des Herstellers), Phenol-Chloroform-Extraktion mit anschließender Fällung (s. 2.10.2 oder Zugabe des Auftragepuffers für die Agarose-Gelelektrophorese (s. 2.15.1) abgestoppt werden.

\subsubsection{Dephosphorylierung}

Um eine Religation restriktionsverdauter Vektor-DNA zu vermeiden, wurde die endständige 5'-Phosphatgruppe des linearisierten Vektors durch Behandlung mit alkalischer Phosphatase abgespalten. Dazu wurde dem Restriktionsansatz während der letzten 30 min der Inkubation $1 \mathrm{U}$ alkalische Phosphatase pro $\mu \mathrm{g}$ DNA zugesetzt. Anschließend wurde das Enzym durch Phenol-Chloroform-Extraktion inaktiviert und die DNA gefällt (s. 2.10.2).

\subsubsection{Auffüllen überstehender 5'-Enden}

Zur Ligation von DNA-Fragmenten mit nicht kompatiblen Restriktionsenden, wurden die überstehenden 5'-Enden mit Hilfe des Klenow-Fragmentes der DNA-Polymerase I aufgefüllt. Nach Hitzeinaktivierung der am Restriktionsverdau beteiligten Enzyme erfolgte die Zugabe des Klenow-Fragments in einer Konzentration von $0.5 \mathrm{U} / \mu \mathrm{g}$ DNA. Hinzugefügt wurden außerdem Desoxynucleotide (dNTP) in einer Endkonzentration von $100 \mu \mathrm{M}$. Nach 15 min Inkubation wurde das Klenow-Fragment durch Hitzeinaktivierung $\left(10 \mathrm{~min}, 70{ }^{\circ} \mathrm{C}\right)$ oder Phenol-Chloroform-Extraktion (s. 2.10.2 inaktiviert. 


\subsubsection{Ligation von DNA-Fragmenten}

Für die Ligation von DNA-Fragmenten wurde die Zusammensetzung der Ansätze so eingestellt, daß das zu klonierende Fragment in etwa zweifachem molaren Überschuß im Vergleich zum dephosphorylierten Vektor vorlag. Die Ligation erfolgte in einem $20 \mu 1$ Ansatz (DNAKonz. 10-100 ng/ $\mathrm{\mu l}$ ) in Gegenwart von $1 \mathrm{U}$ T4-DNA-Ligase in 1 x Ligase-Puffer entweder für $2 \mathrm{~h}$ bei RT oder über Nacht bei $16^{\circ} \mathrm{C}$.

$\begin{array}{lrl}5 \text { x Ligase-Puffer } & 250 \mathrm{mM} & \text { Tris-HCl, pH } 7.6 \\ \text { (Life Technologies) } & 100 \mathrm{mM} & \text { MgCl }_{2} \\ 10 \mathrm{mM} & \text { ATP } \\ 10 \mathrm{mM} & \text { DTE } \\ 25 \%(\mathrm{w} / \mathrm{v}) & \text { PEG } 8000\end{array}$

War eines der zu ligierenden Fragmente aus dem LMP-Agarosegel (s. 2.10.5.2 isoliert worden, so wurde ein äquimolares Verhältnis von Insert- und Vektor-DNA eingestellt, wobei die Menge an Insert-DNA je nach Größe des Fragmentes zwischen 50 und 300 ng lag. Das ausgeschnittene Gelstuickchen wurden durch Erhitzen für 10 min bei $65{ }^{\circ} \mathrm{C}$ geschmolzen und anschließend bei $37^{\circ} \mathrm{C}$ inkubiert, um ein Wiedererstarren zu vermeiden. Der Ligationsansatz setzte sich wie folgt zusammen:

\section{Ligationsansatz}

DNA-Fragment (in LMP-Agarose)

$15-30 \mu 1$

Linearisierte Vektor-DNA

$2-5 \mu 1$

5 x Ligase-Puffer

$24 \mu 1$

$\mathrm{H}_{2} \mathrm{O}$ bidest.

ad $120 \mu 1$

Das Ansatzvolumen wurde so gewählt, daß die Endkonzentration der LMP-Agarose unterhalb von $0.4 \%$ (w/v) lag. Die Ligation wurde durch Zugabe von 2 U T4-DNA-Ligase gestartet und erfolgte für $12-16 \mathrm{~h}$ bei $16{ }^{\circ} \mathrm{C}$. Zur Beendigung der Reaktion wurde die Ligase für $10 \mathrm{~min}$ bei $65{ }^{\circ} \mathrm{C}$ inaktiviert.

\subsubsection{Radioaktive Markierung durch PCR}

Für Gelretardationsexperimente in der PAGE (s. 2.16.1 wurden verschiedene Fragmente der $c b b$-Kontrollregion zunächst durch Standard-PCR (s. 2.20.1) amplifiziert und danach in einer 
sich anschließenden 'heißen PCR' durch den Einbau von $\left[\alpha-{ }^{35}\right.$ S $]$ dATP radioaktiv markiert. Die Markierung erfolgte mit Pfu-DNA-Polymerase (Stratagene, Heidelberg), da diese $\left[\alpha^{-35}\right.$ S $]$ Nucleotide im Vergleich zur Taq-Polymerase wesentlich effektiver einbaut. Im Gegensatz zur Standard-PCR werden zur Markierung nur 5 Cyclen benötigt, wobei im letzten Cyclus unmarkiertes dATP dazugesetzt wurde, um eine vollständige Auffüllung der Fragmente zu gewährleisten ('chase reaction').

\section{Markierungs-Ansatz (50 $\mu \mathrm{l})$}

10x Pfu-DNA-Polymerase-Puffer $10 \mu 1$

3x dNTP-Mix (dCTP, dGTP, dTTP je 2mM) $2.5 \mu 1$

$\left[\alpha-{ }^{35} \mathrm{~S}\right] \mathrm{dATP}(10 \mu \mathrm{Ci})$

$5 \mu l$

Primer 1 (100 pmol)

$1 \mu 1$

Primer 2 (100 pmol)

$1 \mu 1$

PCR-Produkt

$\mathrm{H}_{2} \mathrm{O}$ bidest.

Pfu-DNA- Polymerase

PCR-Programm (5 Cyclen)

\begin{tabular}{|c|c|c|c|}
\hline $4 \mathrm{~min}$ & Denaturierung & $95^{\circ} \mathrm{C}$ & \\
\hline $30 \mathrm{~s}$ & Denaturierung & $95^{\circ} \mathrm{C} 4$ & \\
\hline $30 \mathrm{~s}$ & Anlagerung der Primer & $59^{\circ} \mathrm{C}$ & $3 \mathrm{x}$ wiederholen \\
\hline $1 \mathrm{~min}$ & Polymerisation & $70^{\circ} \mathrm{C}$ & $(+1 \mathrm{x}$ nach Zugabe von $2 \mu 1 \mathrm{dATP} 2 \mathrm{mM}) *$ \\
\hline $5 \mathrm{~min}$ & Polymerisation & $70^{\circ} \mathrm{C}$ & \\
\hline$\infty$ & Abkühlung & $4^{\circ} \mathrm{C}$ & \\
\hline
\end{tabular}

*Zugabe des unmarkierten dATP bei $70^{\circ} \mathrm{C}$-Schritt am Ende des vierten Zyklus)

\subsubsection{Radioaktive Markierung von Oligonucleotiden}

Die Markierung von Olignucleotidprimern mit $\left[\gamma^{32} \mathrm{P}\right] \mathrm{ATP}$ zur Verwendung als Hybridisierungssonde (s. 2.18.2 erfolgte unter Phosphorylierung des 5'-Endes mit Hilfe der T4Polynucleotidkinase. 


\section{Markierungungsansatz}

10x PNK-Puffer

$\left[\gamma^{32} \mathrm{P}\right] \operatorname{ATP}(0.37 \mathrm{MBq}[10 \mu \mathrm{Ci}])$

$1.5 \mu 1$

Oligonucleotid (5 pmol/ $\mu \mathrm{l})$

$4 \mu \mathrm{l}$

T4-Polynucleotidkinase

$4 \mu 1$

$\mathrm{H}_{2} \mathrm{O}$ bidest.

$2 \mu 1$

ad $15 \mu 1$

Der Ansatz wurde $1 \mathrm{~h}$ bei $37^{\circ} \mathrm{C}$ inkubiert. Anschließend erfolgte eine Hitzeinaktivierung der T4-Polynucleotidkinase für $3 \min$ bei $95^{\circ} \mathrm{C}$.

\subsection{Selektion rekombinanter Klone von E. coli}

\subsubsection{Herstellung kompetenter Zellen für die Transformation}

Kulturen von E. coli wurden in $100 \mathrm{ml}$ LB-Medium bis zu einer $\mathrm{OD}_{550}$ von 0.5-0.6 angezogen, anschließend 15 min in Pyrexröhrchen auf Eis inkubiert und danach abzentrifugiert (15 min, 3,500 Upm, $4{ }^{\circ} \mathrm{C}$; Sigma-3K-1). Das Zellpellet wurde auf Eis in $15 \mathrm{ml}$ TFP1-Lösung aufgenommen. Nach 1-2 h Inkubation auf Eis wurde wiederum zentrifugiert und in $4 \mathrm{ml}$ TFP2-Lösung resuspendiert. Die Suspension wurde schließlich aliquotiert (100-200 $\mu$ l) und bei $-70{ }^{\circ} \mathrm{C}$ aufbewahrt. Dabei blieb die Kompetenz für DNA-Aufnahme über mehrere Monate erhalten.

TFP1-Lösung: $\quad 100 \mathrm{mM} \quad \mathrm{RbCl}$

$$
\begin{array}{ll}
50 \mathrm{mM} & \mathrm{MnCl}_{2} \\
10 \mathrm{mM} & \mathrm{CaCl}_{2} \\
30 \mathrm{mM} & \text { K-Acetat }
\end{array}
$$

TFP2-Lösung: $\quad 10 \mathrm{mM} \quad \mathrm{RbCl}$

$$
\begin{aligned}
10 \mathrm{mM} & \text { MOPS } \\
75 \mathrm{mM} & \mathrm{CaCl}_{2} \\
15 \%(\mathrm{w} / \mathrm{v}) & \text { Glycerin }
\end{aligned}
$$

\subsubsection{Transformation}

Die Transformation isolierter Plasmid-DNA in kompetente Zellen von E. coli erfolgte durch Hitzeschock nach Hanahan (1985). Dazu wurden $100 \mu$ l Suspension auf Eis aufgetaut, mit 2-5 
$\mu 1$ Plasmid-DNA oder 5-10 $\mu$ l Ligationsansatz versetzt und für $30 \mathrm{~min}$ auf Eis inkubiert. Es folgte eine Hitzeschockbehandlung für $90 \mathrm{~s}$ bei $42{ }^{\circ} \mathrm{C}$ mit anschließender Abkühlung auf Eis für 3 min. Die Zellen wurden dann nach Durchmischen mit $300 \mu$ LB-Medium für 60 min bei $37{ }^{\circ} \mathrm{C}$ inkubiert. Schließlich wurden 50-200 $\mu$ l auf Selektivagarplatten ausplattiert und diese über Nacht bei $37^{\circ} \mathrm{C}$ inkubiert.

\subsubsection{Selektion rekombinanter Klone}

Zur Selektion von Transformanten mit Plasmid-Derivaten der pUC-Serie (incl. pBluescript) wurde der X-Gal-Plattentest verwendet. Plasmide der pUC- und pBBR1MCS-Reihen enthalten neben dem Promotor- und Operatorbereich des lac-Operons auch das 5'-Ende des lacZ-Gens (Viera \& Messing, 1982). Dieses codiert das sog. $\alpha$-Peptid der $\beta$-Galaktosidase, welches die inaktive $\beta$-Galaktosidase verschiedener Wirtsstämme von $E$. coli, wie z.B. XL1Blue oder JW1, komplementieren kann. Da sich die multiple Klonierungsstelle der oben genannten Vektoren innerhalb des lacZ'-Gens befindet, sind nur Plasmide ohne Insert zur Komplementation fähig. In diesem Fall ist die aktive $\beta$-Galaktosidase anhand der Blaufärbung von Kolonien auf LB-Platten mit dem Induktor IPTG und dem Substrat X-Gal zu erkennen. Inserthaltige Transformanten sind daher an der fehlenden Farbstoffbildung, d.h. in Form von weißen Kolonien, zu erkennen (sog. Blau-Weiß-Selektion).

\subsection{Konjugative Plasmidübertragung}

Plasmide mit breitem Wirtsbereich wurden konjugativ von E. coli S17-1 durch 'agar-spotmating' (Friedrich et al., 1981c) auf $R$. eutropha übertragen. Der Donor E. coli S17-1 verfügt über die für die Konjugation nötigen tra-Genfunktionen des chromosomal integrierten RP4Plasmids. Donor und Rezipient wurden über Nacht in LB- plus Antibiotikum bzw. NBMedium angezogen. Jeweils $10 \mu 1$ Zellsuspension wurden übereinander auf eine frische NBPlatte getropft und für ca. $24 \mathrm{~h}$ bei $30{ }^{\circ} \mathrm{C}$ inkubiert. Anschließend wurden die gewachsenen Zellen unter Verwendung eines mit sterilen Baumwollsamt überzogenen Stempels auf Platten mit Fructose-Mineralmedium plus Antibiotikum übertragen. Nach 1-2 Tagen bei $30{ }^{\circ} \mathrm{C}$ erfolgte ein Verdünnungsausstrich der Transkonjuganten von $R$. eutropha auf FructoseMineralmedium plus Antibiotikum. Im Anschluß wurden Einzelkolonien durch Plasmidpräparation (s. 2.10.4.2) und Restriktionsverdau (s. 2.12.1) analysiert. 


\subsection{Gelelektrophoretische Auftrennung von Nucleinsäuren}

\subsubsection{Agarose-Gelelektrophorese}

Die Auftrennung von DNA erfolgte durch Agarose-Gelelektrophorese in horizontalen Gelkammern. Zur Analyse wurden Mini-Gelkammern mit einer Gelfläche von 7 x $10 \mathrm{~cm}$ verwendet. Der zur Formung der Taschen verwendete Kamm ermöglichte einen Auftrag von bis zu 18 Proben mit einem max. Volumen von $15 \mu$ l. Die Agarosekonzentration in den Gelen war abhängig von der Größe der zu trennenden Fragmente und variierte zwischen 0.8 und $3 \%$ (w/v). Als Elektrophoresepuffer diente TAE-Puffer. Für die Herstellung des Gels wurde die Agarose durch kurzes Aufkochen (Mikrowelle) in TAE-Puffer gelöst und konnte dann nach Abkühlen auf ca. $50{ }^{\circ} \mathrm{C}$ in die Gelkammer gegossen werden. Zur Ausformung der Taschen wurde der Kamm in die noch flüssige Agarose eingesetzt. Nach dem Erstarren des Gels wurde mit Puffer überschichtet und der Kamm entfernt. Vor dem Auftragen wurden die Proben mit 0.1 Vol. des Auftragepuffers versetzt.

Maxi-Agarosegele, die eine bessere Auflösung erlauben, wurden verwendet, wenn eine exakte Größenbestimmung von DNA-Fragmenten erforderlich war. In einer Maxi-Gelkammer konnten auf einer Gelfläche von 14.5 x $12.5 \mathrm{~cm}$ (Gelvolumen $120 \mathrm{ml}$ ) bis zu 25 Proben mit maximal $30 \mu \mathrm{l}$ Volumen aufgetragen werden. Die Agarosekonzentration in den Gelen war abhängig von der Größe der zu trennenden Fragmente und variierte ebenfalls zwischen $0.8 \%$ und $3 \%(\mathrm{w} / \mathrm{v})$.

Die Elektrophorese in Minigelen wurde bei konstanter Spannung von maximal 90 V für 45-90 min durchgeführt, in Maxigelen bei $60 \mathrm{~V}$ für $5 \mathrm{~h}$. Anschließend wurde das Gel für $10 \mathrm{~min}$ in einer Ethidiumbromidlösung $(1.5 \mu \mathrm{g} / \mathrm{ml})$ gefärbt und dann ebenso lange entfärbt. Die Datenarchivierung erfolgte mit Hilfe eines Video-Dokumentationssystems (Cybertech, Berlin).

\begin{tabular}{|c|c|c|}
\hline \multirow[t]{2}{*}{ TAE-Puffer } & $40 \quad \mathrm{mM}$ & Tris-Acetat, $\mathrm{pH} 8.1$ \\
\hline & $\mathrm{mM}$ & EDTA \\
\hline \multirow[t]{5}{*}{ Auftragepuffer } & $400 \mathrm{mM}$ & Tris-Acetat, $\mathrm{pH} 8.1$ \\
\hline & $10 \mathrm{mM}$ & EDTA \\
\hline & $25 \%(\mathrm{v} / \mathrm{v})$ & Glycerin \\
\hline & $0.25 \%(\mathrm{w} / \mathrm{v})$ & Bromphenolblau \\
\hline & $0.25 \%(\mathrm{w} / \mathrm{v})$ & Xylencyanol FF \\
\hline
\end{tabular}


Durch PstI oder HindIII verdaute DNA des Bakteriophagen $\lambda$ wurde zur Größen- und Konzentrationsbestimmung linearer DNA-Fragmente mitgeführt. Die Größe der jeweiligen $\lambda$ DNA-Fragmente ist bekannt (Sanger et al., 1982). Teilweise wurden auch sog. DNA-Leitern ('1-kb Ladder' oder '100-bp Ladder'; MBI Fermentas, St. Leon-Rot) eingesetzt, die aus DNA-Fragmenten definierter Größen bestehen und somit über den gesamten Bereich eine genaue Größenbestimmung erlauben.

\subsubsection{LMP-Agarose-Gelelektrophorese}

Die LMP-Agarose besitzt einen niedrigeren Schmelzpunkt $\left(\leq 65{ }^{\circ} \mathrm{C}\right)$ als herkömmliche Agarose und ist daher besonders geeignet zur Isolierung von DNA-Fragmenten, in Verbindung mit einer sich direkt anschließenden enzymatischen Modifikation der isolierten Fragmente. Da die LMP-Agarose nach Schmelzen und anschließender Verdünnung auf unterhalb $0.4 \%(\mathrm{w} / \mathrm{v})$ nicht mehr erstarrt, ist die weitere enzymatische Behandlung der Fragmente direkt in der Gelmatrix möglich. Wegen des niedrigen Schmelzpunktes sind die Gele sehr weich, weshalb sie in separaten Gelschlitten $(6.5$ x $9 \mathrm{~cm}$; Gelvolumen $25 \mathrm{ml})$ hergestellt wurden, in denen sie auch nach der Elektrophorese verblieben. Die Agarosekonzentration lag, je nach dem aufzutrennenden Größenbereich der Fragmente, zwischen 0.8 und $1.5 \%$ (w/v). Zur Isolierung von Fragmenten $>1 \mathrm{~kb}$ wurde SeaPlaque GTG-Agarose verwendet, für Fragmente $<1$ kb NuSieve GTG-Agarose (Biozym, Hess. Oldendorf). Die LMP-Agarose wurde durch kurzes Aufkochen in TAE-Puffer (s.o.) gelöst und nach dem Abkühlen auf ca. 45 ${ }^{\circ} \mathrm{C}$ mit $2 \mu$ Ethidiumbromidlösung $(10 \mathrm{mg} / \mathrm{ml})$ versetzt. Zur Bildung der Taschen wurde ein achtzähniger Kamm mit einem Volumen von $10 \mu \mathrm{l}$ pro Tasche verwendet. $\mathrm{Zu}$ den Proben wurde vor dem Auftragen 0.1 Vol. Auftragepuffer gegeben. Als Elektrophoresepuffer diente TAE-Puffer. Die Elektrophorese erfolgte bei einer konstanten Spannung von maximal $60 \mathrm{~V}$.

\subsubsection{Polyacrylamid-Harnstoff-Gelelektrophorese}

Zur Bestimmung der Nucleotidsequenz einer DNA wurde eine Polyacrylamid-HarnstoffGelelektrophorese durchgeführt. Die Auftrennung radioaktiv markierter Produkte erfolgte in einer speziellen Sequenzgel-Apparatur (Typ S2; Life Technologies). Dafür wurden $6 \%$ (w/v) Polyacrylamidgele in 1 x TBE-Puffer mit 7.5 M Harnstoff gegossen. Die zur Herstellung der Gele benötigten Glasplatten wurden zunächst nacheinander mit Aceton und mit 96 \% (w/v) Ethanol gründlich gereinigt. Die kleinere Glasplatte, an der das Gel nach dem Lauf haften bleiben sollte, wurde mit Bindesilan beschichtet. Die größere Platte wurde dagegen mit 
Repellsilan behandelt. Nach dem Trocknen wurden die silanisierten Seiten mit $96 \%$ (w/v) Ethanol leicht poliert.

Die angesetzte Gellösung wurde durch 2 Lagen Filterpapier (Whatman 3MM) abgenutscht und $20 \mathrm{~min}$ im Wasserstrahlvakuum entgast. Die Polymerisation wurde durch Zugabe von $550 \mu 110 \%$ (w/v) Ammoniumpersulfat und $28 \mu 1$ TEMED gestartet und die Gellösung luftblasenfrei in die Gelkammer gegossen. Zur Formung des oberen Randes wurde ein glatter Kamm eingesetzt. Die Polymerisationsdauer lag bei mindestens $2 \mathrm{~h}$.

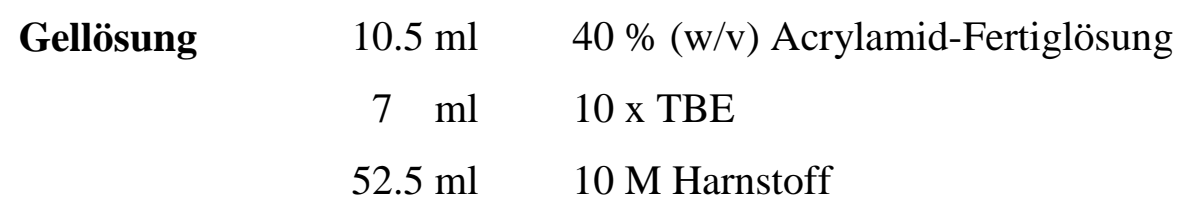

$10 \times$ TBE $\quad 1 \quad \mathrm{M} \quad$ Tris-Borat, $\mathrm{pH} 8.3$

$0.01 \mathrm{M} \quad$ EDTA

$\begin{array}{lll}\text { Bindesilan } & 35 \mu \mathrm{l} & \text { 3-Metacryloxypropyltrimethoxysilan } \\ & 10 \mathrm{ml} & \text { Ethanol }\end{array}$

Repellsilan $\quad 500 \mu \mathrm{l} \quad$ Dimethyldichlorsilan

$10 \mathrm{ml}$ 1,1,1-Trichlorethan

Als Laufpuffer wurde 1 x TBE-Puffer verwendet. Nachdem ein Haifischzahnkamm zur Bildung der Taschen eingesetzt worden war, erfolgte ein Vorlauf für 30 min bei $1500 \mathrm{~V}$. Die Taschen wurden mit Laufpuffer gespült und $3 \mu 1$ der zuvor für 5 min bei $95{ }^{\circ} \mathrm{C}$ denaturierten Proben aufgetragen. Die Elektrophorese erfolgte bei einer Spannung von $1600 \mathrm{~V}$ für ca. 1.5-5 $\mathrm{h}$ je nach gewünschtem Auftrennungsbereich.

Nach dem Lauf wurde die Platte mit dem daran anhaftenden Gel für 10-20 min in $10 \%$ (w/v) Essigsäure geschwenkt danach gewässert und für $1 \mathrm{~h}$ bei $80{ }^{\circ} \mathrm{C}$ getrocknet. Anschließend wurde ein Röntgenfilm zur Autoradiographie (s. 2.19) aufgelegt. Durch 30 min Schwenken in $2 \mathrm{M} \mathrm{NaOH}$ konnte das Gel wieder von der Glasplatte abgelöst werden.

\subsection{Gelretardation von DNA-Protein-Komplexen}

Wechselwirkungen zwischen DNA und Proteinen durch Bildung von Protein-DNAKomplexen wurden anhand von Gelretardationsexperimenten ('mobility shift') untersucht (Ausubel et al., 1988; modifiziert). Die Versuche wurden sowohl mit $\left[\alpha^{-}{ }^{35}\right.$ S $]$ dATP markier- 
tem Fragment (s. 2.12.5) in der nicht-denaturierenden 5\% PAGE (s. 2.16.1), als auch mit unmarkiertem Fragment im 2\% TAE-Agarosegel ( s. 0] durchgeführt.

\subsubsection{In der nicht-denaturierenden PAGE}

Die elektrophoretische Auftrennung erfolgte in nicht-denaturierenden Polyacrylamidgelen (5\% [w/v] Acrylamid; $16 \times 12 \mathrm{~cm}$ ) mit einer Dicke von $0.5 \mathrm{~mm}$. Das maximale Auftragevolumen betrug $10 \mu \mathrm{l}$ pro Tasche $(5 \times 5 \times 0.5 \mathrm{~mm})$. Die Glasplatten wurden zuvor mit Bindebzw. Repellsilan (s. 2.15.3 behandelt. Als Puffersystem diente Tris-Glycin-Puffer.

$\begin{array}{lrl}\text { Gel- und Elektrophorespuffer } & 50 \mathrm{mM} & \text { Tris-HCl, pH 7.4 } \\ \text { (5x Tris-Glycin-HCl-Puffer): } & 960 \mathrm{mM} & \text { Glycin } \\ 5 \mathrm{mM} & \text { EDTA } \\ \text { Gellösung (5\% PAGE; 20ml) } & 3.2 \mathrm{ml} & \text { Bisacrylamid-Lsg.(30:0,8) } \\ 4.0 \mathrm{ml} & 5 x \text { Tris/Glycin pH 7.4 } \\ 0.5 \mathrm{ml} & \text { Glycerin } \\ 12.3 \mathrm{ml} & \mathrm{H}_{2} \mathrm{O} \text { bidest. } \\ 13.3 \mu l & \text { TEMED* } \\ 160 \mu l & \text { APS* }\end{array}$

\footnotetext{
* Zugabe dieser beiden Komponenten erfolgte erst direkt vor dem Gießen der Gellösung, da hierduch die Polymerisierung des Gels eingeleitet wurde.
}

Zur Bindung des/r Proteins/e an die DNA erfolgte eine Inkubation des Bindungsansatzes für 5-20 $\min$ bei $25^{\circ} \mathrm{C}$.

\section{Bindungsansatz}

$$
\begin{array}{lr}
\left.\left[\alpha-{ }^{35} \text { S }\right] \text { dATP }\right] \text { markiertes DNA-Fragment (ca. } 2 \text { ng) } & 2 \mu \mathrm{l} \\
\text { Kompetitor-DNA }(0-2 \mu \mathrm{g}) & 0-2 \mu \mathrm{l} \\
\text { Protein- oder Rohextrakt (max. } 2 \mu \mathrm{g}) & 1-2 \mu \mathrm{l} \\
\text { Bindungspuffer } & \text { ad } 10 \mu \mathrm{l}
\end{array}
$$

Im Anschluß an die Bindungsreaktion wurden dem Ansatz $3 \mu 1$ MS-Beschwerungslösung zugesetzt und dieser bis zur Elektrophorese auf Eis gehalten. Die Elektrophorese erfolgte bei einer konstanten Stromstärke von 9 mA bis zum Austreten des Farbmarkers (Bromphenolblau) aus dem Gel oder zur höheren Auflösung bis max. 3h. Anschließend wurde das an der mit Bindesilan behandelten Glasplatte anhaftende Gel zunächst für 45 min bei $80^{\circ} \mathrm{C}$ getrocknet und danach autoradiographiert (s . 2.19. 


$\begin{array}{rll}\text { Bindungspuffer } & 50 \mathrm{mM} & \text { Tris-HCl, pH 7.4 } \\ 10 \mathrm{mM} & \text { KCl } \\ 1 \mathrm{mM} & \text { EDTA } \\ 1 \mathrm{mM} & \text { DTT }\end{array}$

MS-Beschwerungslösung

$$
\begin{array}{cl}
50 \%(w / v) & \text { Glycerin } \\
0.02 \%(w / v) & \text { Bromphenolblau }
\end{array}
$$

\subsubsection{In Agarosegelen}

Eine vereinfachte Form der Gelretardationen wurden in Agarose Minigelen $(2 \%$ [w/v] Agarose in TAE-Puffer) durchgeführt. Diese Methode fand im wesentlichen zur Kontrolle und Dokumentation der Anreicherung potentieller Transkriptionsregulatoren (s. 2.7) Anwendung. Sie bot die Möglichkeit einer wesentlich beschleunigten, wenn auch im Gegensatz zu den Gelretardationen in der PAGE weniger spezifischen Bestimmung der Spitzenfraktionen (s. 2.16.1).

Die Herstellung des Gels erfolgte wie bei einer Standardgelelektrophorese (s. 2.15.1).

$\begin{array}{ll}\text { 10x TAE-Puffer } & 400 \mathrm{mM} \text { Tris-Acetat, } \mathrm{pH} 7.8 \\ 100 \mathrm{mM} \text { Na-Acetat } \\ 10 \mathrm{mM} \text { EDTA }\end{array}$

Zur Bindung der Proteine an die DNA erfolgte eine Inkubation des Bindungsansatzes für 10$20 \mathrm{~min}$ bei $25^{\circ} \mathrm{C}$.

\section{Bindungsansatz:}

$$
\begin{array}{lr}
\text { DNA-Fragment (50-100 ng) } & 2 \mu \mathrm{l} \\
\text { Kompetitor-DNA (0-2 } \mu \mathrm{g}) & 0-2 \mu \mathrm{l} \\
\text { Protein- bzw. Rohextrakt (max. 2 } \mu \mathrm{g}) & 1-2 \mu \mathrm{l} \\
\text { Bindungspuffer } & \text { ad } 10 \mu \mathrm{l}
\end{array}
$$

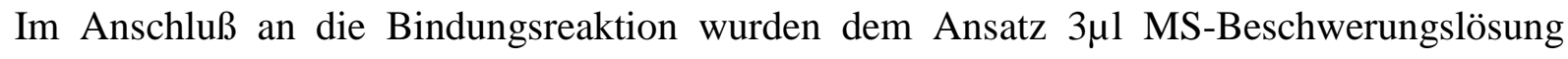
zugesetzt und dieser bis zur Elektrophorese auf Eis gehalten. Die Elektrophorese erfolgte für $1.2 \mathrm{~h}$ bei einer konstanten Spannung von $60 \mathrm{~V}$ und einer Stromstärke von max. $80 \mathrm{~mA}$ bis der Farbmarker (Bromphenolblau) eine Position ca. $2 \mathrm{~cm}$ vor dem Gelende erreicht hatte. 
Anschließend wurde das Gel mit Ethidiumbromid gefärbt und im Videosystem dokumentiert (s. 2.15.1.

\subsection{Sequenzierung von DNA}

Nicht eigenständig durchgeführte Sequenzierungen erfolgten durch das 'Göttingen Genomics Laboratory' (Institut für Mikrobiologie und Genetik, Göttingen) mit dem ABI PRISM 337 DNA-Sequenzer. Die Flureszenssignale wurden automatisch in Sequenzdaten umgewandelt. Dazu wurde das Programm DNA-Sequenzer Datacollection, Version 2.0 (Fa PE Applied Biosystems, Weiterstadt) verwendet.

\subsubsection{Radioaktive Sequenzierung durch 'cycle sequencing'}

Doppelsträngige Plasmid-DNA wurde nach einer Variante der Didesoxy-KettenabbruchMethode von Sanger et al. (1977) sequenziert, die auf einer linearen Amplifikation der Reaktionsprodukte beruht. Die cyclische Sequenzierung wurde mit dem 'SequiTherm Excel Cycle Sequencing Kit' (Biozym) durchgeführt. Der Vorteil dieser Methode zu herkömmlichen Verfahren besteht darin, daß aufgrund der Verwendung einer thermostabilen DNAPolymerase alle zur Sequenzierung notwendigen Schritte (Denaturierung, Primeranlagerung, Polymerisation) in einem PCR-Ansatz durchgeführt werden können. Ein weiterer Vorteil dieser Methode liegt in dem relativ geringen Bedarf an Matrizen-DNA, außerdem bewirken die hohen Reaktionstemperaturen eine Eliminierung von DNA-Sekundärstrukturen, die ansonsten zu unspezifischen Kettenabbrüchen führen.

Da bei der cyclischen Sequenzierung im Gegensatz zur eigentlichen PCR nur ein Primer verwendet wird, erfolgt nur eine linerare und keine exponentielle Amplifikation der Produkte. Diese werden in einer Polyacrylamid-Harnstoff-Gelelektrophorese aufgetrennt (s. 2.15.3 und durch Autoradiographie (s. 2.19) nachgewiesen. Die als Matrizen-DNA verwendeten Plasmide wurden durch Qiagen-Miniprep-Präparation isoliert und gereinigt (s. 2.10.4.3). In pBluescriptSK klonierte Fragmente wurden unter Verwendung sowohl von Universal- als auch Reverse-Primer sequenziert.

Universal-Primer: 5'-CGA CGT TGT AAA ACG ACG GCC AGT-3'

Reverse-Primer: 5'-AAC AGC TAT GAC CAT GAT TAC GCC-3' 
Der Reaktionsansatz für die Sequenzreaktion wurde wie folgt auf Eis angesetzt:

\section{Prämix}

Primer $(20 \mathrm{pmol})$

$1.5 \mu 1$

$\left[\alpha-{ }^{35} \mathrm{~S}\right] \mathrm{dATP}(10 \mu \mathrm{Ci} / \mu \mathrm{l})$

$1.5 \mu 1$

Puffer A

$5 \mu 1$

Puffer B

DNA

$500 \mathrm{fmol}$

SequiTherm-DNA-Polymerase (5U)

$1 \mu \mathrm{l}$

$\mathrm{H}_{2} \mathrm{O}$ bidest.

$\operatorname{ad} 18 \mu 1$

In vier PCR-Reaktionsgefäße $(0.5 \mathrm{ml})$ wurden je $2 \mu \mathrm{l}$ der jeweiligen A-, C-, G- oder TTerminationsmixe pipettiert und im Anschluß mit jeweils $4 \mu 1$ des Prämixes auf Eis gemischt. Für die Reaktion wurde folgendes Programm in einem Thermocycler (PTC-100; MJ Research, Watertown, USA) verwendet:

$\begin{array}{llll}\text { PCR-Programm } & 5 \mathrm{~min} & \text { Denaturierung } & 95^{\circ} \mathrm{C} \\ & 30 \mathrm{~s} & \text { Denaturierung } & 95^{\circ} \mathrm{C} \\ & 30 \mathrm{~s} & \text { Anlagerung der Primer } & 60^{\circ} \mathrm{C} \\ & 1 \mathrm{~min} & \text { Polymerisation } & 70^{\circ} \mathrm{C} \\ 2 \mathrm{~min} & \text { Polymerisation } & 70^{\circ} \mathrm{C} \\ & \infty & \text { Abkühlung } & 4^{\circ} \mathrm{C}\end{array}$

Die Reaktion wurde durch Zugabe von $3 \mu 1$ Stop-Lösung beendet.

Stop-Lösung $95 \%(\mathrm{v} / \mathrm{v})$ Formamid

$10 \mathrm{mM}$ EDTA

$0.1 \%(\mathrm{w} / \mathrm{v})$ Xylencyanol

$0.1 \%(\mathrm{w} / \mathrm{v})$ Bromphenolblau

\subsection{DNA-DNA-Hybridisierung}

\subsubsection{Southern-Blotting}

Zum Nachweis von DNA-Fragmenten durch DNA-DNA-Hybridisierung (s. 2.18.2 wurde die zu analysierende DNA nach Restriktionsspaltung elektrophoretisch in einem MaxiAgarosegel aufgetrennt (s.15.1). Die Laufweiten der Fragmente wurden anhand der Marker (Längenstandards) unter Verwendung eines Lineals als Referenzmaßstab im Videosystem dokumentiert. Der Transfer der DNA auf eine positiv geladene Nylonmembran (Biodyne B; 
Pall, Dreieich) erfolgte mit Hilfe einer Vakuum-Blot-Apparatur (Vacu-Gene XL; Amersham Pharmacia Biotech).

Um durch eine partielle alkalische Hydrolyse die Übertragung großer DNA-Fragmente zu erleichtern, wurde das Gel nach Anlegen des Unterdrucks (55 mbar) zunächst für 20 min mit Depurinisierungslösung und dann für $20 \mathrm{~min}$ mit Denaturierungslösung überschichtet. Im Anschluß wurde das Gel für 20 min mit Neutralisierungspuffer behandelt. Der eigentliche Transfer erfolgte nach Überschichtung des Gels mit 20 x SSC-Lösung für 2 h. Vor Abnahme des Gels wurden die Positionen der Geltaschen durch Einstechen in die Membran markiert. Durch kurzes Waschen mit 5 x SSC erfolgte eine Entfernung der an der Membran anhaftenden Gelreste. Zur Fixierung der übertragenen DNA auf der Membran wurde diese mit UVLicht bestrahlt (254 nm, 3 min). Die Membran konnte im Anschluß direkt zur Hybridisierung (s. 2.18.2 eingesetzt oder in Whatman-Papier und Alufolie eingeschlagen bei RT aufbewahrt werden.

\section{Depurinisierungslösung}

$0.2 \mathrm{M} \mathrm{HCl}$

\section{Neutralisierungspuffer}

$0.1 \mathrm{M}$ Tris- $\mathrm{HCl}, \mathrm{pH} 7.4$

\author{
Denaturisierungslösung \\ $1 \mathrm{M} \mathrm{NaCl}$ \\ $0.5 \mathrm{M} \mathrm{NaOH}$
}

\subsubsection{Radioaktive Hybridisierung}

Die Hybridisierung auf Nylonmembran gebundenener DNA mit radioaktiv markierten Oligonucleotiden (s. 0 erfolgte in verschraubbaren Glasröhrchen in einem Hybridisierungsofen (Hybaid Mini Hybridization Oven, Biometra). Vor der eigentlichen Hybridisierung wurde eine Vorhybridisierung in $30 \mathrm{ml}$ Hybridisierungslösung (QuickHyb Rapid Hybridization Solution; Stratagene) für $2 \mathrm{~h}$ bei $42^{\circ} \mathrm{C}$ durchgeführt. Anschließend wurde dem Ansatz die zuvor für 5 min bei $95^{\circ} \mathrm{C}$ denaturierte Sonden-DNA zugesetzt und über Nacht in Abhängigkeit von der Anlagerungstemperatur der verwendeten Oligonucleotide $\left(10^{\circ} \mathrm{C}\right.$ unterhalb des Schmelzpunkts) hybridisiert. 
Unspezifisch an die Membran gebundene DNA wurde durch folgende Waschschritte entfernt:

$2 \times 5$ min bei RT mit $2 \times$ SSC

$2 \times 30$ min bei $42{ }^{\circ} \mathrm{C}$ mit $2 \times \operatorname{SSC}+3 \%(w / v) \operatorname{SDS}$

$2 \times 30$ min bei RT mit $0.1 \times$ SSC

Die feuchte Membran wurde in Plastikfolie eingeschlagen und zum autoradiographischen Nachweis der Hybridisierungssignale im Phosphor-Imager (Molecular Dynamics) für $1 \mathrm{~h}$ bis 4 Tage exponiert (s. 2.19.

\subsection{Autoradiographie}

Der autoradiographische Nachweis radioaktiv markierter DNA in Gelen erfolgte durch Auflegung von Röntgenfilmen (Hyperfilm $\beta$-max, Amersham Buchler). Nach einer Expositionszeit von einem bis zu mehreren Tagen wurde der Film ca. 5 min entwickelt (Entwickler Kodak LX 24), kurz gewässert und 10 min fixiert (Fixierer Kodak AL 4). Abschließend wurde er nochmals gewässert und getrocknet.

\subsection{PCR-Methoden}

Die In vitro-Amplifikation von DNA mit Hilfe der PCR (Mullis \& Faloona, 1987) wurde sowohl mit Taq-DNA-Polymerase (Qiagen, Hilden) als auch Pfu-DNA-Polymerase (Promega, Mannheim) durchgeführt. Als Matrizen dienten chromosomale DNA, Plasmid-DNA oder isolierte DNA. Für die Amplifikation zu klonierender Fragmente aus chromosomaler DNA wurde $P f u$-DNA-Polymerase verwendet, da diese aufgrund ihrer 3' $\rightarrow$ 5'-'proofreading'Aktivität sehr viel weniger Punktmutationen generiert und damit die Matrize genauer repliziert als Taq-DNA-Polymerase.

\subsubsection{Standard-PCR}

Aufgrund ihrer deutlich höheren Amplifikationseffizienz wurde für Standardamplifikationen Taq-DNA-Polymerase eingesetzt. Die verwendeten Primer variierten in ihrer Länge zwischen 17 und 24 Basen. Für die Amplifikation eines spezifischen DNA-Abschnittes wurden die beiden Primer, die diesen Bereich einschlossen, möglichst so gewählt, daß sie annähernd 
gleiche Hybridschmelzpunkte aufwiesen. Der Schmelzpunkt wurde nach folgender Formel berechnet (Chester \& Marshak, 1993):

$\mathrm{T}_{\mathrm{m}}=69.3+0.41(\% \mathrm{G}+\mathrm{C}-$ Gehalt $)-\frac{650}{\mathrm{~L}}$

G+C-Gehalt: prozentualer molarer Gehalt des Primers an G und C

L: Länge des Primers.

Die PCR wurde in einem Thermocycler mit beheizbarem Deckel (PTC-100; MJ Research, Watertown, USA) durchgeführt. Der Reaktionsansatz setzte sich folgendermaßen zusammen:

\section{PCR-Reaktionsansatz:}

$$
\begin{array}{rll}
0.5 \mu \mathrm{l} & \text { DNA } & (\leq 500 \mathrm{ng} \text { Gesamt-DNA; } \leq 200 \text { ng Plasmid-DNA }) \\
1 \mu \mathrm{l} & \text { Primer } 1 & (100 \mathrm{pmol}) \\
1 \mu \mathrm{l} & \text { Primer } 2 & (100 \mathrm{pmol}) \\
1 \mu \mathrm{l} & 2 \mathrm{mM} \text { dNTP-Mix } & (\mathrm{dATP}, \mathrm{dCTP}, \mathrm{dGTP}, \mathrm{dTTP} ; \text { je } 2 \mathrm{mM}) \\
5 \mu \mathrm{l} & 10 \times \text { Reaktionspuffer } & \\
10 \mu \mathrm{l} & 5 \text { x Q-Solution } & \\
0.5 \mu \mathrm{l} & \text { Taq-Polymerase } & \\
\text { ad } 50 \mu \mathrm{l} & \mathrm{H}_{2} \mathrm{O} \text { bidest. } &
\end{array}
$$

*Die Q-Solution (Qiagen, Hilden) ändert das Schmelzverhalten der DNA und erhöht sowohl die quantitative Ausbeute als auch die Spezifität der Amplifikation von Matrizen, die unter Standardbedingungen nur sehr wenig oder gar kein Produkt liefern.

Die Komponenten wurden auf Eis in ein Eppendorfgefäß $(0.5 \mathrm{ml})$ pipettiert. Die PCR wurde mit dem folgenden Programm durchgeführt.

$\begin{array}{llll}\text { PCR-Programm } & 4 \mathrm{~min} & \text { Denaturierung } & 95^{\circ} \mathrm{C} \\ & 30 \mathrm{~s} & \text { Denaturierung } & 95^{\circ} \mathrm{C} \\ 30 \mathrm{~s} & \text { Anlagerung der Primer } & 59^{\circ} \mathrm{C} \\ 1 \mathrm{~min} & \text { Polymerisation } & 70^{\circ} \mathrm{C} & 29 \mathrm{x} \text { wiederholen } \\ & 5 \mathrm{~min} & \text { Polymerisation } & 70^{\circ} \mathrm{C} \\ \infty & \text { Abkühlung } & 4^{\circ} \mathrm{C}\end{array}$

Die Anlagerungstemperatur war abhängig von den Schmelztemperaturen der verwendeten Primer. Im Regelfall lag sie $2-5{ }^{\circ} \mathrm{C}$ unterhalb der Schmelztemperatur des Primers mit der niedrigeren Schmelztemperatur. Nach Abschluß der PCR wurde der Ansatz auf Eis gehalten. Ein Aliquot wurde elektrophoretisch aufgetrennt (s. 2.15.1, um die Amplifikation zu 
überprüfen. Sollte das Produkt noch weiter verwendet werden, wurde es nach einer präparativen Elektrophorese aus dem Gel extrahiert (s. 2.10.5.1.

\subsubsection{Touchdown-PCR}

Um die Spezifität der PCR zu erhöhen, d.h. eine unspezifische Bindung der Primer besonders zu Beginn zu vermeiden, wurde die Touchdown-PCR (TD-PCR; Don et al., 1990) eingesetzt. $\mathrm{Zu}$ Beginn der PCR wurde die Anlagerungstemperatur so gewählt, daß sie oberhalb der berechneten Schmelztemperatur der Primer lag. Während der Reaktionscyclen erfolgte dann eine kontinuierliche Absenkung der Anlagerungstemperatur auf einen Wert von 2-5 ${ }^{\circ} \mathrm{C}$ unterhalb der Schmelztemperatur des Primers mit dem niedrigeren Schmelzpunkt. Durch die hochstringenten Bedingungen zu Beginn kann in der Regel die Anlagerung der Primer zunächst nur an hochhomologe Bereiche der Matrizen-DNA gewährleistet werden. Dadurch wird sichergestellt, daß bei der Amplifikation mit chromosomaler DNA bei Primern mit stark divergierender Anlagerungstemperatur oder degenerierten Primern das gewünschte Produkt bevorzugt gebildet wird und unspezifische Produkte in verringertem Maße auftreten.

\subsubsection{Ortspezifischer Mutagenese durch asymmetrische PCR}

Zur Einführung von Punkt-Mutationen in DNA-Fragmente (Substitutionen, Insertionen oder Deletionen) wurden ortsspezifische Mutagenesen durch asymmetrische PCR durchgeführt. Die Mutagenese erfolgte in drei aufeinander folgenden PCR-Ansätzen, wobei die zu mutierende Matrizen-DNA in pUC19 kloniert vorlag. Zur Amplifikation wurden ein Mutagenese Primer und die beiden, das Fragment flankierenden pUC-Standard-Primer (Universal- und Reverse-Primer) benötigt. In der ersten PCR wurde der Mutagenese-Primer zusammen mit dem Reverse-Primer verwendet. Das Produkt aus der ersten PCR, das bereits die gewünschte Mutation trug, aber nur einen Teilabschnitt des kompletten, zu mutierenden Fragments darstellte, wurde nach Amplifikation und anschließender Elektrophorese aus dem LMPAgarosegel ausgeschnitten (s. 2.10.5.2). Dieses Fragment fungierte dann im zweiten PCRAnsatz selbst als Primer, diesmal zusammen mit dem Universal-Primer. Während dieser PCR wurde nun das komplette Fragment mit der gewünschten Mutation amplifiziert. Das Amplifikat bildete die Matrizen-DNA für den dritten PCR-Ansatz mit Universal- und ReversePrimer. Die dritte PCR wurde durchgeführt, um ausreichende Fragmentmengen für sich anschließende Klonierungsschritte zu erhalten. 


\section{PCR-Ansatz}

$\begin{array}{rll}0.5 \mu 1 & \text { Plasmid-DNA } & (\leq 200 \mathrm{ng} \text { Plasmid-DNA }) \\ 1 \mu \mathrm{l} & \text { Reverse-Primer } & (100 \mathrm{pmol}) \\ 1 \mu \mathrm{l} & \text { Mutagenese-Primer } & (100 \mathrm{pmol}) \\ 5 \mu \mathrm{l} & 2 \mathrm{mM} \text { dNTP-Mix } & (\mathrm{dATP}, \mathrm{dCTP}, \mathrm{dGTP}, \mathrm{dTTP}) \\ 5 \mu \mathrm{l} & 10 \mathrm{x} \text { Reaktionspuffer } & \\ 10 \mu \mathrm{l} & 5 \mathrm{x} \text { Q-Solution } & \\ 0.5 \mu \mathrm{l} & \text { Taq-Polymerase } & \\ 50 \mu \mathrm{l} & \mathrm{H}_{2} \mathrm{O} \text { bidest. }\end{array}$

$\begin{array}{llll}\text { PCR-Programm } & 4 \mathrm{~min} & \text { Denaturierung } & 95^{\circ} \mathrm{C} \\ & 30 \mathrm{~s} & \text { Denaturierung } & 95^{\circ} \mathrm{C} \\ 30 \mathrm{~s} & \text { Anlagerung der Primer } & 58^{\circ} \mathrm{C} \\ & 1 \mathrm{~min} & \text { Polymerisation } & 70^{\circ} \mathrm{C} \\ & 5 \mathrm{~min} & \text { Polymerisation } & 70^{\circ} \mathrm{C} \\ & \infty & \text { Abkühlung } & 4^{\circ} \mathrm{C}\end{array}$

\section{PCR-Ansatz}

$1.0 \mu 1$ Plasmid-DNA $\quad(\leq 200$ ng Plasmid-DNA)

$2 \mu \mathrm{l}$ Universal-Primer $\quad(100 \mathrm{pmol})$

$20 \mu \mathrm{l} \quad$ Fragment aus 1.PCR in LMP-Agarose

$10 \mu \mathrm{l} 2 \mathrm{mM}$ dNTP-Mix (dATP, dCTP, dGTP, dTTP)

$10 \mu 1 \quad 10 x$ Reaktionspuffer

$20 \mu 15$ x Q-Solution*

$1.0 \mu 1$ Taq-Polymerase

ad $100 \mu \mathrm{l} \quad \mathrm{H}_{2} \mathrm{O}$ bidest.

Im Gegensatz zum ersten PCR-Ansatz mußte die Anlagerungstemperatur bei der zweiten PCR von $58^{\circ} \mathrm{C}$ auf $50^{\circ} \mathrm{C}$ abgesenkt werden, um ein spezifisches Produkt zu erhalten. 


\section{PCR-Ansatz}

$20 \mu 1 \quad$ Amplifiziertes Fragment aus 2.PCR in LMP-Agarose

$2 \mu \mathrm{l}$ Universal-Primer (100 pmol)

$2 \mu \mathrm{l}$ Reverse-Primer (100 pmol)

$10 \mu \mathrm{l} 2 \mathrm{mM}$ dNTP-Mix (dATP, dCTP, dGTP, dTTP)

$10 \mu 1 \quad 10 x$ Reaktionspuffer

$20 \mu 15 \times$ Q-Solution

$1.0 \mu 1 \quad$ Taq-Polymerase

ad $100 \mu \mathrm{l} \quad \mathrm{H}_{2} \mathrm{O}$ bidest.

Die Amplifikation wurde unter gleichen Bedingungen wie bei der ersten PCR durchgeführt.

\subsection{Chemikalien und Materialien}

AGS (Heidelberg)

Amersham/Pharmacia Biotech

(Freiburg)

Biomol (Hamburg)

Biozym (Hess. Oldendorf)

Difco (Augsburg)

Hölzel (München)

IBA Analytik (Göttingen)

ICN (Eschwege)

Kodak (Stuttgart)

Life Technologies (Eggenstein)

MBI Fermentas (St. Leon-Rot)

Metabion (Martinsried)
Restriktionsendonucleasen, IPTG, X-Gal

Agarose NA, Ammoniumpersulfat,

Desoxynucleotide, RNase freie DNase,

Klenow-Fragment der DNA-Polymerase I,

Restriktionsenzyme, Röntgenfilm, TEMED

Dithiothreit, Lysozym, $o$-NPG

SeaPlaque und NuSieve GTG-Agarose,

SequiTherm Excel Cycle Sequencing-Kit

Bacto-Trypton, Hefeextrakt, Nutrient Broth

Acrylamidlösung für Proteingele

Streptavidin-Sepharose

Radiochemikalien

Röntgenfilm MS, Röntgenfilmentwickler und

-fixierer

Agar, Klenow-Fragment der DNA-Polymerase

I, Restriktionsendonucleasen, Protein-Leiter,

T4-DNA-Ligase

DNA-Marker, Restriktionsendonukleasen

Oligodesoxynucleotide 
Millipore (Eschborn)

MWG-Biotech (Ebersberg)

New Englands Biolabs (Schwalbach)

Oxoid (Wesel)

Pall (Dreieich)

Promega (Mannheim)

Qiagen (Hilden)

Roche (früher Boehringer Mannheim)

Roth (Karlsruhe)

Serva (Heidelberg)

Sigma (Deisenhofen)
PVDF-Membran Immobilon

Oligodesoxynucleotide

Restriktionsendonucleasen

Agar No.1

Nylonmembran Biodyne B, Mikrosept-

Mikrokonzentratoren

$P f u$-DNA-Polymerase

QIAprep Spin Miniprep Kit, QIAquick Gel

Extraction Kit, Taq-Polymerase

Alkalische Phosphatase, Ampicillin, DNaseI, NAD, NADH, RNase, Tris

Acrylamid-Lösung für Polyacrylamidgele

(Rotiphorese-Gel 40), Ethidiumbromidlösung, Phenol-Lösung (Rotiphenol)

Bromphenolblau, CTAB, Dimethyldichlorsilan, EDTA, Kanamycin, Rinderserumalbumin, Saccharose, Serva Blau G-250, SDS, Tetracyclin, Xylencyanol FF

Tris, Methacryloxypropyltrimethoxysilan 


\section{EXPERIMENTE UND ERGEBNISSE}

\subsection{Stand der Vorarbeiten}

Die genetischen Grundlagen für eine detaillierte Charakterisierung der transkriptionellen Regulation der autotrophen $\mathrm{CO}_{2}$-Fixierung in $R$. eutropha $\mathrm{H} 16$ lagen zu Beginn dieser Arbeit weitgehend vor. Abgeschlossen waren sowohl die Sequenzierungen des chromosomalen und des plasmidär kodierten $c b b$-Operons, als auch des chromosomalen Aktivatorgens $c b b R$ (Kossmann et al., 1989; Windhövel \& Bowien, 1991; Bednarski, 1992; Kusian et al., 1992; Schäferjohann et al., 1993, 1995; Yoo \& Bowien, 1995; Bömmer et al., 1996). Ebenfalls bekannt war die Sequenz der intergenen $c b b$-Kontrollregion, die zwischen $c b b R$ und dem ersten Strukturgen des $c b b$-Operons ( $c b b L)$ lokalisiert ist (Windhövel \& Bowien, 1991). Innerhalb der Kontrollregion wurden zwei Promotoren, der Operonpromotor $p_{c b b L}$ und der Promotor $p_{c b b R}$ des Regulatorgens detektiert (Kusian et al., 1995). Im Rahmen von Gelretardations ('mobility shift')- und DNA-'footprinting'-Experimenten erfolgte die Identifikation und Charakterisierung des stromaufwärts von $p_{c b b L}$ lokalisierten Operatorbereiches, der Bindungsregion des Transkriptionsaktivators CbbR (Kusian \& Bowien, 1995).

CbbR ist für die Transkription beider $c b b$-Operone essentiell, was anhand der $c b b R$-Mutanten R. eutropha HB13 und HB14 gezeigt wurde, die beide einen autotroph negativen Phänotyp aufwiesen (Windhövel \& Bowien, 1991; Jeffke et al., 1999). Promotorstudien mit der Deletionsmutante HB14 belegten, daß weder unter mixotrophen noch unter dereprimierenden heterotrophen Wachstumsbedingungen eine Aktivierung des Operonpromotors $p_{c b b L}$ erfolgte. Eine Verifikation von $p_{c b b L}$ wurde durch gezielt eingefügte Mutationen innerhalb der vorhergesagten ' -35 ' - und '-10'-Boxen erbracht. Die Boxen wurden dabei teilweise der $\sigma^{70}$ Consensussequenz von E. coli angeglichen, was unter allen Wachstumsbedingungen zu deutlichen Aktivitätssteigerungen der mutierten $p_{c b b L}$ im Vergleich zum Wildtyppromotor führte (Jeffke et al., 1999). Das typische Regulationsmuster des $c b b$-Systems mit hohen Expressionsraten unter autotrophen und niedrigen unter heterotrophen Wachstumsbedingungen blieb aber, wenn auch abgeschwächt, bei allen Promotormutanten prinzipiell bestehen. Eine Restaktivität der Teilconsensusmutanten von $p_{c b b L}$ wurde auch noch im CbbR-freien Hintergrund von HB14 beobachtet.

Zur Detektion potentieller Signalmetabolite, die als Effektoren von CbbR an der Regulation der Expression der Operone beteiligt sein könnten, war ein In vitro-Transkriptionssystem etabliert worden. Obwohl eine Vielzahl von Metaboliten aus dem zentralen Kohlenstoffmetabolismus und dem Energiestoffwechsel getestet wurde, erwies sich keiner davon als Coakti- 
vator, Phosphoenolpyruvat wirkte jedoch als negativer Effektor von CbbR (Grzeszik et al., 2000).

Untersuchungen an der autotroph positiven Revertante HB14R hatten ergeben, daß die Deletion von $c b b R$ durch eine spontane Mutation suppremiert worden war. Das für die Suppression verantwortliche Gen zeigte eine hohe Ähnlichkeit (73\% Identität) zu phcA aus Ralstonia solanacearum, das einen übergeordneten Regulator aus der Gruppe der LysR-TypTranskriptionsregulatoren (LTTR) codiert. Interessanterweise hatte die Revertante nicht nur die Fähigkeit zu autotrophem Wachstum wiedererlangt, sondern auch das $c b b$-Regulationsmuster, wie es im Wildtypstamm bezüglich Expressionsstärke der $c b b$-Operone bei unterschiedlichen Wachstumsbedingungen zu beobachten ist, war in HB14R prinzipiell wiederhergestellt (D.Oed, C. Grzeszik und B. Bowien, persönliche Mitteilung).

Aufgrund all dieser Befunde lagen deutliche Hinweise dafür vor, daß CbbR nicht der alleinige Regulator des $c b b$-Systems sein kann, was auf die potentielle Existenz mindestens eines weiteren Regulators/Modulators hinwies. Unterstützt wurde diese Hypothese durch 'mobility shifts' der $c b b$-Kontrollregion und Rohextrakten von $R$. eutropha H16, bei denen zwei unterschiedlich stark retardierende Komplexe beobachtet worden waren (Kusian, 1994). Das primäre Ziel der vorliegenden Arbeit war nun die Identifikation und weitere funktionelle Charakterisierung dieser potentiellen $c b b$-Regulatoren sowie eine weitere strukturelle und funktionelle Analyse von $p_{c b b L}$.

\subsection{Bindung von Proteinen an die $c b b$-Kontrollregion von R. eutropha H16}

Zur Detektion potentieller Regulatorproteine, die neben CbbR an der Transkriptionskontrolle des $c b b$-Systems beteiligt sein könnten, wurden 'mobility shifts' durchgeführt. Diese hatten sich bereits als ausreichend sensitiv beim Nachweis auch in geringer Konzentration vorliegender Transkriptionsregulatoren, wie z.B. CbbR, erwiesen (Windhövel \& Bowien, 1991; Kusian \& Bowien, 1995). Die Analyse von Rohextrakten zum Nachweis spezifischer ProteinDNA-Komplexe erfolgte mit einem 253 bp-Fragment, das die komplette intergene $c b b$ Kontrollregion (167 bp) enthielt und verschiedenen Subfragmenten dieser Region. Hierzu wurden $R$. eutropha H16 sowie die cbbR-Deletionsmutanten HB14 und HB14R jeweils sowohl lithoautotroph (nur H16 und HB14R), wie auch heterotroph mit Fructose oder Pyruvat bis zu einer $\mathrm{OD}_{436}$ von etwa 3.0 angezogen. Eine Analyse der Rohextrakte im 'mobility shift' erfolgte zunächst mit dem 253 bp-Fragment, das mit den Primern F1X und R1 amplifiziert 
wurde (3.5.3.1, Abb. 18), wobei die radioaktive Markierung des Fragments unter Verwendung von $\left[\alpha{ }^{35}\right.$ S $]$ dATP während eines zweiten PCR-Durchlaufs erfolgte. Um die Entstehung unspezifischer Protein-DNA-Komplexe zu unterdrücken, wurde den Bindungsansätzen generell ein mindestens 100-facher Überschuß von Lachsspermien-DNA als Kompetitor zugesetzt.

Unabhängig von der Anzucht der Zellen wurden mit der kompletten $c b b$-Kontrollregion zwei retardierte Protein-DNA-Komplexe mit in etwa gleichbleibender Intensität beobachtet Abb. 1.

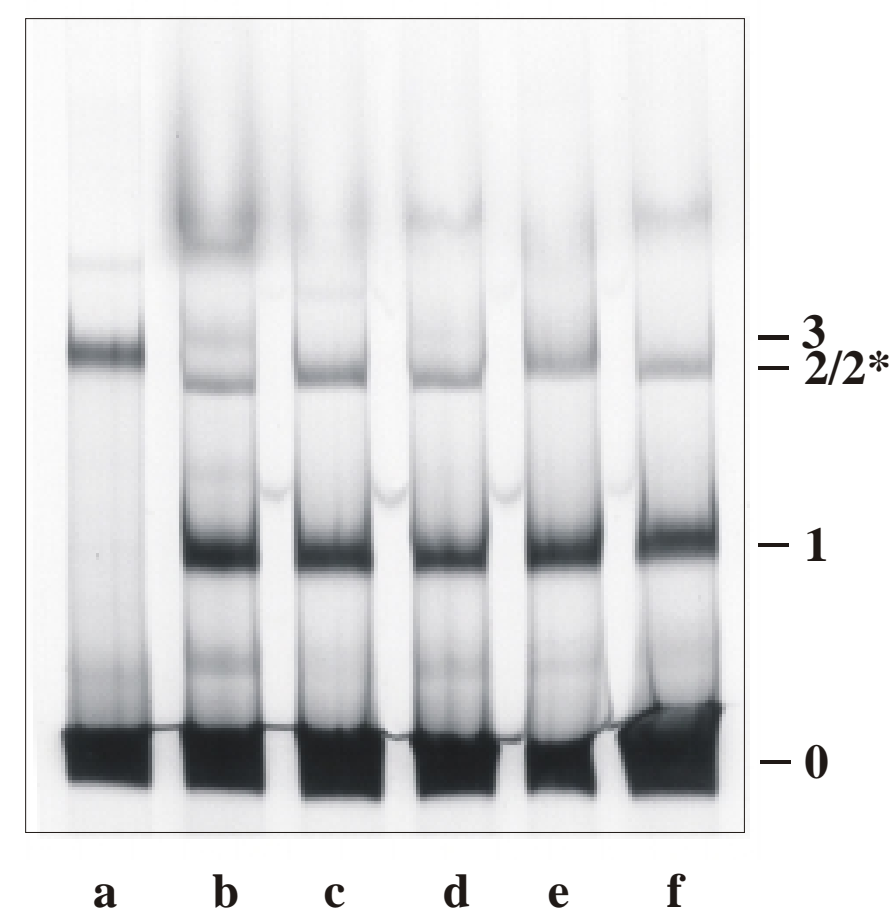

Abb. 1. 'Mobility shifts' mit einem 253 bp-Fragment der chromosomalen $c b b$ Kontrollregion und Rohextrakten aus R. eutropha H16, HB14 oder HB14R.

Es wurden aufgereinigtes CbbR $(0.1 \mathrm{mg} / \mathrm{ml}$; Spur a) oder Rohextrakte $(1 \mathrm{mg} / \mathrm{ml})$ nach lithoautotropher Anzucht von H16 (b) und HB14R (c) oder nach heterotropher Anzucht auf Fructose von H16 (d), HB14R (e) und HB14 (f) eingesetzt. 0, freie DNA; 1, Protein-DNA-Komplex P1; 2, Protein-DNA-Komplex P2; 2*, ProteinDNA-Komplex P2* (mit HB14R-Rohextrakt); 3, CbbR-DNA-Komplex; PAGE (5 $\%[\mathrm{w} / \mathrm{v}]$ Acrylamid).

Der stärker retardierte Komplex 2 war verglichen mit Komplex 1 schwach, aber noch sehr viel auffälliger als der noch etwas langsamer laufende CbbR-Komplex (3). Da Komplex 2 auch mit Rohextrakten aus HB14 und HB14R auftrat, konnte es sich nicht um einen CbbRDNA-Komplex handeln. Auffällig war die im Vergleich zu Komplex 2 etwas stärkere Retardation von Komplex 2*, der mit HB14R beobachtet wurde. Der schwächer retardierte 
Komplex 1 war von starker Intensität, was auf eine relativ hohe Konzentration des entsprechenden Proteins und/oder Stabilität des Komplexes hindeutete.

Ein Vergleich der Retardationsmuster der von lithoautotrophen und heterotrophen Anzuchten stammenden Rohextrakte von H16 ergab keine signifikanten Unterschiede hinsichtlich der Intensitäten der Komplexe 1 und 2 in Bezug auf die Wachstumsbedingungen Abb. 2. Dies sprach für eine konstitutive Synthese der entsprechenden Proteine. Ein sehr schwach ausgeprägter CbbR-Komplex wurde nur mit lithoautotroph gewachsenen Zellen gefunden, was auf sehr niedrige Konzentrationen des Transkriptionsaktivators in $\mathrm{H} 16$ hindeutete.

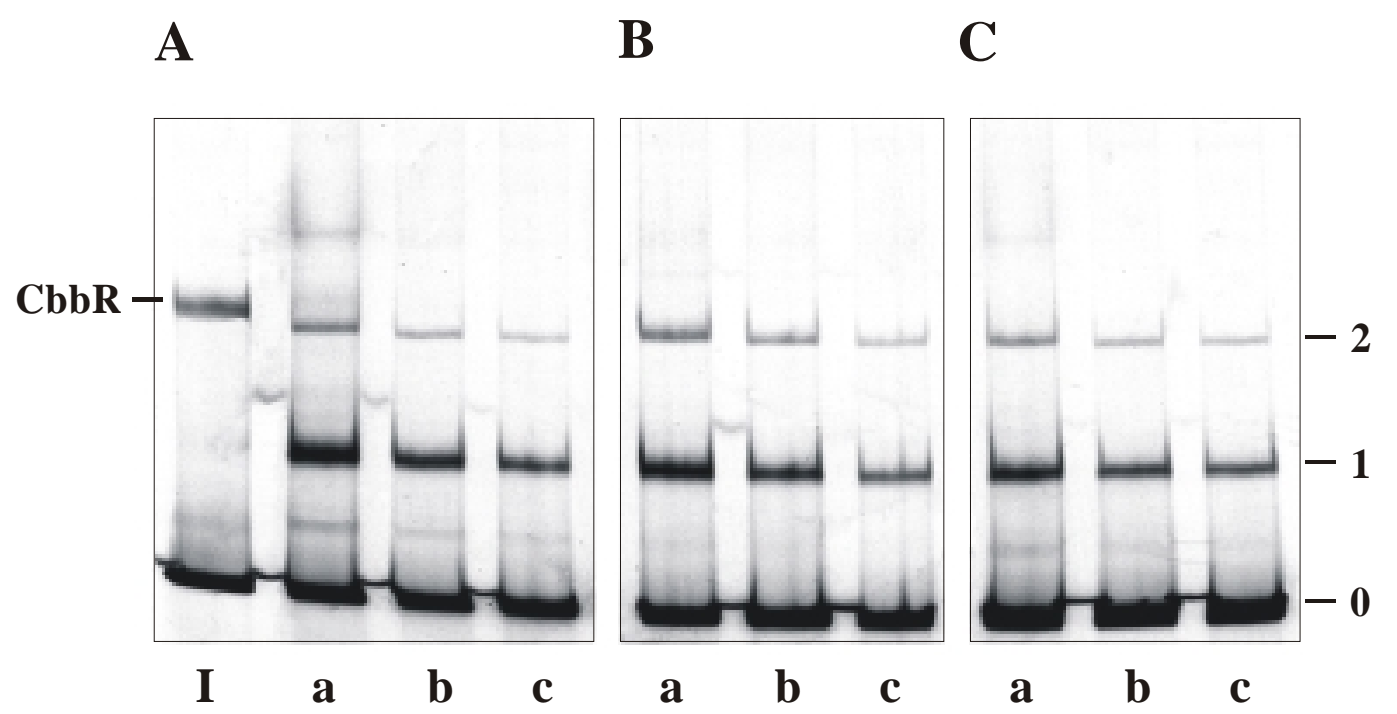

Abb. 2. 'Mobility shifts' mit einem 253 bp-Fragment der $c b b$-Kontrollregion und Rohextrakten von $R$. eutropha H16 nach lithoautotropher Anzucht der Zellen (A) oder heterotropher Anzucht mit Fructose (B) oder Pyruvat (C). Spur I, aufgereinigtes CbbR $(0.1 \mathrm{mg} / \mathrm{ml})$; Spuren a-c, Rohextrakte $(5 \mathrm{mg} / \mathrm{ml})$ in Verdünnungsstufen von $2^{-3}$ bis $2^{-5}$. 0 , freie DNA; 1, Protein-DNA-Komplex P1; 2 Protein-DNA-Komplex P2. PAGE (5\% [w/v] Acrylamid).

'Mobility shifts' mit einem 120 bp-Subfragment aus der cbb-Kontrollregion Abb. 3A, Fragment III), das den bis dato postulierten kompletten Operator/Promotorbereich umfasste, bestätigten, daß der stärker retardierte Komplex 2 nicht mit dem CbbR-Komplex identisch ist. Der Komplex 2 war mit diesem Fragment deutlich stärker retardiert als der CbbR-Komplex Abb. 3B), als dies mit der kompletten cbb-Kontrollregion der Fall war Abb. 1. Bei Rohextrakten aus H16 erfolgte scheinbar eine Auftrennung von Komplex 2 in zwei Komplexe. Ein von der Intensität her sehr schwacher Komplex lief dabei etwa auf gleicher Höhe wie der authentische CbbR-Komplex (Spuren b und d). Interessanterweise war dieser Komplex bei autotroph und heterotroph gewachsenen Zellen von gleicher Intensität. Der Komplex trat mit 
HB14-Rohextrakt nicht auf, was wiederum auf einen CbbR-DNA-Komplex hinzudeuten schien.

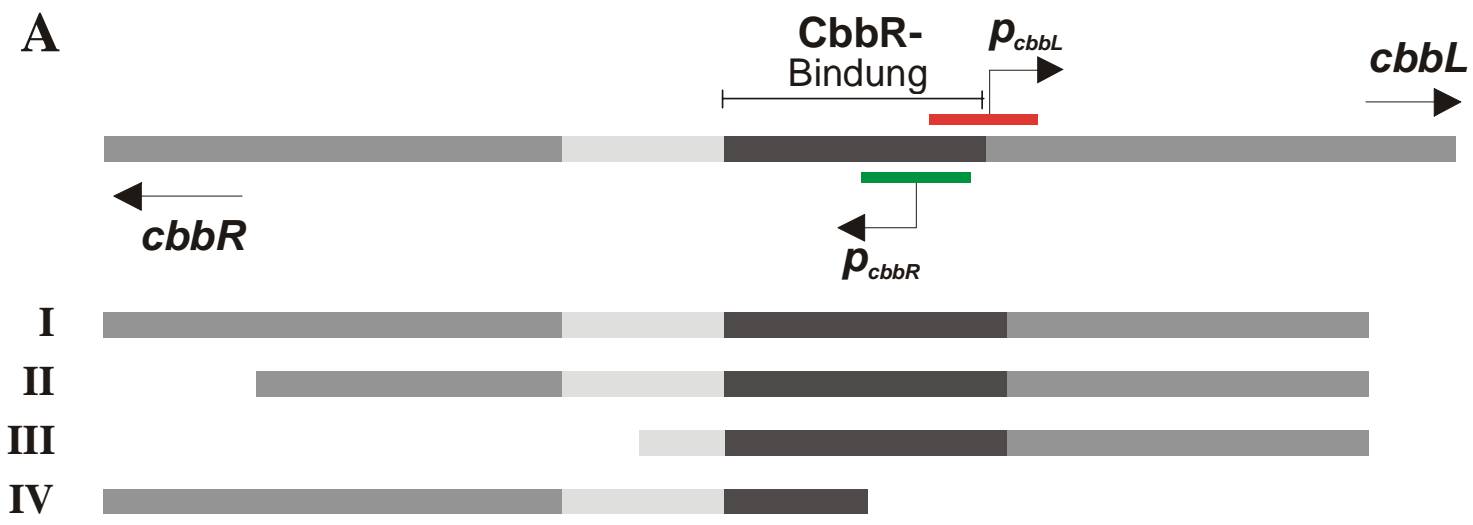

B

C
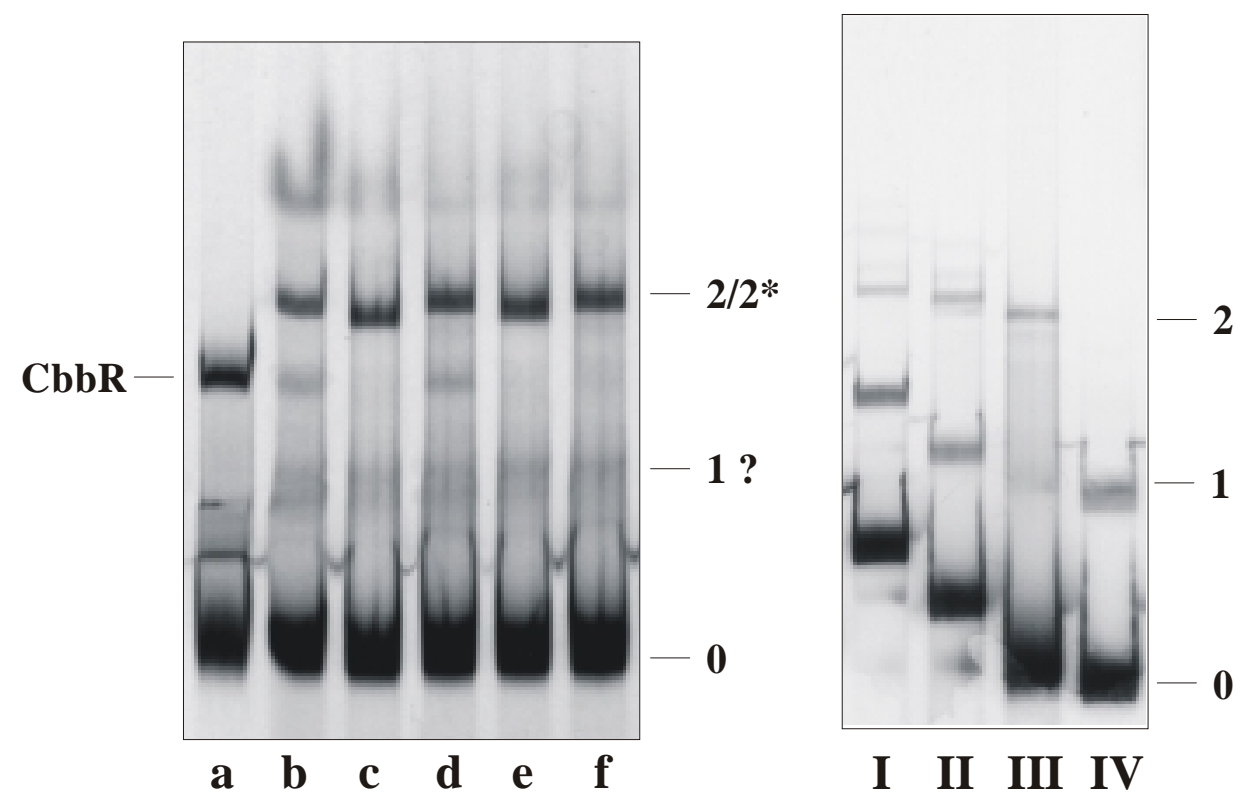

Abb. 3. 'Mobility shifts' mit Subfragmenten der $c b b$-Kontrollregion und Rohextrakten von $R$. eutropha H16, HB14 und HB14R.

A: Subfragmente I (226 bp), II (179 bp), III (132 bp) und IV (134 bp; $\rightarrow$ Primer: s. 3.5.3.1 Abb. 18, B: 'Mobility shifts'mit Subfragment III und aufgereinigten CbbR $(0.1 \mathrm{mg} / \mathrm{ml})$ oder Rohextrakten $(1 \mathrm{mg} / \mathrm{ml})$ aus Zellen lithoautotropher Anzucht von H16 (b) und HB14R (c) oder heterotropher Anzucht von H16 (d), HB14R (e) und HB14 (f) mit Fructose. C: 'Mobility shifts' mit Subfragmenten I-IV und H16Rohextrakt $(0.5 \mathrm{mg} / \mathrm{ml})$ nach heterotropher Anzucht mit Fructose; 0, freie DNA; 1, Protein-DNA-Komplex P1; 2, Protein-DNA-Komplex P2; 3, CbbR-DNAKomplex. PAGE (5\% [w/v] Acrylamid). 
Daß die Komplexe 1 und 2 auf die Bindung von zwei verschiedenen Proteinen an die $c b b$ Kontrollregion zurückzuführen ist, verdeutlicht Abb. 3 C. Bei diesem Experiment wurden 'mobility shifts' mit verschiedenen Subfragmenten der $c b b$-Kontrollregion durchgeführt. Die Fragmente I-III trugen den bislang postulierten Operator/Promotorbereich. Während aber in den Fragmenten I und II noch der Bereich direkt stromaufwärts von der Operator/Promotorregion vorlag, fehlte dieser zusätzliche Sequenzabschnitt in Fragment III fast vollständig Abb. 3A). Dieses bewirkte bei Fragment III eine starke Abnahme von Komplex 1, hatte aber im Vergleich zu den Fragmenten I und II keine Auswirkungen auf die Intensität von Komplex 2. Bei Fragment IV, das nur noch einen 36 bp großen Teilbereich der Operator/Promotorregion und einen 98 bp großen Abschnitt stromaufwärts vom Operator umfasste, wurde hingegen nur Komplex 1 nachgewiesen, Komplex 2 fehlte ganz (Abb. 3C). Diese Ergebnisse sprachen dafür, daß die Komplexe 1 und 2 auf zwei verschiedene, spezifisch an die $c b b$-Kontrollregion bindende Proteine zurückzuführen sind, wobei ein Protein innerhalb des Operator/Promotorbereiches bindet, während die Bindungsregion des anderen Proteins stromaufwärts lokalisiert ist. In Bezug auf Fragment III war mit Rohextrakten von HB14R erneut ein abweichendes Laufverhalten des P2*-Komplexes im Vergleich zu dem P2Komplex, der mit H16 und HB14-Rohextrakten auftrat, festzustellen. Die beiden Proteine wurden im weiteren Verlauf der Arbeit als P2 bzw. P1 bezeichnet und galten als potentiell an der Regulation der $c b b$-Operone beteiligt.

\subsection{Anreicherungen von P1 und P2 aus R. eutropha HB14}

Um eine funktionelle Analyse der an die $c b b$-Kontrollregion bindenden Proteine P1 und P2 vornehmen zu können, sollte ihre Anreicherung möglichst bis zur apparenten Homogenität erfolgen. Dieses würde die Möglichkeit der Identifizierung der entsprechenden Gene über die Bestimmung der N-terminalen Aminosäuresequenzen der Proteine eröffnen (s. 3.3.6.1. Zur Vermeidung einer Interferenz mit CbbR, wurde die Anreicherung aus Rohextrakt der CbbRDeletionsmutante HB14 durchgeführt. Die Dokumentation der Anreicherung von P1 und P2 erfolgte anhand von 'mobility shifts' und durch SDS-PAGE, wobei bei der Durchführung von einem bereits für CbbR etablierten Anreicherungsverfahren ausgegangen wurde (Kusian \& Bowien, 1995). P1 konnte in insgesamt vier Schritten bis zur Homogenität in ausreichender Konzentration aufgereinigt werden Abb. 8) und stand somit für eine N-terminale Ansequenzierung zur Verfügung. 
Eine Identifikation des P2-Gens auf diesem Wege erwies sich im weiteren Verlauf dieser Arbeit allerdings als nicht mehr notwendig, da sie indirekt im Rahmen von Untersuchungen an der autotrophen Revertante HB14R gelang (s. 3.4).

\subsubsection{Fraktionierte Ammoniumsulfatfällung}

Der Rohextrakt von Stamm HB14 wurde einer fraktionierten Ammoniumsulfatfällung unterworfen. P1 wurde zwar zu einem geringen Anteil bereits bei einer Salzsättigung von 20 $\%$ ausgefällt, was aber aufgrund der relativ hohen P1-Konzentration in Extrakt vernachlässigbar war. Das Protein wurde dann bei einer Sättigung von $45 \%$ vollständig präzipitiert. P2 fiel bis zu $20 \%$ Sättigung nicht detektierbar aus, wurde aber bereits bei $30 \%$ Sättigung quantitativ ausgefällt. Daher wurde eine fraktionierte Ammoniumsulfatfällung in zwei Schritten durchgeführt, um beide Proteine zu erfassen. Die erste Fällung erfolgte bei einer Sättigung von $20 \%$, wobei vom Überstand lediglich ein Proteinanteil von $8 \%$ abgetrennt wurde. Nach dem zweiten Fällungsschritt bis $45 \%$ Sättigung befanden sich die Hauptanteile von P1 und P2 im Pellet, das etwa ein Drittel des Gesamtproteingehalts des Rohextrakts enthielt (Tab. 1.

\subsubsection{Hydrophobe Interaktionschromatographie}

Da eine Hydrophobe Interaktionschromatographie (HIC) unter Hochsalzbedingungen (1 M $\left.\left(\mathrm{NH}_{4}\right)_{2} \mathrm{SO}_{4}\right)$ durchzuführen ist, war nach der Ammoniumsulfatfällung keine Entsalzung des Proteins notwendig. Die Bindung der Proteine erfolgte an eine Fractogel-TSK-Butylsäule, und wobei mit einem abnehmenden $\left(\mathrm{NH}_{4}\right)_{2} \mathrm{SO}_{4}$-Gradienten (bis $0 \mathrm{M}$ ) eluiert wurde. 
A

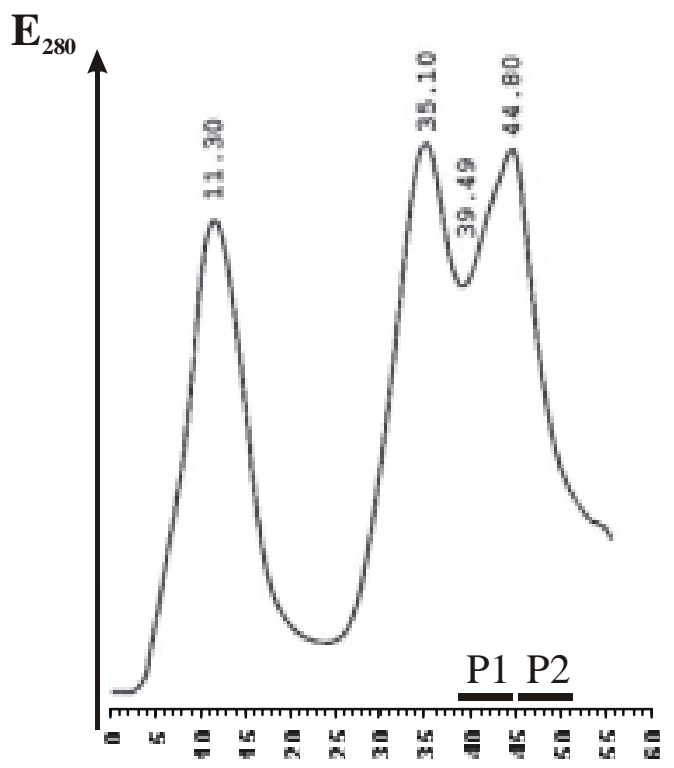

Elutionszeit [min]

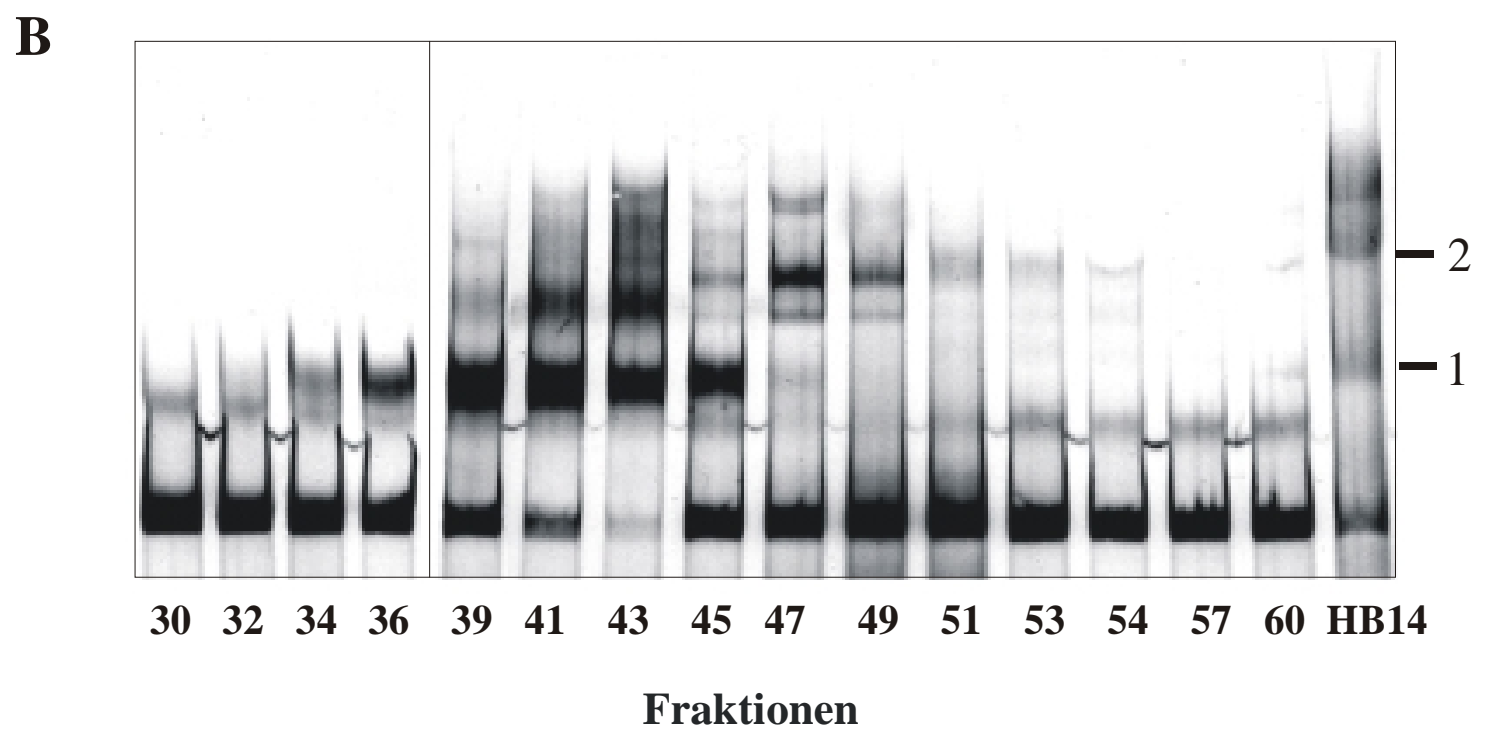

Abb. 4. Elutionsprofil von P1 und P2 bei Auftrennung durch hydrophobe Interaktionschromatographie. Analyse der Fraktionen im 'mobility shift' mit dem 253 bpFragment.

A: Elution mit linear abnehmendem $\left(\mathrm{NH}_{4}\right)_{2} \mathrm{SO}_{4}$-Gradienten $(1 \mathrm{M}-0 \mathrm{M})$ in HICPuffer: 10-40 min; Flußrate: $1 \mathrm{ml} / \mathrm{min}$, Fraktionsgröße: $1 \mathrm{ml}$. B: Detektion der P1und P2-Spitzenfraktionen (unverdünnt; $1-2 \mathrm{mg} / \mathrm{ml}$ ) im 'mobility shift' mit dem 253 bp-Fragment (PAGE, $5 \%$ [w/v] Acrylamid) im Vergleich zu HB14-Rohextrakt (Proteinkonz.: $5 \mathrm{mg} / \mathrm{ml}$ ). Die entsprechenden Fraktionsnummern sind unterhalb der Spuren angegeben. 0, freie DNA; 1, P1-DNA-Komplex; 2, P2-DNA-Komplex.

Die Elution beider Proteine begann gegen Ende des Salzgradienten bei etwa $0 \mathrm{M}\left(\mathrm{NH}_{4}\right)_{2} \mathrm{SO}_{4}$ Abb. 4A). P1 wurde im wesentlichen im Anstiegsbereich des dritten Proteinpeaks (Fraktionen 39-45) desorbiert. Ähnlich wie bei CbbR (Kusian \& Bowien, 1995) erfolgte die Elution 
von P2 erst während des isokratischen Nachspülen der Säule, wie die Analyse im 'mobility shift' ergab (Abb. 43). Durch die HIC konnten die beiden Proteine also weitgehend getrennt voneinander aufgereinigt werden (Pool 1: Fraktionen 39-44 bzw. Pool 2: 46-50).

\subsubsection{Kationenaustauschchromatographie}

Die Pools 1 und 2 der HIC wurden getrennt auf einen stark sauren Kationenaustauscher, eine Fractogel EMD $\mathrm{SO}_{3}$-Säule aufgetragen. Dazu mußten die Proteinlösungen von Tris- $\mathrm{HCl}$ auf $\mathrm{KPO}_{4}$-Puffer, $\mathrm{pH}$ 6.5, umgepuffert werden, wozu eine Verdünnung mit 2 Volumen $\mathrm{SO}_{3}$ Bindungspuffer durchgeführt wurde. Die Elutionen erfolgten jeweils mit einem linear ansteigenden KCl-Gradienten (0.05 M - $1 \mathrm{M})$. Spitzenfraktionen von P1 (38-44) wurden erst während des isokratischen Nachspülens von der Säule desorbiert, während P2-Fraktionen (3539) mit Beendigung des Gradienten eluierten Abb. 6 .

Durch die $\mathrm{SO}_{3}{ }^{-}$-Säule gelang eine weitere deutliche Abtrennung störender Proteine, wobei die P2-Fraktionen im Vergleich zu P1 weiterhin sehr stark mit anderen Proteinen kontaminiert waren Abb. 6. In diesem Anreicherungsstadium reichten Reinheit und Konzentration von P1 bereits für DNA-Bindungsstudien aus, eine N-terminale Ansequenzierung erforderte jedoch eine weitere Aufreinigung durch DNA-Affinitätschromatographie.

A

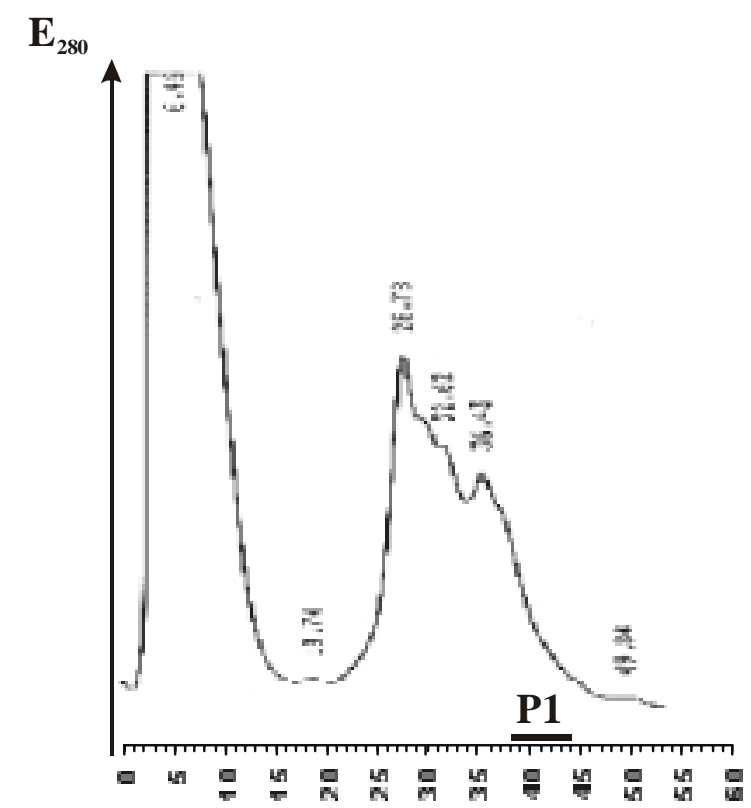

Elutionszeit [min]
B

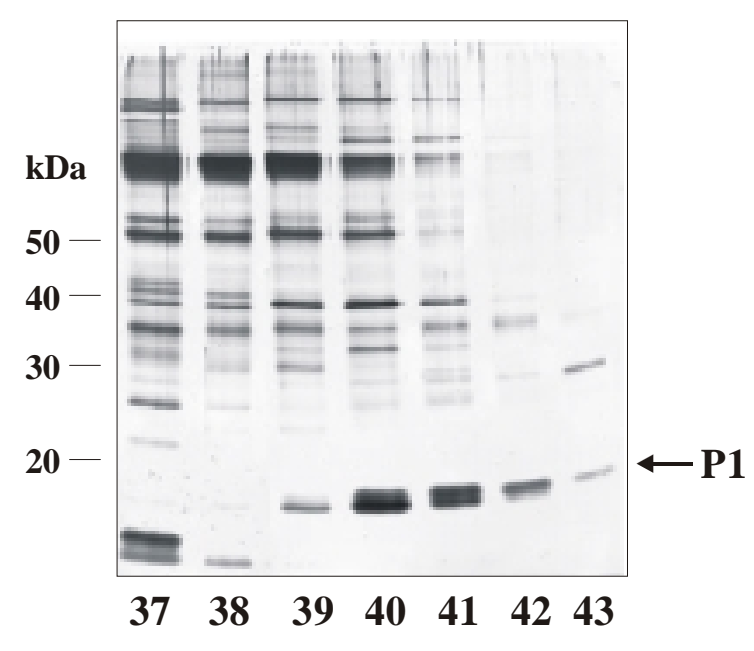

Fraktion

Legende (s. nächste Seite) 
C

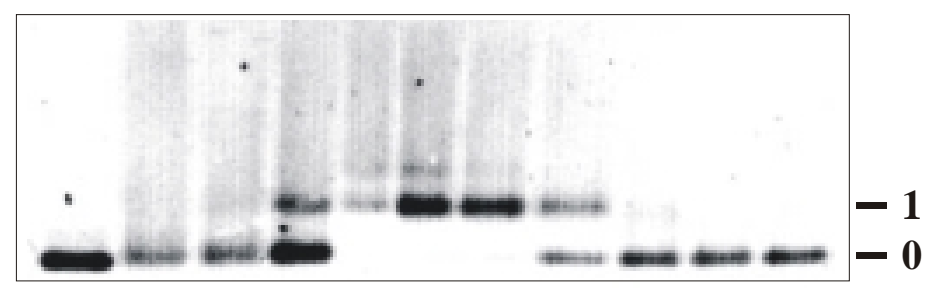

$\begin{array}{llllllllll}35 & 37 & 39 & 40 & 41 & 42 & 43 & 44 & 45 & 46\end{array}$

D

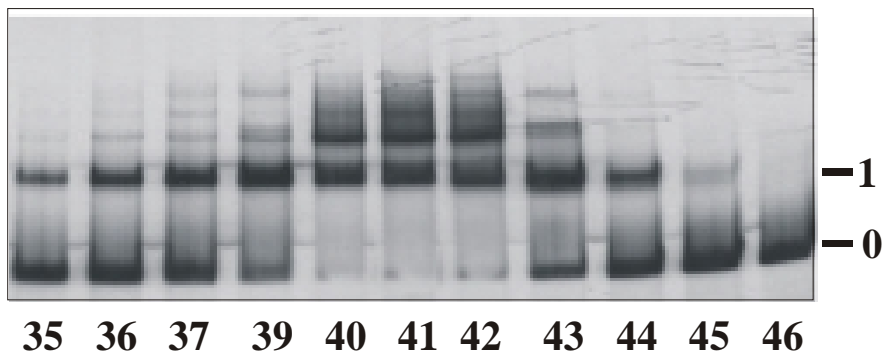

Abb. 5. Elutionsprofil von P1 bei Auftrennung durch Kationenaustauschchromatographie. Analyse der Spitzenfraktionen im 'mobility shift' und durch SDSPAGE.

A: Elution mit linear ansteigendem $\mathrm{KCl}$-Gradienten $(0.05 \mathrm{M}-1 \mathrm{M})$ in $\mathrm{SO}_{3}$-Puffer: 10-40 min, Flußrate: $1 \mathrm{ml} / \mathrm{min}$, Fraktionsgröße: $1 \mathrm{ml}$. B: Auftrennung der Fraktionen in der SDS-PAGE (14\% [w/v] Acrylamid; Angabe der Molekularmasse in $\mathrm{kDA}$ ). C: Detektion der P1-Spitzenfraktionen (38-44; unverdünnt; 0.04-0.1 $\mathrm{mg} / \mathrm{ml}$ ) im 'mobility shift' mit dem 253 bp-Fragment im TAE-Agarosegel (2\% [w/v] Agarose). D: Detektion der Spitzenfraktionen durch PAGE (5\% [w/v] Acrylamid). Die entsprechenden Fraktionsnummern sind unterhalb der Spuren angegeben. 0, freie DNA; 1, P1-DNA-Komplex; Pfeil, Position von P1 im SDSGel.

A

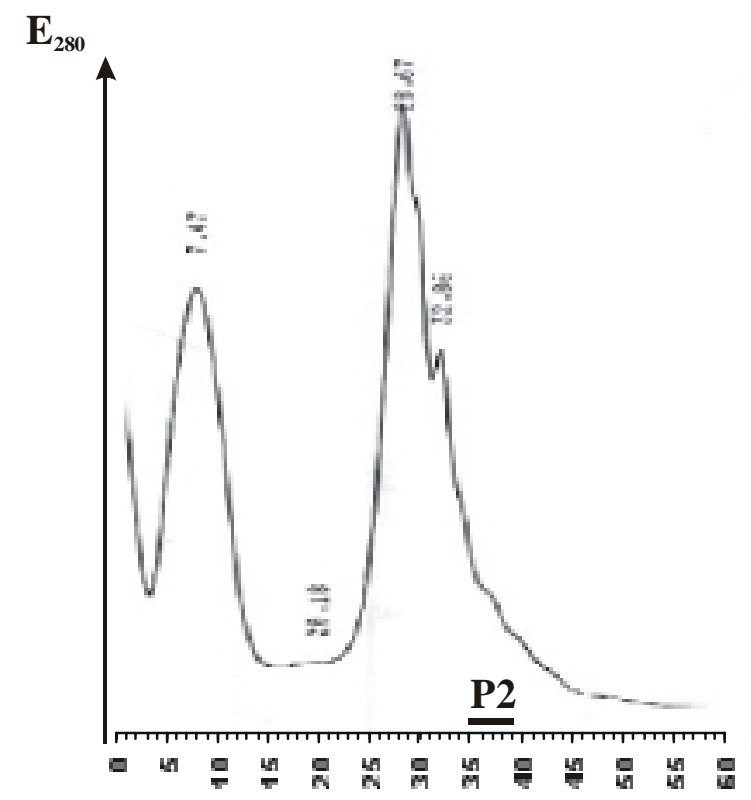

Elutionszeit [min]
B

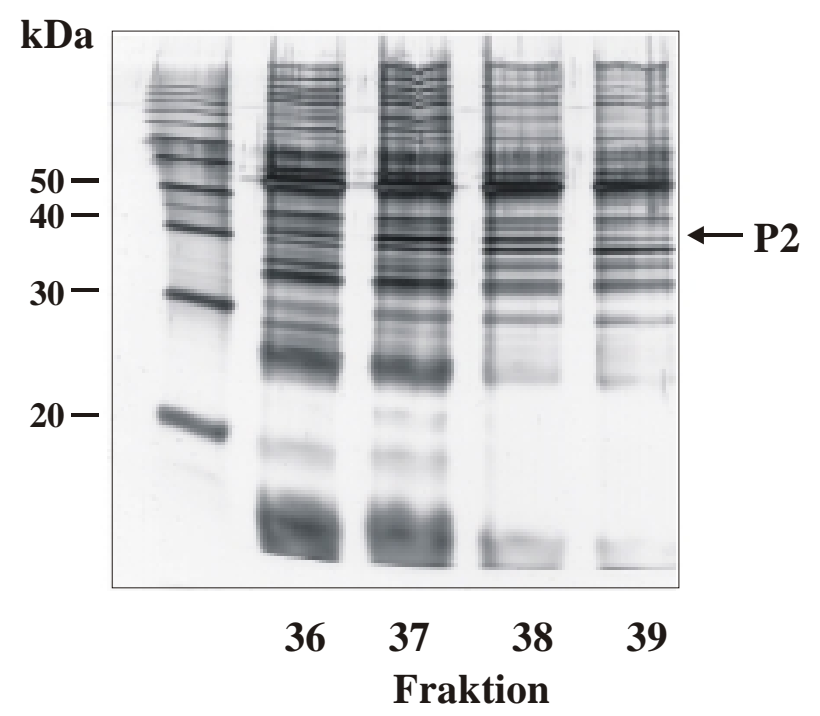

Legende (s. nächste Seite) 


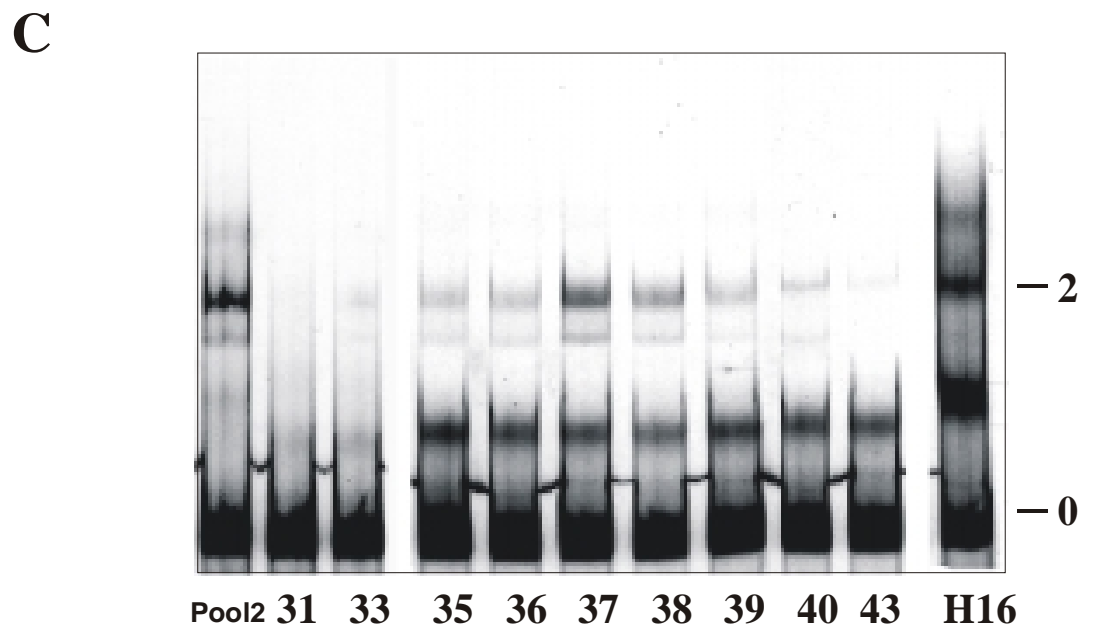

Abb. 6. Elutionsprofil von P2 bei Auftrennung durch Kationenaustauschchromatographie. Analyse der Spitzenfraktionen im 'mobility shift' und durch SDSPAGE.

A: Elution mit einem linear ansteigenden $\mathrm{KCl}-$ Gradienten $(0.05 \mathrm{M}-1 \mathrm{M})$ in $\mathrm{SO}_{3^{-}}$ Puffer: 10-40 min; Flußrate: $1 \mathrm{ml} / \mathrm{min}$, Fraktionsgröße: 1ml. B: Auftrennung der Fraktionen in der SDS-PAGE (14\% [w/v] Acrylamid). C: Detektion der P2Spitzenfraktionen (35-39; unverdünnt: $0.07-0.2 \mathrm{mg} / \mathrm{ml}$ ) im 'mobility shift' mit dem 253 bp-Fragment durch PAGE (5\% [w/v] Acrylamid). Die entsprechenden Fraktionsnummern sind unterhalb der Spuren angegeben. 0, freie DNA; 1, P1DNA-Komplex; Pfeil, Position von P2 im SDS-Gel; Angabe der Molekularmasse in $\mathrm{kDa}$.

\subsubsection{DNA-Affinitätschromatographie}

Für die DNA-Affinitätschromatographie wurde Streptavidin-Sepharose verwendet, die mit biotinylierten 233 bp-Fragmenten (amplifiziert mit Hilfe biotinylierter Primer: F1 und R2, s. 3.5.3.1 der $c b b$-Kontrollregion ligandiert war. Dieser Aufreinigungsschritt wurde nur mit P1 durchgeführt, da im Gegensatz zu P2 Reinheit und Konzentration von P1 nach der KAC ausreichend waren. Zur Herabsetzung der hohen Salzkonzentration (ca. $1 \mathrm{M} \mathrm{KCl}$ ), die oberhalb von ca $0.4 \mathrm{M}$ die Bindungsaffinität von P1 deutlich vermindert, wurden die P1Fraktionen zuvor mit 3 Volumen HIC-Elutionspuffer verdünnt. In Abhängigkeit von der Beladung der Säulenmatrix mit Liganden-DNA erfolgte eine Zugabe von Kompetitor-DNA (Lachsspermien-DNA, durch Ultraschall zerkleinert) im 3-5-fachen Überschuß zum Puffer. Die Konzentration von P1 wurde vor der Auftragung anhand von 'mobility shifts' im Agarosegel abgeschätzt. Zur Verbesserung der Trennleistung wurde nur etwa ein Drittel der Säulenkapazität ausgenutzt. Nach dieser Aufreinigung lag P1 in scheinbar homogener Form vor Abb. 7. 
A

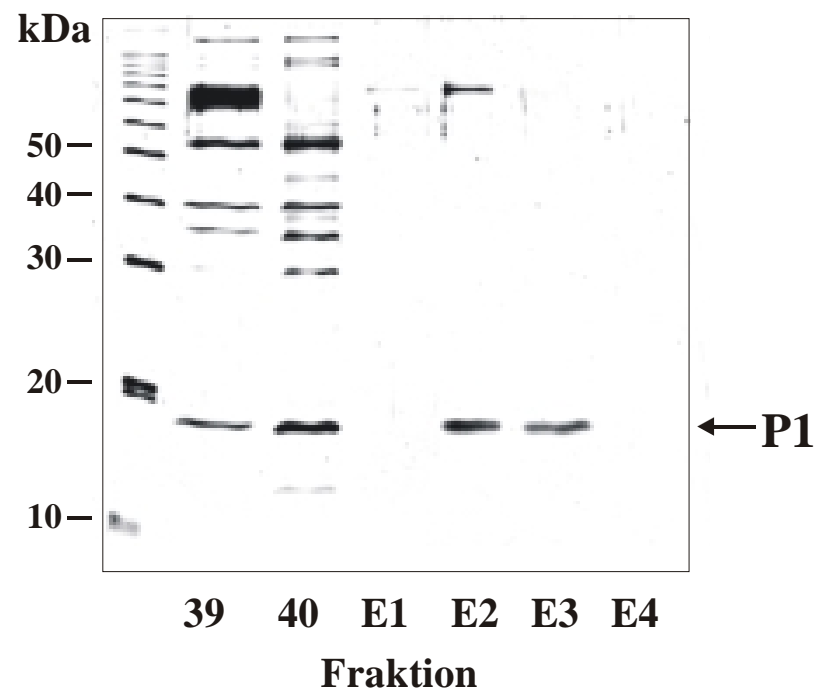

B

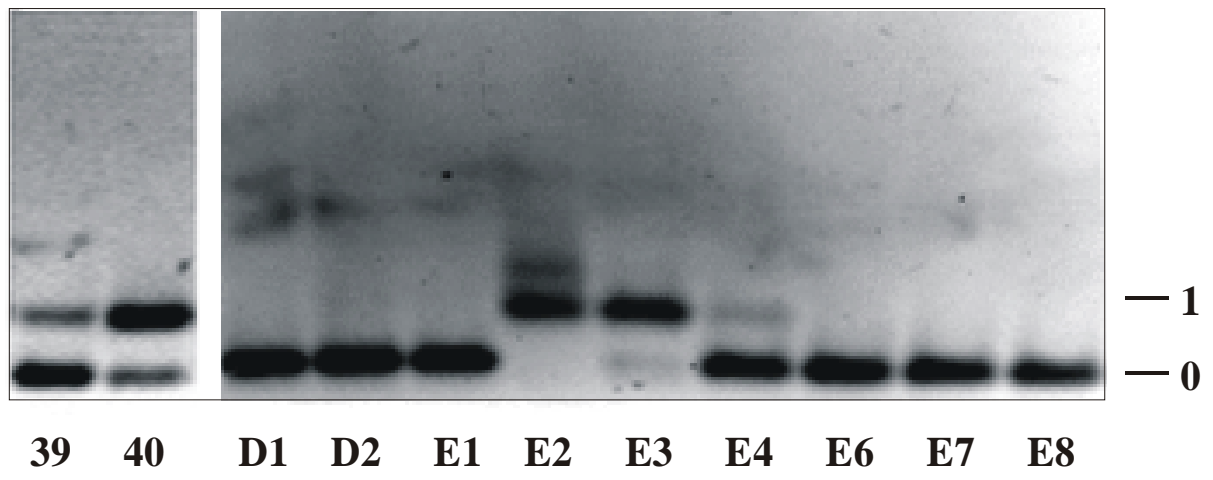

Abb. 7. SDS-PAGE (A) und 'mobility shift'-Analyse (B) der P1-Spitzenfraktionen nach Kationenaustauschchromatographie $(39,40)$ und anschließender Aufreinigung durch DNA-Affinitätschromatographie (D- und E-Fraktionen).

A: SDS-PAGE (14\% [w/v] Acrylamid ). B: 'Mobility shifts' (E2, E3; unverdünnt;

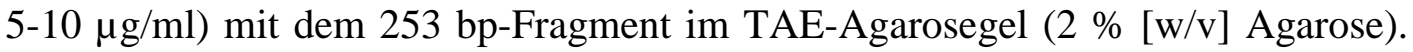
Die entsprechenden Fraktionsnummern sind unterhalb der Spuren angegeben. 0, freie DNA; 1, P1-DNA-Komplex; 2, P2-DNA-Komplex; D, Durchlauffraktionen; E, Eluatfraktionen; Angabe der Molekularmasse in kDa.

\subsubsection{Ergebnis der Anreicherung von P1 und P2}

P1 und P2 wurden in drei Anreicherungsschritten soweit angereichert, daß sie für funktionelle Analysen im 'mobility shift' eingesetzt werden konnten. Eine Trennung der beiden Proteine wurde durch HIC erreicht. Erst in einem vierten Anreicherungsschritt, einer DNAAffinitätschromatographie gelang die vollständige Aufreinigung von P1, während bei P2 aufgrund einer zu geringen Ausbeute auf eine weitere Anreicherung verzichtet wurde.

Bereits bei der Ammoniumsulfatfällung wurden ca. $50 \%$ der Begleitproteine abgetrennt. Durch HIC erfolgte die Abtrennung weiterer ca 40 \% störender Proteine Tab. 1. Die P1- 
Fraktionen aus der KAC mit der höchsten Bindungsaktivität zur Ziel-DNA ( $c b b$ Kontrollregion) zeigten in der SDS-PAGE eine Doppelbande bei ca. $17 \mathrm{kDa}$ Abb. 5. In der abschließenden Analyse nach der DNA-Affinitätschromatographie wurde deutlich, daß die obere der beiden Banden P1 entsprach Abb. 8). Aus 6 g Feuchtzellen von R. eutropha HB14 wurden ca. $5 \mu \mathrm{g}$ homogenes P1 erhalten (Tab. 1.

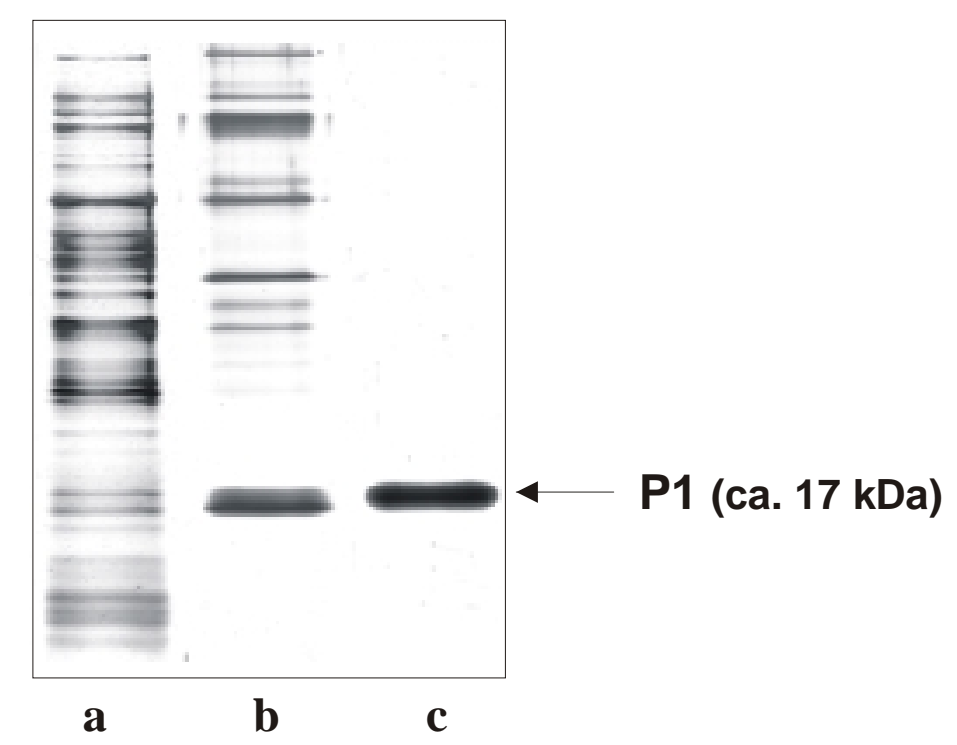

Abb. 8. SDS-PAGE der Anreicherungsfraktionen von P1.

Auftrennung der P1-Anreicherungsfraktionen nach a, hydrophober Interaktionschromatographie $(0.5 \mu \mathrm{g})$; b, Kationenaustauschchromatographie $(0.1 \mu \mathrm{g})$; c, DNAAffinitätschromatographie (ca. 0.02); 14\% [w/v] Acrylamid; Angabe der Molekularmasse von P1 in kDa. 
Tab. 1. Proteinausbeuten bei der Anreicherung von P1 und P2 aus R. eutropha HB14.

\begin{tabular}{|c|c|c|c|c|}
\hline Fraktion & $\begin{array}{l}\text { Proteinkonz. } \\
{[\mathrm{mg} / \mathrm{ml}]}\end{array}$ & $\begin{array}{c}\text { Gesamtvol. } \\
{[\mathrm{ml}]}\end{array}$ & $\begin{array}{c}\text { Gesamtprotein } \\
{[\mathrm{mg}]}\end{array}$ & $\begin{array}{c}\text { Ausbeute } \\
{[\%]}\end{array}$ \\
\hline Rohextrakt & 24.3 & 7.5 & 182 & 100 \\
\hline \multicolumn{5}{|l|}{ Ammoniumsulfatfällung } \\
\hline (0-20 \% Sättigung) & 3.7 & 4.0 & 15 & 8 \\
\hline Überstand (20-45 \% Sättigung) & 5.2 & 11.5 & 60 & 33 \\
\hline Pellet $\quad$ (20-45 \% Sättigung) & 26.3 & 3.5 & 92 & 51 \\
\hline \multicolumn{5}{|l|}{ Butyl-Fraktionen } \\
\hline Pool 1 (P1): F38-44 & 1.1 & 11.8 & 13 & 7 \\
\hline Pool 2 (P2): F46-50 & 1.3 & 7.8 & 10 & 6 \\
\hline \multicolumn{5}{|l|}{$\mathrm{SO}_{3}$-Fraktionen (P1) } \\
\hline F38 & 0.04 & 1 & 0.04 & n.r. ${ }^{b}$ \\
\hline $\mathrm{F} 39$ & 0.09 & 1 & 0.09 & n.r. \\
\hline $\mathrm{F} 40$ & 0.10 & 1 & 0.10 & n.r. \\
\hline F41 & 0.08 & 1 & 0.08 & n.r. \\
\hline $\mathrm{F} 42$ & 0.08 & 1 & 0.08 & n.r. \\
\hline $\mathrm{F} 43$ & 0.05 & 1 & 0.05 & n.r. \\
\hline $\mathrm{F} 44$ & 0.04 & 1 & 0.04 & n.r. \\
\hline Summe F38-44 & 0.48 & 1 & 0.48 & n.r. \\
\hline \multicolumn{5}{|l|}{$\mathrm{SO}_{3}$-Fraktionen (P2) } \\
\hline F35 & 0.18 & 1 & 0.18 & n.r. \\
\hline $\mathrm{F} 36$ & 0.15 & 1 & 0.15 & n.r. \\
\hline F37 & 0.14 & 1 & 0.14 & n.r. \\
\hline F38 & 0.09 & 1 & 0.09 & n.r. \\
\hline F39 & 0.08 & 1 & 0.08 & n.r. \\
\hline Summe: F35-39 & 0.46 & 1 & 0.46 & n.r. \\
\hline $\begin{array}{l}\text { Biotin-Streptavidin- } \\
\text { Fraktionen (P1) }\end{array}$ & & & ca. $0.005^{\mathrm{a}}$ & n.r. \\
\hline
\end{tabular}

${ }^{a}$ Abgeschätzt über Agarose- 'mobility shifts'

${ }^{\mathrm{b}}$ n.r., nicht relevant

\subsubsection{N-terminale Aminosäuresequenz von P1}

Zur eingehenden funktionellen Charakterisierung von P1 ist die Identifikation seines korrespondierenden Gens notwendig. Daher erfolgte eine N-terminale Ansequenzierung des angereicherten P1, das dazu nach Auftrennung in der SDS-PAGE durch Western-Blot auf eine PVDF-Membran übertragen wurde. Die P1-Bande wurde nach Anfärbung ausgeschnitten 
und direkt zur Sequenzierung eingesetzt. Durch automatisierten Edman-Abbau konnte ein Sequenzabschnitt von 14 Aminosäuren identifiziert werden.

$$
\begin{array}{lllllllllllllllll} 
& \text { 1 } & \text { M } & \text { N } & \text { S } & \text { T } & \text { A } & \text { V } & \text { P } & \text { R } & \text { G } & \text { A } & \text { S } & \text { E } & \text { P } & \text { F } \\
\text { Codonhäufigkeit: } & 1 & 2 & 6 & 4 & 4 & 4 & 4 & 6 & 4 & 4 & 6 & 2 & 4 & 2
\end{array}
$$

Durch Sequenzabgleich der N-terminalen Sequenz von P1 mit erst seit kurzem zugänglichen Rohsequenzen aus dem Genom eines Stammes von $R$. eutropha konnte in diesen Sequenzen ein 372 bp großer offener Leserahmen (ORF) detektiert werden, dessen abgeleitete Nterminale Aminosäuresequenz vollständig mit der von P1 übereinstimmte. Der ORF scheint daher mit hoher Wahrscheinlichkeit das gesuchte P1-Gen darzustellen (s. Diskussion; 4.6.1).

\subsubsection{Ableitung degenerierter Oligonucleotide}

Ausgehend von der N-terminalen Sequenz des P1 wurden degenerierte Oligodesoxynucleotide abgeleitet, die u.a. zum Durchmustern einer Phagen-Genombank von $R$. eutropha H16 eingesetzt werden könnten. Unter Berücksichtigung der Codonverwendung von $R$. eutropha wurden die Oligonucleotide von dem Sequenzabschnitt TAVPRGASE abgeleitet (Tab. 2).

Um später noch detektierbare Hybridisierungssignale zu erhalten, wurde die Anzahl verschiedener Oligonukleotide innerhalb des Gemisches auf eine Zahl von 128 beschränkt. Dies gelang unter anderem dadurch, daß an der dritten Codonposition ('Wobble') teilweise die universelle Base Inosin verwendet wurde, die mit allen vier natürlichen Basen mit unterschiedlich hoher Affinität paaren kann. Die beiden einzelnen Oligonucleotide (Forward-Oligo und Reverse-Oligo) wurden vor allem im Hinblick auf eine denkbare Identifikation des P1Gens über eine vektorverankerte PCR abgeleitet. 
Tab. 2. Aus der N-terminalen Sequenz von P1 abgeleitete Oligonucleotide.

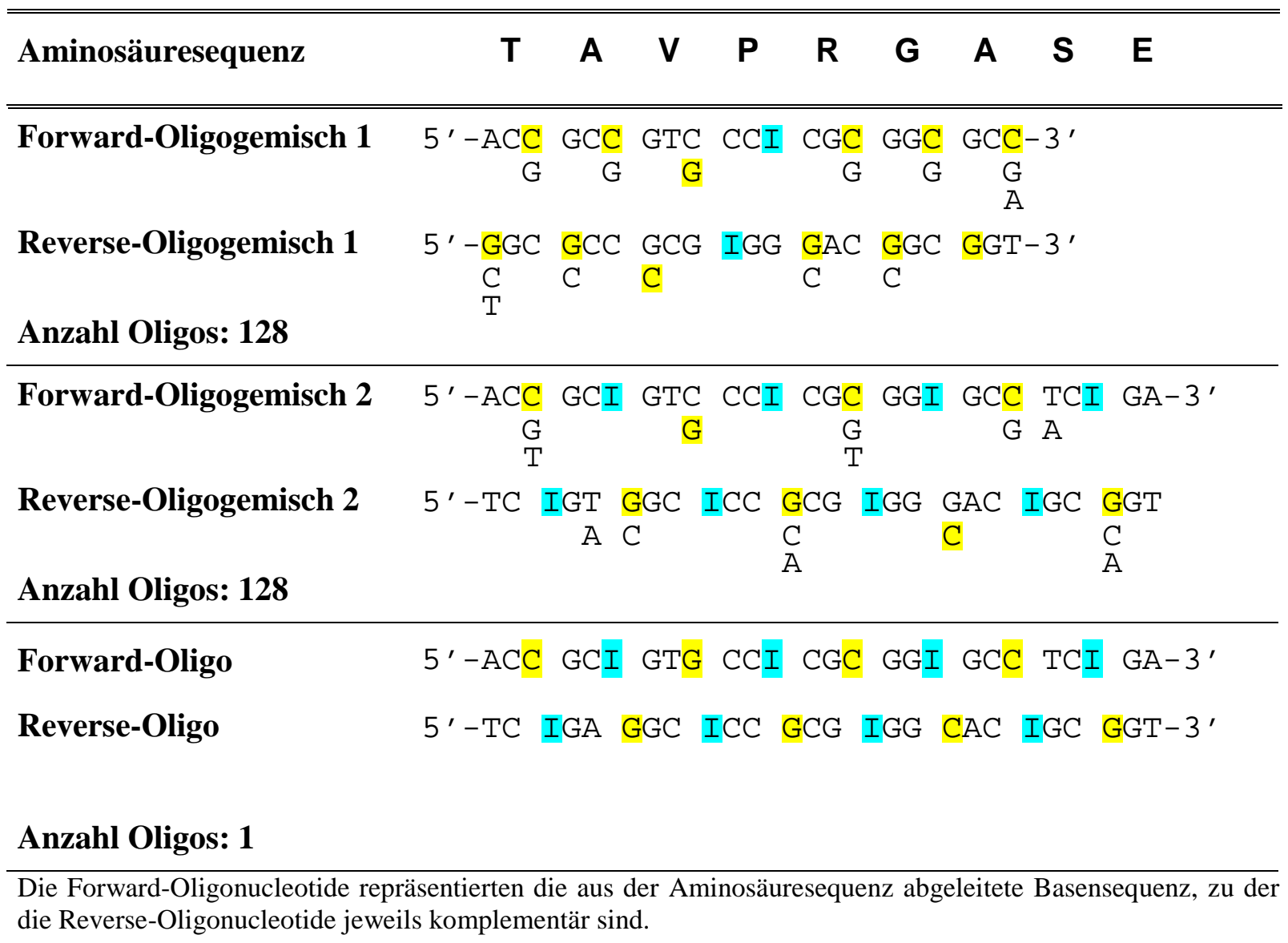

\subsection{Untersuchungen zur Identität von P2}

Untersuchungen an $R$. eutropha HB14R, einer autotroph wachsenden Suppressormutante der autotroph negativen CbbR-Deletionsmutante HB14 führten zur Identifikation des P2-Gens auf indirektem Wege. Bei phänotypischen Komplementationsstudien mit HB14 war ein Gen detektiert worden, dessen Proteinprodukt eine Punktmutation in seinem N-terminal gelegenen Helix-Turn-Helix-DNA-Bindemotiv aufwies und so wahrscheinlich die Suppression der CbbR-Deletion ermöglichte (C. Grzeszik, D. Oed und B. Bowien, persönliche Mitteilung). Das detektierte Gen zeigte große Ähnlichkeit (73\% Identität) zu phcA aus Ralstonia solanacearum, das in diesem Stamm einen übergeordneten Regulator, PhcA codiert und wie CbbR zur LTTR-Familie gehört. Da aufgrund großer Ähnlichkeiten vermutlich eine Homologie zu phcA aus $R$. solanacearum besteht, wurde das neu identifizierte Gen aus $R$. eutropha ebenfalls als $p h c A$ bezeichnet. Durch Deletion des mutierten $p h c A$ ( $\left.p h c A^{*}\right)$ mittels 'gene replacement'Mutagenese in $R$. eutropha HB14R sollte nun überprüft werden, ob die Mutation für die 
Suppression der $c b b$-Deletion verantwortlich war. Durch Deletion von $p h c A$ in $R$. eutropha H16 erfolgte parallel eine Funktionsüberprüfung des Gens im Wildtyp.

\subsubsection{Deletion von phcA in $R$. eutropha}

Die Deletion von $p h c A$ erfolgte durch 'gene-replacement'-Mutagenese unter Verwendung des Suizidvektors pNHG.

Bei dieser Methode wird zunächst in ein kloniertes Fragment des entsprechenden Gens eine gezielte Mutation gesetzt. Anschließend wird das mutierte Fragment mit Hilfe eines SuizidVektors durch doppelte homologe Rekombination mit dem Wildtypallel ausgetauscht (van Spanning et al., 1991; Quandt \& Hynes, 1993; Lenz et al., 1994). Das phcA-Gen wurde im konkreten Fall zum größten Teil deletiert, wovon auch das Helix-Turn-Helix-DNABindungsmotiv im N-terminalen Bereich von PhcA betroffen war. Die Deletion verursachte weder einen Rasterschub noch berührte sie die beiden flankierenden, entgegengesetzt orientierten offenen Leserahmen.

\subsubsection{Konstruktion des Suizidvektors pNHG $\Delta p h c A$}

Zur Erzeugung von phcA-Nullmutanten von $R$. eutropha H16 und HB14R wurde in dem Plasmid pCG12, das ein $p h c A$ enthaltendes, 2.15 kb großes SalI-Fragment enthielt, zunächst ein 806 bp langes StuI-Fragment deletiert, wodurch $p h c A$ nahezu komplett entfernt wurde. Das auf $1.34 \mathrm{~kb}$ verkürzte SalI-Fragment in pCG12 $\Delta p h c A$ wurde anschließend in den Suizidvektor pNHG umkloniert $(\rightarrow$ pNHGphcA; Abb. 9): 
A pCG12

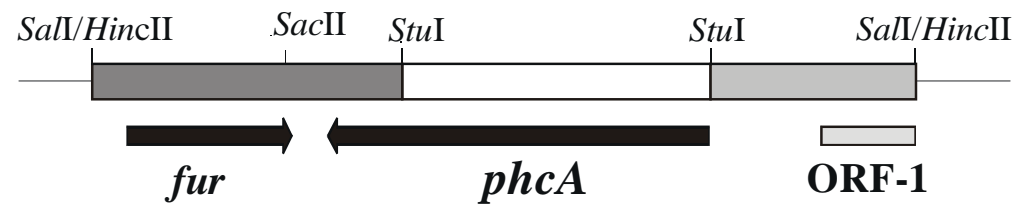

\section{pCG12 $\Delta p h c A$}

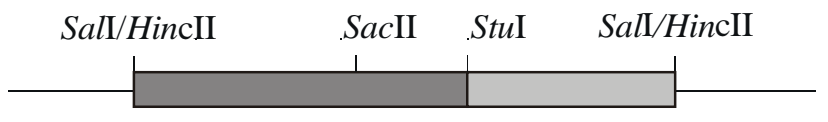

B
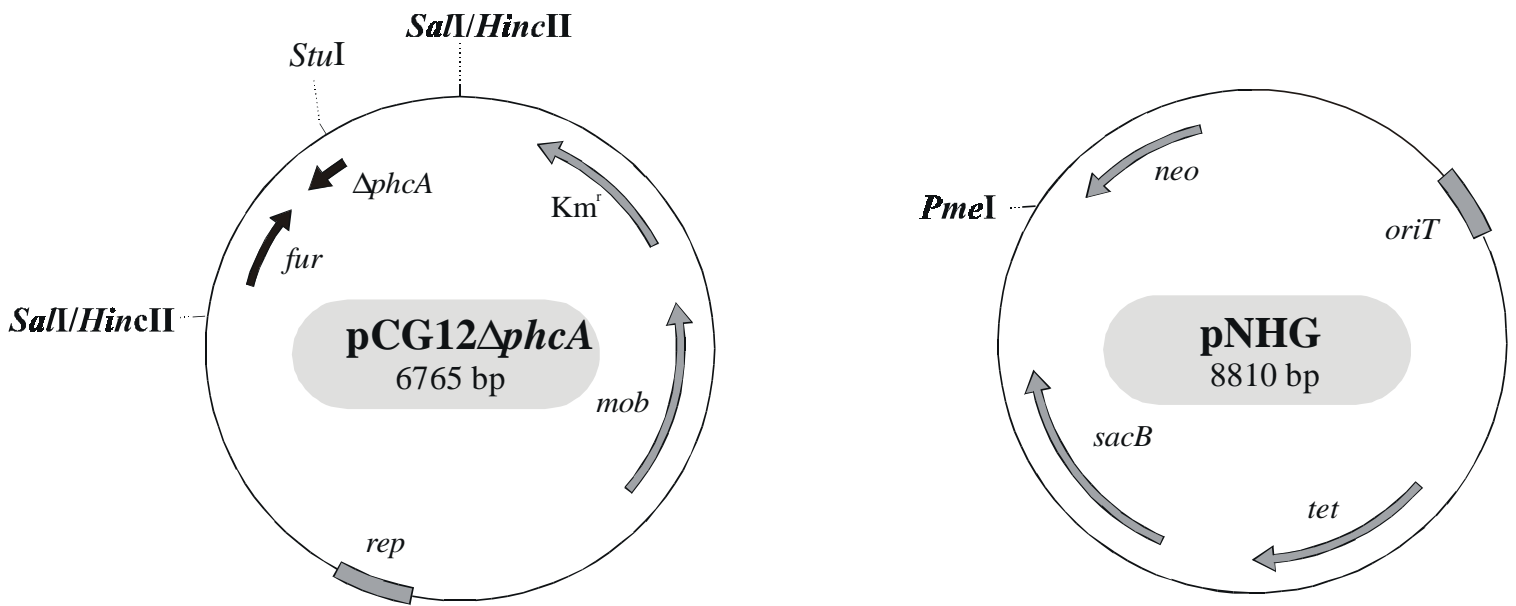

(1344 bp)

Verdau mit StuI

Religation des linearisierten Plasmids

B

Verdau mit HincII

Isolierung des

1.34 kb-HincII Fragments
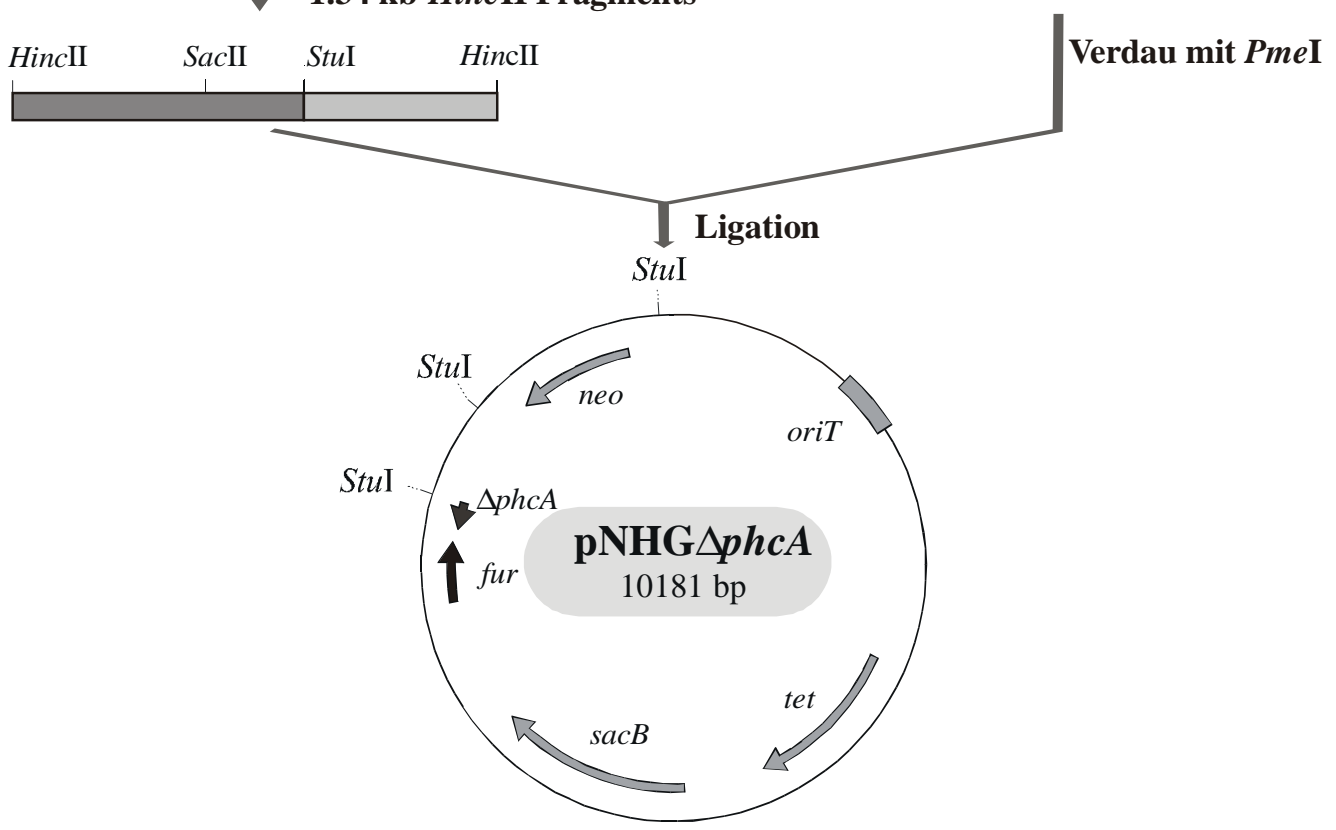

Abb. 9. Erzeugung eines phcA-Deletionsfragments (A) und Konstruktion des Suizidvektors pNHG $\Delta p h c A(B)$.

Relevante Restriktionsschnittstellen: HincII, PmeI, StuI; mob, Gene für Mobilisierung; neo, Gen für Kanamycinresistenz; $s a c B$, Gen für Levansucrase; tet, Gen für Tetracyclinresistenz; oriT, Transferursprung; rep, Replikationsursprung. 


\subsubsection{Isolierung von Homogenoten}

Der Suizidvektor pNHG $\Delta p h c A$ wurde durch Konjugation von E. coli S17-1 nach R. eutropha H16 und HB14R übertragen. Bei dem ersten homologen Rekombinationsschritt erfolgte eine Integration des Plasmids in das Chromosom Abb. 10). Die resultierenden Heterogenoten wurden anhand der durch pNHG vermittelten Tetracyclinresistenz selektiert und anschließend durch PCR überprüft. Um isogene Deletionsmutanten (Homogenoten) zu erhalten, war die Entfernung des Vektors aus dem Chromosom durch ein zweites homologes Rekombinationsereignis notwendig. Dazu wurden die Heterogenoten zunächst für 16-32 h in NB-Medium ohne Antibiotikum angezogen. Bei den darauf folgenden Plattierungen auf NB-SaccharoseAgar diente das die Laevansucrase kodierende $s a c B$-Gen als Selektionsmarker, das durch Saccharose induziert wird. Die Laevansucrase synthetisiert aus Saccharose Laevan (Gay et al., 1985) und ist vermutlich im periplasmatischen Raum der Zellen lokalisiert. In Anwesenheit einer hohen Konzentration von Saccharose (15\% [w/v]) wirkt das überproduzierte Levan letal für R. eutropha (Lenz et al., 1994). Da von den Heterogenoten die Laevansucrase gebildet wurde, konnten sie unter diesen Bedingungen nicht wachsen, während sich die Homogenoten aufgrund des Fehlens von $s a c B$ als saccharoseresistent erwiesen. Potentielle Homogenoten wurden schließlich auf einen tetracyclinsensitiven Phänotyp überprüft. 


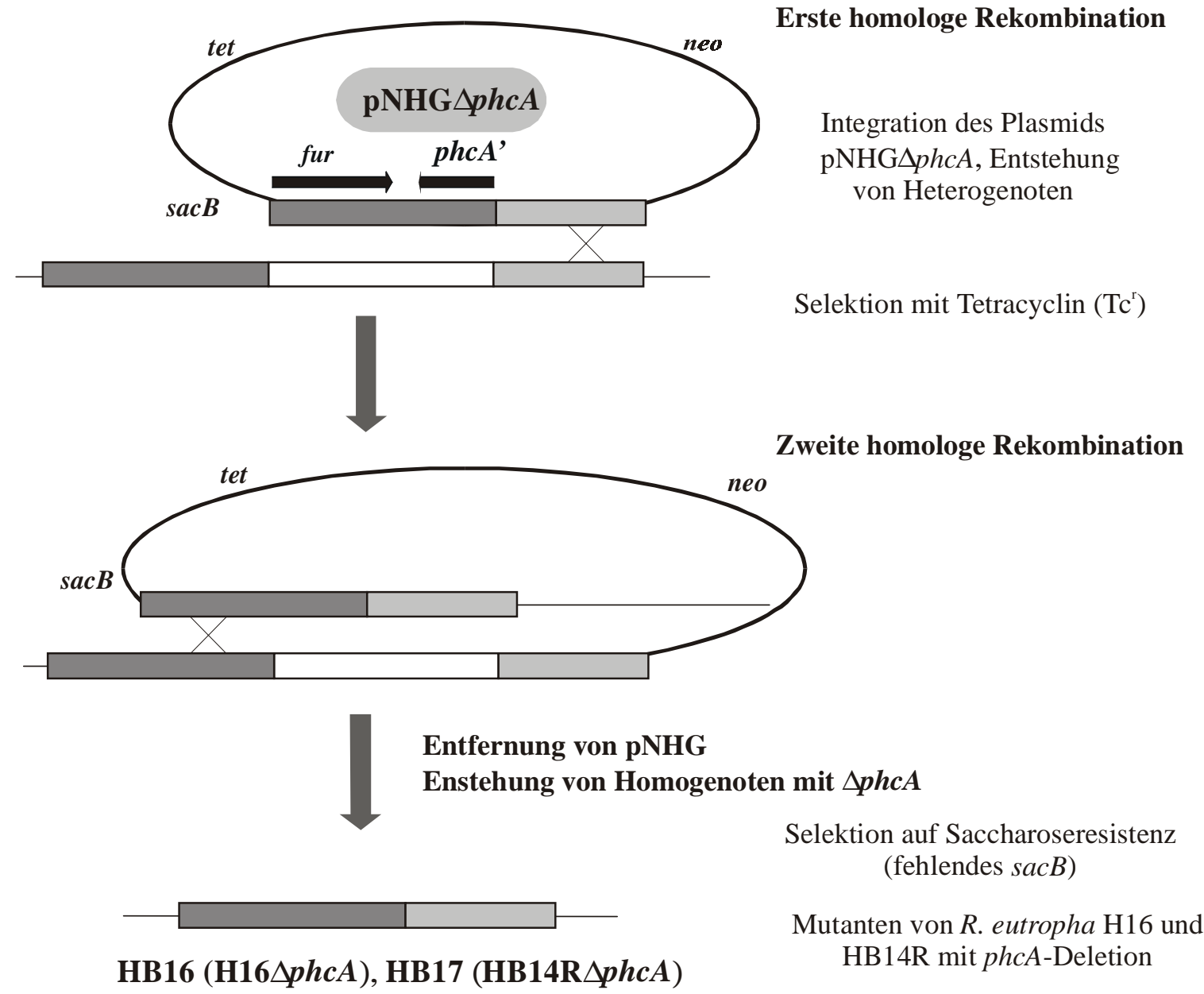
Abb. 10. 'Gene-replacement'-Mutagenese des phcA-Gens in R. eutropha $\mathbf{H 1 6}$ und
HB14R durch doppelt homologe Rekombination.

\subsubsection{Verifikation der $p h c A$-Deletion durch PCR}

Die Verifikation der Cointegration des Suizidvektors im Chromosom der Heterogenoten und des potentiellen $p h c A$-Allelaustausches mit eingefügter Deletion bei den Homogenoten wurde durch PCR mit Gesamt-DNA aus verschiedenen Klonen (H16, HB14R, HB16 und HB17) sowie einigen Heterogenoten durchgeführt. Es wurden Primer verwendet, deren Anlagerungspositionen innerhalb des chromosomalen $\mathrm{KpnI} /$ BamHI-Fragments direkt stromaufwärts bzw. stromabwärts von phcA lokalisiert waren Abb. 11.

Bei Integration des Deletionsfragments lieferte die PCR mit Gesamt-DNA tetracyclinsensitiver Homogenoten ein Amplifikat von 654 bp Länge, während bei nicht erfolgtem Allelaustausch, d.h. nach Reversion zum Ausgangsstamm mit komplettem $p h c A / p h c A *_{\text {-Gen, ein } 1460}$ bp-Fragment amplifiziert wurde. Erwartungsgemäß entstanden bei den Heterogenoten beide Amplifikate Abb. 12. 
CAGGATGCTGCTCAGGGTGCCTGCAGGTCTTGCAGGTCCTGTTCGGTGACCACCCGTGCCGGGCGTGCCGGCGGCAGTCCGACAAACTCG GTCCTACGACGAGTCCCACGGACGTCCAGAACGTCCAGGACAAGCCACTGGTGGGCACGGCCCGCACGGCCGCCGTCAGGCTGTTTGAGC

GTGTTCAGTTCCGACGGCAGCGGGAAGGCCTTCAGGCCATAGGTCTCGCAGGCCATGTCCTTGGTCAGCGCATTGACGGTGAAGATCATG CACAAGTCAAGGCTGCCGTCGCCCTTCCGGAAGTCCGGTATCCAGAGCGTCCGGTACAGGAACCAGTCGCGTAACTGCCACTTCTAGTAC $\begin{array}{llllllllllllllllllllllllllllllllllllllll}G & V & V & Q & R & F & L & N & R & A & W & V & L & M & P & H & T & N & R & S & R & H & W & F & M & N & L & G & L & M\end{array}$

1630

GATACGGCCGGTGCGGTCATATGCATCTTTTCCGCTACATAAGTGGCATTTCGCTTGCTCAGTAGTTCGGTGAAGATCACTAAAAGCTTC CTATGCCGGCCACGCCAGTATACGTAGAAAAGGCGATGTATTCACCGTAAAGCGAACGAGTCATCAAGCCACTTCTAGTGATTTTCGAAG

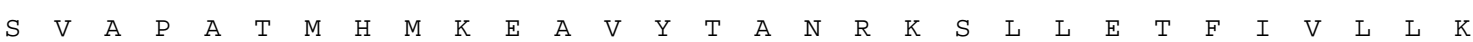
1730 StuI
1750
1770
1790

GTGTCTACGTTCACCATGATCAGGCCTCGGTCAGATTATTCTTAGCTAGATGGCCCCACCACTTGCACTGGCTGCACATCAGATTTCAAC CACAGATGCAAGTGGTACTAGTCCGGAGCCAGTCTAATAAGAATCGATCTACCGGGGTGGTGAACGTGACCGACGTGTAGTCTAAAGTTG

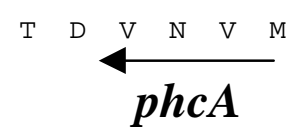
2170
2190
2210
2230
2250

TCGCCCCGCCCAAGGTGGCAGTGGTGCTGGACAAGAGCACCTGGACCCGGCACCTGCTGGAAGACAGCGGCGAGTTCGTGTTGCAGGTCC AGCGGGGCGGGT TCCACCGTCACCACGACCTGTTCTCGTGGACCTGGGCCGTGGACGACCTTCTGTCGCCGCTCAAGCACAACGTCCAGG deltaStu2

Abb. 11. Sequenzausschnitt des phcA enthaltenden chromosomalen 3.46 kb-BamHIKpnI-Fragments. Die Positionen der Primer (deltaStu1, deltaStu2) und der 806 bp StuI-Deletion in R. eutropha HB16 und HB17 sind markiert (unterstrichen).

A

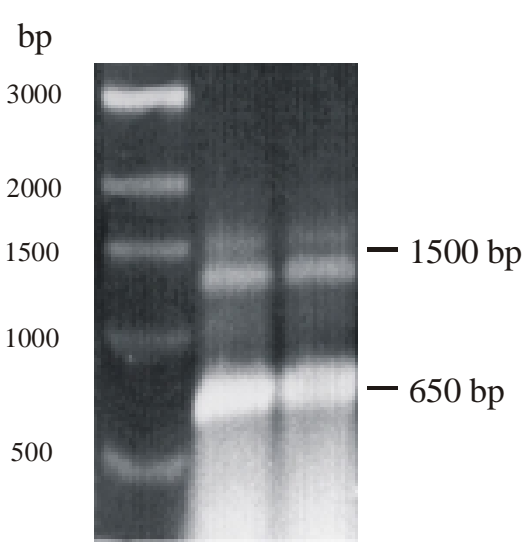

a $\quad \mathbf{b} \quad \mathbf{c}$
B

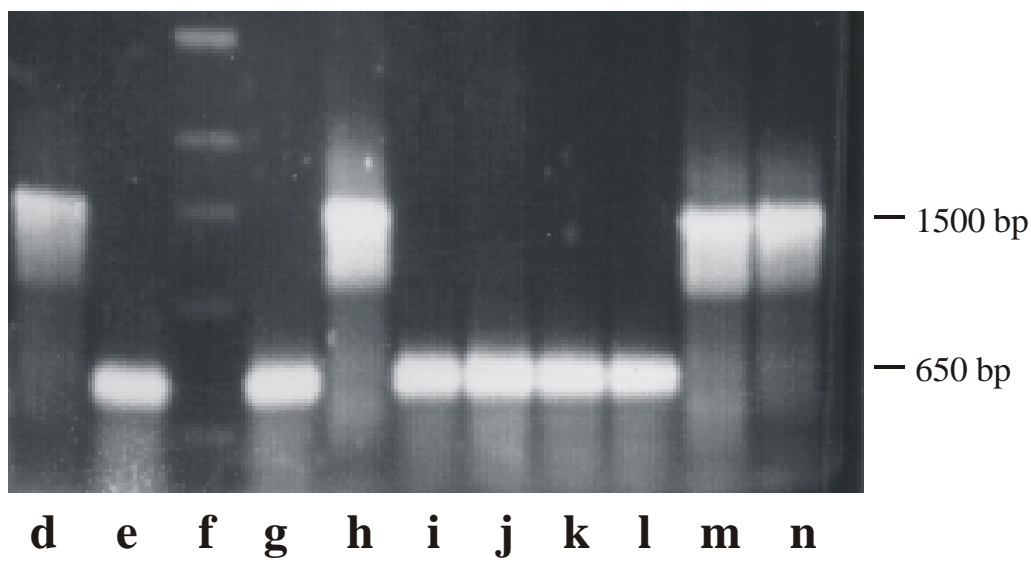

Legende (s. nächste Seite) 
Abb. 12. PCR mit Gesamt-DNA zur Verifikation der phcA-Deletionen in den Mutanten R. eutropha HB16 und HB17.

Nachweis der $p h c A$-Deletion (654 bp-Fragment) und des vollständigen $p h c A$-Gens (1460 bp-Fragment). a und f, 1 kb DNA-Leiter; b, H16-Heterogenote; c, HB14RHeterogenote; d, H16; e, pNHG $\Delta p h c A$; g, i und j, HB16; h Wildtyprevertante H16; $\mathrm{k}$ und 1, HB17; m und n, HB14R-Revertanten.

\subsection{2 'Mobility shifts' mit Rohextrakten der Deletionsmutanten}

Zur Charakterisierung der Deletionsmutanten HB16 und HB17 wurden 'mobility shifts' der $c b b$-Kontrollregion mit Rohextrakten durchgeführt, um eventuelle Änderungen im Muster der bindenen Proteine festzustellen. Tatsächlich zeigte sich, daß der mit H16, HB14 und HB14R auftretende P2-DNA-Komplex mit Rohextrakten von HB16 und HB17 nicht mehr nachweisbar war. Dieser Befund sprach nun dafür, daß PhcA und P2 durch dasselbe Gen codiert werden und somit identisch sind.

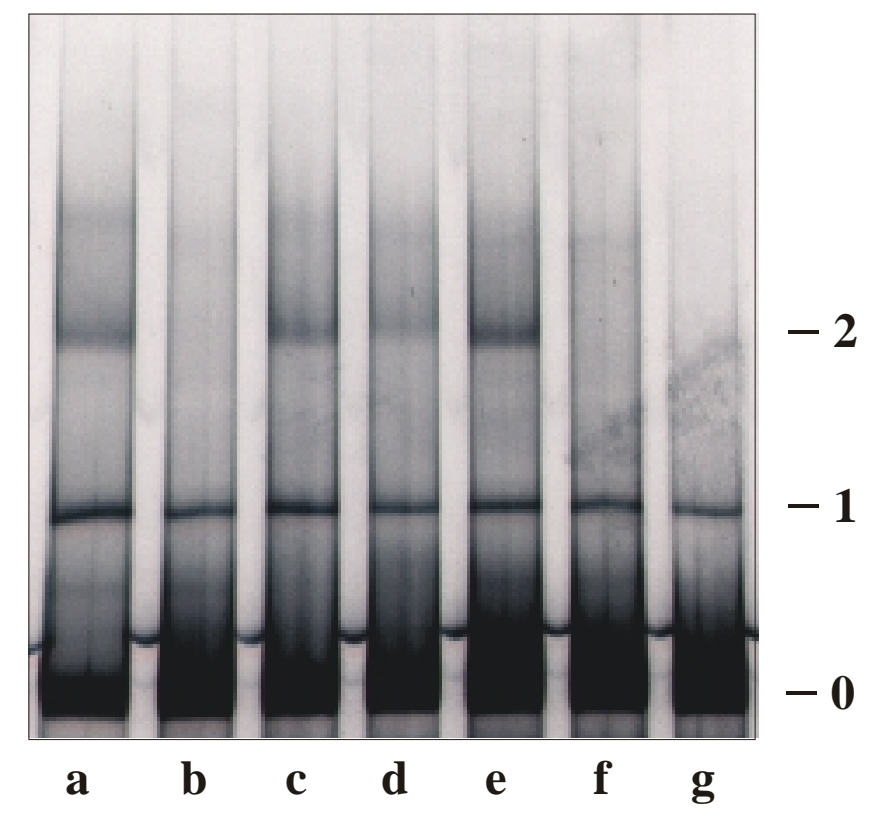

Abb. 13. 'Mobility shifts' mit der $c b b$-Kontrollregion (253 bp-Fragment) und Rohextrakten von H16, HB14R, HB14 oder den phcA-Deletionsmutanten HB16 und HB17.

Rohextrakte $(5 \mathrm{mg} / \mathrm{ml})$ nach lithoautotropher Anzucht: a, H16; b, HB16; nach heterotropher Anzucht mit Fructose: c, H16; d, HB14R; e, HB14; f, HB16; g, HB17. 0, freie DNA; 1, P1-DNA-Komplex; 2, P2-DNA-Komplex.

\subsubsection{Phänotypische Charakterisierung $\operatorname{der} p h c A$-Deletionsmutanten}

Die Deletion des $p h c A-G e n s$ führte bei der autotroph positiven Revertante HB14R zu einem Verlust der Autotrophie. Dieser Phänotyp belegte, daß die Suppression der CbbR-Deletion in HB14R tatsächlich auf die Punktmutation in $p h c A^{*}$ zurückzuführen war. Dagegen blieb bei 
der aus dem Wildtyp H16 hervorgegangenen phcA-Deletionsmutante HB16 die Autotrophieeigenschaft unverändert erhalten und zunächst wurde auch anderweitig kein vom Wildtyp abweichender Phänotyp festgestellt. HB16 wuchs sowohl litho- $\left(\mathrm{H}_{2}-\mathrm{CO}_{2}\right)$ als auch organoautotroph (Formiat) und zeigte wie HB17 auch keine Unterschiede zum Wildtyp bei Wachstum auf verschiedenen heterotrophen Substraten Abb. 14.

Zur weiteren Charakterisierung des Wachstumsverhaltens von HB16 wurden die Raten für lithoautotrophes Wachstum und heterotrophes Wachstum mit Fructose oder Pyruvat im Vergleich zum Wildtyp H16 ermittelt. Die Verdopplungszeiten $\left(t_{d}\right)$ waren bei H16 und HB16 unter allen Wachstumsbedingungen nahezu identisch (Tab. 3 .

Tab. 3. Verdopplungszeiten von $R$. eutropha H16 und HB16 bei Wachstum auf verschiedenen Substraten.

\begin{tabular}{|c|c|c|}
\hline \multirow[t]{2}{*}{ Substrat } & H16 & HB16 \\
\hline & \multicolumn{2}{|c|}{$\begin{array}{c}\text { Verdopplungszeit } \mathrm{t}_{\mathrm{d}}{ }^{\mathrm{a}} \\
(\mathrm{h})\end{array}$} \\
\hline $\mathrm{H}_{2}-\mathrm{CO}_{2}$ & 4.4 & 4.2 \\
\hline Fructose & 2.4 & 2.5 \\
\hline Pyruvat & 1.7 & 1.8 \\
\hline
\end{tabular}

${ }^{\mathrm{a}}$ Wachstum bei $30^{\circ} \mathrm{C}$

Ein deutlicher Phänotyp war hingegen in der stationären Wachstumsphase sowohl bei HB16 als auch bei HB17 zu beobachten. Nach 3-4 Tagen unter Schütteln bei $30^{\circ} \mathrm{C}$ neigten die Zellen stark zur Verklumpung. Ein ähnliches Verhalten zeigte sich nach zwei bis drei Wochen Lagerung bei $4^{\circ} \mathrm{C}$. Zum Anwachsen in frischem Medium benötigten solche Kulturen bis zu drei Tage (jeweils nur ein Tag bei H16 und HB14R), zuweilen wuchsen sie gar nicht mehr an. Die Vitalität der beiden Mutanten unter Stressbedingungen schien also deutlich vermindert. Auch mehrmaliges Auftauen der Stammkulturen erwies sich in dieser Hinsicht als problematisch. 
A
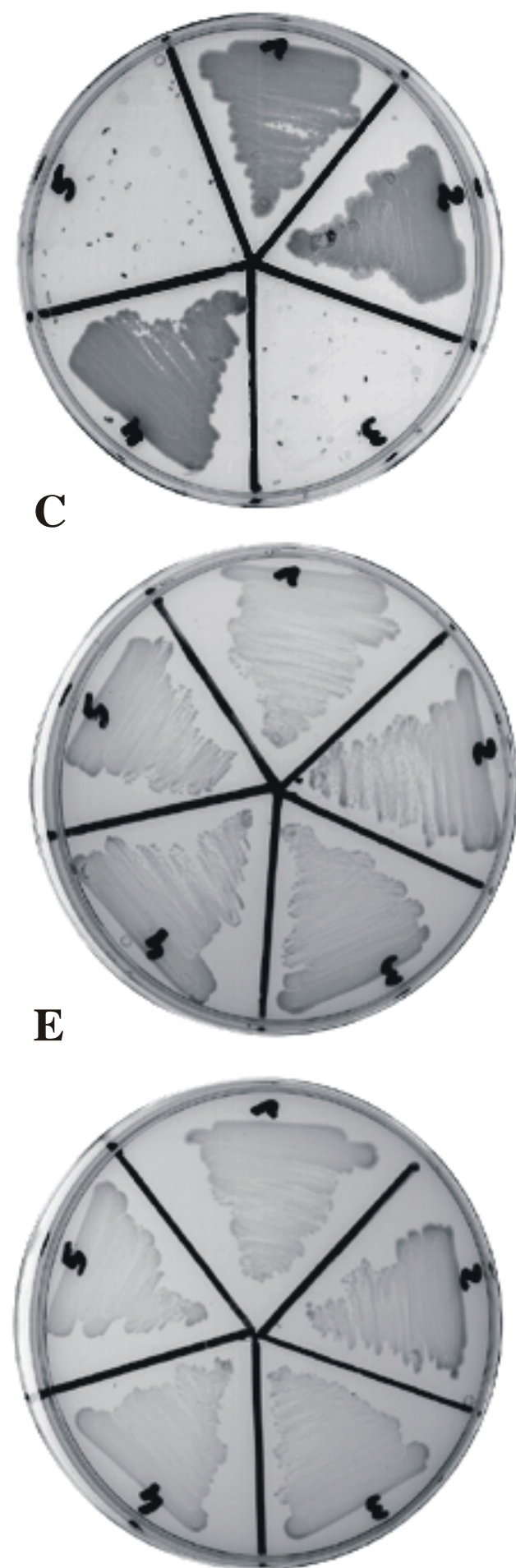

B

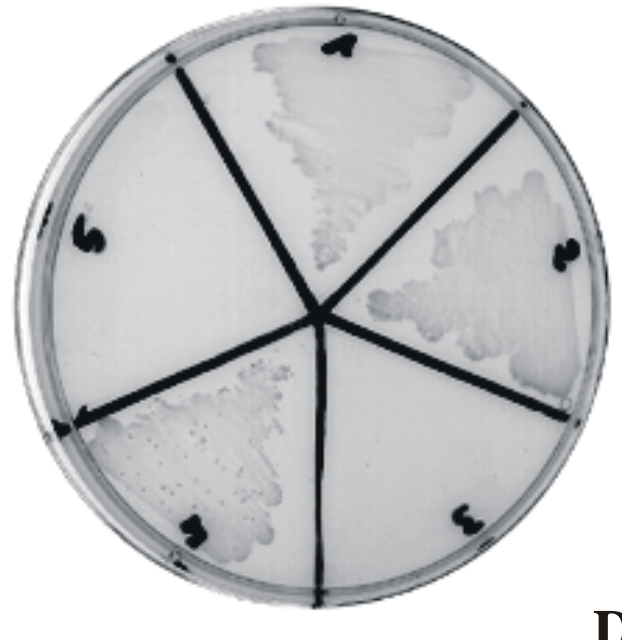

D
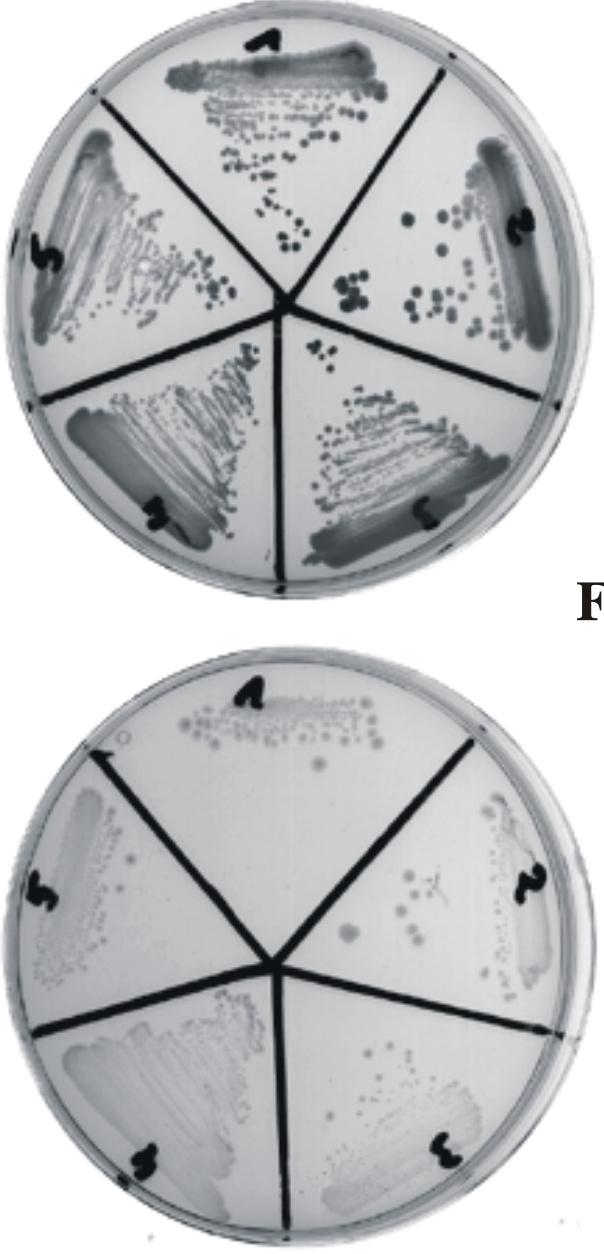

Abb. 14. Wachstum von $R$. eutropha H16, HB16, HB14, HB14R und HB17 auf verschiedenen Substraten.

Ausstrich von H16 (1), HB16 (H16 $p$ phcA) (2), HB14 (3), HB14R (4) und HB17 (HB14 $4 p h c A)$ (5) auf Mineralagar mit verschiedenen Substraten. A, $\mathrm{H}_{2}-\mathrm{CO}_{2}$; B, Formiat; C, Fructose; D, Gluconat; E, Pyruvat; F, Succinat. Wachstum nach drei Tagen bei $30^{\circ} \mathrm{C}$. 
Um einer potentiellen Funktion von PhcA bei der transkriptionellen Regulation der $c b b$ Operone von $R$. eutropha H16 nachzugehen, wurden die Aktivitäten des Operonpromotors $p_{c b b L}$ sowohl in H16 als auch in HB16 nach Anzucht auf verschiedenen Substraten bestimmt. Die Messungen erfolgten anhand transkriptioneller $p_{c b b L}:$ :lacZ-Fusionen über die B-Galaktosidase-Reporteraktivität in Rohextrakten der entsprechenden Transkonjuganten H16 (pBK2241) und HB16 (pBK2241) Tab. 4.

Tab. 4. Aktivitäten des $c b b$-Operonpromotors $p_{c b b L}\left(p_{c b b L}:: l a c Z\right.$-Fusion in pBK2241) in Transkonjuganten des Wildtypstamms $R$. eutropha $\mathrm{H16}$ und der phcA-Deletionsmutante HB16

\begin{tabular}{lrrr}
\hline Substrat & Plasmid & H16 & HB16 \\
\cline { 2 - 4 } & & \multicolumn{2}{c}{$\begin{array}{c}\text { Spez. Aktivität der } \\
\text { B-Galaktosidase } \\
(\mathrm{mU} / \mathrm{mg})\end{array}$} \\
\hline $\mathbf{H}_{\mathbf{2}}-\mathbf{C O}_{2}$ & $\mathrm{pBK}$ & 2 & 3 \\
& $\mathrm{pBK} 2241$ & 730 & 730 \\
Fructose & $\mathrm{pBK}$ & 2 & 1 \\
& $\mathrm{pBK} 2241$ & 95 & 90 \\
Pyruvat & $\mathrm{pBK}$ & 3 & 3 \\
& $\mathrm{pBK} 2241$ & 4 & 5 \\
\hline
\end{tabular}

\subsection{DNA-Bindungsstudien mit PhcA (P2), PhcA*, CbbR und P1}

Interessanterweise war bei der Revertante $R$. eutropha HB14R durch die Mutation in phcA* nicht nur die Fähigkeit zum autotrophen Wachstum wieder hergestellt worden, sondern auch das $c b b$-Regulationsmuster entsprach, wenn auch abgeschwächt, dem des Wildtyps (D. Oed und B. Bowien, persönliche Mitteilung). Diese Ergebnisse lieferten weitere indirekte Hinweise darauf, daß weder CbbR in H16 noch PhcA* in HB14R alleinverantwortlich für die $c b b$ Regulation sind, sondern daß dazu vielmehr mindestens ein weiterer Regulator oder Modulator benötigt wird. Das Wiltyp-PhcA konnte nicht beteiligt sein (s. 3.4.2 3.4.3), obwohl es an die $c b b$-Kontrollregion bindet. Vor diesem Hintergrund wurde untersucht, inwieweit es zu einer möglicherweise kooperativen Bindung der verschiedenen an die $c b b$-Kontrollregion bindenden Proteine kommt. Zu diesem Zweck wurden 'mobility shifts' mit PhcA (P2), PhcA* 
und CbbR in Kombination mit P1 durchgeführt. Gleichzeitig sollten diese Experimente weiteren Aufschluß über die postulierte Identität von P2 mit PhcA erbringen (s. 3.5.4.

Die Experimente erforderten die vorherige Überexpression des Wildtypgens phcA und des Mutantengens $p h c A^{*}$ in $E$. coli, um ausreichend Protein zur Verfügung zu haben.

\subsubsection{Heterologe Expression von $p h c A / p h c A *$ und $c b b R$ in E. coli}

Die Durchführung von DNA-Bindungsstudien mit PhcA/PhcA* aus $R$. eutropha setzt ein Anreicherungsverfahren für diese Proteine voraus, bei dem ausreichende Mengen aufgereinigt und ein möglichst hoher Reinheitsgrad der zu untersuchenden Proteine gewährleistet werden kann. Eine bis zur Homogenität durchgeführte Anreicherung ist essentiell für den Einsatz der Proteine im bereits etablierten In vitro-Transkriptionssystem für den $c b b$-Operonpromotor. Zur Expression in E. coli wurden die entsprechenden Gene zunächst in verschiedene Vektoren umkloniert, deren Gemeinsamkeit in einer durch IPTG induzierbaren vom lacPromotor gesteuerten Expression lag.

Für die Klonierung wurden pUC18/19 und pBBR1MCS2 verwendet. Die Expressionstärke der Gene erwies sich in E. coli JW1 als ausreichend für die 'mobility shift'-Experimente zur Charakterisierung von $p h c A / p h c A *$ Zu Vergleichszwecken wurde $c b b R$ ebenfalls in pUC19 kloniert. Bei In vivo-Studien mit diesen Vektoren wurde auf eine Induktion verzichtet, da bereits ohne Zusatz von IPTG eine Expression der klonierten Gene auf niedrigem Niveau stattfand. Hierbei war anzunehmen, daß die vergleichsweise niedrige Expression im heterologen System ohne Induktion am ehesten den in $R$. eutropha vorliegenden Bedingungen entsprach.

Die $p h c A / p h c A^{*}$ und $c b b R$-Gene lagen bereits kloniert in den Plasmiden pCG3 (pBBR1MCS2::phcA*; Grzeszik, unveröffentlicht), pCG4 (pBBR1MCS2::phcA; Walburg \& Bowien, unveröffentlicht) bzw. pAECR5 (pT7-7::cbbR; Windhövel \& Bowien, 1991) vor.

Um eine Steigerung der Expressionsrate zu erreichen, wurde $p h c A^{*}$ aus dem 'broad host range' Vektor pCG3 (pBBR1MCS2::phcA*), der nur in niedriger Kopienzahl in der Zelle vorliegt, in den 'multicopy' Vektor pUC19 umkloniert und $c b b R$ aus pAECR5 nach pUC18 gebracht. 


\subsubsection{Expressionsanalyse im 'mobility shift'}

Zur Bewertung der Effizienz der heterologen Expressionen von $p h c A / p h c A^{*}$ und $c b b R$ wurden 'mobility shifts' mit der $c b b$-Kontrollregion und Rohextrakten der entsprechenden Transformanten von E. coli JW1 durchgeführt.

Für $p h c A / p h c A^{*}$ zeigte sich eine leicht erhöhte Expression bei Induktion der in pUC19 klonierten Gene gegenüber den pBBR1MCS2-Derivaten. Zunächst war wiederum festzustellen, daß der mit überproduzierten PhcA verursachte Protein-DNA-Komplex die gleiche Mobilität wie der 'P2'-Komplex $(\mathrm{P} 2=\mathrm{PhcA})$ mit Rohextrakt von R. eutropha H16 zeigte Abb. 15A, Spuren a und b). Entsprechend verhielten sich die Komplexe mit Rohextrakt der phcA-Mutante HB14R (Spur c) und überproduzierten PhcA* (Spur d). Die Bindungsaffinität

A

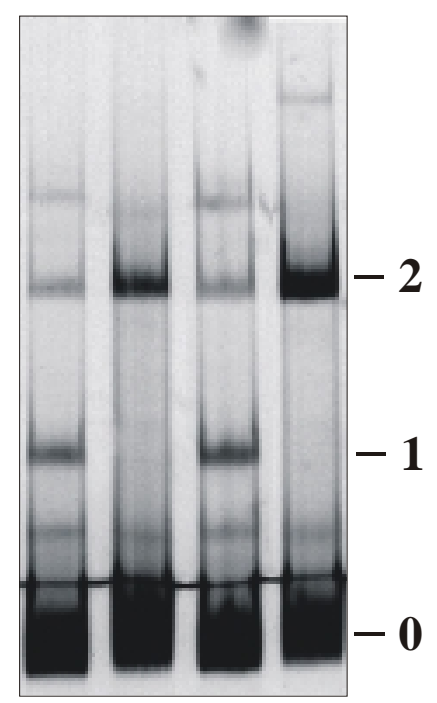

a $\quad \mathbf{b} \quad \mathbf{c} \quad \mathbf{d}$
B

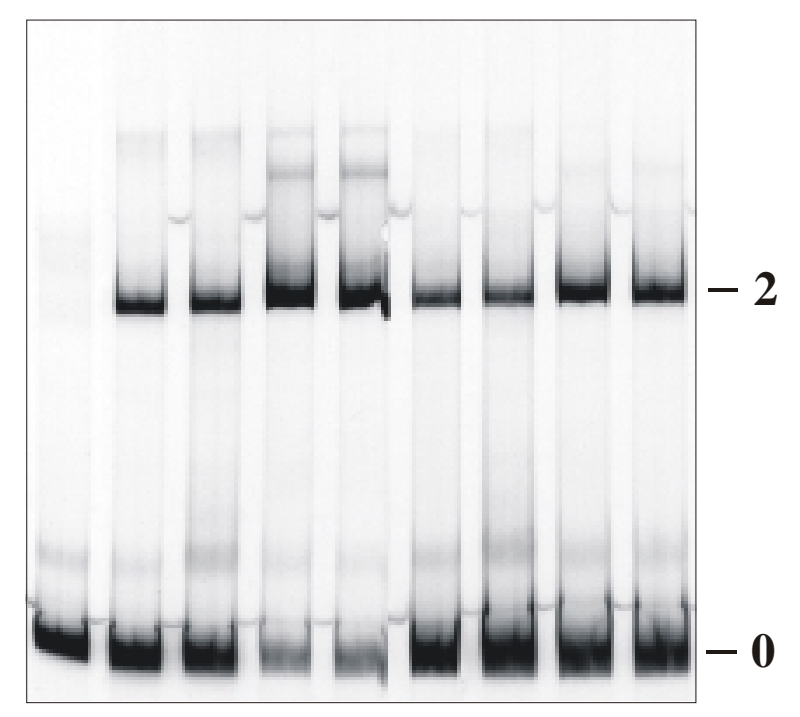

$\begin{array}{lllllllll}\text { a } & \mathbf{b} & \mathbf{c} & \mathbf{d} & \mathbf{e} & \mathbf{f} & \mathbf{g} & \mathbf{h} & \mathbf{i}\end{array}$
C

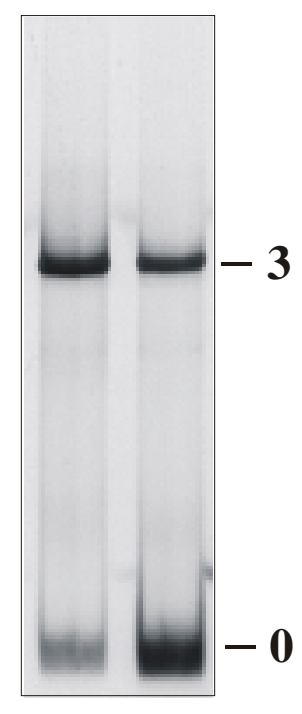

a b

Abb. 15. 'Mobility shifts' der $c b b$-Kontrollregion und Rohextrakten von $R$. eutropha H16 oder HB14R sowie verschiedenen Transformanten von $E$. coli JW1 nach heterologer Expression von $p h c A / p h c A *$ oder $c b b R$.

A: a und c, Rohextrakte $(0.6 \mathrm{mg} / \mathrm{ml})$ von $R$. eutropha H16 (a) bzw. HB14R (c) nach Anzucht auf Fructose; b und d, Rohextrakte (1 mg/ml) von E. coli JW1 pCG8 (pUC19::phcA) bzw. E. coli JW1 pCG7 (pUC19::phcA*). B: a, E. coli pUC19 (2.5 $\mathrm{mg} / \mathrm{ml})$; b und c, pCG8 (2.5 bzw. $0.6 \mathrm{mg} / \mathrm{ml})$ mit (pUC19::phcA); d und e, pCG7 (2.5 bzw. $0.6 \mathrm{mg} / \mathrm{ml}$ ); f und g, pCG4 (pBBR1MCS2::phcA; 2.5 bzw. $0.6 \mathrm{mg} / \mathrm{ml}$ ); h und i, pCG3 (pBBR1MCS2::phcA*; 2.5 und $0.6 \mathrm{mg} / \mathrm{ml}$ ).C: a und b, E. coli JW1 pAECR7 (pUC18::cbbR; 1.2 bzw. $0.3 \mathrm{mg} / \mathrm{ml}$ ). 0, freie DNA; 1, P1-DNA-Komplex; 2, PhcA bzw. PhcA*-DNA-Komplex; 3, CbbR-DNA-Komplex. 
von PhcA* war dabei wesentlich höher als die von PhcA (Abb. 15B). Es bestätigte sich, daß der CbbR-Komplex eine signifikant geringere Mobilität als die PhcA/PhcA*-Komplexe aufwies (Abb. 15.).

Aufgrund der Überproduktion von $\mathrm{PhcA} / \mathrm{PhcA} *$ in E. coli JW1 war hierdurch eine weitere Grundlage für Untersuchungen der Funktionsweise dieser Proteine im Wildstamm R. eutropha H16 und in der Revertante HB14R gegeben. An den in Abb. 15B dargestellten Retardationskomplexen war bereits zu erkennen, daß das überproduzierte PhcA* eine gegenüber dem Wildtyp-PhcA erhöhte Bindungsaffinität an die $c b b$-Kontrollregion zeigte. Durch die Umklonierung von $p h c A / p h c A^{*}$ in pUC19 konnte die Effizienz gegenüber den entsprechenden pBBR1MCS2-Klonen sichtbar erhöht werden. Daher wurden bei anschlieBenden Expressionen bevorzugt die pUC-Konstrukte verwendet und die dabei überproduzierten Proteine für weitere DNA-Bindungsstudien eingesetzt. Obwohl eine deutliche Expression von $p h c A / p h c A *$ und $c b b R$ in $E$. coli JW1 erfolgte, war in der SDS-PAGE keine signifikante Überproduktion der korrespondierenden Proteine zu beobachten (Daten nicht gezeigt).

\subsubsection{Expression in E. coli mit dem Impact-CN-System}

Um eine effizientere Expression von $p h c A / p h c A *$ zu erreichen, wurde das Impact-CN-System gewählt. Dieses basiert auf der Konstruktion von Fusionsproteinen mit einem selbstspleißenden Intein-'TAG', der eine chitinbindende Domäne enthält und dadurch eine schnelle Anreicherung des Fusionsproteins über eine Chitin-Affinitätssäule ermöglicht.

\subsubsection{Konstruktion und Expression $\operatorname{der} p h c A / p h c A^{*}$-Intein-Fusionsgene}

Für die Konstruktion C-terminaler $p h c A / p h c A *$-Intein-Fusionen wurde der Expressionsvektor pCYB2 gewählt, wobei die für die Fusion benötigten Schnittstellen (NdeI und SmaI) des zu klonierenden Fragments durch PCR generiert wurden. Die Klonierung von $p h c A / p h c A *$ erfolgte in mehreren Schritten Abb. 16. Die Richtigkeit des resultierenden Konstrukts wurde durch Sequenzierung verifiziert. 


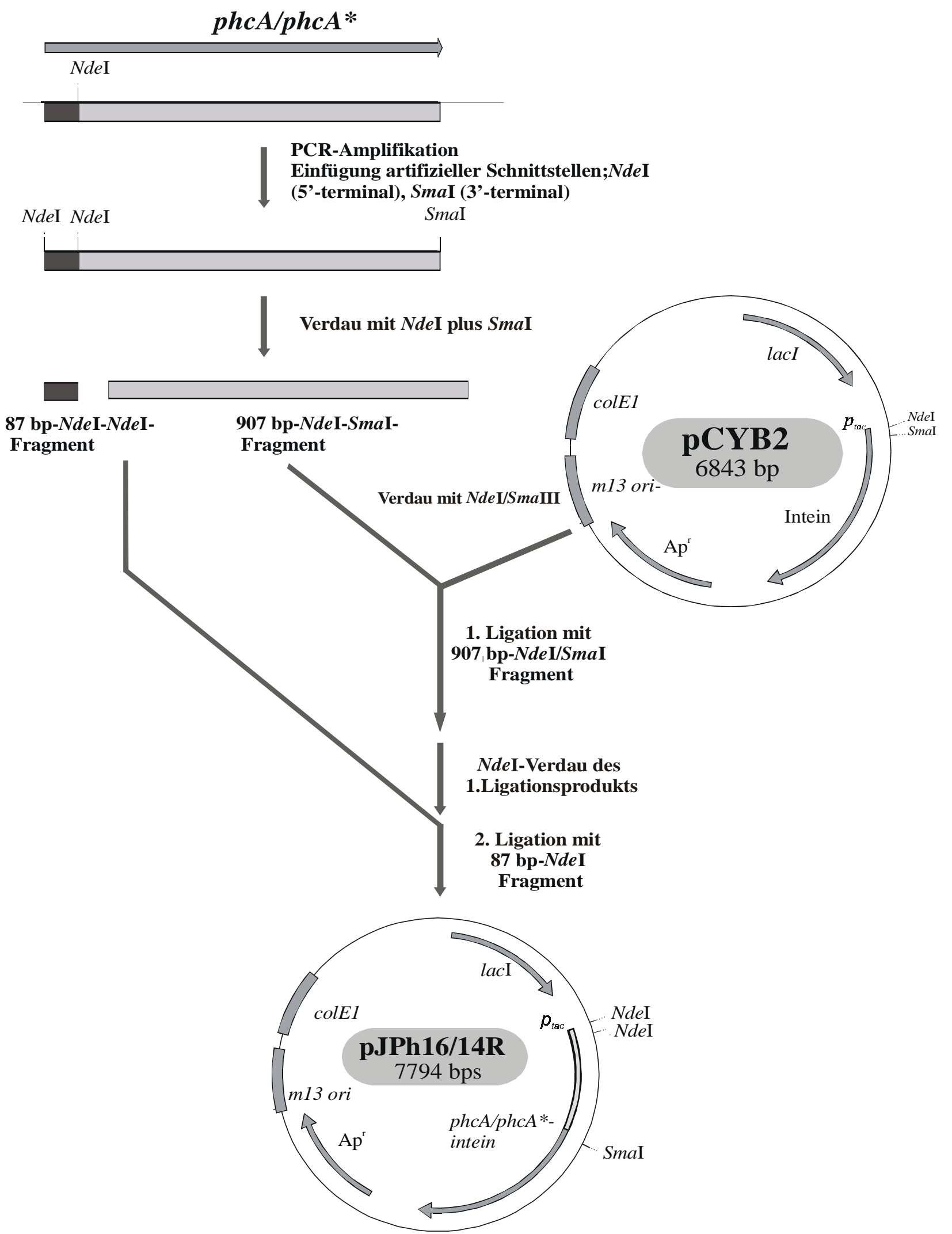

Abb. 16. Konstruktion einer C-terminalen Intein-PhcA-bzw. PhcA*-Fusion in pCYB2. Für die Klonierung wurden durch PCR Restriktionsschnittstellen an 5'- und 3'Ende von $p h c A / p h c A^{*}$ eingefügt. Relevante Schnittstellen: NdeI, SmaI. Ap ${ }^{\mathrm{r}}$, Ampicillinresistenz; lacI, lac-Repressorgen; colE1, Replikationsursprung; m13 ori, Replikationsursprung des Bakteriophagen M13. 


\subsubsection{Expressionsanalyse im 'mobility shift'}

Eine Analyse der heterologen Produktion der PhcA/PhcA*-Inteinfusionen wurde im 'mobility shift' mit Rohextrakten der entsprechenden Transformanten von E. coli durchgeführt Abb. 17. Die Abtrennung des Intein-TAG erfolgte durch die selbstspaltende Aktivität des Inteins unter reduzierenden Bedingungen. Die Effizienz der Expression war allerdings relativ niedrig und in der SDS-PAGE im Gegensatz zum 'mobility shift' nicht nachweisbar. Die Rohextrakte wiesen eine leichte Pelletbildung auf, die möglicherweise im Zusammenhang mit der Bildung von PhcA/PhcA*-haltigen Einschlußkörpern ('inclusion bodies') stand, was durch weitere Experimente überprüft werden müßte. Die Bildung von Einschlußkörpern würde die niedrigen nachgewiesenen Konzentrationen von PhcA und PhcA* erklären.

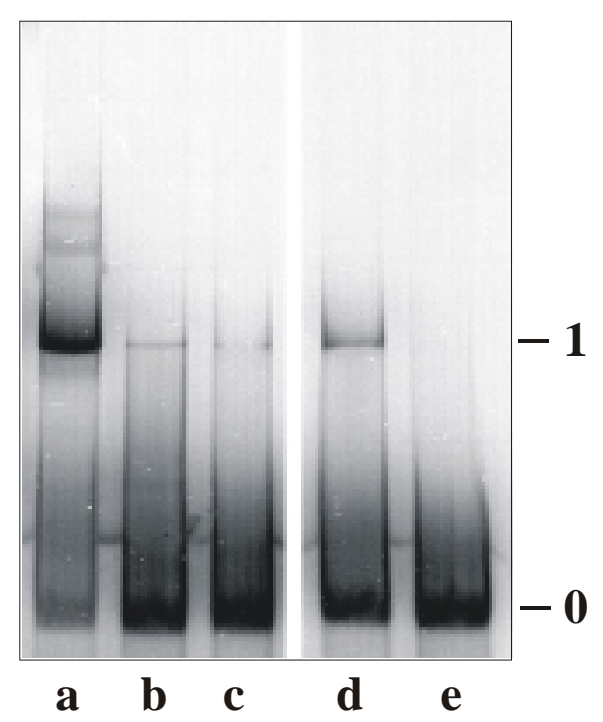

Abb. 17. 'Mobility shifts' der $c b b$-Kontrollregion mit Rohextrakten von $E$. coli JW1Transformanten nach heterologer Expression von $p h c A / p h c A *$

Rohextrakte von: a und b, E. coli JW1 (pCG7) (pUC19::phcA*; 10mg/ml, Verdünnungsfaktor: $2^{3}$ bzw. $\left.2^{6}\right)$; c, pCYB2::phcA (10 mg/ml, Verdünnungsfaktor: $\left.2^{3}\right)$; d und e, pCYB2::phcA* (10 mg/ml, Verdünnungsfaktor: $2^{3}$ und $\left.2^{6}\right) ; 0$, freie DNA; 1, CbbR- bzw. PhcA- oder PhcA*-DNA-Komplex.

\subsubsection{Identifikation der Bindungsregion von P1 und PhcA}

Um die Funktion von P1 als potentiell zusätzlichen $c b b$-Regulator in $R$. eutropha H16 und von PhcA* als CbbR-Ersatz verstehen zu können, erfolgte eine Bestimmung ihrer Bindungsregionen. Hierzu wurden zwei unterschiedliche Ansätze gewählt. Bei der ersten Methode wurden unmarkierte Subfragmente der $c b b$-Kontrollregion als spezifische Kompetitor-DNA in 'mobility shifts' (Kompetitionsshifts) der kompletten $c b b$-Kontrollregion verwendet. Zur 
Gewährleistung der Spezifität wurde gleichzeitig Lachsspermien-DNA als unspezifische Kompetitor-DNA im Überschuß zugesetzt. Auf diese Weise sollten DNA-Subfragmente mit entsprechenden DNA-Erkennungssequenzen von P1 und PhcA* detektiert werden können, die aufgrund ihrer Kompetition mit dem markierten 253 bp-Fragment zu einer deutlichen Abschwächung der Retardationskomplexe führen.

Die zweite Methode bestand darin, die verschiedenen Subfragmente der $c b b$-Kontrollregion in nicht-radioaktiven 'mobility shifts' in Agarosegelen (Agaroseshifts) mit P1 oder PhcA* einzusetzen. Da im Agaroseshift wegen der geringeren Detektionsempfindlichkeit größere Mengen an Fragment-DNA verwendet werden müssen, gleichzeitig jedoch die einsetzbaren Mengen an Kompetitor-DNA begrenzt sind, waren hier die Bindungsbedingungen für P1 und PhcA* weniger stringent als im radioaktiven 'mobility shift'. Daher dienten die Agaroseshifts vor allem der Überprüfung der aus den Kompetitionsshifts gewonnenen Ergebnisse.

\subsubsection{Amplifikation von Subfragmenten der $c b b$-Kontrollregion durch PCR}

Zur Eingrenzung der Bindungsregionen von P1 und PhcA* durch 'mobility shift'Experimente wurde eine Anzahl verschiedener Subfragmente der $c b b$-Kontrollregion durch PCR amplifiziert. Für ebenfalls durchzuführende Aktivitätsmessungen des $c b b$ Operonpromotors wurden in diese Fragmente artifizielle Schnittstellen eingefügt, durch die lacZ-Fusionen in dem Operonfusionsvektor pBK hergestellt werden konnten (s.u. 3.8.4). Als Matrizen-DNA diente für alle Amplifikationen das Plasmid pBH2241, das die komplette $c b b$ Kontrollregion beinhaltet. Die Schnittstellen wurden hierbei so gewählt, daß die Fragmente in beiden Orientierungen in den Operonfusionsvektor pBK kloniert werden konnten Abb. 18. Durch vergleichende 'mobility shifts' von korrespondierenden Subfragmenten wurde sichergestellt, daß die eingefügten Schnittstellen keinen Effekt auf die Bindung der zu untersuchenden Proteine ausübten. 

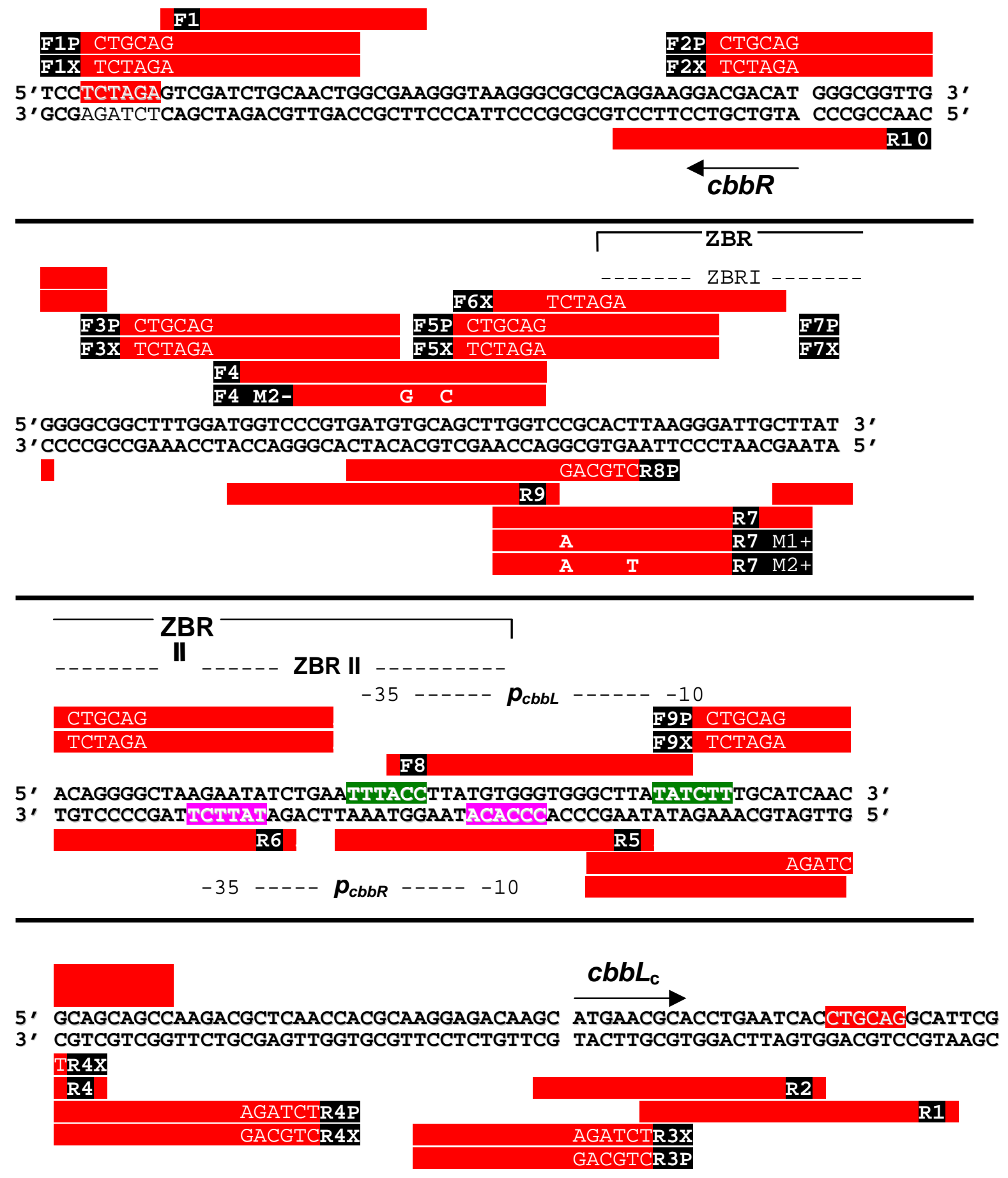

Abb. 18. Primer zur Amplifikation von Subfragmenten der intergenen $c b b$ Kontrollregion mit pBH2241 als Matrizen-DNA.

Primerbezeichnungen: F, Primer ist colinear $\mathrm{zu} c b b L$; R, Primer ist colinear $\mathrm{zu}$ cbbR; X, Primer mit XbaI-Schnittstelle; P, Primer mit PstI-Schnittstelle. Primer F4M2- sowie R7M1+ und M2+ mit Mutationen in der potentiellen P1Bindungsregion. ZBR, zentrale CbbR-Bindungsregion bestehend aus den zwei Unterregionen ZBRI und ZBRII, $c b b$-Operonpromotor $p_{c b b L}$ und der Promotor des Regulatorgens sind innerhalb der $c b b$-Kontrollregion dunkel hervorgehoben, PstIund XbaI-Schnittstellen sind in weißer Schrift dargestellt. 


\subsubsection{Identifikation der Bindungsregion von P1}

In 'mobility shifts' mit markierten Subfragmenten der $c b b$-Kontrollregion war bereits gezeigt worden, daß die Bindung von P1 wahrscheinlich an einen Bereich am 5'-Ende oder direkt stromaufwärts der bis dato identifizierten Operator/Promotorregion stattfindet (3.2, Abb. 3 . Anhand der nun durchgeführten kompetitiven 'mobility shifts' und der 'mobility shifts' im Agarosegel gelang eine Eingrenzung der P1-Bindungsregion auf einen ca. 30 bp langen Sequenzabschnitt unmittelbar stromaufwärts der CbbR-Bindungsregion. Eine deutliche Kompetition zwischen markiertem Gesamtfragment und Subfragmenten fand nur statt, wenn letztere diesen 30 bp-Sequenzabschnitt vollständig enthielten Abb. 19. In Gegenwart der unmarkierten Fragmente a, b, c und f kam es zu einer deutlichen Abschwächung des retardatierten P1-DNA-Komplexes (Komplex 1). Die Fragmente d und e, die nur einen Teilbereich dieser Region umfassten, bewirkten hingegen keine Abschwächung des Retardationskomplexes. Bestätigt wurden diese Ergebnisse durch die 'mobility shifts' im Agarosegel, wobei Fragment b, das dem Fragment $\mathrm{f}$ aus den Kompetitionshifts entsprach, deutlich durch P1 retardiert wurde Abb. 20. 
A

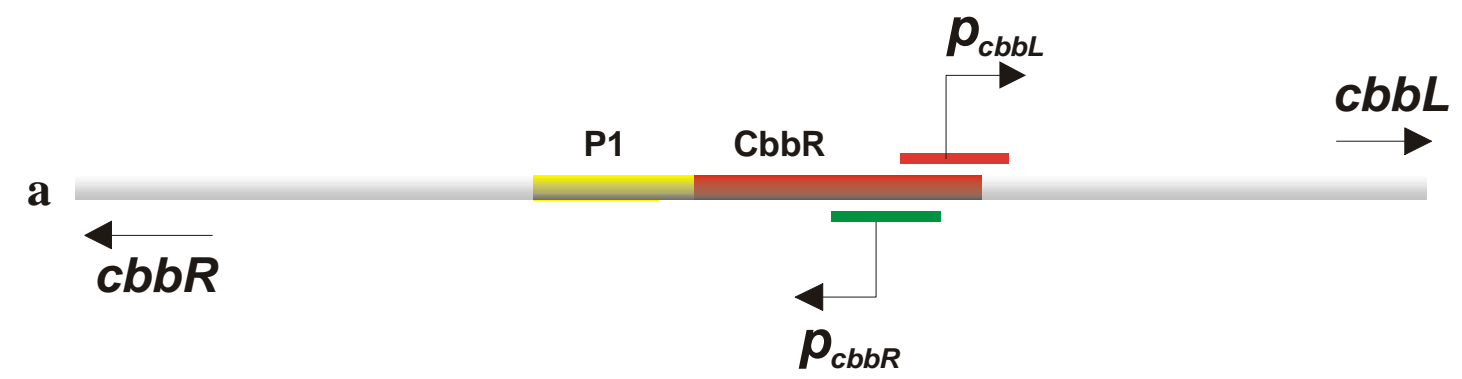

b

c

d

e

f

g

B

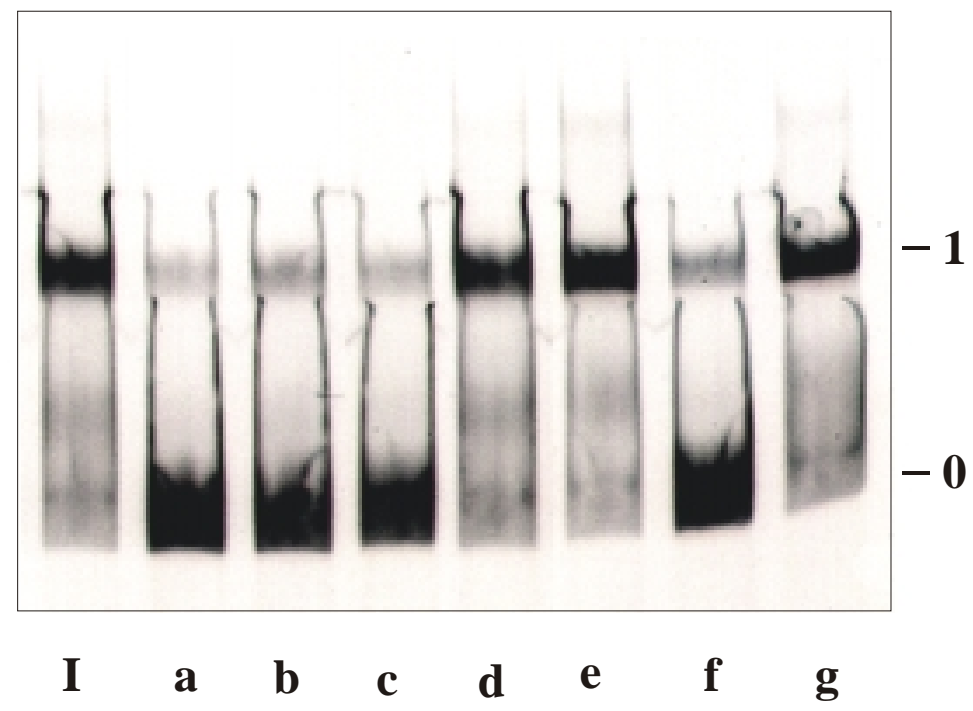

Abb. 19. 'Mobility shifts' mit angereichertem $P 1$ und radioaktiv markierter $c b b$ Kontrollregion (253 bp-Fragment) in Gegenwart unmarkierter Subfragmente der Region.

A: Unmarkierte, zur spezifischen Kompetition eingesetzte Fragmente a-g der $c b b$ Kontrollregion: a, 253 bp; b, 144 bp; c, 124 bp; d, 105 bp; e, 139 bp; f, 45 bp; g, 82 bp. Die CbbR- und die potentielle P1-Bindungsregion sind unterschiedlich grau unterlegt. B: 'Mobility shifts' mit angereichertem P1 (5 ng) in Abwesenheit (I) oder Gegenwart der unmarkierten Fragmente a-g. 0, freie DNA; 1, P1-DNA-Komplex. PAGE (5\% [w/v] Acrylamid). 
A

$\mathbf{a}$

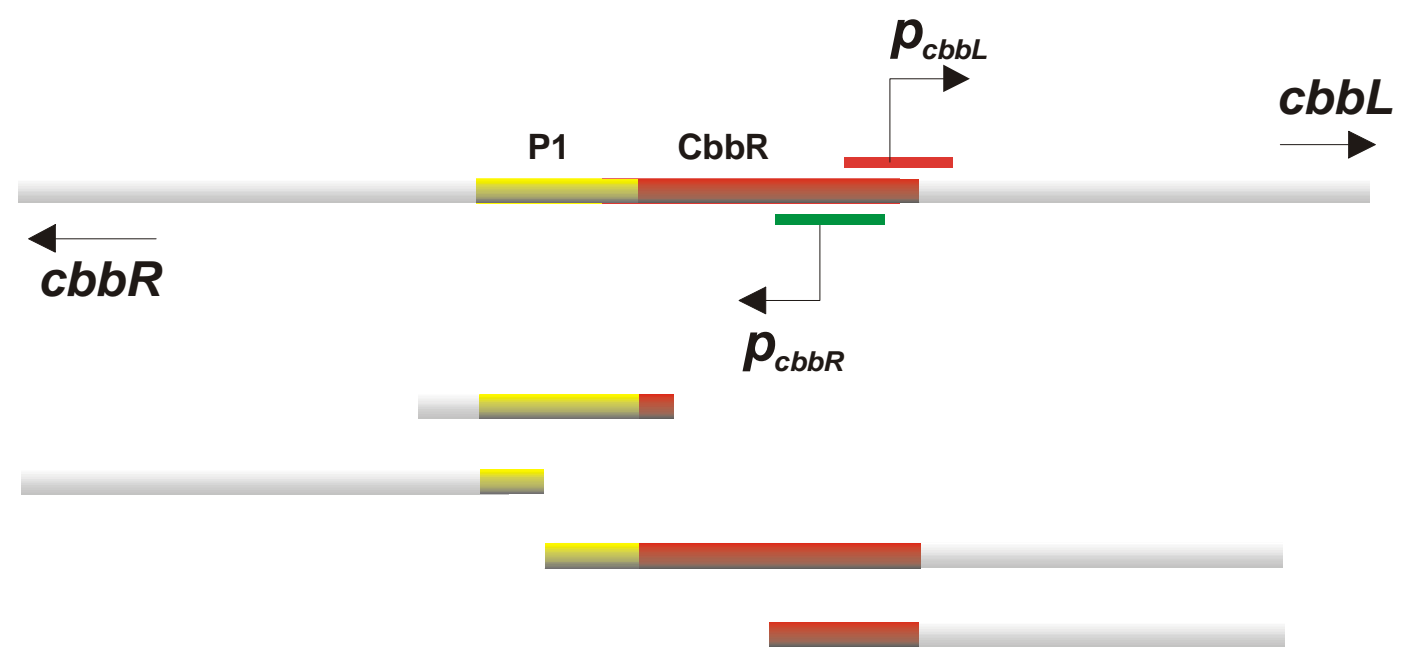

B

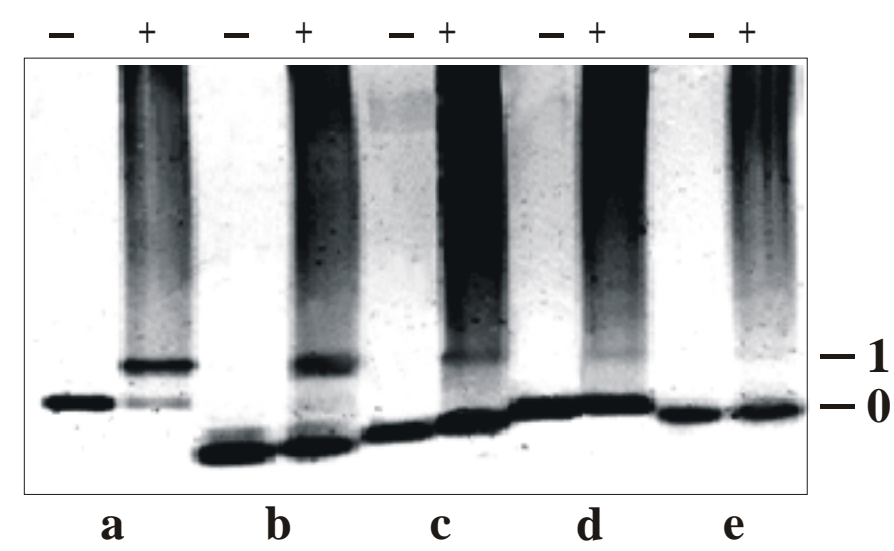

Abb. 20. 'Mobility shifts' mit angereichertem P1 und verschiedenen unmarkierten Fragmenten der $c b b$-Kontrollregion im Agarosegel.

A: Fragmente der $c b b$-Kontrollregion; a, 253 bp; b, 45 bp; c, 105 bp; d, 139 bp; e, 105 bp. B: 'Mobility shifts' mit angereichertem P1 (20 ng) und den Subfragmenten a-e; - / +; ohne bzw. mit P1. 0, freie DNA; 1, P1-DNA-Komplex. TAE-Agarosegel $(2 \%[\mathrm{w} / \mathrm{v}]$ Agarose $)$.

Innerhalb des 30 bp-Sequenzabschnitts wurde ein 'inverted repeat' identifiziert, der durch das Sequenzmotiv GTGC-N ${ }_{10}$-GCAC charakterisiert war. Eingefügte Punktmutationen innerhalb dieses Motivs in Form von zwei Basensubstitutionen (s.u.) führten zu einem fast vollständigen Verlust der Bindung von P1 Abb. 21.

\section{Sequenz des postulierten P1-Bindungsmotivs}

\section{a) AtgtgCAGCtiggtCcGCACtT \\ b) AtGGGCcGCttgGtCCGCACtT}

a) Potentielles P1-Bindungsmotiv (beim Wildtyp R. eutropha H16); b) P1-Bindungsmotiv mit eingefügten Mutationen (fett markiert); inverted repeat (als Block hervorgehoben) 


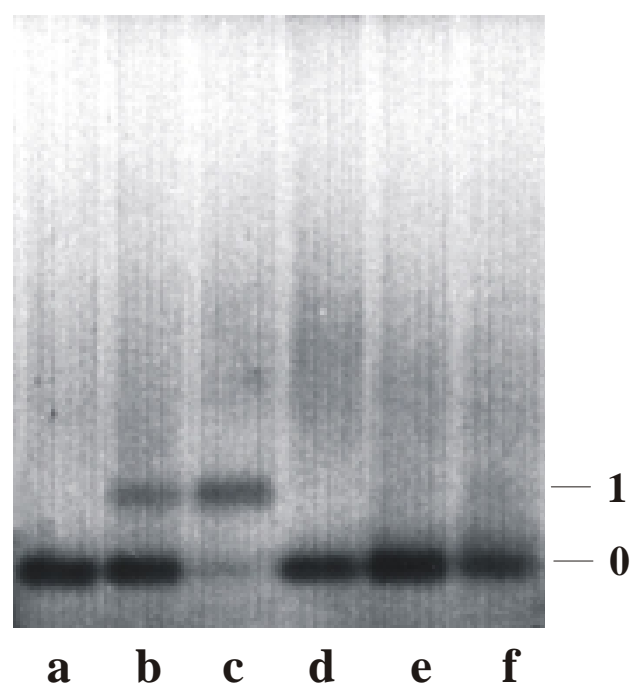

Abb. 21. 'Mobility shifts' mit angereichertem P1 und einem Fragment der $c b b$ Kontrollregion mit Mutationen in der P1-Bindungsregion.

a-c, Wildtyp-Fragment (151 bp); d-e, mutiertes Fragment; b, e, Zugabe von $15 \mathrm{ng}$ P1; c, f, 30 ng P1; 0, freie DNA; 1, P1-DNA-Komplex. TAE-Agarosegel (2\% [w/v] Agarose).

\subsubsection{Identifikation der PhcA*-Bindungsregion}

Kompetitionsexperimente wurden ebenfalls mit $\mathrm{PhcA}^{*}$ im direkten Vergleich zu CbbR durchgeführt, dessen Bindungsregion bereits bekannt war (Kusian \& Bowien, 1995). Die beobachtete Kompetition durch spezifische Subfragmente der $c b b$-Kontrollregion war in Bezug auf die Bindung von $\mathrm{PhcA}^{*}$ und $\mathrm{CbbR}$ nahezu identisch und erfolgte bei allen Fragmenten, welche die komplette CbbR-Bindungsregion enthielten Abb. 22. Die Bindungsregion des mutierten $\mathrm{PhcA}^{*}$ muß weitgehend mit der von $\mathrm{CbbR}$ identisch sein, wodurch die Suppression der $c b b R$-Deletion durch $p h c A^{*}$ in $R$. eutropha HB14R prinzipiell erklärt werden konnte. Obwohl die Kompetition bei PhcA* und CbbR zwar durch die gleichen Fragmente erfolgte, war der kompetitive Effekt bei CbbR jedoch wesentlich stärker ausgeprägt, was auf eine deutlich höhere Bindungsaffinität von CbbR zum $c b b$-Operator hindeutete.

Die anhand der Kompetitionsexperimente postulierte PhcA*-Bindungsregion konnte mittels 'mobility shifts' im Agarosegel bestätigt werden Abb. 23. Eine deutliche Retardation durch PhcA* erfolgte wiederum bei allen Fragmenten mit der kompletten CbbR-Bindungsregion (a, $\mathrm{d}$ und e) und bei Fragment $\mathrm{b}$ mit dem $c b b R$-seitigen Teil der Bindungsregion (entsprechend Fragment c im Kompetitionsshifts). 


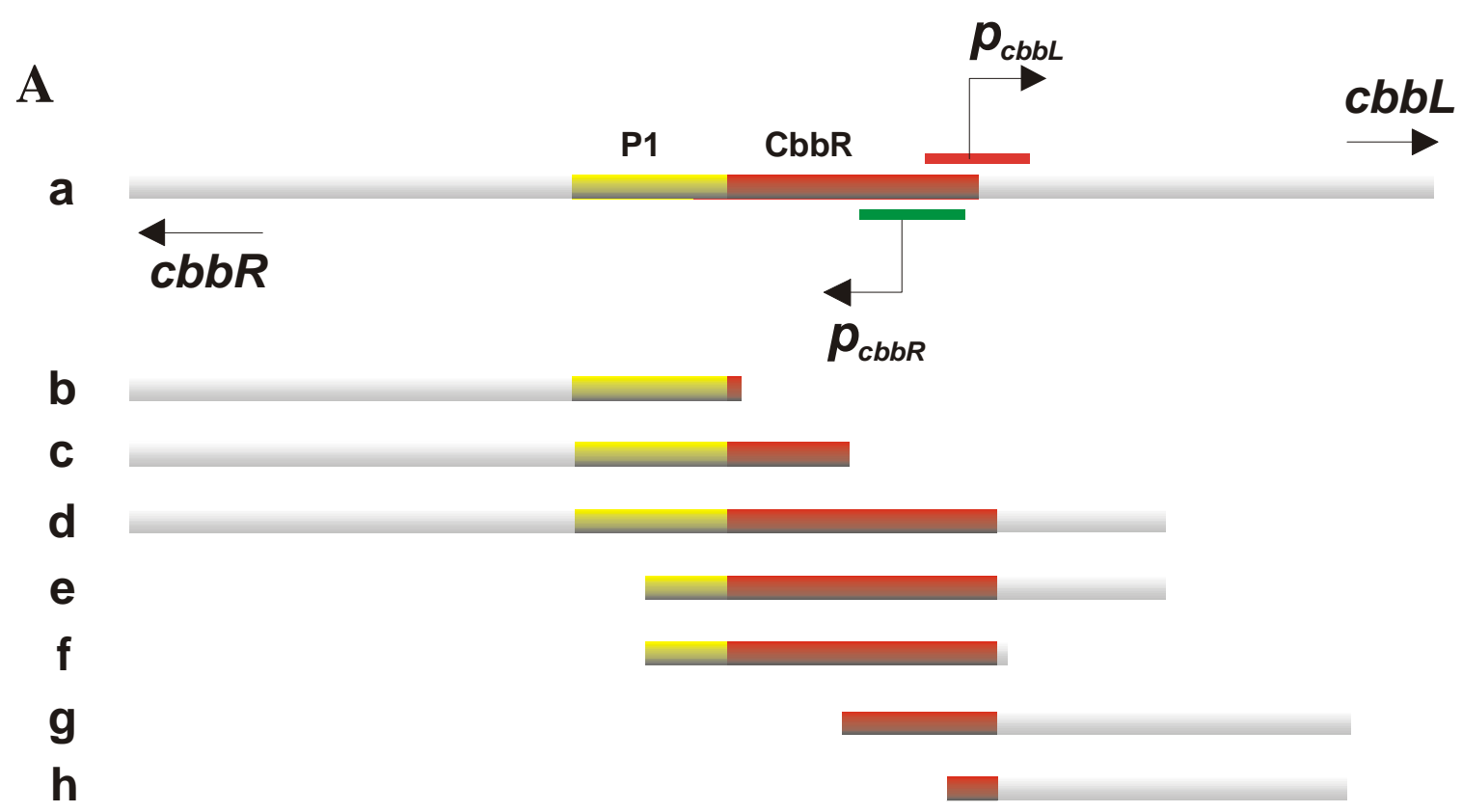

B

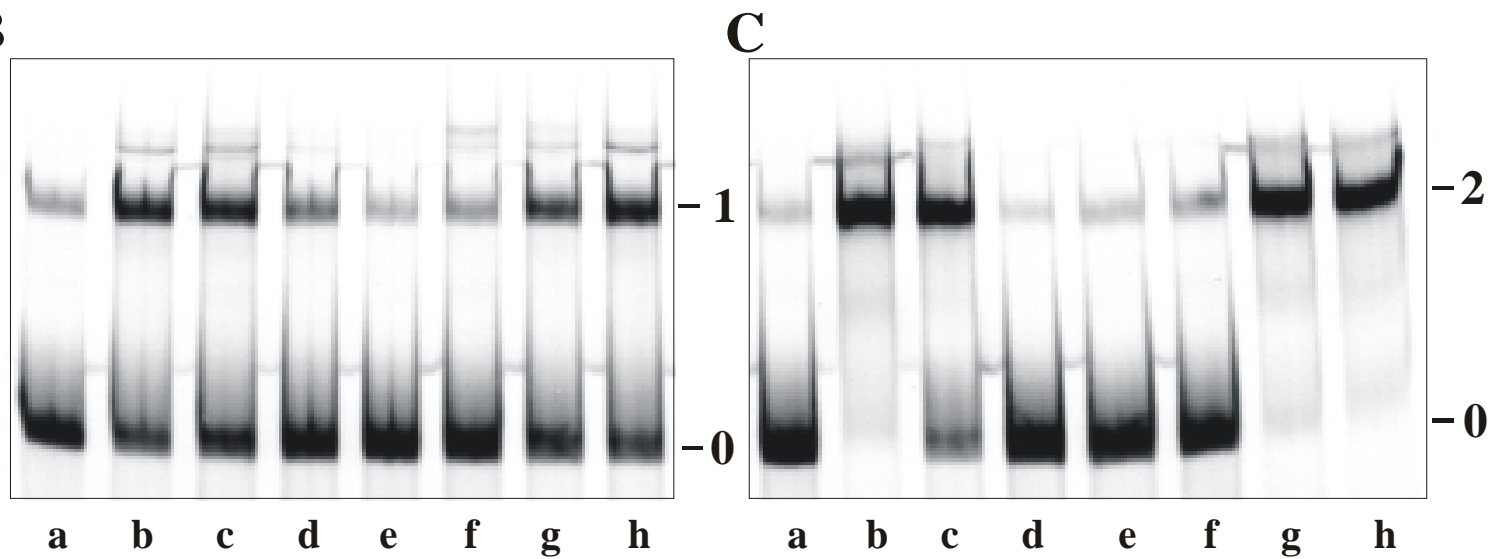

Abb. 22. 'Mobility shifts' mit Rohextrakten von $E$. coli JW1 nach heterologer Expression von $p h c A^{*}, c b b R$ und radioaktiv markierter $c b b$-Kontrollregion (253 bpFragment) in Gegenwart unmarkierter Subfragmente.

A: Unmarkierte, zur spezifischen Kompetition eingesetzte Fragmente a-g der $c b b$ Kontrollregion; a, 253 bp; b, 124 bp; c, 144 bp; d, 191 bp; e, 92 bp; f, 77 bp; g, 112 bp; h, 82 bp. B: 'Mobility shifts' mit Rohextrakten ( $2^{7}$-fache Verdünnung: 0.08 $\mathrm{mg} / \mathrm{ml}$ ) von E. coli pCG7 nach Expression von $p h c A^{*}$. C: 'Mobility shifts' mit Rohextrakten $\left(2^{7}\right.$-fache Verdünnung: $\left.0.08 \mathrm{mg} / \mathrm{ml}\right)$ von E. coli pAECR7 nach Expression von $c b b R$. Unterhalb der Spuren in B und $\mathrm{C}$ ist der Zusatz der Fragmente als spezifische Kompetitor-DNA angegeben. 0, freie DNA; 1, PhcADNA-Komplex; 2, CbbR-DNA-Komplex. PAGE (5\% [w/v] Acrylamid). 
A

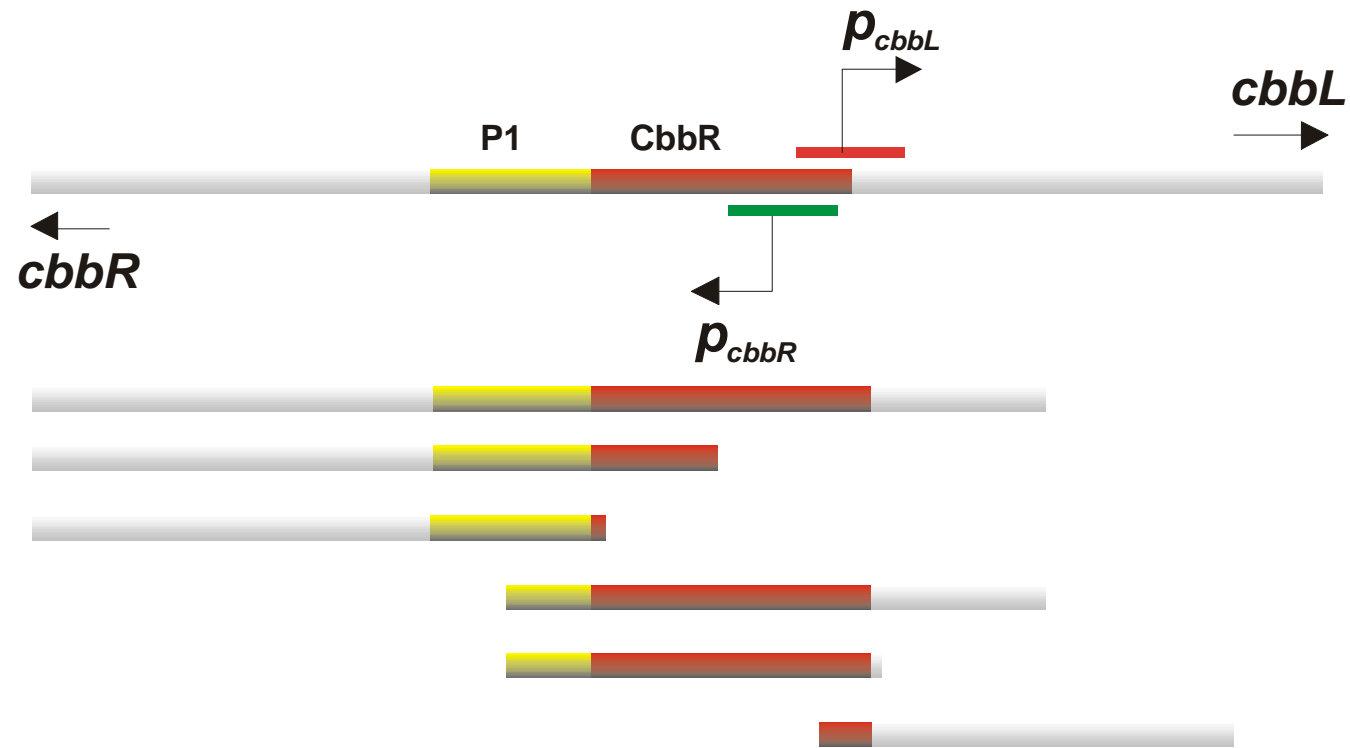

B

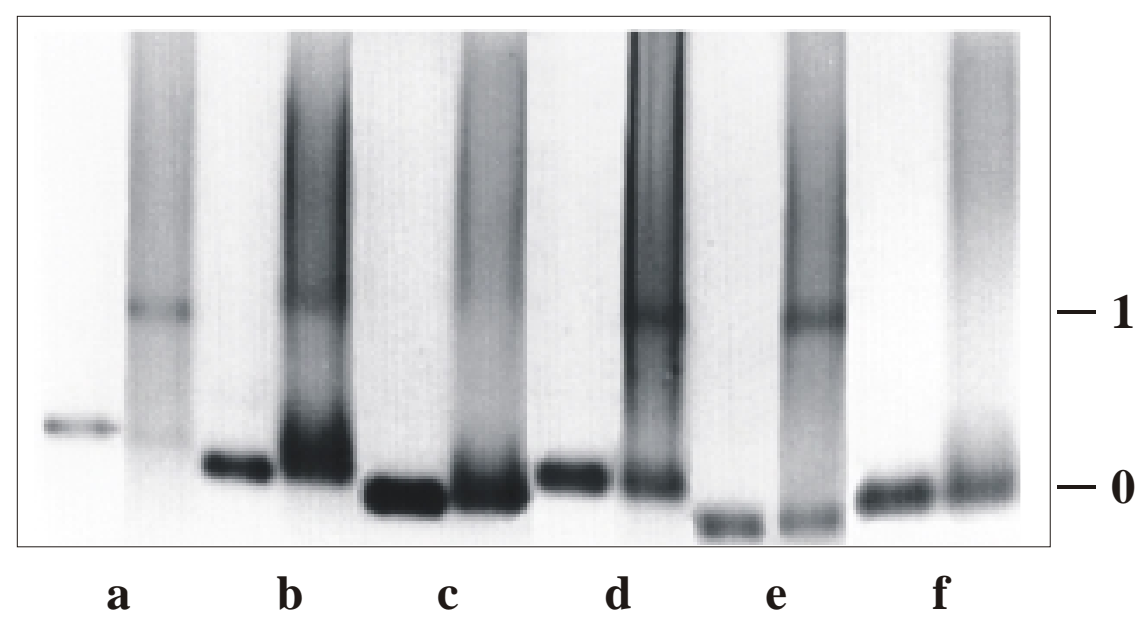

Abb. 23. 'Mobility shifts' mit Rohextrakten von $E$. coli JW1 pCG7 nach heterologer Expression von $p h c A *$ und verschiedenen Fragmenten der $c b b$-Kontrollregion. A: Verwendete Fragmente der $c b b$-Kontrollregion; a, 191 bp; b, 144 bp; c, 124 bp; d, 139 bp; e, 77 bp; f 82 bp. B: 'Mobility shifts' mit Rohextrakten $\left(2^{3}\right.$-fache Verdünnung, $2.5 \mathrm{mg} / \mathrm{ml}$ ) nach Expression von $p h c A^{*}$ in Kombination mit den Subfragmenten a-f. 0, freie DNA; 1, PhcA*-DNA-Komplex. TAE-Agarosegel (2\% $[\mathrm{w} / \mathrm{v}])$.

\subsubsection{Bindungsstudien mit P1, PhcA (P2) und PhcA*}

Sowohl PhcA als auch PhcA* bildeten spezifische Protein-DNA-Komplexe aus, die im 'mobility shift' auf gleicher Höhe liefen wie die mit angereichertem P2 aus R. eutropha HB14 zu beobachtenden Komplexe Abb. 24, Komplex 2). Wurde P1 gemeinsam mit P2 oder PhcA eingesetzt, kam es zur Entstehung höherer dimerer Protein-DNA-Komplexe, wobei besonders auffällig war, daß der Komplex aus P1 und PhcA auf gleicher Höhe lief wie der Komplex aus P1 und P2 Abb. 24, Komplex 4). Hiermit lag nun ein weiterer deutlicher Hinweis für die 
Identität von $\mathrm{P} 2$ und $\mathrm{PhcA}$ vor. $\mathrm{P} 1$ bildete in Gegenwart von $\mathrm{PhcA}^{*}$ ebenfalls einen höheren Komplex, der aber deutlich weniger retardiert wurde Abb. 24. Komplex 3), was ein durch die Mutation verursachtes, verändertes Bindungsverhalten von $\mathrm{PhcA}^{*}$ im Vergleich zum Wildtypprotein PhcA nahelegte.

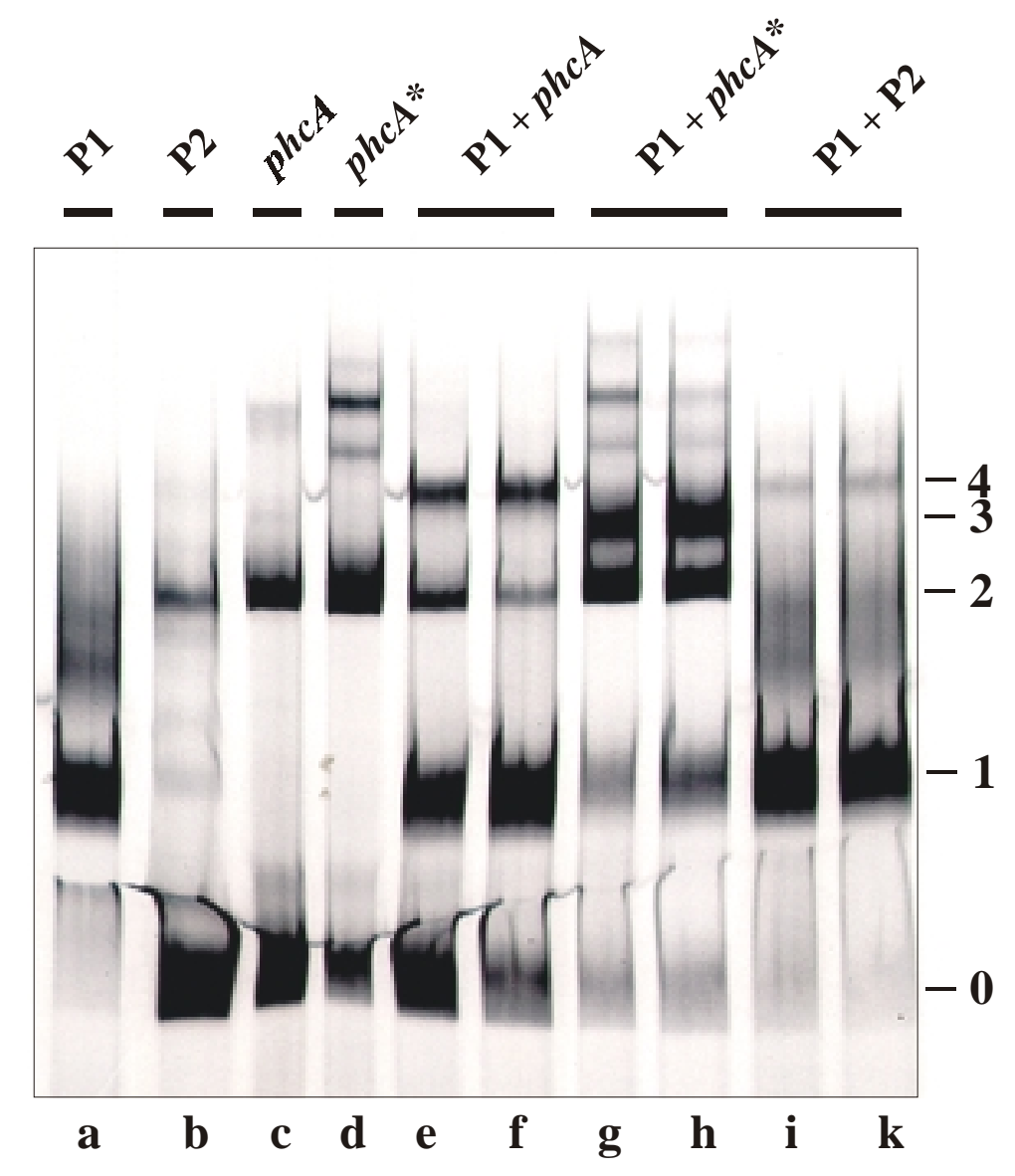

Abb. 24. 'Mobility shifts' der $c b b$-Kontrollregion (253 bp Fragment) und P2 sowie heterolog in $E$. coli überproduzierten PhcA (Wildtyp).

a, angereichertes P1 $(5 \mu \mathrm{g} / \mathrm{ml})$; b, angereichertes P2 $(5 \mu \mathrm{g} / \mathrm{ml})$; c, in E. coli pCG8 überproduziertes PhcA (1 $\mathrm{mg} / \mathrm{ml}$, IPTG induziert); d, in E. coli pCG7 überproduziertes mutiertes PhcA* (1 mg/ml Rohextrakt, IPTG induziert); e und $\mathrm{f}$, P1 (5 bzw. $10 \mu \mathrm{g} / \mathrm{ml}$ ) plus PhcA (1 mg/ml); g und h, P1 plus PhcA*; i und k, P1 mit P2 ; 0, freie DNA; 1, P1-DNA-Komplexe; 2, DNA-Komplexe mit P2, PhcA oder PhcA*; 3, multimerer Protein-DNA-Komplex mit P1 und PhcA*; 4, höherer Protein-DNA-Komplex mit P1 plus PhcA oder P2.

\subsubsection{Bindungsstudien mit CbbR und P1}

Nachdem die Bindungsregion von P1 direkt stromaufwärts von der CbbR-Bindungsregion lokalisiert worden war, ergab sich die Frage, ob P1 als potentieller Regulator möglicherweise zusammen mit CbbR, ähnlich wie mit PhcA*, gleichzeitig an die Kontrollregion binden kann. Die Bildung eines P1-CbbR-Komplexes könnte die Voraussetzung für eine effiziente 
Aktivierung des $c b b$-Operonpromotors sein, die bei alleiniger Bindung von CbbR möglicherweise nur auf sehr geringem Niveau stattfindet und dadurch im In vitro-Transkriptionssystem nicht nachweisbar ist. Dazu wurden 'mobility shift'-Experimente durchgeführt. In einer ersten Versuchsreihe wurde die P1-Konzentration bei gleichbleibender CbbR-Konzentration variiert, während in der zweiten die P1-Konzentration unter Variation der CbbR-Konzentration konstant gehalten wurde. Unter dem gleichen Aspekt waren bereits ähnliche Studien mit P1 und $\mathrm{PhcA}^{*}$ angestellt worden, bei denen tatsächlich die Bildung eines vermutlichen P1PhcA*-Komplexes beobachtet wurdet 3.5.4 Abb. 24.

Mit ansteigender Konzentration sowohl von P1 als auch CbbR kam es zur Bildung eines stärker retardierten Komplexes, der mit hoher Wahrscheinlichkeit einen P1-CbbR-DNAKomplex darstellte Abb. 25. Komplex 3). Für einen solchen Komplex sprach auch die Tatsache, daß in zuvor individuell mit P1 oder CbbR durchgeführten 'mobility shifts', trotz vollständiger Retardation des DNA-Fragments bei hohen Proteinkonzentrationen, dieser Komplex nicht auftrat.

A

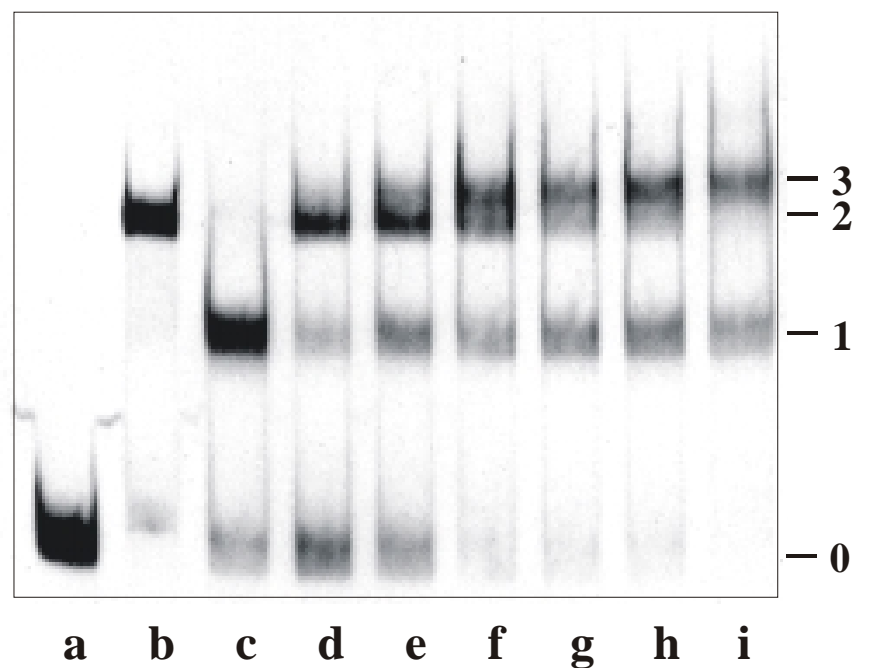

B

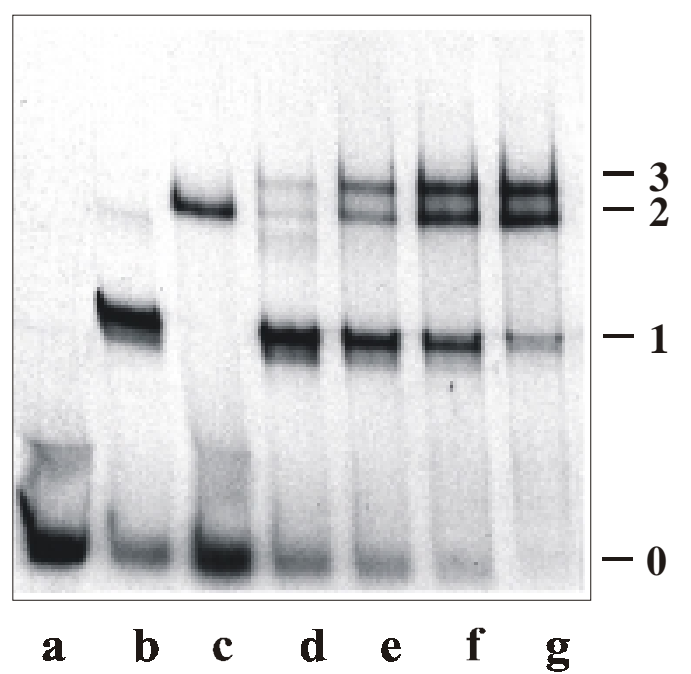

Abb. 25. 'Mobility shifts' mit der $c b b$-Kontrollregion und P1 in Gegenwart von CbbR. A: Konstante CbbR-Konzentration bei ansteigender P1-Konzentration. a, freies 253 bp-Fragment; b, CbbR (Rohextrakt aus E. coli JW1 [pAECR7], $0.04 \mathrm{mg} / \mathrm{ml}$ ); c, P1 (5 ng); d- i, P1 plus CbbR: CbbR (Rohertrakt, konstant 0.02 mg), ansteigende P1-Konzentration (in ng): 0.5, 1, 2 , 5, 7.5, 10. B: Konstante P1-Konzentration bei ansteigender CbbR-Konzentration. a, freies 253 bp-Fragment; b, P1 (5 ng); c, CbbR (Rohextrakt, $0.04 \mathrm{mg} / \mathrm{ml}$ ); d-i, P1 plus CbbR: P1 konstant (2 ng), ansteigende CbbR-Konzentration (Rohextrakt in $\mathrm{mg} / \mathrm{ml}$ ): 1, 2 , 4 und 6. 0, freie DNA; 1, P1DNA-Komplex; 2, CbbR-DNA-Komplex; 3, P1-CbbR-DNA-Komplex. 


\subsection{Analyse der durch P1, PhcA* und CbbR induzierten DNA-Krümmungen}

Einen wichtigen Mechanismus bei der Funktionsweise vieler Transkriptionsregulatoren stellt deren Fähigkeit dar, nach Bindung an die Erkennungssequenz Veränderungen in der dreidimensionalen Struktur der DNA hervorzurufen. Häufig wird bei diesem Vorgang eine DNAKrümmung induziert, das sogenannte 'bending'. Hierzu sollte im Vergleich zu CbbR untersucht werden, ob und in welchem Umfang solche Krümmungen durch P1 oder PhcA* induziert werden können. Bezüglich $\mathrm{PhcA}^{*}$ wurden davon weitere Erkenntnisse über die Funktionsweise des Proteins als CbbR-Ersatz bei der Aktivierung des Operonpromotors $p_{c b b L}$ in R. eutropha HB14R erwartet.

Für die notwendigen 'mobility shift'-Experimente wurden Fragmente der Kontrollregion von gleicher Größe amplifiziert, wobei die relative Lage der Bindungsregionen von P1 und $\mathrm{CbbR} / \mathrm{PhcA}^{*}$ in den verschiedenen Fragmenten variierte. Die unterschiedliche Mobilität der resultierenden Protein-DNA-Komplexe ist dann von der Krümmung der DNA und der Lage des Krümmungszentrums abhängig. Allgemein werden Protein-DNA-Komplexe mit einem in der Mitte des Fragments liegenden Krümmungszentrum stärker retardiert als solche mit weiter außen liegenden Krümmungszentrum (Lane et al., 1993).

\subsubsection{Amplifikation von Fragmenten der $c b b$-Kontrollregion}

Für die 'bending'-Experimente wurde zwei Serien von Fragmenten amplifiziert (โab. 5). Als Matrizen-DNA diente ein in pUC19 kloniertes 554 bp-BamH1-Fragment, das die komplette $c b b$-Kontrollregion mit flankierenden Bereichen der Gene $c b b L$ und $c b b R$ umfasste. Zur Bestimmung des Zentrums der durch P1 induzierten DNA-Krümmung wurden die Fragmente A-F amplifiziert Abb. 26, bei denen die P1-Bindungsregion entweder zentral oder fortschreitend zum linken oder rechten Ende der Fragmente hin lokalisiert war. Zur genauen Bestimmung des durch P1 verursachten Krümmungswinkels wurden 'mobility shifts' mit den zusätzlich amplifizierten Fragmenten 1-8 durchgeführt Abb. 28. Die Fragmente A-F wurden auch zur Bestimmung und Berechnung der durch CbbR und PhcA* induzierten DNAKrümmung bzw. des Krümmungswinkels verwendet. Anhand der Fragmente 1-8 konnte wiederum die genaue Lage des durch CbbR induzierten Krümmungszentrums bestimmt werden. 
Tab. 5. Zur Amplifikation der Fragmente A-F und 1-8 verwendete PCR-Primer.

\begin{tabular}{|c|c|c|}
\hline $\begin{array}{l}\text { Fragment } \\
(202 \text { bp) }\end{array}$ & Forward Primer: $5^{\prime} \rightarrow 3^{\prime}$ & Reverse Primer: $5^{\prime} \rightarrow 3^{\prime}$ \\
\hline $\mathbf{A}$ & $\begin{array}{l}\text { BFA: } \\
\text { TTCGGCCGCGCGCACGAAGCT }\end{array}$ & $\begin{array}{l}\text { BRA: } \\
\text { AGCCCACCCACATAAGGTAAATTC }\end{array}$ \\
\hline B & $\begin{array}{l}\text { BFB: } \\
\text { AAGCTGGCGTGCCTGGCCACG }\end{array}$ & $\begin{array}{l}\text { BRB: } \\
\text { TTGATGCAAAGATATAAGCCCACC }\end{array}$ \\
\hline $\mathbf{C}$ & $\begin{array}{l}\text { BFC: } \\
\text { GGCCACGGTGACGAAGATCTG }\end{array}$ & $\begin{array}{l}\text { BR1: } \\
\text { TCTTGGCTGCTGCGTTGATGCAAA }\end{array}$ \\
\hline D & $\begin{array}{l}\text { BFD: } \\
\text { AGATCTGCAACTGGCGAAGGGTAA }\end{array}$ & $\begin{array}{l}\text { BR3: } \\
\text { TGCGTGGTTGAGCGTCTTGGCTGC }\end{array}$ \\
\hline $\mathbf{E}$ & $\begin{array}{l}\text { BF0: } \\
\text { CGAAGGGTAAGGGCGCGCAGGAA }\end{array}$ & $\begin{array}{l}\text { BR5: } \\
\text { CATGCTTGTCTCCTTGCGTGGTTG }\end{array}$ \\
\hline $\mathbf{F}$ & $\begin{array}{l}\text { BF2: } \\
\text { GCGCAGGAAGGACGACATGG }\end{array}$ & $\begin{array}{l}\text { BR7: } \\
\text { GATTCAGGTGCGTTCATGCTTGTC }\end{array}$ \\
\hline \multicolumn{3}{|l|}{$\begin{array}{l}\text { Fragment } \\
(167 \text { bp })\end{array}$} \\
\hline 1 & $\begin{array}{l}\text { BF0: } \\
\text { CGAAGGGTAAGGGCGCGCAGGAA }\end{array}$ & $\begin{array}{l}\text { BR0: } \\
\text { TGCTGCGTTGATGCAAAGATATAA }\end{array}$ \\
\hline 2 & $\begin{array}{l}\text { BF1: } \\
\text { TAAGGGCGCGCAGGAAGGACGACA }\end{array}$ & $\begin{array}{l}\text { BR1: } \\
\text { TCTTGGCTGCTGCGTTGATGCAAA }\end{array}$ \\
\hline 3 & $\begin{array}{l}\text { BF2: } \\
\text { GCGCAGGAAGGACGACATGG }\end{array}$ & $\begin{array}{l}\text { BR2: } \\
\text { TTGAGCGTCTTGGCTGCTGCGTTG }\end{array}$ \\
\hline 4 & $\begin{array}{l}\text { BF3: } \\
\text { AAGGACGACATGGGCGGTTG }\end{array}$ & $\begin{array}{l}\text { BR3: } \\
\text { TGCGTGGTTGAGCGTCTTGGCTGC }\end{array}$ \\
\hline 5 & $\begin{array}{l}\text { BF4: } \\
\text { ACATGGGCGGTTGGGGGCGGCTTT }\end{array}$ & $\begin{array}{l}\text { BR4: } \\
\text { GTCTCCTTGCGTGGTTGAGCGTCT }\end{array}$ \\
\hline 6 & $\begin{array}{l}\text { BF5: } \\
\text { CGGTTGGGGGCGGCTTTGGATGGT }\end{array}$ & $\begin{array}{l}\text { BR5: } \\
\text { CATGCTTGTCTCCTTGCGTGGTTG }\end{array}$ \\
\hline 7 & $\begin{array}{l}\text { BF6: } \\
\text { GGGCGGCTTTGGATGGTCCC }\end{array}$ & $\begin{array}{l}\text { BR6: } \\
\text { GTGCGTTCATGCTTGTCTCCTTGC }\end{array}$ \\
\hline 8 & $\begin{array}{l}\text { BF7: } \\
\text { GATTCAGGTGCGTTCATGCTTGTC }\end{array}$ & $\begin{array}{l}\text { BR7: } \\
\text { GATTCAGGTGCGTTCATGCTTGTC }\end{array}$ \\
\hline
\end{tabular}

Abb. 26. Fragmente der $c b b$-Kontrollregion (A-F: 202 bp; 1-8: 167 bp), die für 'bending'-Experimente mit P1, PhcA* und CbbR verwendet wurden.

Die relative Lage der Bindungsregionen von P1 und CbbR bzw. PhcA* sowie die der ' -35 ' - und '-10'-Regionen des $c b b$-Operonpromotors $p_{c b b L}$ ist durch die Unterlegung gekennzeichnet. Die zwei aus früheren 'footprinting'-Experimenten bekannten Bindungsregionen von CbbR sind durch eine hypersensitive Region (hell unterlegt) voneinander getrennt. 


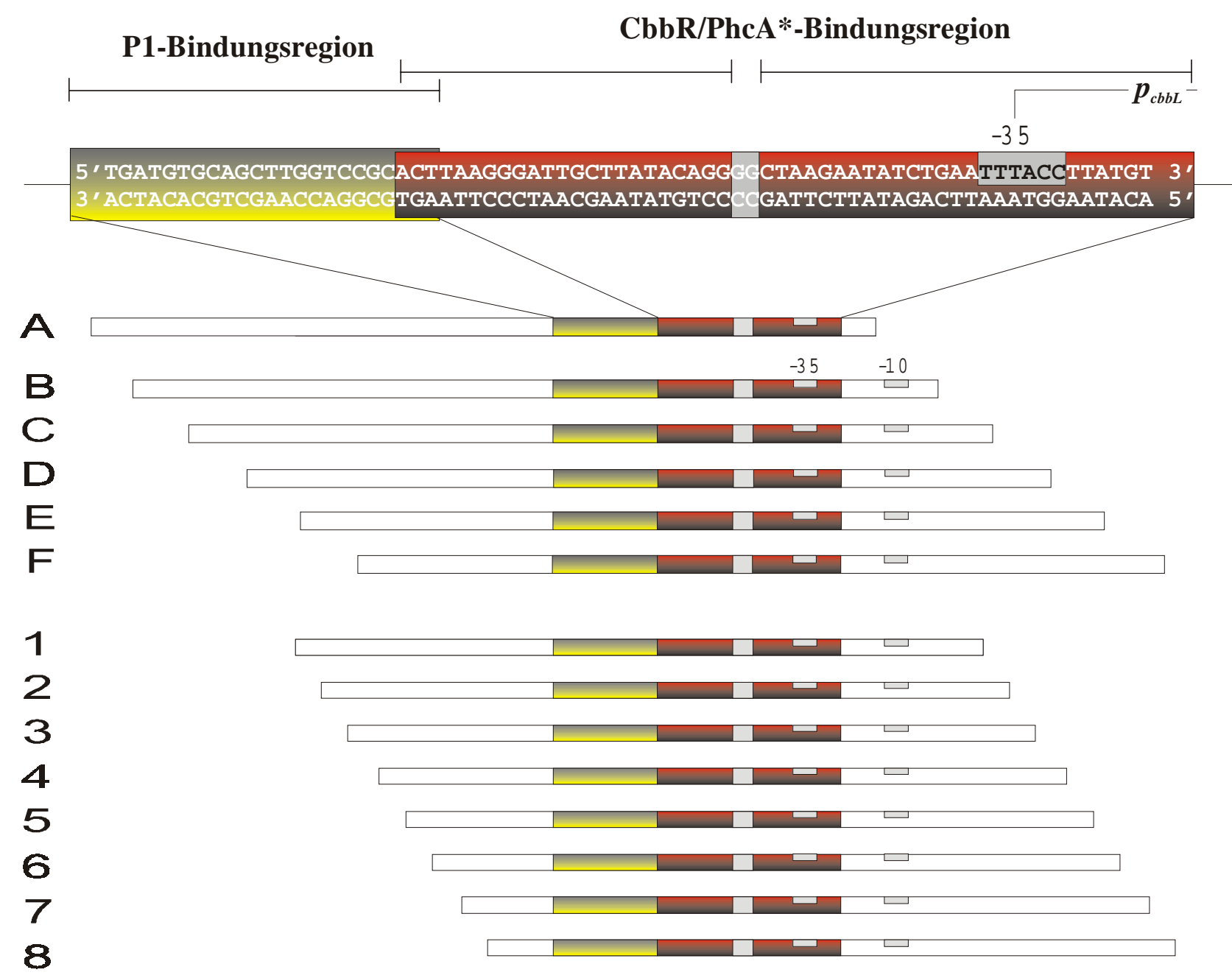

\subsubsection{P1-induzierte DNA-Krümmung}

Unter der Verwendung der Fragmente A-F wurde das durch P1 induzierte DNAKrümmungszentrum durch 'mobility shifts' bestimmt Abb. 27. Die Fragmente 1-8 dienten zur Ermittlung des Krümmungswinkels Abb. 28). Näherungsweise wurde ein Krümmungswinkel von $\alpha=52^{\circ}$ berechnet.

Die Berechnung des DNA-Krümmungswinkels erfolgte nach folgender Formel (Zwieb \& Adhya, 1994):

$$
\mu_{\mathrm{m}} / \mu_{\mathrm{e}}=\cos (\alpha / 2)
$$

$\mu_{\mathrm{m}}$ : relative Mobilität des Fragments mit mittig liegendem Krümmungszentrum

$\mu_{\mathrm{e}}$ : relative Mobilität des Fragments mit außen liegendem Krümmungszentrum

$\alpha$ : Krümmungswinkel 
Das Krümmungszentrum lag im Zentrum der postulierten Bindungsregion von P1. Fragment $\mathrm{C}$, in dem die Bindungsregion zentral lokalisiert war, wurde am stärksten retardiert.

a

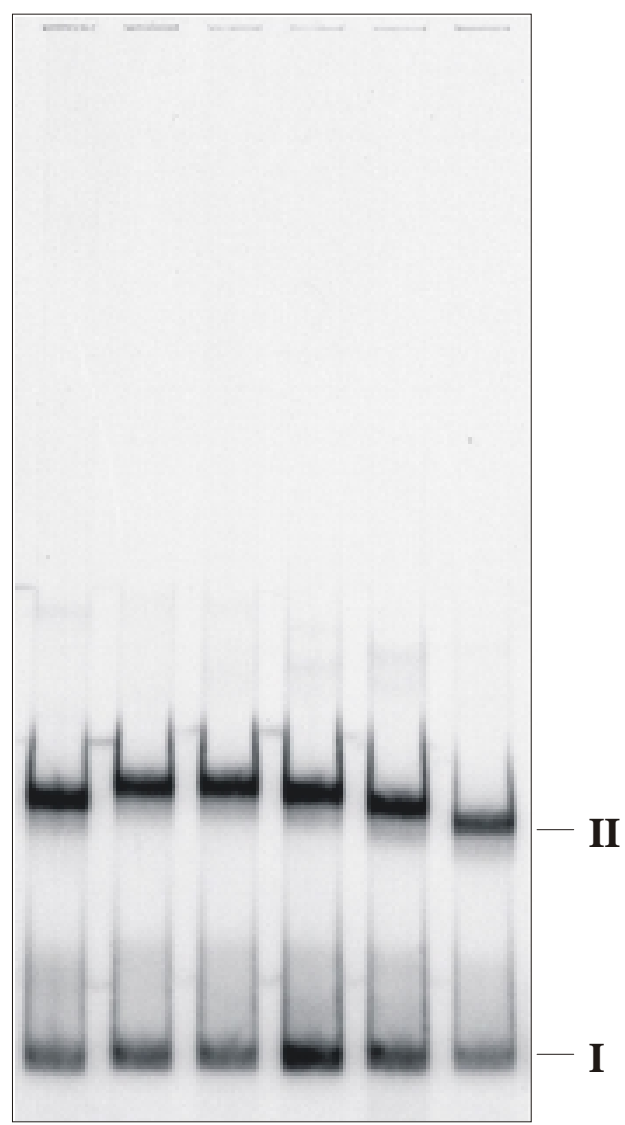

b

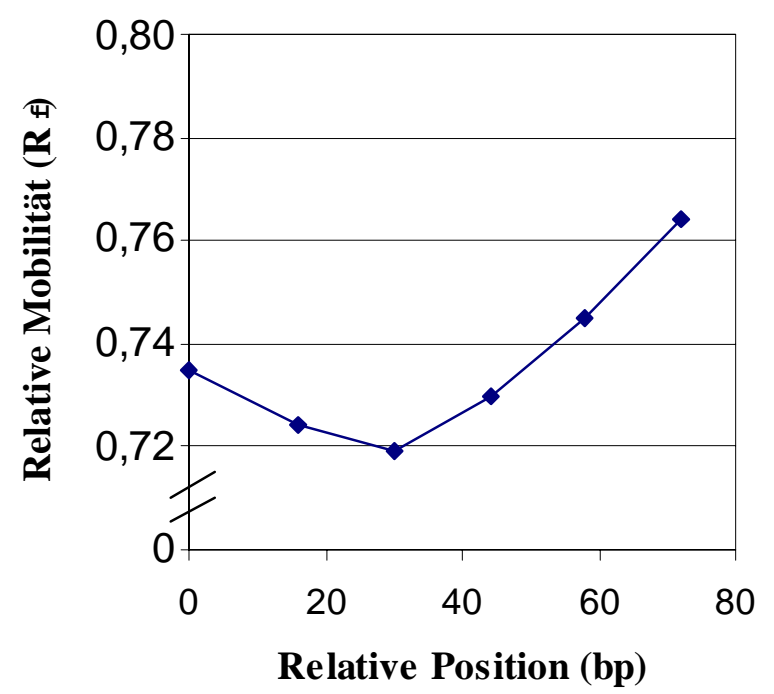

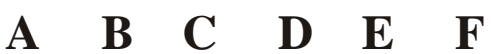

Abb. 27. 'Mobility shifts' mit verschiedenen, gleichlangen Fragmenten (A-F) der $c b b$ Kontrollregion und P1 zur Bestimmung des DNA-Krümmungszentrum.

a: 'Mobility shifts' mit P1 (10 ng) und den Fragmenten A-F (je 202 bp). b: Die relativen Mobilitäten der retardierten Fragmente wurden gegen ihre relative Position innerhalb der $c b b$-Kontrollregion bezogen auf diejenige von Frament A (Position 0) aufgetragen. Die Fragmente sind ausgehend von Fragment A um jeweils 14-16 bp in Richtung von $c b b L$ versetzt. I, freie DNA; II P1-DNAKomplexe. 
$\mathbf{a}$

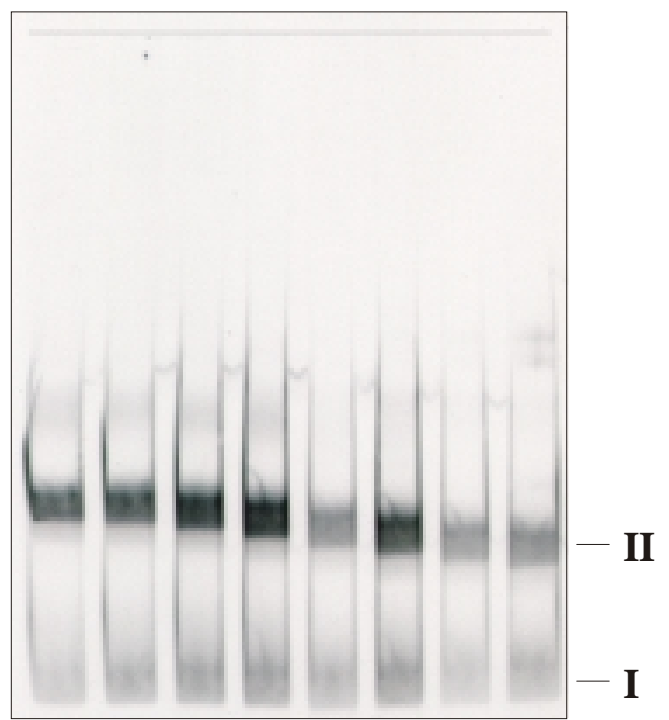

$\begin{array}{llllllll}1 & 2 & 3 & 4 & 5 & 6 & 7 & 8\end{array}$ b

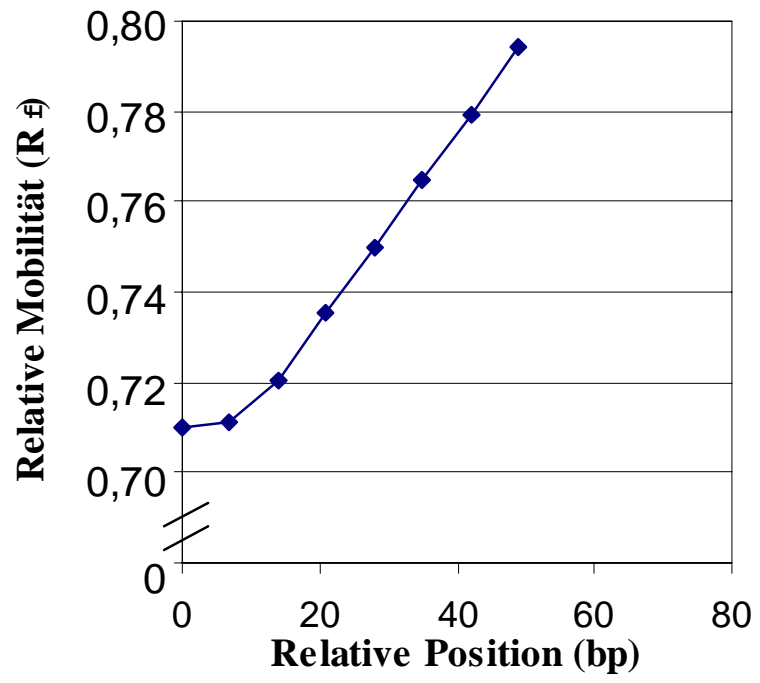

Abb. 28. 'Mobility shifts' mit verschiedenen, gleichlangen Fragmenten (1-8) der $c b b$ Kontrollregion und P1 zur Berechnung des Krümmungswinkels.

a: 'Mobility shifts' mit P1 (10 ng) und den Fragmenten 1-8 (je 167 bp). b: Die relativen Mobilitäten der retardierten Fragmente wurden gegen ihre relative Position innerhalb der $c b b$-Kontrollregion bezogen auf diejenige von Frament 1 (Position 0) aufgetragen. Die Fragmente sind ausgehend von Fragment 1 um jeweils 7 bp in Richtung von $c b b L$ versetzt. I, freie DNA; II P1-DNA-Komplexe.

\subsubsection{CbbR- und PhcA*- induzierte DNA-Krümmungen}

In diesen 'mobility shift'-Experimenten sollte untersucht werden, ob es zwischen CbbR und PhcA* Ähnlichkeiten bezüglich der durch sie induzierten Krümmung innerhalb der $c b b$ Kontrollregion gibt. Zur Berechnung der jeweiligen DNA-Krümmungswinkel wurden die Fragmente A-F verwendet. Danach verursachte CbbR einen DNA-Krümmungswinkel von $\alpha=48^{\circ}$, während die Krümmung durch PhcA* mit $\alpha=18^{\circ}$ deutlich schwächer ausfiel $\mathrm{Abb}$. $29 ;$ Abb. 30.

Im Gegensatz zu den Bindungsstudien mit P1 erwiesen sich die Fragmente 1-8 aufgrund der unterschiedlichen relativen Lage der P1- und CbbR-Bindungsregionen als besser geeignet zur exakten Lokalisation des CbbR-Krümmungszentrums Abb. 31). Die Fragmente 4-6, in denen die CbbR-Bindungsregion relativ zentral lokalisiert war, wurden hierbei am stärksten retardiert. Das DNA-Krümmungszentrum stimmte demnach mit der Bindungsregion von CbbR überein.

Die Lage des PhcA*-Krümmungszentrum stimmte mit dem für CbbR bestimmten überein. Nicht dargestellt sind vergleichende Studien, in denen kein Unterschied zwischen PhcA und 
PhcA* festgestellt werden konnte. Das gegenüber CbbR abweichende Krümmungsverhalten von PhcA* kann daher nicht alleiniger Grund für die Suppression der $c b b R$-Deletion in HB14R sein.

$\mathbf{a}$

b

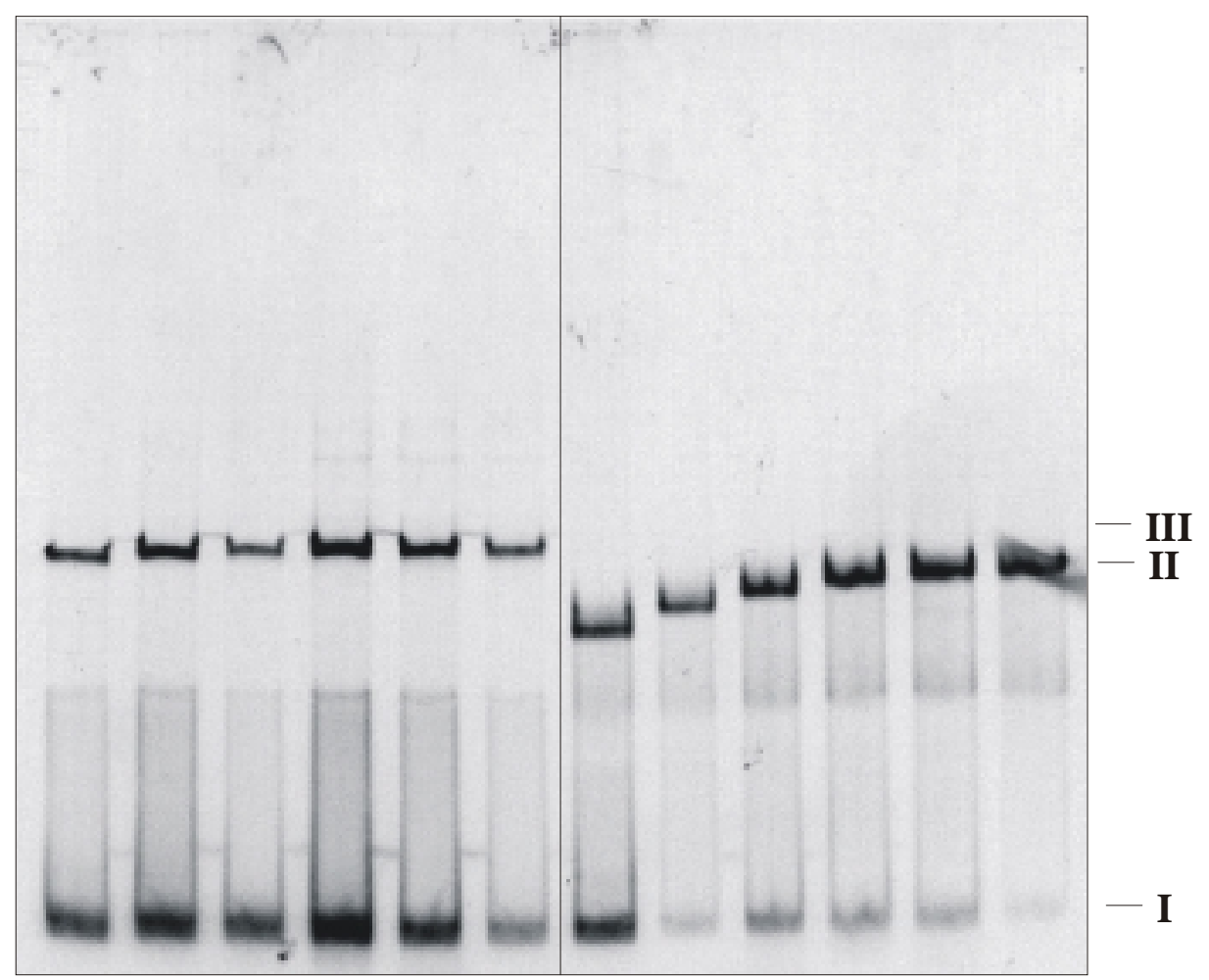

$\begin{array}{llllllllllll}\mathbf{A} & \mathbf{B} & \mathbf{C} & \mathbf{D} & \mathbf{E} & \mathbf{F} & \mathbf{A} & \mathbf{B} & \mathbf{C} & \mathbf{D} & \mathbf{E} & \mathbf{F}\end{array}$

Abb. 29. 'Mobility shifts' mit verschiedenen, gleichlangen Fragmenten (A-F) der $c b b$ Kontrollregion mit Rohextrakten von $E$. coli JW1 (pCG7) sowie E. coli JW1 (pAECR7) nach heterologer Expression von phcA* bzw. cbbR.

a: Fragmente plus PhcA*-Rohextrakt (Verdünnungsfaktor: $2^{-7}, 0.08 \mathrm{mg} / \mathrm{ml}$ ). b: Fragmente plus CbbR-Rohextrakt (Verdünnungsfaktor: $2^{-7}, 0.08 \mathrm{mg} / \mathrm{ml}$ ). I, freie DNA; II, CbbR-DNA-Komplexe; III, PhcA*-DNA-Komplexe. 
$\mathbf{a}$

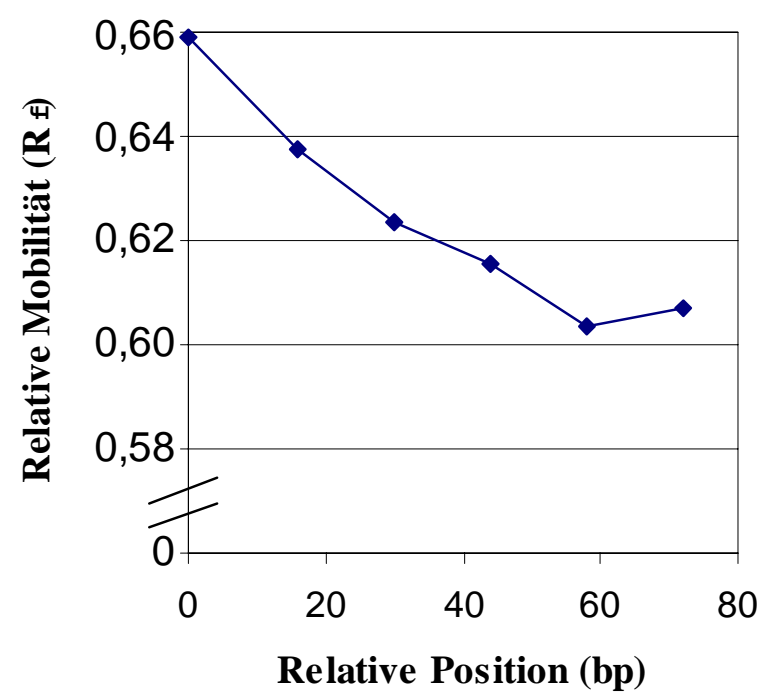

b

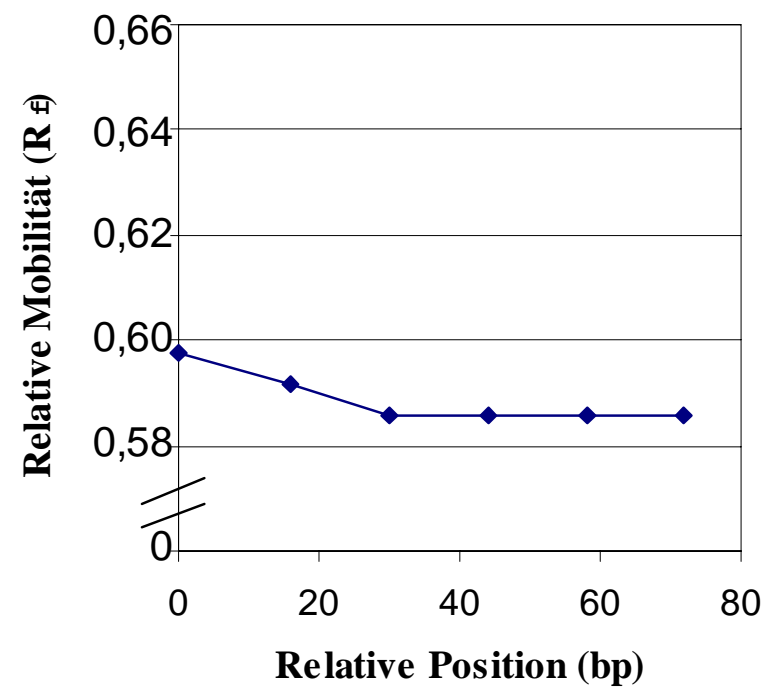

Abb. 30. Relativen Mobilitäten der PhcA-(a) und CbbR-Retardationskomplexe (b) zur Berechnung des DNA-Krümmungswinkels.

Die relativen Mobilitäten der retardierten Fragmente A-F (202 bp) wurden gegen ihre relative Position innerhalb der $c b b$-Kontrollregion bezogen auf diejenige von Frament A (Position 0) aufgetragen. Die Fragmente sind ausgehend von Fragment A um jeweils 14-16 bp in Richtung von $c b b L$ versetzt. a: Relative Mobilitäten von CbbR-DNA-Komplexen. b: Relative Mobilitäten von PhcA*-DNA-Komplexen (s. Abb. 29.

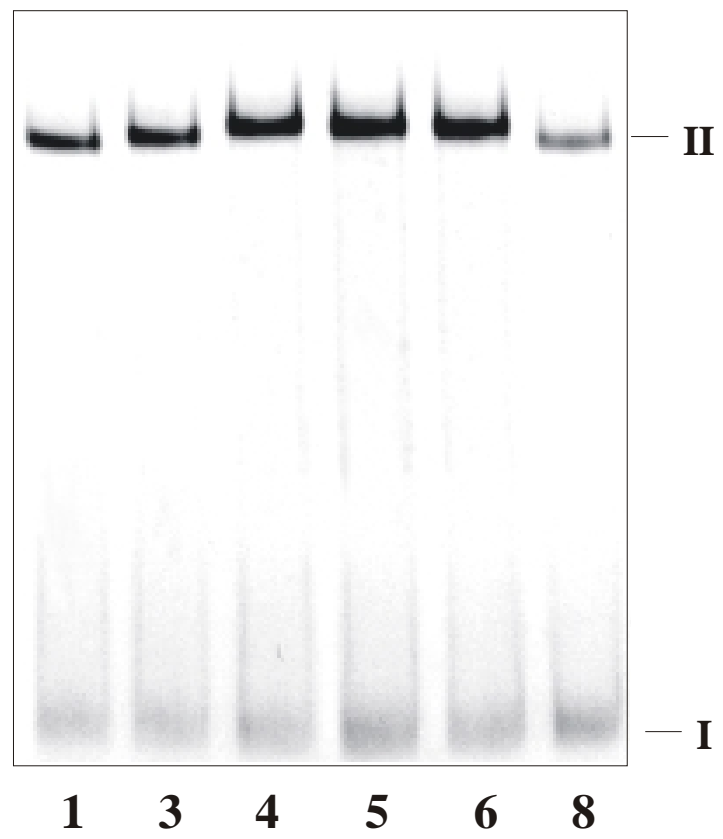

Abb. 31. 'Mobility shifts' mit verschiedenen, gleichlangen Fragmenten (1-8) der $c b b$ Kontrollregion und Rohextrakten von $E$. coli JW1 (pAECR7) nach heterologer Expression von $\boldsymbol{c} b \boldsymbol{b} R$ zur Bestimmung des DNA-Krümmungszentrum.

Die 'Mobility shifts' wurden mit Rohextrakt $(0.08 \mathrm{mg} / \mathrm{ml})$ und den Fragmenten 1-8 (je 167 bp) durchgeführt. I, freie DNA; II, CbbR-DNA-Komplexe. 


\subsubsection{P1-CbbR- und P1-PhcA*-induzierte DNA-Krümmungen}

Aufgrund der vorangegangenen Befunde schien es denkbar, daß es bei gleichzeitiger Bindung von P1 und CbbR zu einer Veränderung der DNA-Krümmung im Vergleich zu den individuell durch P1 und CbbR induzierten Krümmungen kommt.

DNA-Bindungsstudien mit den Fragmenten A-F ergaben, daß das P1-CbbRKrümmungszentrum mit dem durch CbbR allein induzierten identisch war Abb. 32. Im Vergleich zu der durch CbbR induzierten DNA-Krümmung war jedoch die durch gleichzeitige Bindung von P1 und CbbR verursachte Krümmung deutlich abgeschwächt, was möglicherweise auf eine relaxierende Wirkung von P1 zurückzuführen ist.

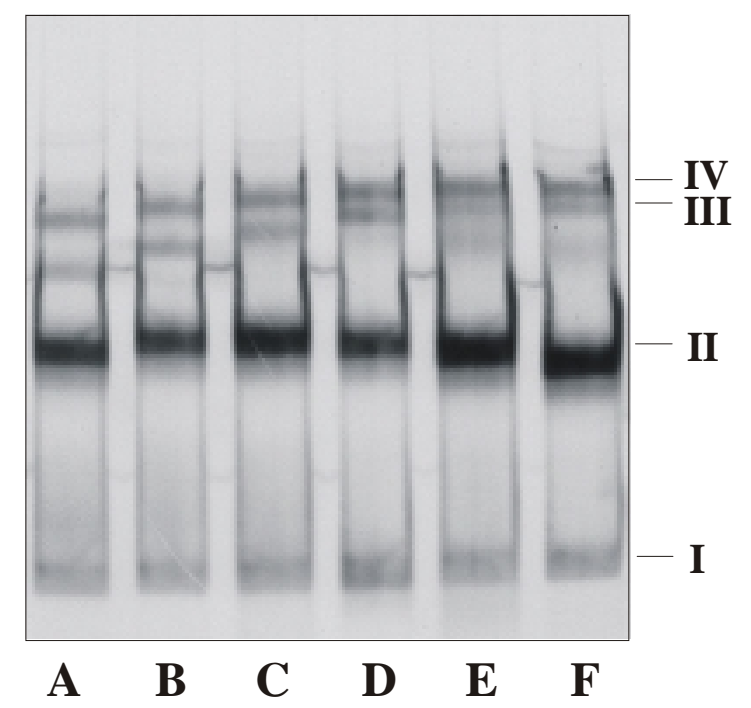

Abb. 32. 'Mobility shifts'mit angereichertem P1 in Kombination mit Rohextrakten von E. coli JW1 (pAECR7)-Transformanten nach heterologer Expression von $c b b R$ und 202 bp-'bending'Fragmenten der $c b b$-Kontrollregion (A-F).

'Bending'-Fragmente A-F mit angereichertem P1 (5 ng) in Kombination mit CbbRRohextrakt (Verdünnungsfaktor: $2^{-8}: 0.04 \mathrm{mg} / \mathrm{ml}$ ); I, freie DNA; II P1-DNAKomplex; III CbbR-DNA-Komplexe; IV CbbR/P1-DNA-Komplex.

Bei Studien mit den Fragmenten 1-8 wurden deutliche Unterschiede bei der durch P1 plus CbbR induzierten DNA-Krümmung im Vergleich zum P1-PhcA*-Komplex festgestellt Abb. 33). Während die Lage des durch den P1-CbbR-Komplex IV hervorgerufenen Krümmungszentrums derjenigen des CbbR-Krümmungszentrum entsprach (Komplex III), so war das Krümmungszentrum des multimeren $\mathrm{P} 1 / \mathrm{PhcA}^{*}$-Komplexes VI hingegen identisch mit dem P1-Krümmungszentrum (Komplex I). Dies kann wahrscheinlich auf die nur schwache, von PhcA* induzierte Krümmung und dem somit dominierenden Krümmungseffekt von P1 zurückgeführt werden (vgl. Abb. 30. 


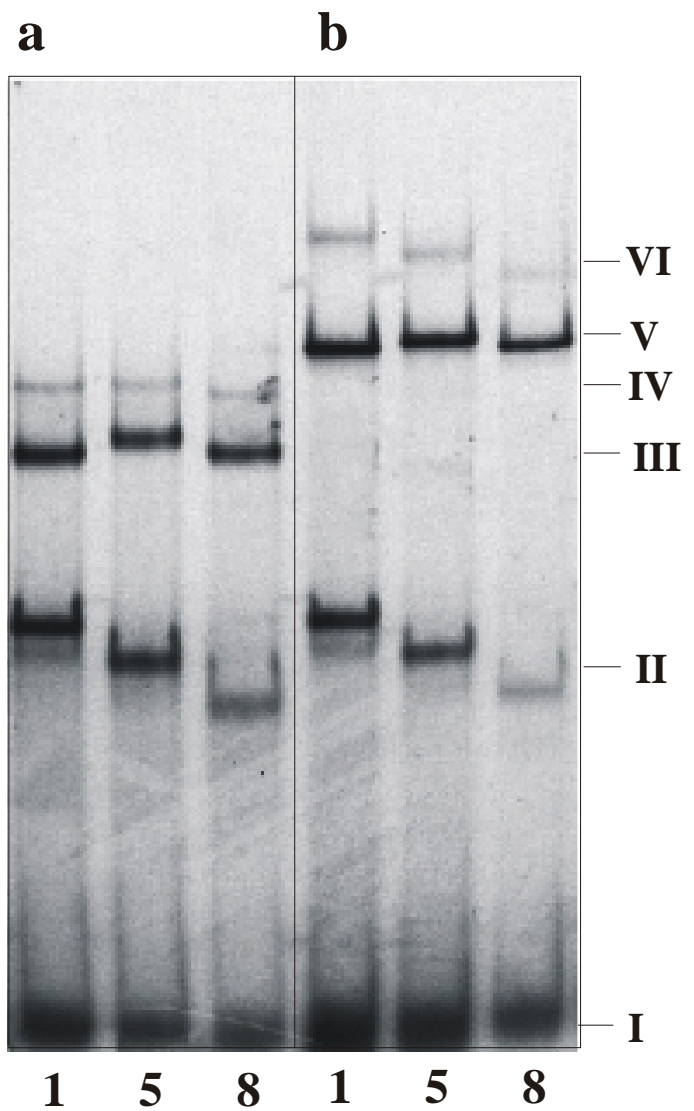

Abb.33. 'Mobility shifts' mit verschiedenen, gleichlangen Fragmenten der $c b b$ Kontrollregion und P1 in Gegenwart von CbbR oder PhcA*.

a: Fragmente 1, 5 und 8 (je 167 bp) mit angereichertem P1 (5 ng) und Rohextrakt $(0.04 \mathrm{mg} / \mathrm{ml})$ von $E$. coli JW1 (pAECR7) nach heterologer Expression von $c b b R$. b: Fragmente 1, 5 und 8 mit angereichertem P1 $(5 \mathrm{ng})$ und Rohextrakt $(0.04 \mathrm{mg} / \mathrm{ml})$ von $E$. coli JW1 (pCG7) nach heterologer Expression von $p h c A^{*}$. I, freie DNA; II, P1-DNA-Komplex; III, CbbR-DNA-Komplex; IV, CbbR-P1-DNA-Komplex; V, PhcA*-DNA-Komplex; VI, PhcA*-P1-DNA-Komplex.

Die vergleichenden Bindungsstudien mit CbbR und PhcA* wiesen auf eine deutlich unterschiedliche Funktionsweise der beiden Proteine bei der Aktivierung des $c b b$-Operonpromotors in R. eutropha H16 bzw. HB14R hin.

\subsection{Effekte potentieller Signalmetaboliten des $c b b$-Systems}

Für eine physiologisch sinnvolle Regulation der $c b b$-Operone von $R$. eutropha H16 ist die Existenz von Signalmetaboliten zu fordern, die als Effektoren von CbbR und mindestens eines weiteren Transkriptionsregulators an der strengen Kontrolle der $c b b$-Transkription in Abhängigkeit von den Wachstumsbedingungen beteiligt sind. Weder in 'mobility shift'Experimenten (Kusian, 1994) noch im In vitro-Transkriptionssystem (Grzeszik et al., 2000) 
konnte bisher allerdings ein Coaktivator von CbbR gefunden werden. In In vitroTranskriptionsstudien war hingegen festgestellt worden, daß PEP ein negativer Effektor von CbbR ist, durch den die aktivierende Wirkung von CbbR auf die $c b b$-Operonpromotoren moduliert wird (Grzeszik et al., 2000).

In 'mobility shifts' wurde daher der Effekt von PEP auf die DNA-Bindungseigenschaften von CbbR untersucht.

Da P1 direkt stromaufwärts von der CbbR-Bindungsregion bindet (s. 3.5.3.2 und somit ein potentieller zusätzlicher Regulator des $c b b$-Systems ist, sollte durch 'mobility shifts' mit P1 festgestellt werden, ob Metabolite einen Effekt auf die DNA-Bindung von P1 an die $c b b$ Kontrollregion ausüben.

\subsubsection{Beeinflussung der Bindungsaffinität von CbbR durch PEP}

'Mobility shifts' mit der $c b b$-Kontrollregion und CbbR in Gegenwart von PEP ergaben, daß die Bindungsaffinität von CbbR zur $c b b$-Kontrollregion mit ansteigender Konzentration des Metaboliten deutlich zunahm (Abb. 34A). Diese Wirkung von PEP konnte auch gezeigt werden, wenn bei konstant hoher PEP-Konzentration (2 mM) die CbbR-Konzentration erhöht wurde Abb. 34 3 und C). Die Bindungsstudien ergaben außerdem, daß PEP keinen Einfluß auf die Mobilität der CbbR-DNA-Komplexe ausübte, d.h. der reprimierende Effekt von PEP ist in der erhöhten Bindungsaffiniät von CbbR an den Operator zu suchen. 
A

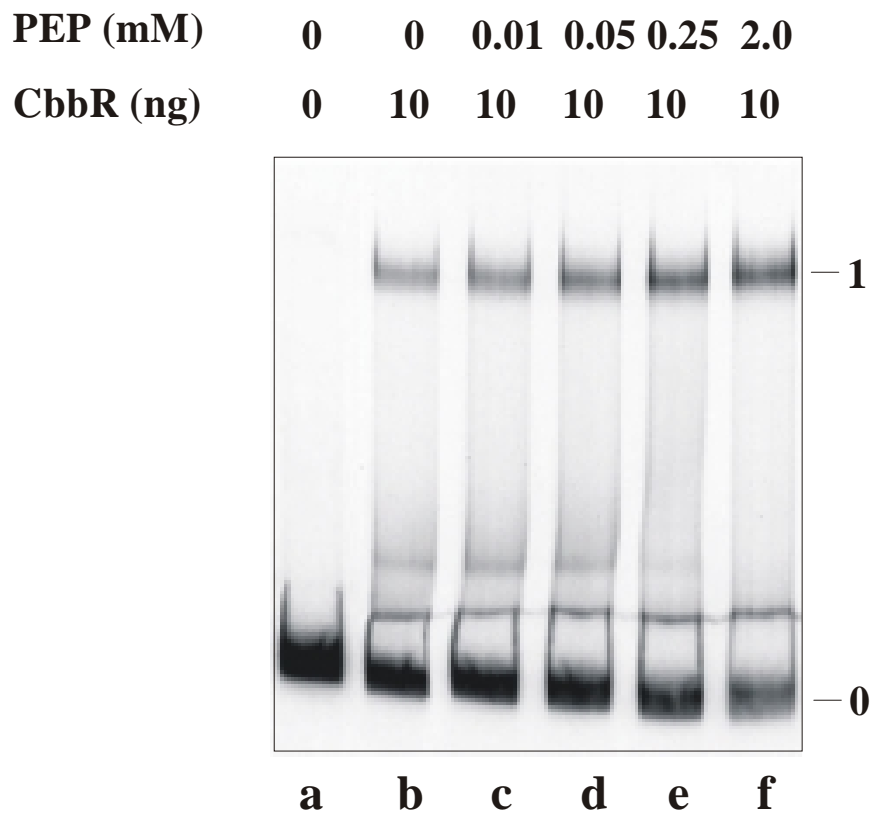

B

C
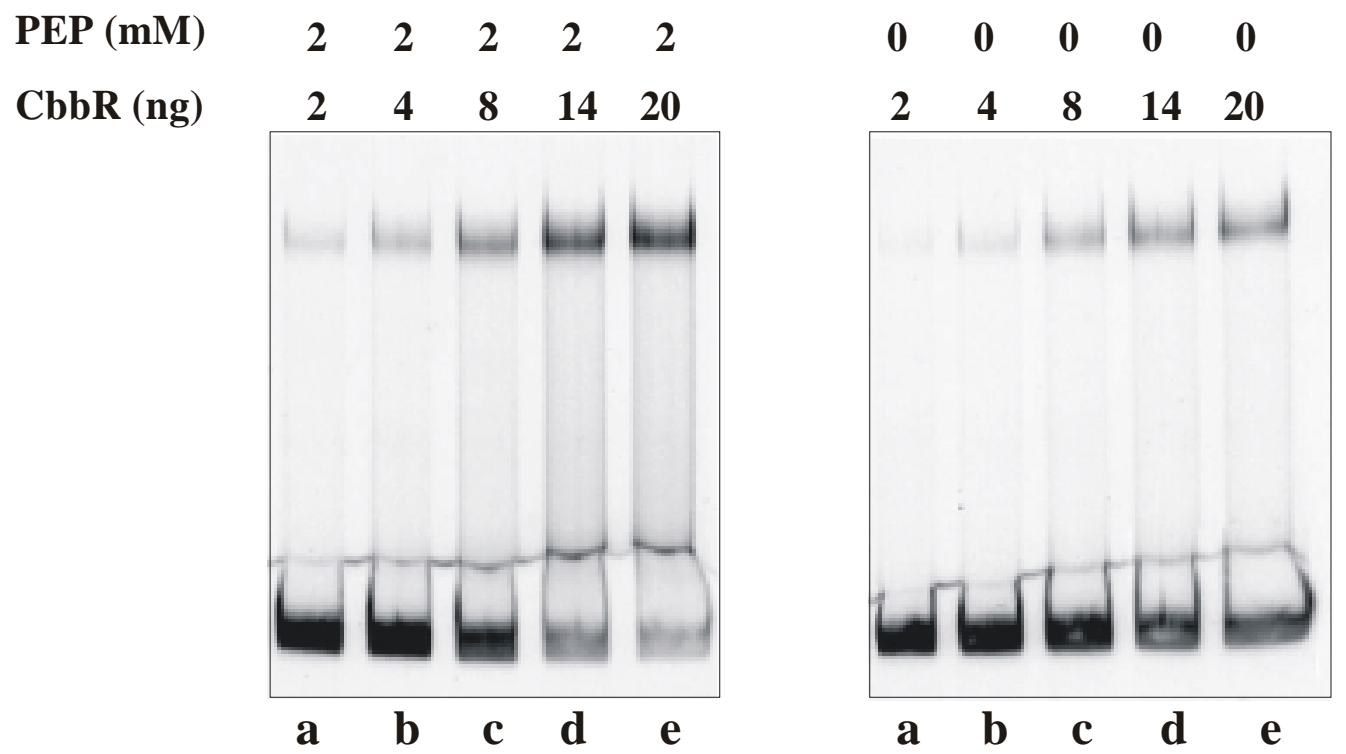

Abb. 34. 'Mobility shifts' der $c b b$-Kontrollregion (253 bp-Fragment) und CbbR in Anund Abwesenheit von Phosphoenolpyruvat (PEP).

A: Ansteigende PEP-Konzentrationen bei konstanter Menge von CbbR. B: Ansteigende CbbR-Mengen in Gegenwart von $2 \mathrm{mM}$ PEP. C: kein Zusatz von PEP. Die eingesetzten Mengen von CbbR und PEP sind jeweils oberhalb der entsprechenden Spuren angegeben. 0, freie DNA; 1, CbbR-DNA-Komplex. 


\subsubsection{Einfluß des intrazellulären PEP-Spiegels auf die heterologe Aktivität des $c b b$ - Operonpromotors in $E$. coli}

Bei den bereits erwähnten In vitro-Transkriptionsstudien, die zur Identifikation von PEP als negativem Effektor von CbbR geführt hatten, war anhand mutierter $c b b$-Operonpromotoren festgestellt worden, daß $p_{c b b L}$ die Transkription durch die RNA-Polymerase (RNAP) aus $E$. coli auf einem vergleichbaren Niveau aktivierte wie mit der homologen RNAP aus $R$. eutropha (Grzeszik et al., 2000). Daher erschienen In vivo-Studien im heterologen System mit E. coli JW1 geeignet zur Verifizierung der Rolle des intrazellulären PEP-Spiegels bei der Aktivierung von $p_{c b b L}$. Entsprechende Aktivitätsmessungen erfolgten anhand einer transkriptionellen lacZ-Fusion des Promotors in pBK2241. Es ist seit langem bekannt, daß der intrazelluläre PEP-Spiegel in E. coli bei aeroben Wachstum auf Glucose mit ca. $0.1 \mathrm{mM}$ um etwa 10 fach niedriger liegt als bei Wachstum auf Succinat (ca. 1 mM; Lowry et al., 1971). Daher wurden verschiedene Transformanten von E. coli JW1, welche außerdem die Plasmide pAECR7, pCG3 und/oder pCG4 enthielten, auf ihre $p_{c b b L}$-Aktivitäten nach Wachstum auf Glucose oder Succinat getestet. In den Transformanten wurden $c b b R$ und/oder $p h c A / p h c A *$ in Abwesenheit des lac-Induktors IPTG auf niedrigem Niveau exprimiert, um in dieser Hinsicht möglichst physiologische Bedingungen zu simulieren.

In CbbR-produzierenden Transformanten (pAECR7) war die Aktivität von $p_{c b b L}$, gemessen als ß-Galaktosidase-Aktivität, in Glucosezellen etwa 5-fach höher als in den entsprechenden Succinatzellen, die nur Hintergrundaktivitäten zeigten. Keine Aktivierung des Promotors wurde in Klonen beobachtet, die PhcA anstelle von CbbR bildeten. Dagegen kam es zu einer deutlichen, in der Höhe sehr ähnlichen Aktivierung von $p_{c b b L}$ bei Expression von $p h c A^{*}$, und zwar zu etwa gleicher Stärke nach Wachstum auf Glucose oder Succinat (Tab. 6. Im Unterschied zu CbbR hatte der PEP-Spiegel offenbar keinen Einfluß auf die aktivierende Wirkung von PhcA*. Die zusätzliche Expression von $c b b R$ in Kombination mit $p h c A^{*}$ führte nach Wachstum auf Glucose zu einer geringen Erniedrigung des Aktivitätsniveaus. Wachstum auf Succinat bewirkte jedoch in diesem Fall eine deutliche Aktivitätsabnahme von $p_{c b b L}$ Tab. \$), was vermutlich auf die durch PEP verursachte erhöhte Bindungsaffinität von CbbR zum Operator und die damit einhergehende, verringerte Aktivierung des Promotors zurückzuführen war. 
Tab. 6. Aktivitäten des $c b b$-Operonpromotors $p_{c b b L}$ anhand von lacZ-Fusionen in verschiedenen Transformanten von $E$. coli JW1 nach Wachstum auf Glucose oder Succinat.

Plasmide

$$
\text { Expression von }
$$

Spez. Aktivität (mU/mg) $\operatorname{der} \beta$-Galaktosidase

$\begin{array}{ccc}c b b R \quad p h c A / p h c A^{*} & \text { Glucose } & \text { Succinat } \\ & (0.1 \mathrm{mM} \text { PEP })^{\mathrm{e}} & (1.0 \mathrm{mM} \text { PEP })^{\mathrm{e}}\end{array}$

\begin{tabular}{|c|c|c|c|c|}
\hline $\mathrm{pBK} 2241^{\mathrm{a}}$ & - & - & $<1$ & $<1$ \\
\hline $\mathrm{pBK} 2241, \mathrm{pAECR} 7^{\mathrm{b}}$ & + & - & 10 & 2 \\
\hline pBK2241, pCG4 ${ }^{\mathrm{c}}$ & - & + & 2 & 2 \\
\hline pBK2241, pCG4, pAECR7 & + & + & 2 & 2 \\
\hline pBK2241, pCG3 $^{\mathrm{d}}$ & - & $+*$ & 137 & 120 \\
\hline pBK2241, pCG3, pAECR7 & + & $+*$ & 118 & 61 \\
\hline
\end{tabular}

${ }^{\mathrm{a}} \mathrm{pBK} 2241$ : Operonfusion des Wildtyp- $p_{c b b L}$ mit lacZ

${ }^{\mathrm{b}} \mathrm{pAECR} 7: c b b R$ in pUC18 kloniert

c pCG4: phcA in pBBR1MCS2 kloniert

${ }^{\mathrm{d}}$ pCG3: $p h c A^{*}$ in pBBR1MCS2 kloniert

${ }^{\mathrm{e}}$ Jeweilige intrazelluläre PEP-Konzentration

\subsubsection{Suche nach potentiellen Effektoren von P1}

Nachdem mit PEP als negativer Effektor von CbbR ein wichtiger $c b b$-Signalmetabolit aus dem zentralen Kohlenstoffmetabolismus gefunden worden war, erfolgte nun im Hinblick auf P1 eine erste Suche nach weiteren potentiellen Signalmetaboliten. Hierzu wurden 'mobility shifts' mit der $c b b$-Kontrollregion und P1 in An- und Abwesenheit von CbbR durchgeführt, wobei im wesentlichen die Effekte von Metaboliten aus dem Energiestoffwechsel (NADH, NADPH, NAD, NADP, ATP, ADP, AMP, cAMP) auf Bildung und Mobilität der betreffenden Protein-DNA-Komplexe getestet wurden. Die Wahl dieser Metabolite erschien unter physiologischen Aspekten bezüglich der Aktivierung der $c b b$-Operone zunächst am plausibelsten. In X. flavus war NADPH als vermutlicher Coaktivator von CbbR gefunden worden (van Keulen et al., 1998), was für CbbR aus $R$. eutropha bisher jedoch nicht bestätigt werden konnte (Kusian, 1994; Grzeszik et al., 2000). Das Bindungsverhalten von P1 zur cbbKontrollregion wurde allerdings durch keinen der getesteten Metabolite signifikant beeinflußt (keine Abb.). 


\subsection{Strukturelle und funktionelle Analyse der $c b b$-Promotoren}

Zur weiteren strukturellen und funktionellen Analyse der verschiedenen regulatorischen Elemente des $c b b$-Systems in $R$. eutropha wurden Promotoraktivitätsstudien durchgeführt. Anhand transkriptioneller lacZ-Fusionen des $c b b$-Operonpromotors $p_{c b b L}$ und des $c b b R$ Promotors $p_{c b b R}$, erfolgte die Bestimmung der Promotoraktivitäten über die BGalaktosidaseaktvitäten in Zellextrakten. Aus verschiedenen Untersuchungen war bekannt, daß die Expression der $c b b$-Gene einer strikten Regulation in Abhängigkeit zu den Wachstumsbedingungen unterliegt (Friedrich et al., 1981b, Bowien et al., 1990). Das generell auftretende Regulationsmuster wurde auch für die Aktivitäten von $p_{c b b L}$ bestätigt. Nach lithoautotropher Anzucht zeigte der Promotor eine hohe Aktivität, während heterotrophes Wachstum auf Pyruvat oder Succinat eine totale Repression von $p_{c b b L}$ bewirkte. Heterotrophes Wachstum auf Fructose hingegen hatte eine teilweise Derepression von $p_{c b b L}$ zur Folge (Kusian \& Bowien, 1995). Der Operonpromotor hat deutliche Ähnlichkeiten zu typischen $\sigma^{70}$ abhängigen Promotoren aus E. coli. Trotz dieser Ähnlichkeit erfolgte heterolog nur eine äußerst schwache Aktivierung des Promotors. Zur Verifikation der bisher nur abgeleiteten Promotorsequenz und zur strukturellen und funktionellen Analyse wurden Mutationen in $p_{c b b L}$ eingefügt, die eine Angleichung an die $\sigma^{70}$-Consensussequenz von E. coli bewirkten. Die Aktivitätsmessungen der mutierten Operonpromotoren wurden sowohl in R. eutropha als auch heterolog mit E. coli durchgeführt.

Um den Einfluß von CbbR und des zusätzlichen potentiellen Regulators P1 auf Aktivierung und Repression der beiden $c b b$-Promotoren unter unterschiedlichen Wachstumsbedingungen untersuchen zu können, wurde außerdem eine Deletionsanalyse mit der $c b b$-Kontrollregion durchgeführt, wobei die Bindungsregionen von P1 und CbbR teilweise oder vollständig entfernt wurden. Weiterhin wurde Hinweisen auf eine negative Autoregulation von $c b b R$ nachgegangen, die auf früheren Aktivitätsmessungen von $p_{c b b R}$ beruhten (Kusian \& Bowien, 1995). Zur Herstellung der lacZ-Fusionen wurden alle Fragmente der $c b b$-Kontrollregion in den Operonfusionsvektor pBK kloniert.

\subsubsection{Erzeugung von Promotormutationen durch gerichtete Mutagenese}

Bereits vor Beginn dieser Arbeit war $p_{c b b L}$ teilweise verifiziert worden (Jeffke et al., 1999). Dabei waren durch gerichtete Mutagenese mittels PCR Punktmutationen in Form von Substitutionen in die ' -35 '- und '-10'-Regionen des Promotors eingeführt worden. Dadurch wurde bereits eine schrittweise Angleichung oder Abweichung dieser Regionen in Bezug auf 
den $\sigma^{70}$-Consensus von E. coli erreicht. Zur Komplettierung dieser Untersuchungen wurden nun zunächst die '-10'-und die '-35'-Region separat komplett dem E. coli- $\sigma^{70}$-Consensus angeglichen (Tab. 7). Außerdem erfolgte die Konstruktion einer Vollconsensusmutante mit kompletter E. coli- $\sigma^{70}$-Consensussequenz in beiden Promotorregionen. Durch Zufallsmutation im Verlauf der PCR ging aus dieser Mutante eine weiter $p_{c b b L}-$ Mutante hervor, mit einer von der Consensusstruktur abweichenden Base in der '-35'-Region. Die Funktion des 17 bp umfassenden 'spacers' zwischen der ' -35 '- und '-10'-Region wurde durch Insertion einer Base innerhalb dieses Sequenzabschnitts untersucht. Die Aktivitätsmessungen der mutierten Operonpromotoren wurden in Transkonjuganten der Stämme R. eutropha H16, HB14, HF210 und HB15 bei unterschiedlichen Wachstumsbedingungen vorgenommen.

Zur Einfügung der Punktmutationen in $p_{c b b L}$ wurde eine ortsspezifische Mutagenese durch asymmetrische PCR durchgeführt. In drei aufeinanderfolgenden PCR-Schritten wurde ein Mutagenese-Primer zusammen mit dem Universal und dem Reverse-Primer der pUC-Serie verwendet. Die entsprechenden Amplifikate wurden zur Sequenzierung in pKS kloniert und nach abgeschlossener Überprüfung in pBK umkloniert Abb. 35. Abschließend erfolgte die konjugative Übertragung der pBK-Derivate mit mutierter Kontrollregion von E. coli S17-1 nach R. eutropha.

Tab. 7. Sequenzen der mutierten $c b b$-Operonpromotoren von $R$. eutropha H16

\begin{tabular}{lccc}
\hline Promotor & \multicolumn{3}{c}{$\begin{array}{c}\text { DNA-Sequenz von } p_{c b b L} \\
-\mathrm{N}_{17} \text {-Spacer }-\end{array}$} \\
\hline Wildtyp & TTTACC & -TTATGTGGGTGGGCTTA - & TATCTT \\
M1 $^{\text {a }}$ & TTTACC & $-\mathrm{N} 17$ - & TATAAT \\
M2 & TTTACC & $-\mathrm{N} 17-$ & TATCAT \\
M6 & TTGACA & $-\mathrm{N} 17--$ & TATCTT \\
M9 & TTGACA & $-\mathrm{N} 17--$ & TATAAT \\
M10 & CTGACA & $--N 17--$ & TATAAT \\
M13 & TTTACC & -TTATGTGGGTGGGGCTTA - & TATCTT
\end{tabular}

${ }^{\mathrm{a}}$ Die mutierten Basen sind fett gedruckt.

${ }^{\mathrm{b}}$ M10 leitet sich von M9 ab. 


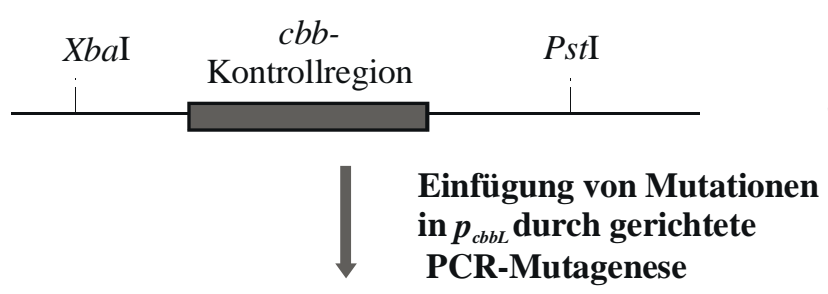

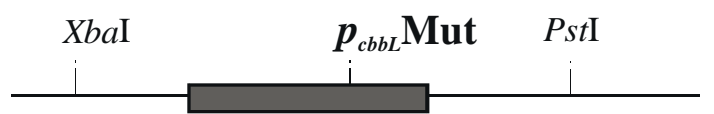

Verdau mit $X b a \mathrm{I} / P$ stI

Klonierung in pKS

Verifizierung der eingefügten

Mutation durch Sequenzierung
PCR-Fragmente mit mutiertem $\boldsymbol{p}_{c b b L}$
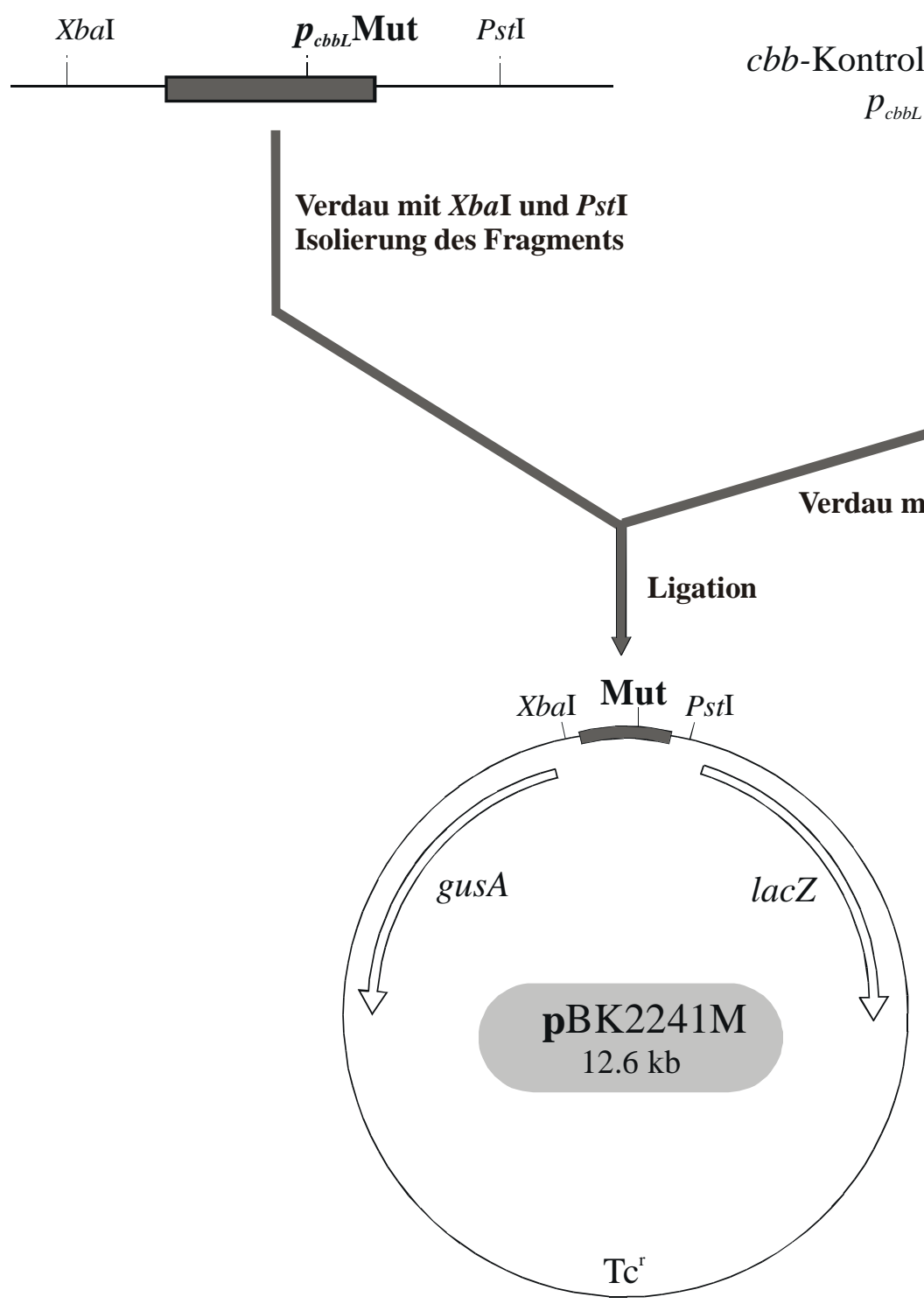

$c b b$-Kontrollregion mit mutiertem $p_{c b b L}$ in $\mathrm{pKS} 2241 \mathrm{M}$ 


\subsubsection{Aktivitäten der mutierten $c b b$-Operonpromotoren in $R$. eutropha}

In den Transkonjuganten des Wildtypstamms $R$. eutropha H16 mit den $p_{c b b L}$-Mutanten M1M10, bei denen der Promotor teilweise oder vollständig an den $\sigma^{70}$-Consensus von E.coli angeglichen worden war, wurden im Vergleich zum Wildtyppromotor deutlich erhöhte Aktivitäten unter allen Wachstumsbedingungen festgestellt. Die höchsten Aktivitäten zeigten die Teilconsensusmutanten M1 und M6, vor allem aber die Vollconsensusmutante M9. Bei M9 lagen die Aktivitäten nach normalerweise total reprimierenden Wachstum auf Pyruvat noch höher als beim Wildtyppromotor nach lithoautotropher Anzucht. Im Vergleich zum Wildtyp konnte daher M9 als nahezu konstitutiver Promotor betrachtet werden (Tab. 8. Zu einer Abnahme der $p_{c b b L^{-}}$Aktivität kam es nur bei M13, bei der eine Base innerhalb der $\mathrm{N}_{17^{-}}$ Spacerregion eingefügt worden war, was offensichtlich zu einer Abschwächung der $\sigma^{70-}$ Consensusstruktur des Promotors führte.

Diese Ergebnisse bestätigten den $p_{c b b L}$-Promotor eindeutig in Struktur und Funktion als typischen $\sigma^{70}$-Promotor. Alle Mutanten mit angeglichener Consensusstruktur bezüglich E. coli zeigten unter den gegebenen Wachstumsbedingungen deutliche Aktivitätssteigerungen, blieben aber stets unter Kontrolle des $c b b$-Systems, wie dies an den Aktivitätsabstufungen vom autotrophen zum heterotrophen Wachstum erkennbar war.

Tab. 8. Aktivitäten der mutierten $c b b$-Operonpromotoren anhand transkriptioneller lacZ-Fusionen in Transkonjuganten von R. eutropha H16 nach Anzucht auf verschiedenen Substraten.

\begin{tabular}{lccc}
\hline Plasmid & \multicolumn{3}{c}{$\begin{array}{c}\text { Spez. Aktivität der } \\
\text { B-Galaktosidase (mU/mg) }\end{array}$} \\
\cline { 2 - 4 } & H2-CO2 $_{2}$ & Fructose & Pyruvat \\
\hline pBK & 4 & 3 & 3 \\
pBK2241 & 750 & 100 & 6 \\
pBKM1 & 1590 & 1100 & 90 \\
pBKM2 & 1120 & 560 & 16 \\
pBKM6 & 1740 & 1440 & 90 \\
pBKM9 & 2000 & 1610 & 1270 \\
pBKM10 & 1300 & 320 & 24 \\
pBKM13 & 320 & 70 & 6 \\
\hline
\end{tabular}


Zur weiteren Aktivitätsanalyse der $p_{c b b L}$-Mutanten M1, M6 und M9 wurden diese auch im CbbR-freien Hintergrund der CbbR-Deletionsmutanten HB14 und HB15 getestet. Der Stamm HB15 ist aus dem megaplasmidfreien Stamm HF210 hervorgegangen und trägt die gleiche CbbR-Deletion wie HB14. Die Messungen mit den Transkonjuganten der Stämme HF210 und HB15 wurden durchgeführt, um einen möglichen Einfluß des Megaplasmids pHG1 auf die $p_{c b b L}$-Aktivitäten einschätzen zu können.

Im Gegensatz zum Wildtyppromotor wurden mit den beiden $\sigma^{70}$-Teilconsensus (M1, M6) und der $\sigma^{70}$-Vollconsensusmutante M9 deutliche $p_{c b b L}$-Aktivitäten selbst in HB14 und HB15 gefunden. Sie waren jedoch insbesondere bei M1 und M6 niedriger als bei den jeweiligen Elternstämmen H16 und HF210. Interessanterweise war nach wie vor das typische $c b b$ Regulationsmuster erkennbar. M1 und M6 zeigten unter mixotrophen Bedingungen (Formiat + Fructose) signifikant höhere Aktivitäten als nach rein heterotropher Anzucht mit Fructose oder Pyruvat ( Tab. 9]. Auch diese Befunde waren ein erneuter Hinweis darauf, daß neben CbbR noch mindestens ein weiterer Regulator an der Kontrolle des $c b b$-Systems beteiligt sein muß, da auch in Abwesenheit von CbbR eine, wenn auch schwache, Restaktivierung der mutierten $p_{c b b L}$ erhalten blieb. 
Tab. 9. Aktivitäten der mutierten $c b b$-Operonpromotoren anhand transkriptioneller lacZ-Fusionen in Transkonjuganten von $R$. eutropha H16, HB14, HF210 und HB15 nach Anzucht auf verschiedenen Substraten.

\begin{tabular}{|c|c|c|c|c|}
\hline \multirow[t]{3}{*}{ Plasmid } & \multicolumn{4}{|c|}{$\begin{array}{c}\text { Spez. Aktivität der } \\
\text { B-Galaktosidase (mU/mg) }\end{array}$} \\
\hline & \multicolumn{4}{|c|}{ Fructose + Formiat } \\
\hline & H16 & HB14 & HF210 & HB15 \\
\hline pBK & 4 & 3 & 3 & 2 \\
\hline pBK2241 & 780 & 6 & 490 & 5 \\
\hline pBKM1 & 1980 & 160 & 1100 & 130 \\
\hline pВKM6 & 1570 & 170 & 1590 & 70 \\
\hline \multirow[t]{3}{*}{ pВКМ9 } & 1800 & 1150 & 1630 & 790 \\
\hline & \multicolumn{4}{|c|}{ Fructose } \\
\hline & H16 & HB14 & HF210 & HB15 \\
\hline pBK & 2 & 5 & 8 & 3 \\
\hline pBK2241 & 90 & 8 & 8 & 8 \\
\hline pBKM1 & 1240 & 115 & 92 & 94 \\
\hline рВКМ6 & 1440 & 126 & 82 & 103 \\
\hline \multirow[t]{3}{*}{ рВКМ9 } & 1600 & 880 & 890 & 760 \\
\hline & \multicolumn{4}{|c|}{ Pyruvat } \\
\hline & H16 & HB14 & HF210 & HB15 \\
\hline pBK & 3 & 3 & 3 & 4 \\
\hline pBK2241 & 6 & 4 & 6 & 2 \\
\hline pBKM1 & 90 & 60 & 60 & 40 \\
\hline pВКМ6 & 90 & 60 & 40 & 30 \\
\hline pBKM9 & 1270 & 860 & 730 & 480 \\
\hline
\end{tabular}

\subsubsection{Aktivitäten der mutierten $c b b$-Operonpromotoren in $E$. coli}

Da die mutierten $p_{c b b L^{-}}$Operonpromotoren auf der Consensussequenz des $\sigma^{70}$-Promotors von

E. coli basierten, wurden die Aktivitätsmessungen mit diesen Promotoren zum Vergleich auch 
in E. coli JW1 durchgeführt. Dabei zeigte der Wildtyppromotor und M13 keine die angeglichenen Promotoren M1, M6 und M9 jedoch relativ hohe Aktivitäten Tab. 10). Erwartungsgemäß war die Aktivität bei der Vollconsensusmutante M9 am höchsten. Sie lag auf einem ähnlichem Niveau, wie die Aktivitäten beim Wildtyppromotor in R. eutropha unter autotrophen Bedingungen. Als besonders kritischer Parameter erwies sich die Mutation der stark konservierten ersten Base in der '-35'-Region von $p_{c b b L}$ M10, die zu einem deutlichen Aktivitätsverlust im Vergleich zu M9, aus der sich M10 ableitete, führte.

Tab. 10. Aktivitäten der mutierten $c b b$-Operonpromotoren in Transformanten von $E$. coli JW1 nach Anzucht auf LB-Medium.

\begin{tabular}{lc}
\hline Plasmid & $\begin{array}{c}\text { Spez. Aktivität der } \\
\text { B-Galaktosidase (mU/mg) }\end{array}$ \\
\hline pBK & 1 \\
pBK2241 & 1 \\
pBKM1 & 590 \\
pBKM2 & 20 \\
pBKM6 & 512 \\
pBKM9 & 925 \\
pBKM10 & 30 \\
pBKM13 & 1 \\
\hline
\end{tabular}

Der $c b b$-Operonpromotor wurde aufgrund dieser Befunde als typischer $\sigma^{70}$-abhängiger Promotor bestätigt, wobei die Hierarchie bevorzugter Basenkombinationen innerhalb der Promotorsequenz bei $R$. eutropha und E. coli ähnlich zu sein scheint.

\subsubsection{Aktivitäten der $c b b$-Promotoren in Subfragmenten der $c b b$-Kontrollregion}

\subsubsection{1 $c b b$-Operonpromotor}

Durch schrittweise Deletion des stromaufwärts der CbbR-Bindungsregion liegenden Abschnittes der $c b b$-Kontrollregion sollte die Bedeutung dieses Bereiches, der unter anderem die Bindungsregion des potentiellen Regulators P1 umfasst, für die Aktivität des $c b b$ Operonpromotors in R. eutropha untersucht werden. Dazu wurden entsprechende Subfrag- 
mente der $c b b$-Kontrollregion amplifiziert und wiederum in den Transkriptionsfusionsvektor pBK kloniert.

Im Wildtypstamm H16 zeigte $p_{c b b L}$ bei weitgehend vollständiger $c b b$-Kontrollregion (pBK1671, pBK1451) unter allen getesteten Wachstumsbedingungen ähnlich hohe Aktivitäten wie im Fall von pBK2241 (Tab. 10). Dagegen fielen die Aktivitäten in den Transkonjuganten mit pBK1201 oder pBK1141, die eine teilweise bzw. vollständig deletierte P1Bindungsregion aufwiesen, sehr deutlich ab. Der Aktivitätsverlust betrug bei pBK1201 50-70 $\%$, bei den pBK1141 sogar bis zu $90 \%$ Tab. 11. Eine zusätzliche Deletion eines Teilabschnitts der CbbR-Bindungsregion in pBK0911 führte zu einem kompletten Aktivitätsverlust $\operatorname{von} p_{c b b L}$.

Die Befunde deuteten nun auf eine erhebliche Bedeutung der P1-Bindungsregion bei der Regulation von $p_{c b b L}$ hin und zeigten erneut die essentielle Bedeutung von CbbR bei der Aktivierung von $p_{c b b L}$. Es ist davon auszugehen, daß die Bindung von P1 an den stromaufwärts der CbbR-Bindungsregion gelegenen Abschnitt im direktem Zusammenhang mit der Regulation von $p_{c b b L}$ zu sehen ist.

Tab. 11. Aktivitäten des $c b b$-Operonpromotors in Subfragmenten der $c b b$-Kontrollregion in Transkonjuganten von $R$. eutropha H16 nach Anzucht auf verschieden Substraten

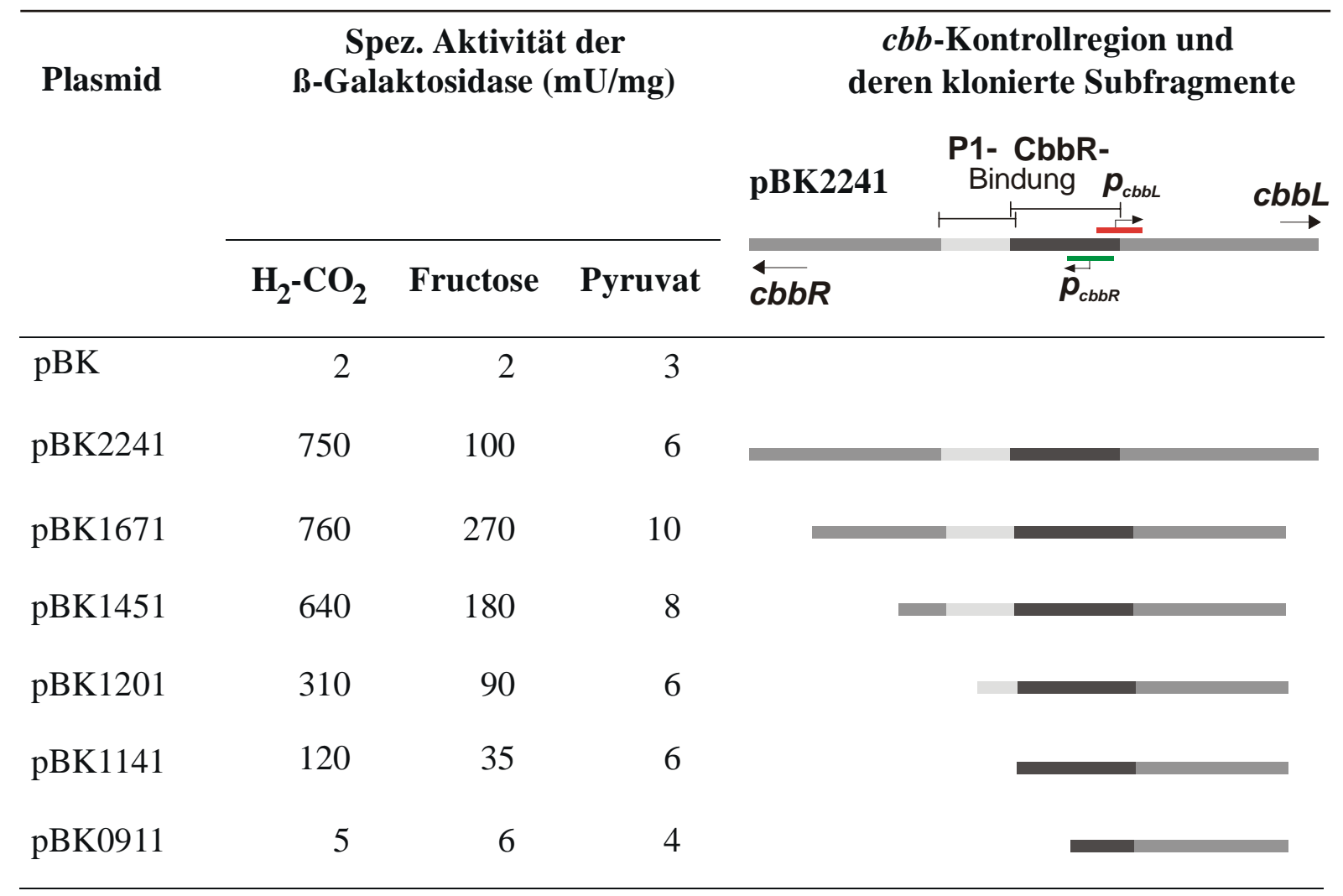




\subsubsection{2 cbbR-Promotor}

Die Aktivitäten des $c b b R$-Promotors $p_{c b b R}$, der divergent $\mathrm{zu} \quad p_{c b b L}$ orientiert ist, wurden ebenfalls anhand verschiedener, in $\mathrm{pBK}$ klonierter Subfragmente der $c b b$-Kontrollregion gemessen. Frühere Untersuchungen mit zwei verschieden Subfragmenten der Region hatten Hinweise auf eine negative Autoregulation von $c b b R$ ergeben. Dabei waren bei einem Fragment, bei dem der $c b b R$-seitige, stromabwärts von $p_{c b b R}$ gelegene Abschnitt der CbbRBindungsregion deletiert worden war, signifikant erhöhte Aktivitäten von $p_{c b b R}$ mit gusATranskriptionsfusionen in pBK gemessen worden (Kusian \& Bowien, 1995). Zur Überprüfung dieser Befunde anhand von $p_{c b b R^{-}}$lacZ-Fusionen wurden nun Subfragmente in $\mathrm{pBK}$ kloniert, bei denen Sequenzabschnitte sowohl stromabwärts als auch stromaufwärts von $p_{c b b R}$ deletiert worden waren. Die Aktivitätsmessungen von $p_{c b b R}$ wurden nicht nur im Wildtyp $R$. eutropha H16 sondern auch in der cbbR-Deletionsmutante HB14 sowie der phcA/cbbRDoppeldeletionsmutante HB17 durchgeführt. Die Mutanten HB14 und HB17 ermöglichten aufgrund ihres CbbR-freien Hintergrundes eine weitergehende Aussage zur negativen Autoregulation von $p_{c b b R}$ durch CbbR, im Falle von HB17 außerdem einen Hinweis auf die potentielle Bedeutung von PhcA für die Regulation des Promotors.

Unabhängig von der Anzucht auf verschiedenen Substraten waren zwischen den entsprechenden Transkonjuganten von H16 und HB14 generell keine signifikanten Unterschiede zu erkennen Tab. 12. Eine negative Autoregulation des Promotors scheint also nicht vorzuliegen. Denn sonst wäre in HB14 eine deutliche Aktivierung von $p_{c b b R}$ zu erwarten gewesen. In HB14 (pBK2240) lagen die Aktivitäten überraschenderweise sogar um das 2-6 fache niedriger als in H16 (pBK2240). Tendenziell bewirkten $c b b L$ - und $c b b R$-seitige Verkürzungen der Fragmente eine Abnahme der $p_{c b b R}$-Aktivität. Die höchsten Aktivitäten wurden jeweils bei den Transkonjuganten gemessen, in denen sowohl die CbbR- und auch die P1Bindungsregion vollständig vorlag. 
Tab. 12. Aktivitäten von $p_{c b b R}$ nach Klonierung von Subfragmenten der $c b b$-Kontrollregion in pBK bei transkonjuganten Stämmen von H16 und HB14 nach Anzucht auf verschieden Substraten.

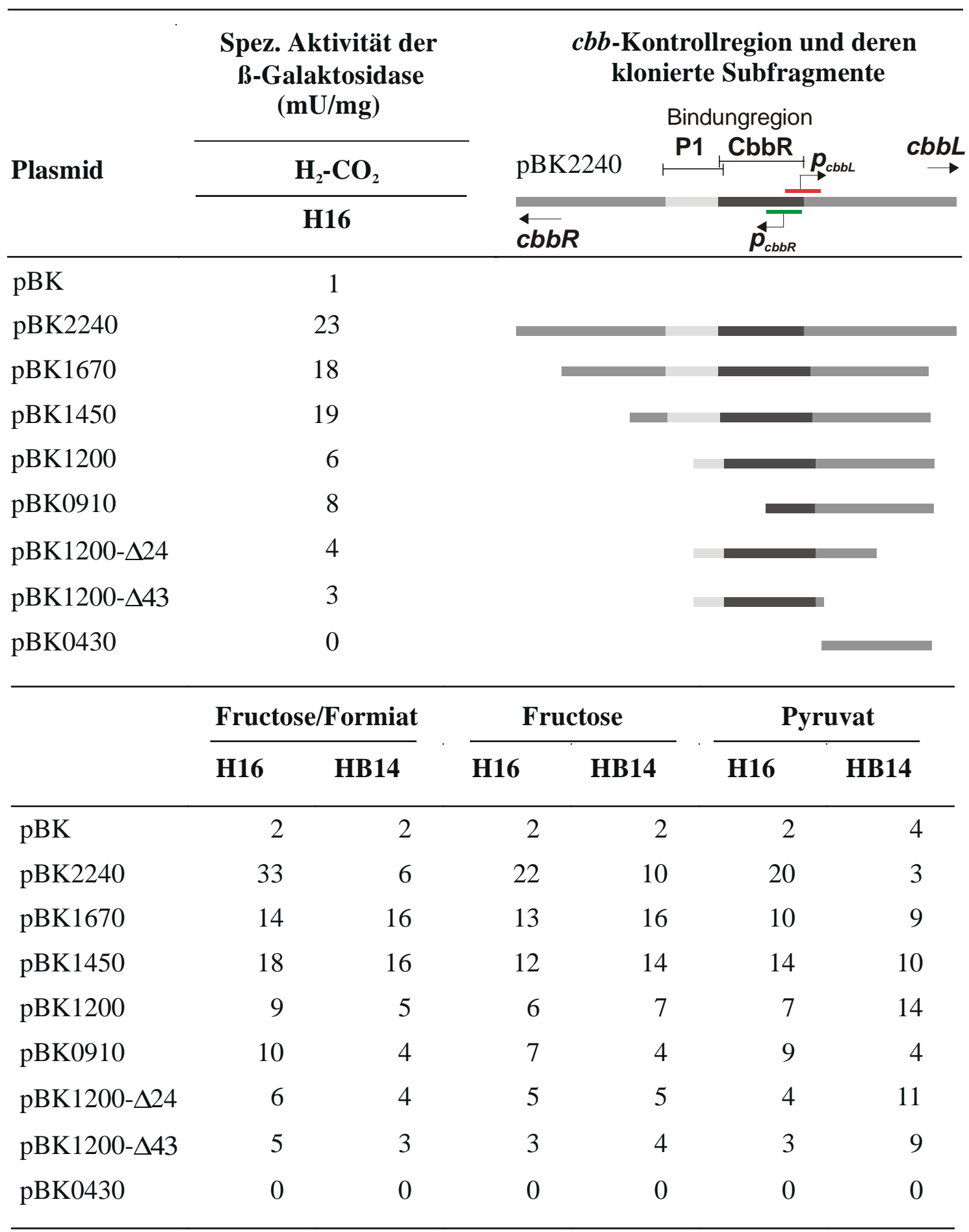

Auch die vergleichenden Messungen mit Transkonjuganten von HB17 ergaben keine auffälligen Abweichungen in den $p_{c b b R}$-Aktivitäten Tab. 13), so daß PhcA keine Bedeutung bei der Regulation von $p_{c b b R}$ zukommt. 
Tab. 13. Aktivitäten des cbbR-Promotors in Subfragmenten der $c b b$-Kontrollregion in Transkonjuganten von $R$. eutropha H16, HB14 und HB17 nach Anzucht auf verschieden Substraten.

\begin{tabular}{|c|c|c|c|c|}
\hline \multirow[t]{2}{*}{ Substrat } & \multirow[t]{2}{*}{ Plasmid } & \multicolumn{3}{|c|}{$\begin{array}{c}\text { Spez. Aktivität der } \\
\text { B-Galaktosidase } \\
\text { (mU/mg): }\end{array}$} \\
\hline & & H16 & H14 & HB17 \\
\hline Fructose + & $\mathrm{pBK}$ & 1 & 1 & 2 \\
\hline \multirow[t]{2}{*}{ Formiat } & pBK2150 & 13 & 14 & 11 \\
\hline & pBK0910 & 6 & 4 & 6 \\
\hline \multirow[t]{3}{*}{ Fructose } & $\mathrm{pBK}$ & 1 & 2 & 1 \\
\hline & pBK2150 & 9 & 10 & 9 \\
\hline & pBK0910 & 6 & 4 & 4 \\
\hline \multirow[t]{3}{*}{ Pyruvat } & $\mathrm{pBK}$ & 1 & 1 & 1 \\
\hline & pBK2150 & 9 & 8 & 5 \\
\hline & pBK0910 & 5 & 4 & 4 \\
\hline
\end{tabular}




\section{DISKUSSION}

\subsection{Regulation von $c b b$-Operonen durch CbbR}

Untersuchungen der letzten Jahre haben gezeigt, daß die Organisation von Genen des CalvinCyclus in gemeinsamen $c b b$-Operonen sowohl in fakultativ als auch bei obligat autotrophen Bakterien relativ weit verbreitet ist, wobei die Komplexität dieser Operone in den entsprechenden Organismen deutlich differiert. Sie betrafen bisher nahezu ausnahmslos Vertreter aus der Klasse der Proteobakterien, wobei besonders umfangreiche $c b b$-Operone in Xanthobacter flavus, Rhodobacter capsulatus, Rhodobacter sphaeroides, Rhodospirillum rubrum und in $R$. eutropha $\mathrm{H} 16$ gefunden wurden. Einfacher strukturierte $c b b$-Operone, die lediglich die Strukturgene der RubisCO ( $c b b L S$ oder $c b b M$ ) z.T. zusammen mit $c b b Q$, einem Gen noch unbekannter Funktion, beinhalten, kommen z.B. bei Thiobacillus ferrooxidans, Thiobacillus denitrificans und Allochromatium vinosum vor (Kusian \& Bowien, 1997; Shively et al., 1998).

Allen bisher näher untersuchten $c b b$-Operonen hingegen gemeinsam ist die Regulation durch den Transkriptionsaktivator CbbR, dessen Strukturgen meist direkt stromaufwärts in divergenter Orientierung $\mathrm{zu}$ den von ihm regulierten $c b b$-Operonen lokalisiert ist. Mit Ausnahmen von $T$. denitrificans und $R$. capsulatus verfügen die übrigen bereits genannten Organismen lediglich über ein einziges funktionelles cbbR-Gen. In T. denitrificans und $R$. capsulatus liegen zwei funktionelle, aber nicht äquivalente $c b b R$ vor, die typischerweise vor den von ihnen regulierten $c b b$-Operonen lokalisiert sind (Shively et al., 1998; Paoli et al., 1998). Die beiden $c b b$-Operone von $R$. capsulatus unterliegen einer komplexen Regulation durch $\mathrm{CbbR}_{\mathrm{I}}$ und $\mathrm{CbbR}_{\mathrm{II}}$, die in Abhängigkeit von den Wachstumsbedingungen auf unterschiedlichem Niveau an der Aktivierung der $c b b$-Operone beteiligt sind (Vichivanives et al., 2000).

Die $c b b$-Kontrollregion ist in den meisten bisher darauf untersuchten Organismen zwischen $c b b R$ und dem jeweils benachbarten $c b b$-Operon lokalisiert. Eine spezifische Bindung von CbbR innerhalb dieser Region wurde bereits mehrfach gezeigt (R. eutropha: Windhövel \& Bowien, 1991; X. flavus: van Keulen et al., 1998; R. capsulatus: Vichivanives et al., 2000; R. sphaeroides: Dubbs et al., 2000; T. ferrooxidans: Kusano \& Sugawara, 1993).

Bei $R$. eutropha H16 erfolgte durch DNA-'footprinting'-Experimente die genaue Lokalisierung der CbbR-Bindungsregion (Operator). Es wurde ein Bereich mit einer Länge 
von etwa $52 \mathrm{bp}$ identifiziert, der sich zwischen den Positionen -24 bis -75 relativ zum Transkriptionsstartpunkt des $c b b$-Operons erstreckt. Die CbbR-Bindungsregion überlappt mit der '-35'-Region des $c b b$-Operonpromotors $p_{c b b L}$ und praktisch dem gesamten $c b b R$-Promotor $p_{c b b R}$, der divergent $\mathrm{zu} p_{c b b L}$ orientiert ist. Innerhalb der CbbR-Bindungsregion liegen zwei voneinander getrennte CbbR-Bindungsstellen vor, die aufgrund ihrer relativen Position und vermutlichen Funktion als R-( $c b b R$-seitig) bzw. A-Region ( $c b b L$-seitig) definiert sind. Innerhalb dieser beiden Regionen wurde jeweils ein partielles Palindrom mit dem für LTTR typischen T-N ${ }_{11}$-A-Bindemotiv gefunden (Harrison, 1991; Kusian \& Bowien, 1995).

Charakteristisch für die durch LTTR vermittelte Transkriptionsaktivierung ist die Bindung eines Coaktivators oder Induktors. Diese Effektoren stammen meist aus dem unmittelbaren metabolischen Umfeld der regulierten Gene (Schell, 1993). Eine solcher vermutlicher Coaktivator für CbbR wurde bisher nur bei X. flavus in Form von NADPH gefunden. Durch Bindung von NADPH an CbbR verändert sich das DNA-Bindungsverhalten des Regulators signifikant (van Keulen et al., 1998). Hohe NADPH-Konzentrationen scheinen in X. flavus eine mangelnde C-Quellenversorgung zu signalisieren, woraufhin die Transkriptionsaktivierung der $c b b$-Gene eingeleitet wird. Weitgehend ungeklärt war bisher die Beteiligung zusätzlicher Regulatoren oder auch Modulatoren, die in Interaktion mit $\mathrm{CbbR}$ an der Regulation der $c b b$-Operone beteiligt sein könnten. In $R$. capsulatus und $R$. sphaeroides ergaben neuere Studien den Nachweis einer Beteiligung des Response-Regulators RegA des RegB/RegA-Zweikomponenten-Regulationssystems. Innerhalb eines übergeordneten regulatorischen Netzwerks agiert RegA scheinbar modulierend in Bezug auf die durch CbbR vermittelte Aktivierung der $c b b$-Operone (Dubbs et al., 2000; Vichivanives et al., 2000).

\subsection{Identifikation eines PhcA-Homologs in R. eutropha}

Studien mit einer wieder autotroph wachsenden Revertante HB14R der autotroph negativen CbbR-Deletionsmutante HB14 hatten ergeben, daß die im Wildtyp essentielle Funktion von CbbR bei der Aktivierung der $c b b$-Operone in der Revertante durch eine spontane Mutation in einem anderem Regulator aus der Gruppe der LysR-Typ-Transkriptionsregulatoren übernommen werden kann (D. Oed und B. Bowien, pers. Mitteilung). Die Suppression in HB14R beruhte nicht etwa auf der Aktivierung eines alternativen $c b b R$, sondern wurde durch das Produkt des mutierten $p h c A^{*}$-Gens bewirkt. PhcA, das ursprünglich als globaler Regulator in $R$. solanacearum entdeckt worden war, gehört zu den LTTR (Brumbley et al., 1993). In HB14R trägt $p h c A^{*}$ im Unterschied zum Wildtypgen eine Punktmutation, die zu 
einem Aminosäureaustausch (H 37 Y) innerhalb des Helix-Turn-Helix-DNA-Bindemotivs von PhcA führte (G. Grzeszik und B. Bowien, pers. Mitteilung). Durch Deletion von phcA gelang es nun in der vorliegenden Arbeit zu zeigen, daß PhcA mit dem P2 Protein identisch ist. P2 war bereits zuvor als ein Protein aufgefallen, das an die $c b b$-Kontrollregion bindet und daher zunächst als potentieller Regulator des $c b b$-Systems galt. Die Deletion von $p h c A$ bewirkte in Bindungsstudien mit Rohextrakten der phcA-Deletionsmutanten HB16 und HB17 ein Verschwinden des P2-Protein-DNA-Komplexes, was darauf hindeutete, daß P2 und PhcA potentiell durch dasselbe Gen codiert wurden (s. 3.4.3). Bestätigt wurde dies anhand vergleichender Bindungsstudien von P2 mit dem Wildtyp PhcA als auch mit dem mutierten $\mathrm{PhcA}^{*}$, die in Kombination mit P1 durchgeführt wurden. Es zeigte sich ein absolut identisches Bindungsverhalten der P2-P1- und der PhcA-P1-Komplexe, während der PhcA*P1-Komplex ein abweichendes Laufverhalten aufwies und schwächer retardiert wurde (s. 3.5.4).

Datenbankabgleiche ergaben, daß PhcA aus $R$. eutropha $\mathrm{H} 16\left(\mathrm{PhcA}_{\mathrm{H} 16}\right)$ zu $88 \%$ mit PhcA aus $R$. eutropha $\mathrm{CH} 34$ ( $\mathrm{PhcA}_{\mathrm{CH} 34}$; Garg et al., 2000) und zu $73 \%$ zu PhcA aus $R$. solanacearum $\left(\mathrm{PhcA}_{\mathrm{sol}}\right.$; Brumbley \& Denny, 1990) identisch ist. Die großen Ähnlichkeiten zwischen den verschiedenen $p h c A$-Orthologen und die nahe phylogenetische Verwandtschaft der drei Ralstonia-Spezies (Yabuuchi et al., 1995) deuten darauf hin, daß die PhcA auf einen gemeinsamen Vorläufer zurückgehen, der im Verlauf der Evolution entsprechend der zum Teil unterschiedlichen Lebensweise der drei Spezies modifiziert wurde. Deutliche Sequenzähnlichkeiten der PhcA wurden ebenfalls zu NarR aus Pseudomonas putida und zu MexT aus Pseudomonas aeruginosa (jeweils $46 \%$ bei $24 \%$ Identität) festgestellt Abb. 1 . Mit CbbR aus R. eutropha besteht eine Sequenzähnlichkeit von $39 \%$ (bei $19 \%$ Identität). Interessanterweise war der einzige signifikante Sequenzunterschied bei den drei PhcA-

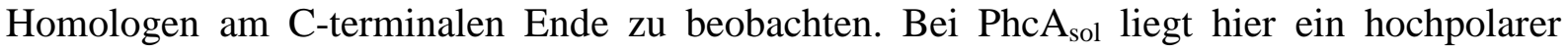
Bereich aus 25 Aminosäureresten vor, der bei $\mathrm{PhcA}_{\mathrm{H} 16}$ und $\mathrm{PhcA}_{\mathrm{CH} 34}$ fehlt. 


\author{
PhCA ReH16 \\ PhCA ReCH34 \\ PhcA Rso \\ NhaR Ppu \\ Mext Pae \\ PhcA Cons.
}

PhCA ReH16

PhCA ReCH34

PhCA Rso

NhaR Ppu

MexT Pae

PhcA.cons.

PhCA ReH16

PhCA ReCH34

PhcA Rso

NhaR Ppu

MexT Pae

PhcA.cons.

PhcA ReH16

PhCA ReCH34

PhcA Rso

NhaR Ppu

MexT Pae

PhcA. cons.

PhCA ReH16

PhCA ReCH34

PhcA Rso

NhaR Ppu

MexT Pae

PhcA. cons.

PhCA ReH16

PhCA ReCH34

PhcA Rso

NhaR Ppu

MexT Pae

PhcA.cons.

Helix-Turn-Helix

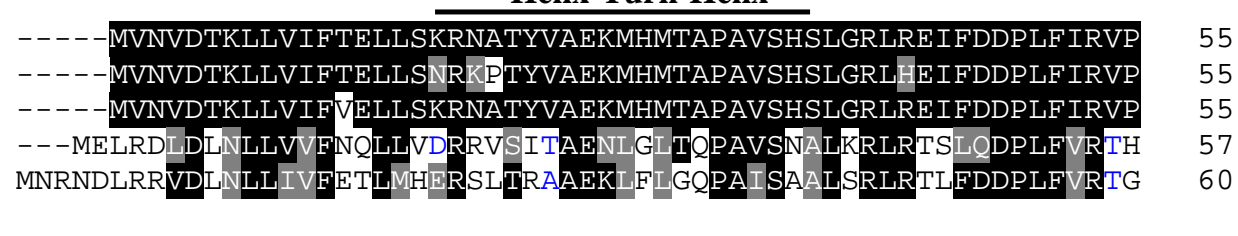

HGLTP TPRALELGPKIRDMLDLWSS INEGDADNFDPAIATGTLSIGFAAELGDTVFNRFV 114 HGLTP TPRALELGP K IRD IADLWS INEGDADNFDP A I ATGT LNIGFAAELGDTVFNRFV 114 HGLTP TPKALELGPKVREMLDLWAAINEGD IATFDPAEAAGTFNVSFAGTLGDALFDRFL 114 Q GMEPTPYAAHLAEPVTSAMHALRNALQ-HHESFDPLTSERTFTLAMTDIGEIYFMPRLM 115 RSMEPTARAAEIFAHLSPALDS ISTAMS-RÄSEFDPATSTAVERIGLSDDVEFGLLPPLI 118

HGLTP TPRALELGPKiRDMLDLWss INEGDadnFDPAiATGTFnIGFAaeLGDTvFnRFv

LRIKQLAPDLHIKLVESHSWE IDVASMRANELDLAF SPFP TRHPE IVEEMVTSLNLWVCA 174 LRIKQLARDLH IRLVESQFVEADVASMRANELDLAF SPFP TRHPE IVEEVVTSLNLWVCA 174 LRVKRLAP GLQVRLTESSSWEADVAAMRSNELDLAF SPFP TRHPE IVEEVVTSFNMWVCA 174 DVLAHQAPNCVISTVRD S-SMSLMQALQNGTVDLAVGLLPNLQTGFFQRRLLQNHYVCLC 174 RRLRAEAPGIVLVVRRAN-YLLMPNLLASGEISVGVSYTDELPANAKRKTVRRSKRKILR 176

LRiKQLAPLLhirLVES . SwEADVAAMRaNELDLAF SPFP TRHPEIVEEVVTSLNIWVCA

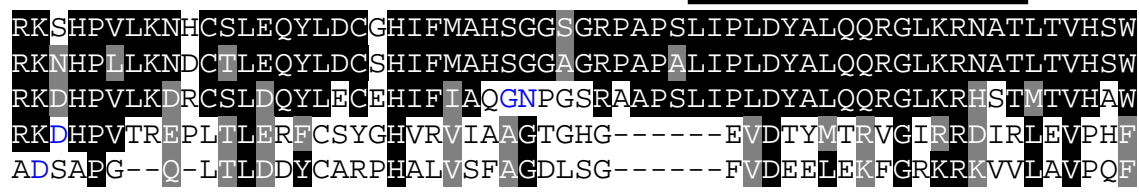

RK. HPVLKN . CsLEQYLdC . HIFmAhsgg • gRPAP s LIP LDYALQQRGLKRnaTLTVHsW

RAQAELASQTDMIFTVNALTKDMACETYGLKAFP LP SELNTMLGLNMFWHRSRNTHPMLV RAQAELASQTDMIFTVNALTKDMACETYGLKAYP LPAELNTMLGLNMFWHRSRNTHPMLV RTQAEVAAQTDLIFTVNSLMKDLVCEAYNLNAFP LP SELETVLGLNMLWHRSRNTHPMLV

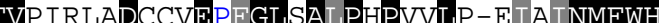
作 NGLGTLLAATDIIATVPDYAAQALIAÄGGLRAEDPPFETR-AFELSMAWRGAQDNDPAER 287

RaQAEIASQTDMIFTVNaLTKDmACEtYgLkAFPLPSELeTVLGLNMfWHRSRNTHPMLV

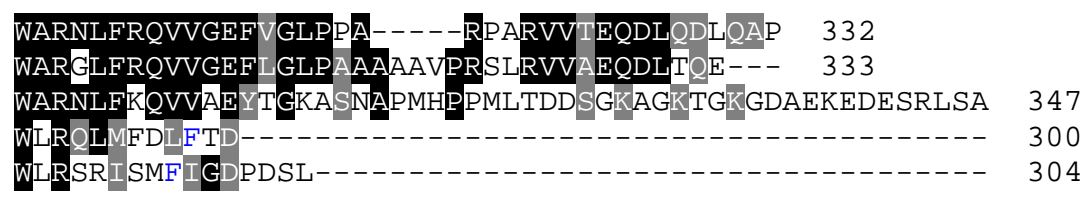

WARnLFrQVVgEF.Glp..aA...pr..rvv.eqdl

Abb. 1. Bestimmung einer PhcA-Consensussequenz durch Vergleich der PhcASequenzen von $R$. eutropha H16 und CH34 und $R$. solanacearum. In den Vergleich einbezogen wurden NahR aus $P$. putida und MexT aus $P$. aeruginosa. Schwarz unterlegte Boxen stellen identische oder stark konservierte Regionen dar. Grau unterlegt sind die schwächer konservierten Bereiche. Linien oberhalb der Sequenzen kennzeichnen besonders stark konservierte Blöcke innerhalb der fünf dargestellten Proteine. 
Die vergleichenden Studien mit $R$. eutropha H16 und HB14R ergaben eine relativ spezifische Bindung des Wildtyp und des mutierten PhcA an die $c b b$-Kontrollregion. Dabei war die beobachtete Bindungsaffinität von PhcA um ca. eine Größenordnung niedriger als die von PhcA* und letztere wiederum um ca. zwei Größenordnungen niedriger als die von CbbR (s. 3.5.1.1, 3.5.3.3). Es ist anzunehmen, daß die bereits vorhandene spezifische Bindung von PhcA die Selektion der autotroph wachsenden PhcA*-Suppressormutante (Revertantenhäufigkeit: $10^{-7}$; B. Bowien, persönliche Mitteilung) begünstigte. Das Helix-Turn-HelixDNA-Bindemotiv der PhcA-Homologen ist sehr stark konserviert und zeigt auch deutliche Ähnlichkeiten zu dem von vier weiteren LTTR Abb. 2.

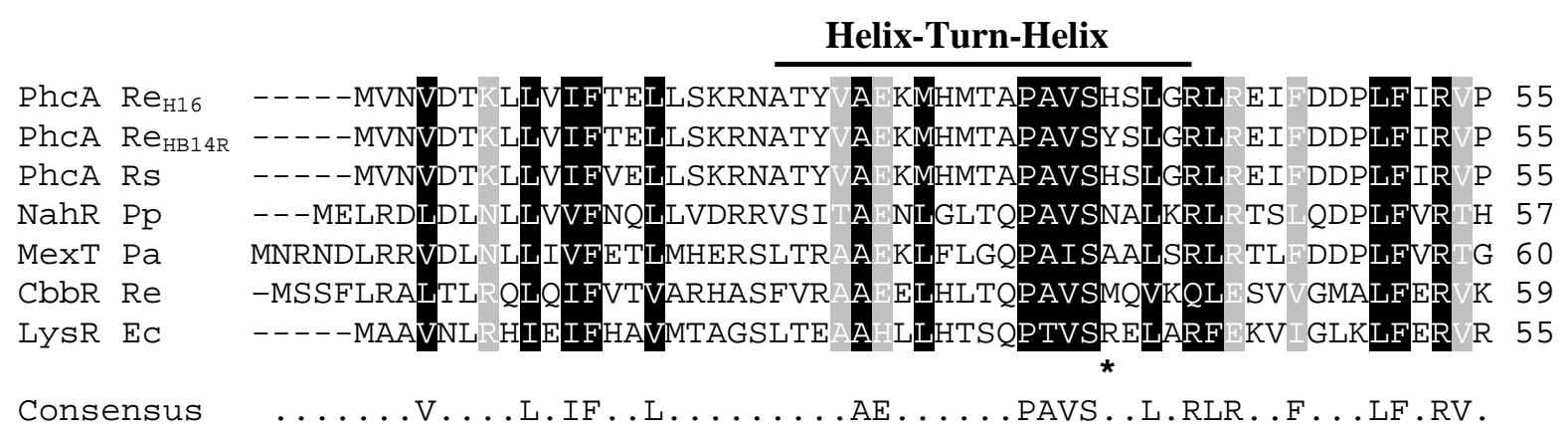

Abb. 2. Sequenzähnlichkeiten innerhalb des N-Terminus von PhcA/PhcA* aus $R$. eutropha H16 bzw. HB14R sowie aus $R$. solanacearum und von vier weiteren Vertretern aus der LTTR-Familie.

Schwarz unterlegte Boxen stellen identische oder stark konservierte Regionen/Reste dar, grau unterlegt sind schwächer konservierte Reste. Der Stern markiert die Mutation im Helix-Turn-Helix-DNA-Bindemotiv von PhcA*. Die Linie oberhalb der Sequenzen kennzeichnet den Bereich des Helix-Turn-HelixDNA-Bindemotivs von PhcA.

\subsubsection{Funktion von PhcA und PhcA* in R. eutropha H16 und HB14R}

\subsubsection{PhcA in $R$. solanacearum und $R$. eutropha}

Das $\mathrm{PhcA}$ von $R$. solanacearum $\left(\mathrm{PhcA}_{\mathrm{sol}}\right)$ mit $73 \%$ Identität $\mathrm{zu} \mathrm{PhcA}_{\mathrm{H} 16}$ stellt einen übergeordneten Regulator der LTTR-Familie dar, der in einer komplexen Regulationskaskade für die Aktivierung verschiedener, voneinander unabhängiger Gene verantwortlich ist (Brumbley et al., 1993). Dieses betrifft sowohl für die Virulenz verantwortliche Gene, die unter anderem im Zusammenhang mit der Bildung von Exopolysacchariden stehen, als auch Exoproteine kodierende Gene (Huang et al., 1995; Clough et al., 1997a). Gleichzeitig bewirkt PhcA $_{\text {sol }}$ die Repression von Genen, die im Zusammenhang mit der Zellmobilität, der Bildung von Siderophoren sowie von Polygalacturonase in $R$. solanacearum stehen (Huang et al., 1993; Clough et al., 1997b). Die transkriptionelle Regulation des $p h c A_{s o l}$-Regulons erfolgt 
entweder direkt durch $\mathrm{PhcA}_{\text {sol }}$ oder wird indirekt über von $\mathrm{PhcA}_{\text {sol }}$ kontrollierte Regulatoren wie XpsR oder PehR vermittelt (Huang et al., 1995; Allen et al., 1997). PhcA $\mathrm{A}_{\text {sol }}$ selbst unterliegt einer negativen Regulation durch PhcS/PhcR, einem typischen Zwei-KomponentenSystem (Clough et al., 1997b) und PhcB, dem für die Synthese von 3Hydroxypalmetinsäuremethlyester (3-OH PAME) verantwortlichen Enzym. In dem sogenannten Phc-System, das sich aus phcA und phcBSR zusammensetzt, fungiert das Signalmolekül 3-OH PAME als Autoinduktor, der in Abhängigkeit von der Zelldichte ab einer Konzentration von $5 \mathrm{nM}$ eine Verringerung der Repression von PhcA und somit indirekt eine Aktivierung oder Repression der PhcA-Zielgene bewirkt (Flavier et al., 1997). Das PhcSystem scheint demnach wie herkömmliche 'quorum sensing'-Systeme analog zum LuxR/LuxI-System (Fuqua et al., 1996) zu funktionieren, bei denen Acyl-Homoserinlactone als Signalmoleküle fungieren. 'Quorum sensing' ermöglicht verschiedenen Gram-negativen Bakterien eine interzelluläre Kommunikation durch die Produktion spezifischer Signalmoleküle. In Abhängigkeit von der Zelldichte und der Wachstumsphase werden über komplexe Regulationskaskaden Aktivierung und Repression einer Vielzahl verschiedener Gene reguliert (Fuqua et al., 1996; Salmond, et al., 1995; Swift et al., 1996).

Neueste Untersuchungen haben gezeigt, daß ein Phc-System, welches bisher nur in verschiedenen Stämmen von $R$. solanacearum nachgewiesen wurde, in ähnlicher Form auch in $R$. eutropha $\mathrm{CH} 34$ vorkommt, einem phylogenetisch zu $R$. eutropha $\mathrm{H} 16$ näher stehenden Verwandten als $R$. solanacearum. Bei der Charakterisierung von Siderophoren überproduzierenden Mutanten war in CH34 stromabwärts von fur (ferric uptake regulator) ein phcA-homologes Gen ( $\left.p h c A_{C H 34}\right)$ identifiziert worden (Garg et al., 2000). Eine entsprechende Genorganisation liegt in R. solanacearum (Garg et al., 2000) und R. eutropha H16 (C. Grzeszik und B. Bowien, pers. Mitteilung) vor. Direkte und indirekte Hinweise zeigten, daß $\mathrm{PhcA}_{\mathrm{CH} 34}$ mit hoher Wahrscheinlichkeit ebenfalls als übergeordneter Regulator in $R$. eutropha $\mathrm{CH} 34$ fungiert. Die phcA-Expression wurde wie in $R$. solanacearum durch einen 3-OHPAME ähnlichen Metaboliten reguliert, der wie in $R$. solanacearum als Autoinduktor aktiv zu sein scheint. Außerdem wurde ein $p h c B$ - und ein $p h c S$-ähnliches Gen detektiert. PhcS ist die für die Erkennung von 3-OH-PAME zuständige Sensorkinase.

Die Charakterisierung von PhcA als übergeordneter Regulator in $R$. eutropha $\mathrm{CH} 34$ erfolgte im wesentlichen durch indirekte Untersuchungen, die im Rahmen von Komplementationsstudien mit einer phcA-Nullmutante von $R$. solanacearum durchgeführt wurden. Dabei konnte $\mathrm{PhcA}_{\mathrm{CH} 34}$ prinzipiell die Funktion von $\mathrm{PhcA}_{\text {sol }}$ übernehmen. In $\mathrm{CH} 34$ wurden anhand 
einer $p h c A_{C H 34}$-Deletionsmutante deutliche Unterschiede in der Wirkungsweise von $\mathrm{PhcA}_{\mathrm{CH} 34}$ im Vergleich zu $\mathrm{PhcA}_{\text {sol }}$ in $R$. solanacearum gezeigt. Im Gegensatz $\mathrm{zu} R$. solanacearum bewirkte die Inaktivierung von phcA in CH34 keine Erhöhung sondern eine Abnahme der Zellmobilität. Unterschiede waren auch in der Siderophorenproduktion festzustellen, die bei der phcA-Mutante von $R$. solanacearum gegenüber dem Wildtyp etwa 10-fach verstärkt war, während sie in CH34 unbeeinflußt blieb. Ein weiterer Autoinduktor von $R$. solanacearum, ein Acyl-Homoserinlacton-Derivat, dessen Produktion durch PhcA aktiviert wird, wurde in $R$. eutropha CH34 nicht nachgewiesen (Garg et al., 2000).

Die phcA-Komplementationsstudien bestätigten die nahe phylogenetische Verwandtschaft von $R$. solanacearum und $R$. eutropha, die aus 16S-rRNA-Sequenzvergleichen, DNA-DNAHomologien und Vergleichen der Fettsäurezusammensetzung abgeleitet worden war (Yabuuchi et al., 1995). Deutliche Unterschiede zeigten sich jedoch in der Wirkungsweise des in Abhängigkeit von der Zelldichte regulierten Phc-Systems, wodurch sich wahrscheinlich die gravierenden Unterschiede in der Lebensweise und Physiologie der beiden Ralstonia-Arten manifestieren. Es wird angenommen, daß die geno- und phänotypischen Variationen innerhalb der Gattung Ralstonia vor allem auf die Existenz von Insertionssequenzen und verschiedener Megaplasmide, wie z.B. pHG1 in R. eutropha H16, zurückzuführen sind (Garg, et al., 2000). Zur Aufklärung dieser Frage müßten vergleichende Untersuchungen des PhcARegulons in verschiedenen Ralstonia-Arten durchgeführt werden.

Ähnlich wie in $R$. eutropha CH34 hatte die Deletion von phcA in R. eutropha H16 und HB14R einen deutlichen Phänotyp zur Folge. Im Verlauf der stationären Wachstumsphase war eine starke Aggregation ('clumping') der Zellen bei den phcA-Deletionsstämmen HB16 (H16 $\Delta p h c A)$ und HB17 (HB14R $\Delta p h c A)$ zu beobachten. Dies legte die Vermutung nahe, daß in $\mathrm{H} 16$ wie in $\mathrm{CH} 34$ und $R$. solanacearum ein von der Zelldichte abhängiges, dem PhcSystem entsprechendes Regulationsnetzwerk existiert.

Für $R$. solanacearum wurde neben den bereits erwähnten Effekten gezeigt, daß PhcA bei der Expression von Virulenzgenen in die Regulation der Exopolysaccharidproduktion (EPS I) involviert ist (Huang et al., 1998). Auch dies könnte ein potentieller Faktor bei der Bildung von Zellaggregaten durch HB16 und HB17 sein, obwohl es bisher keine Hinweise auf eine Produktion von EPS bei $R$. eutropha $\mathrm{H} 16$ gibt. Ein verändertes Mobilitätsverhalten, wie in $R$. eutropha $\mathrm{CH} 34 \Delta p h c A$ beobachtet, könnte ebenfalls bei dem Aggregationsprozeß eine Rolle spielen. Ein potentiell analoger Prozeß zur Aggregation in R. eutropha H16 wurde bei dem 
fakultativ phototrophen Purpurbakterium $R$. sphaeroides gefunden. In diesem Fall erfolgte durch ein über N-Acyl-Homoserinlacton reguliertes LuxR/LuxI-homologes Autoinduktionssystem eine starke Überproduktion von EPS, die auf eine Mutation im luxI-Homolog zurückzuführen war. Diese Überproduktion bewirkte die Entstehung großer Zellaggregate (Puskas et al., 1997).

In der Handhabung von HB16 und HB17 fiel zudem eine gegenüber den Elterstämmen stark eingeschränkte Lagerungsfähigkeit der Kulturen auf, wobei sich schon eine Haltung für lediglich 1-2 Wochen bei $4^{\circ} \mathrm{C}$ als ebenso problematisch erwies, wie häufigeres Auftauen der bei $-70^{\circ} \mathrm{C}$ gelagerten Stammkulturen. In beiden Fällen war eine deutlich eingeschränkte Überlebensfähigkeit festzustellen. Eine Erklärung hierfür würde die potentiell veränderte Struktur der Zellwand (s. EPS) liefern, die gegenüber äußeren Einflüssen eine verminderte Stressresistenz von HB16 und HB17 zur Folge haben könnte. Bei vielen Bakterien wird in der stationären Wachstumsphase durch unterschiedliche Autoinduktionssysteme die Struktur der Zellwand modifiziert, was unter anderem als Schutz vor Autolyse oder osmotischen Stress dient (Kolter et al., 1993; Siegele \& Kolter, 1992). Die notwendige Modifikation der Zellwand könnte in den Mutanten HB16 und HB17 durch das Fehlen von PhcA gestört sein.

In $R$. solanacearum aktiviert PhcA zusammen mit einem RpoS-Homolog die Synthese eines Acyl-Homoserinlactons, das einen wichtigen Signalmetaboliten weiterer untergeordneter Autoinduktionssysteme darstellt (Flavier et al., 1998). RpoS selbst stellt in vielen Bakterien einen übergeordneten Regulator beim Eintritt in die stationäre Wachstumsphase dar und aktiviert dabei eine Vielzahl von Genen, die eine Anpassung an sich verschlechternde Milieubedingungen und eine erhöhte Stressresistenz bewirken (Kolter et al., 1993; Loewen \& Hengge-Aronis, 1994; Hengge- Aronis, 1996). Die fehlende Interaktion von PhcA und einem potentiellen RpoS-Homolog in R. eutropha H16 könnte neben der starken Verklumpung einen weiteren wichtigen Faktor darstellen, der für die verringerte Überlebensfähigkeit der Mutanten nach Eintritt in die stationäre Wachstumsphase verantwortlich ist.

Obwohl die Expression von phcA schon innerhalb der log-Phase erfolgt, wurde bei der Deletionsmutante HB16 keine Veränderung im Wachstumsverhalten während der exponentiellen Wachstumsphase festgestellt (s. 3.4.4). Ein ähnlicher Effekt wurde bei einer hexA-Mutante von Erwinia carotovora beobachtet. Das Fehlen von HexA, das wie PhcA zu den LTTR gehört, bewirkte eine veränderte Regulation verschiedener Virulenzgene und hatte 
einen deutlichen Einfluß auf die Produktion von EPS und die Mobilität von E. carotovora. Im Gegensatz dazu hatte die Inaktivierung von hexA keinen Einfluß auf die Wachstumsrate von (Mukherjee et al., 2000). Die mit HB16 und HB17 gemachten Beobachtungen weisen auf die potentielle Funktion von PhcA als übergeordneten Regulator in R. eutropha H16 hin, der ähnlich wie PhcA in $R$. eutropha $\mathrm{CH} 34$ und $R$. solanacearum agiert. Die entscheidende Funktion von PhcA scheint in der Regulation von Genen zu liegen, die im besonderen Maße während der stationären Wachstumsphase benötig werden. Für eine übergeordnete Funktion von PhcA spricht außerdem die relativ hohe Konzentration dieses Regulators in R. eutropha H16, die im Rahmen der DNA-Bindungsstudien auffiel (s. 3.2).

\subsubsection{PhcA* ersetzt CbbR in der Mutante HB14R}

Interessanterweise schien die Mutation in $R$. eutropha HB14R keinen weiteren Einfluß auf die Regulation anderer, potentiell unter der Kontrolle von PhcA stehender Gene zu haben. Der einzige, wenn auch der entscheidende phänotypische Effekt war die Übernahme der Funktion von CbbR, wodurch die Fähigkeit zu autotrophem Wachstum bei der Revertante wiederhergestellt wurde. Daß dazu PhcA* essentiell war, zeigte der autotroph negative Phänotyp der von HB14R abgeleiteten phcA-Deletionsmutante HB17 (s. 3.4.3). Die Übernahme der Funktion eines inaktivierten LTTR durch spontane Mutation eines weiteren LTTR konnte unter anderem bei Bacillus subtilis gezeigt werden. Bei der Regulation der Glutamat-Synthase Genexpression wurde ein 'cross talk' beobachtet, bei dem die Inaktivierung des verantwortlichen Regulators GltC durch eine Mutation in GltR, einem weiteren LTTR, kompensiert werden konnte (Belitsky \& Sonenshein, 1997).

'Mobility shifts' mit CbbR und PhcA* ergaben interessante Details (s. 3.6.3-3.6.4). Zwar binden beide Proteine innerhalb derselben Operatorregion proximal zu $p_{c b b L}$, im Gegensatz zu $\operatorname{CbbR}\left(\alpha=48^{\circ}\right)$ induziert PhcA jedoch nur eine schwache Krümmung $\left(\alpha=18^{\circ}\right)$ innerhalb der Region. Kombinatorische 'shifts' mit CbbR und dem potentiell zusätzlichen $c b b$-Regulator P1 ergaben, daß beide Proteine gleichzeitig an die $c b b$-Kontrollregion binden, wobei die zusätzliche Bindung von P1 eine Abschwächung der durch CbbR allein induzierten Krümmung bewirkte. Dieser Mechanismus trägt möglicherweise entscheidend zur erfolgreichen Aktivierung des cbb-Operonpromotors bei (s.u. 4.5). Da PhcA* allein im Gegensatz zu CbbR nur eine schwache Krümmung innerhalb der Operator/Promotorregion induziert, wäre es vorstellbar, daß diese annährend derjenigen im Wildtyp entspricht, die durch P1 in Kooperation mit CbbR induziert wird. Ein solcher zu postulierender 
Regulationsmechanismus für CbbR und P1 bzw. PhcA*, bei dem durch Relaxierung der DNA innerhalb der Operator/Promotorregion die Aktivierung der Transkription eingeleitet wird, wurde unter anderem mit den LTTR CysB und OccR beobachtet (Wang et al., 1992; Hryniewicz \& Kredich, 1991).

Da das $c b b$-Regulationsmuster in der Revertante HB14R noch grundsätzlich dem im Wildtyp H16 entspricht (B. Bowien, pers. Mitteilung) kann geschlußfolgert werden, daß P1 auch in HB14R noch als Modulator, wenn auch vielleicht weniger effizient, agieren sollte.

\subsection{Struktur und Funktion der $c b b$-Promotoren}

Die innerhalb der $c b b$-Kontrollregion von $R$. eutropha H16 lokalisierten Promotoren des $c b b$ Operons, $p_{c b b L}$, und des Regulatorgens, $p_{c b b R}$, liegen in einer eng benachbarten, überlappenden 'back-to-back'-Konfiguration vor, und der Abstand der entsprechenden Transkriptionsstartpunkte beträgt 51 bp (Kusian \& Bowien, 1995). Eine überlappende Anordnung der Promotoren ist typisch für LTTR-regulierte Systeme (Schell, 1993) und hat meist eine gegenseitige Beeinflussung in der Regulation zur Folge, was u.a. auf der transkriptionell induzierten Veränderung der superspiralisierten Konformation innerhalb der jeweils divergenten Promotorregion zurückzuführen zu sein scheint (Rhee et al., 1999). Im direkten Zusammenhang mit einer solch kompakten Promotorkonfiguration steht auch die häufig bei LTTR beobachtete Autoregulation des Regulatorgens. Analysen zur differentiellen Genexpression der RubisCO-Gene $c b b L S$ von $R$. eutropha hatten gezeigt, daß das $c b b$-Operon als eine polycistronische Transkriptionseinheit ausgehend von $p_{c b b L}$ transkribiert wird, wobei innerhalb der $c b b$-Operone keine weiteren Subpromotoren detektiert wurden. Die erhöhte Expression von cbbLS war hingegen auf eine als vorzeitiger Transkriptionsterminator wirkende Haarnadelstruktur zurückzuführen, die unmittelbar stromabwärts von $c b b S$ lokalisiert ist (Schäferjohann et al., 1996).

\subsubsection{Strukturelle Analyse des $c b b$-Operonpromotors $p_{c b b L}$}

Trotz der signifikanten Ähnlichkeit von $p_{c b b L}$ zum $\sigma^{70}$-Consensuspromotor von $E$. coli erfolgte bei heterologen Expressionsstudien in E. coli nur eine geringfügige Aktivierung des Promotors. Daher wurden eingehende strukturelle und funktionelle Analysen mit mutativ veränderten $p_{c b b L}$-Promotoren (Tab. 1) sowohl im homologen Hintergrund von R. eutropha als auch heterolog in E. coli durchgeführt. Die Untersuchungen, die zum Teil bereits im Vorfeld 
dieser Arbeit begonnen worden waren, bestätigten $p_{c b b L}$ in seiner zuvor nur abgeleiteten Position und Struktur als typischen Vertreter $\sigma^{70}$-abhängiger Promotoren.

Tab. 1. Sequenzen mutierter $p_{c b b L}-$ Promotoren von $R$. eutropha

\begin{tabular}{|c|c|c|c|}
\hline & ‘-35’-Region & $\begin{array}{l}\text { DNA-Sequenz von } p_{c b b L}- \\
\text { 'spacer'-Region }\left(\mathrm{N}_{17}\right)\end{array}$ & '-10'-Region \\
\hline WT & TTTACC & -TTATGTGGGTGGGCTTA - & TATCTT \\
\hline \multicolumn{4}{|l|}{ '-10'-Mutanten } \\
\hline $\mathbf{M 1}^{\mathrm{a}}$ & TTTACC & $-\mathrm{N}_{17}-$ & TATAAT \\
\hline M2 & TTTACC & $-\mathrm{N}_{17}-$ & TATCAT \\
\hline M3 & TTTACC & $-\mathrm{N}_{17}-$ & TATATT \\
\hline M4 & TTTACC & $-\mathrm{N}_{17}-$ & сC्TCTT \\
\hline \multicolumn{4}{|l|}{ '-35'-Mutanten } \\
\hline M5 & TTGACC & $-\mathrm{N}_{17}-$ & TATCTT \\
\hline M6 & 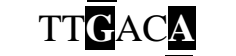 & $-\mathrm{N}_{17}-$ & TATCTT \\
\hline M7 & TTTACA & $-\mathrm{N}_{17}-$ & TATCTT \\
\hline M8 & $\underline{\text { CCTACC }}$ & $-\mathrm{N}_{17}-$ & TATCTT \\
\hline \multicolumn{4}{|l|}{ '-35/-10'-Mutanten } \\
\hline M9 & TTGACA & $-\mathrm{N}_{17}-$ & TATAAT \\
\hline M10 & CTGACA & $-\mathrm{N}_{17}-$ & TATAAT \\
\hline M11 & TTTACA & $-\mathrm{N}_{17}-$ & TA $\underline{C} C T T$ \\
\hline \multicolumn{4}{|l|}{ 'spacer'-Mutanten } \\
\hline M12 & TTTACC & -TTATGTGGG_GGGCTTA - & TATCTT \\
\hline M13 & TTTACC & 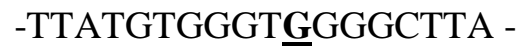 & TATCTT \\
\hline M14 & TTTACC & -TTAT息GGGTGGGCTTA - & TATCTT \\
\hline $\begin{array}{l}\sigma^{70} \text {-abhängiger Consensus- } \\
\text { promotor von } E \text {. coli }\end{array}$ & TTGACA & $-\mathrm{N}_{17}-$ & TATAAT \\
\hline
\end{tabular}

${ }^{\mathrm{a}}$ Mutationen die eine Angleichung an den $\sigma^{70}$-Consensus von E. coli darstellen, sind als Block hervorgehoben, vom Consensus abweichend eingefügte Mutation sind fett markiert und unterstrichen.

Zur Aufklärung von Struktur und Funktionsweise von $p_{c b b L}$ wurden Punktmutationen in den Promotor eingefügt, die zu einer Angleichung an den $\sigma^{70}$-Consensus von E. coli führten. Zusätzlich wurden $p_{c b b L}$-Mutanten konstruiert, deren Sequenz stärker vom E. coli-Consensus abwich. Die Sensitivität der Promotorarchitektur zeigte sich bereits bei Insertion oder Deletion einer einzige Base in der 17 bp umfassenden 'spacer'-Region, die zu einer drastischen Abnahme der Aktivitäten bei M12 und M13 führten Tab. 2. Die optimale Länge des 'spacers' erwies sich mit 17 bp als kritischer Parameter, während ein doppelter Basenaustausch in dieser Region bei M14 keine Auswirkungen auf die Aktivierbarkeit von $p_{c b b L}$ hatte.

Mutanten mit angeglichener Sequenz an den $\sigma^{70}$-Consensus zeigten grundsätzlich eine erhöhte Basalaktivität im Vergleich zum Wildtyppromotor. Bei normalerweise total 
reprimierendem Wachstum auf Pyruvat kam es bei den Teilconsensusmutanten M1 und M6 zu einer deutlichen Derepression. Die Vollconsensusmutante M9 wiese sogar eine nahezu konstitutiv hohe Aktivität von autotrophem Niveau unabhängig vom angebotenem Substrat auf, wobei aber die dennoch zu beobachtenden Abstufungen nach wie vor dem generellen $c b b$-Regulationsmuster entsprachen (Tab. 2).

Der Vergleich mit anderen chemo- und photoautotrophen Bakterien zeigte, daß das TTTACPentamer der ' -35 '-Region bei diesen Organismen offensichtlich sehr stark konserviert ist (Gibson \& Tabita, 1996; Kusian \& Bowien, 1997; Shively et al., 1998). In Anbetracht dessen erwies sich die Substitution des distalen $\mathrm{T}$ durch $\mathrm{C}$ in der '-35'-Region der Vollconsensusmutante M9 als sehr aussagekräftig, da diese Mutation bei M10 zu einem drastischen Verlust der zuvor extrem hohen Basalaktivität von M9 führte. Die durchgeführten Studien belegten, daß Promotorstrukturen, die dem E.coli $\sigma^{70}$-Consensus stärker ähneln, auch eine Optimierung der Promotorarchitektur in R. eutropha zur Folge haben. Daß die Hierarchie bevorzugter Basenkombinationen in den ' -10 ' und '-35'-Regionen in E.coli und R. eutropha sehr ähnlich ist, zeigten die Resultate mit den Teilconsensusmutanten M1 und M6 und der Vollconsensusmutante M9. Diese wiesen im Vergleich zu den übrigen Promotormutanten sowohl in R. eutropha als auch in E . coli ein stark erhöhtes Aktivitätsniveau auf (s. 3.8.23.8.3).

Tab. 2. Aktivitäten von mutierten $p_{c b b L}$-Promotoren (lacZ-Fusionen) in R. eutropha H16 nach Wachstum auf verschieden Substraten.

\begin{tabular}{lrrr}
\hline & \multicolumn{3}{c}{$\begin{array}{c}\text { Spezif. Aktivität der } \\
\text { B-Galaktosidase (mU/mg) }\end{array}$} \\
\cline { 2 - 4 } & H2-CO$_{2}$ & Fructose & Pyruvat \\
\hline Wildtyp & 750 & 100 & 6 \\
M1 & 1590 & 1100 & 90 \\
M2 & 1120 & 560 & 16 \\
M3 & 930 & 360 & 8 \\
M4 & 5 & 5 & 6 \\
M5 & 1770 & 300 & 16 \\
M6 & 1740 & 1440 & 90 \\
M7 & 1580 & 240 & 12 \\
M8 & 15 & 7 & 5 \\
M9 & 2000 & 1610 & 1270 \\
M10 & 1300 & 320 & 24 \\
M11 & 1580 & 120 & 6 \\
M12 & 40 & 9 & 6 \\
M13 & 320 & 70 & 6 \\
M14 & 1140 & 100 & 6 \\
\hline
\end{tabular}


Analysen von $p_{c b b L}$ in einem CbbR-freien Hintergrund ergaben weitere Aufschlüsse über die potentielle Interaktion verschiedener an der Regulation des $c b b$-Systems beteiligter Komponenten. Für diese Untersuchungen wurden die $c b b R$-Deletionsmutanten HB14 und HB15 verwendet. Der Mutante HB15 fehlte das Megaplasmid pHG1, wodurch eine Einschätzung des Einflusses des Plasmids auf die Expression der $c b b$-Operone möglich war.

Der Vergleich der $p_{c b b L}$-Aktivitäten in den verschiedenen Transkonjuganten von HB14 und HB15 mit denen der Elterstämme H16 und HF210 zeigte erneut, daß CbbR absolut essentiell für die Aktivierung des Wildtyppromotors $p_{c b b L}$ ist. Durch Angleichung von $p_{c b b L}$ an den $\sigma^{70}$ Consensus erfolgte hingegen bei den Teil- und Vollconsensusmutanten M1 und M6 bzw. M9 auch in einem CbbR-freien Hintergrund eine Teilaktivierung von $p_{c b b L}$ unter normalerweise streng reprimierenden Wachstumsbedingungen (s. 3.8.2). Die Aktivierung war jedoch vor allem bei M1 und M6 auf einem deutlich niedrigeren Basalniveau als in den Elterstämmen.

Interessanterweise blieb jedoch das prinzipielle Regulationsmuster auch in Abwesenheit von CbbR erhalten. Es wurde eine 1.3- bis 3.2-fach erhöhte Induktion des $c b b$-Operons unter mixotrophen Wachstumsbedingungen für $p_{c b b L}$ M1, M6 und M9 beobachtet. Auffällig war, daß die Transkonjuganten von HB14 ein nahezu doppelt so hohes Aktivitätsniveau wie die von HB15 besaßen. Diese Differenz spiegelt möglicherweise einen stimulierenden Einfluß des Megaplasmids auf die Aktivierung von $p_{c b b L}$ wieder.

Abschließend ist festzuhalten, daß die 'Optimierung' der Promotorstruktur von $p_{c b b L}$ zu einer verringerten Abhängigkeit bei der Aktivierung von $p_{c b b L}$ von CbbR führte. Erwähnenswert ist vor allem die Vollconsensusmutante M9, die auch in einem CbbR-freien Hintergrund ein nahezu konstitutives Aktivitätsniveau unter allen Wachstumsbedingungen zeigte, wobei Aktivitäten erreicht wurden, die denen des Wildtyppromotors unter autotrophen Bedingungen entsprachen. Das auch im CbbR-freien Hintergrund der 'verbesserten' Mutanten von $p_{c b b L}$ erhalten gebliebene $c b b$-Regulationsmuster wies deutlich auf die Existenz eines weiteren regulatorischen Elements hin, was durch die Identifikation und Charakterisierung von P1 ansatzweise bestätigt wurde (s. 4.5).

\subsubsection{Aktivität des $c b b R$-Promotors $p_{c b b R}$}

Die überlappende Promotoranordnung in vielen durch LTTR-regulierten Systemen erlaubt eine gleichzeitige bidirektionale Regulation der Transkription. Viele LTTR reprimieren die Transkription ihres Strukturgens um den Faktor 3 bis 10, verursachen also eine negative 
Autoregulation (Schell, 1993). Ausnahmen bilden MauR (Delorme et al., 1997), MleR (Renault et al., 1989) und AlsR (Renna et al., 1993). Einige LTTR, wie PhcA aus R. solanacearum (Brumbley et al., 1993) und verschiedene NodD-Proteine (Schell, 1993), wirken hingegen aktivierend auf ihre eigene Transkription, wobei bis $\mathrm{zu}$ 6-fache Aktivitätssteigerungen beobachtet wurden.

Zur Charakterisierung potentieller regulatorischer Elemente von $p_{c b b R}$ wurden Untersuchungen mit Subfragmenten der $c b b$-Kontrollregion sowohl im Wildtyp als auch im CbbR-freien Hintergrund von HB14 und der $c b b R-p h c A$-Doppelmutante HB17 durchgeführt (s. 3.10.5.2). Die Ergebnisse wiesen nicht darauf hin, daß $c b b R$ einer Autoregulation unterliegt. Zuvor gemachte Beobachtungen mit dem B-Glucuronidase-Reportersystem, bei denen aufgrund einer partiellen Deletion der $c b b L$-seitigen CbbR-Bindungsregion ein deutlicher Anstieg der $p_{c b b R}$-Aktivität beobachtet worden war (Kusian \& Bowien, 1995), konnten mit dem ß-Galaktosidase-Reportersystem nicht bestätigt werden. Das ß-Glucuronidase-Reportersystem erwies sich auch bei Untersuchungen zu Beginn dieser Arbeit im Vergleich zu entsprechenden $\beta$-Galaktosidasemessungen als weniger aussagekräftig (Daten wurden nicht gezeigt) und wurde daher anschließend nicht mehr eingesetzt.

Die Ergebnisse weisen auf eine konstitutive Expression von $c b b R$ auf niedrigem Niveau hin. Die Aktivitäten von $p_{c b b R}$ waren bei Fragmenten mit kompletter P1- und CbbRBindungsregion unter allen Wachstumsbedingungen im CbbR-freien Hintergrund nahezu unverändert und mehr oder weniger identisch mit denen im Wildtyp. Aufgrund der Ergebnisse mit der Doppelmutante HB17 wurde auch ein modulierender Effekt von PhcA bei der Aktivierung von $p_{c b b R}$ nahezu ausgeschlossen. Eine unter allen Wachstumsbedingungen signifikante Verringerung der Aktivität von $p_{c b b R}$ war bei Fragmenten mit partieller und kompletter Deletion der P1-Bindungsregion im Vergleich zu den zuvor beschriebenen Fragmenten zu beobachten. Der relative Aktivitätsabfall war jeweils nahezu gleich. Da die Deletionen in unmittelbarer Nähe zum $c b b R$-Promotor erfolgt waren und der Aktivitätsabfall sowohl in H16 als auch in HB14 und HB17 zu beobachten war, scheint ein negativer Einfluß der Deletion auf die Promotorarchitektur von $p_{c b b R}$ naheliegend, was einen Aktivitätsabfall von $p_{c b b R}$ zur Folge hätte. Ein direkter Einfluß durch die nicht erfolgte Bindung von P1 bei diesen Fragmenten ist wenig wahrscheinlich, da stromabwärts eines Promotors bindende Proteine nur selten aktivierend wirken, sondern meist einen eher reprimierenden Einfluß ausüben (Perez-Martin et al., 1994). 
Zusammenfassend deuten die Ergebnisse auf eine konstitutiv niedrige Expression von $p_{c b b R}$ hin, die z.B. auch bei Paracoccus denitrificans zu beobachten ist. Für die Regulation des mau-Operons wird ähnlich wie für das $c b b$-Operon von $R$. eutropha die Existenz eines weiteren Regulators diskutiert (Delorme et al., 1997). Möglicherweise stehen die komplexeren Regulationsstrukturen im direkten Zusammenhang mit der nicht vorhandenen Autoregulation in beiden Systemen.

\subsection{Phosphoenolpyruvat als negativer Effektor von CbbR}

Die Interaktion mit Signalmetaboliten aus dem metabolischen Umfeld der regulierten Gene ist typisch für LTTR (Schell, 1993). Bei der Regulation der $c b b$-Operone kommen grundsätzlich sowohl interne als auch externe Signale als Effektoren der Transkriptionsaktivierung in Betracht (Kusian \& Bowien, 1997; Shively, et al., 1998). Die bisherigen Befunde für $R$. eutropha H16 deuten allerdings auf intrazellulär generierte Signale hin, die in Form mindestens eines Metaboliten vorliegen.

Für eingehende Studien der Regulationsmechanismen des $c b b$-Systems in R. eutropha H16 ist ein In vitro-Transkriptionssystem (IVTS) etabliert worden, mit dem potentielle Signalmetabolite und weitere regulatorische Komponenten detektiert und in ihrer Funktion näher charakterisiert werden können. Die Hauptkomponenten des IVTS bildeten die RNAPolymerase (RNAP) aus $R$. eutropha, angereichertes CbbR und die in superspiralisierter Form im Transkriptionsvektor pMP7 vorliegende $c b b$-Kontrollregion. Anstelle der homologen RNAP wurde auch heterologe RNAP aus E. coli eingesetzt (Grzeszik et al., 2000). Im Hinblick auf die Aktivierung des $c b b$-Operonpromotors $p_{c b b L}$ war die Interaktion potentieller Signalmetabolite mit CbbR von größtem Interesse. Doch wurden bisher weder im IVTS noch in 'mobility shift'-Experimenten Hinweise auf Signalmetabolite erhalten, die als Coaktivator oder Induktor von CbbR zu einer Aktivierung von $p_{c b b L}$ geführt oder eine Veränderung des Bindungsverhaltens von CbbR bewirkt hätten (Kusian, 1994; Grzeszik et al., 2000).

Diese Untersuchungen mit Metaboliten aus dem zentralen Kohlenstoff- und Energiemetabolismus führten hingegen zur Identifikation von PEP als negativem Effektor von CbbR. Dabei wurden die mutierten $p_{c b b L}$ eingesetzt, da mit dem Wildtyppromotor im IVTS keine Transkriptionsaktivierung erreicht wurde. Die spezifische Eigenschaft der verwendeten Promotormutanten bestand darin, daß diese aufgrund einer größeren Ähnlichkeit zum $\sigma^{70}$ Consensuspromotor von E. coli eine gut meßbare Basalaktivität aufwiesen (s.a.4.3.1. Da das 
prinzipielle $c b b$-Regulationsmuster bei den Mutanten jedoch bestehen geblieben war, stellten sie ideale Werkzeuge für die In vitro-Transkriptionsversuche mit PEP dar, weil sie die Detektion sowohl einer Aktivierung als auch einer Repression des Promotors erlaubten. Die Ergebnisse zeigten, daß CbbR in Gegenwart von PEP eine Repression von $p_{c b b L}$ verursacht, die in direkter Beziehung $\mathrm{zu}$ den eingesetzten PEP-Konzentrationen stand. Die PEPKonzentrationen lagen in dem physiologisch relevanten Bereich bis $2 \mathrm{mM}$ (Grzeszik et al., 2000).

\subsubsection{Einfluß von PEP auf die DNA-Bindung von CbbR}

Zur Charakterisierung der Wirkungsweise von PEP als negativem Effektor von CbbR wurden in der vorliegenden Arbeit DNA-Bindungsstudien durchgeführt. Diese zeigten, daß PEP zu einem Anstieg der Bindungsaffinität von CbbR zum Operator in der $c b b$-Kontrollregion führte (s. 3.7.1). Aus den Ergebnissen der In vitro-Transkription und der 'mobility shifts' kann vorläufig geschlußfolgert werden: CbbR ist zwar essentiell für die Aktivierung von $p_{c b b L}$, fungiert dabei aber als Sensor des intrazellulären PEP-Spiegels und bewirkt bei ansteigenden Konzentrationen des Metaboliten eine Repression der $c b b$-Operone. Ein ähnlicher Mechanismus wurde für CysB, dem Aktivator des cys-Operons in Salmonella typhimurium und E. coli, beobachtet. Die Bindung des Antiinduktors Thiosulfat führte zu einer Veränderung der Bindungseigenschaften von CysB, das auch in Abwesenheit eines Induktors an die cys-Kontrollregion bindet und bewirkt so eine Repression des cys-Operons (Hryniewicz \& Kredich, 1991). Möglicherweise analog zu PEP agiert bei der Regulation des clc-Operons in Pseudomonas putida Fumarat als Corepressor des essentiellen Aktivators ClcR, wie CbbR ein LTTR. Fumarat fungiert dabei scheinbar als C-Quellensignal und verursacht eine Repression des $c l c$-Operons durch ClcR. Ähnlich wie im Falle von PEP bewirkt die Interaktion mit Fumarat keine Dissoziation von ClcR von der $c l c$-Kontrollregion (McFall et al., 1997).

Das modifizierte Bindungsverhalten von CbbR durch PEP hat möglicherweise auch indirekten Einfluß auf die Bindung von P1, dem potentiellen zweiten Regulator des $c b b$ Systems, dessen Bindungsregion mit der von CbbR leicht überlappt (s. 4.5. Ein Ansteigen der intrazellulären PEP-Konzentration, von dem bei der Umstellung von autotrophem auf heterotrophes Wachstum auszugehen ist, könnte daher durch eine veränderte Interaktion von CbbR mit P1 zu einer Repression von $p_{c b b L}$ führen. In direkter Abhängigkeit vom PEP- 
Spiegel, der als C-Quellensignal zu verstehen wäre, würde eine mehr oder weniger starke Repression der Transkription der $c b b$-Operone durch CbbR erfolgen.

\subsubsection{PEP-abhängige Regulation von $p_{c b b L}$ in $E$. coli}

Indirekte Evidenzen, welche die Wirkungsweise von PEP als negativem Effektor von CbbR bestätigten, wurden durch heterologe In vivo-Studien in E.coli erhalten. Es ist bekannt, daß der intrazelluläre PEP-Spiegel in E. coli bei Wachstum auf Succinat (ca. $1 \mathrm{mM}$ ) um etwa eine Größenordnung höher liegt als bei Wachstum auf Glucose (ca. $0.1 \mathrm{mM}$; Lowry et al., 1971). Die $p_{c b b L}$-Aktivitäten waren nach Wachstum auf Glucose tatsächlich etwa fünfmal höher als nach Wachstum auf Succinat. Überzeugend bestätigt wurden diese Befunde bei gleichzeitiger Expression von $c b b R$ und $p h c A^{*}$ (s. 3.7.2). Unabhängig vom PEP-Spiegel führte PhcA* allein zu einer etwa 15-fach erhöhten Aktivierung von $p_{c b b L}$ im Vergleich zu CbbR nach Wachstum auf Glucose. Bei gleichzeitiger Expression von $p h c A^{*}$ und $c b b R$ und niedrigem PEP-Spiegel (Glucoseanzucht) wurde keine signifikante Veränderung des Aktivitätsniveaus im Vergleich zur alleinigen Expression von $p h c A^{*}$ beobachtet. Im Gegensatz dazu bewirkte ein hoher PEPSpiegel (Succinatanzucht) bei gleichzeitiger Expression von $p h c A^{*}$ und $c b b R$ einen $50 \%$ igen Abfall des Aktivitätsniveaus von $p_{c b b L}$ gegenüber entsprechenden Glucosenanzuchten. Die durch PEP erhöhte Bindungsaffinität von CbbR schien hier zu einer signifikanten Verdrängung von PhcA* vom Operator geführt zu haben, was sich in der Aktivitätsabnahme von $p_{c b b L}$ äußerte. Diese Ergebnisse belegten zusätzlich die postulierte Rolle von PEP als Corepressor (Antiinduktor) von CbbR.

Der intrazelluläre PEP-Spiegel scheint demnach eine wichtige Regelgröße für die Expression der $c b b$-Operone bei der wechselseitigen Umstellung zwischen autotrophem und heterotrophem Wachstum zu sein. Die Funktion von PEP im zentralen Kohlenstoffwechsel von $R$. eutropha könnte folgendermaßen beschrieben werden: PEP ist ein wichtiger Metabolit des C-Stoffwechsels und zudem indirektes Produkt des Calvin-Cyclus. Ein steigender PEPSpiegel, wie er beim Wechsel vom autotrophen zum heterotrophen Stoffwechsel anzunehmen ist, führt zu einer Repression der $c b b$-Operone. Dagegen signalisiert ein sinkender PEPSpiegel die Notwendigkeit zur Fixierung von $\mathrm{CO}_{2}$ als C-Quelle und führt somit zur Expression der Operone. Auch während des autotrophen Wachstums signalisiert PEP dem $c b b$-System die Effizienz der $\mathrm{CO}_{2}$-Assimilation, also den Status der verfügbaren C-Metabolite, und moduliert so die Expressionshöhe des Systems. Für die Aktivierung der $c b b$ - 
Operone mag jedoch ein weiterer Signalmetabolit aus dem Energiemetabolismus erforderlich sein, mit P1 als potentiellem Sensor.

\subsection{P1 als potentieller Modulator des $c b b$-Systems}

Für $R$. eutropha H16 lagen eine Anzahl von Hinweisen auf die Existenz mindestens eines weiteren Regulators/Modulators vor, der neben dem essentiellen Aktivator CbbR ebenfalls für eine effiziente Transkription der $c b b$-Operone benötigt wird: (i) Die Studien mit den $p_{c b b L^{-}}$ Promotormutanten zeigten (s. 4.3.1), daß auch im CbbR-freien Hintergrund der CbbRDeletionsmutante HB14 das generelle Regulationsmuster der $c b b$-Operone bestehen blieb, jedoch auf einem deutlich niedrigeren Aktivitätsniveau als im Wildtyp. (ii) Die fehlende Aktivierung des Wildtyp- $p_{c b b L}$ in der In vitro-Transkription durch die bisher noch kein Signalmetabolit mit der Funktion eines Coaktivators von CbbR detektiert werden konnte. Ebenso führten 'mobility shift'-Experimente in Gegenwart von Metaboliten aus dem zentralen Kohlenstoff- und Energiestoffwechsel zu keiner Veränderung des Bindungsverhaltens von CbbR, die auf eine Coaktivatorfunktion hätte schließen lassen. (iii) Außer CbbR und PhcA (P2) bindet mit P1 noch ein weiteres Protein spezifisch an die $c b b$ Kontrollregion.

\subsubsection{Zur Identität von P1}

Die N-terminale Ansequenzierung des P1 ergab eine aus 16 Aminosäureresten bestehende Sequenz. Der Vergleich mit seit kurzem öffentlich verfügbaren Rohdaten des Genoms eines Stammes von $R$. eutropha (möglicherweise CH34; s. www.jgi.doe.gov/tempweb/JGI_microbial /html/index.html) führte zur Identifikation eines potentiellen P1-Homologs in diesem Organismus. Die N-terminale Sequenz von P1 stimmte vollständig mit dem des potentiellen Produkts (Molekularmasse $12.6 \mathrm{kDa}$ ) eines $372 \mathrm{bp}$ großen offenen Leserahmens (ORF innerhalb von Contig 217) überein Abb. 3. Der G+C-Gehalt des ORF entsprach mit 65.6 mol\% weitgehend dem Gehalt des Genoms von R. eutropha H16 (66.7 mol\%). Anhand einer Codonpräferenz-Analyse war zu erkennen, daß das potentielle P1-Gen einen hohen Anteil seltener Aminosäuren aufwies und in der Häufigkeitsverteilung des G+C-Gehalts in der dritten Base der Codons nicht einheitlich war. Diese Beobachtungen trafen insbesondere auf den 3'-Bereich der P1-Nucleotidsequenz zu. Die Gründe dafür sind in noch vorhandenen Ungenauigkeiten dieser Rohdaten zu suchen. Solche Sequenzfehler haben möglicherweise 

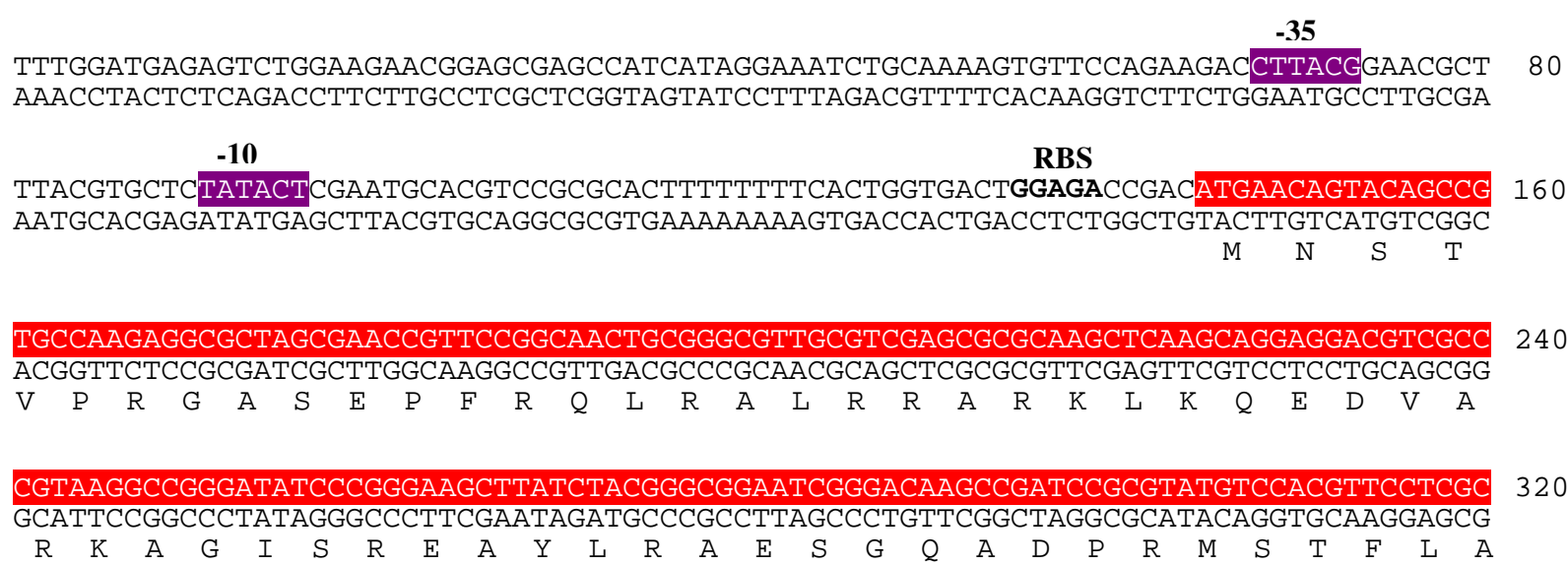
ACGGTTCTCCGCGATCGCTTGGCAAGGCCGTTGACGCCCGCAACGCAGCTCGCGCGTTCGAGTTCGTCCTCCTGCAGCGG

TCGGGCTCGACGCCCGAAGGTCACAAGCCCGTCTGAGCCCGGTAGGGCTCCGGATTTCTCGGCACGGCGAACGTTTGTTC 560 AGCCCGAGCTGCGGGCTTCCAGTGTTCGGGCAGACTCGGGCCATCCCGAGGCCTAAAGAGCCGTGCCGCTTGCAAACAAG

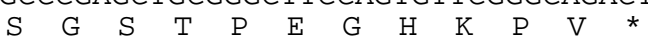

\section{Abb. 3. Nucleotid- und abgeleitete Aminosäuresequenz eines P1-Homologs eines Stammes von $R$. eutropha. \\ Die potentiellen '-35' und '-10'-Regionen des präsumptiven P1-Promotors und die Sequenz von P1 sind als Block unterlegt, die vermutliche Ribosomenbindungsstelle (RBS) ist fettmarkiert.}

auch zur Entstehung eines vorzeitigen Stoppcodons geführt, denn die durch SDS-PAGE abgeschätzte apparente Molekularmasse von P1 war mit $17 \mathrm{kDa}$ deutlich größer als die des abgeleiteten P1-Homologs. Diese deutliche Diskrepanz mag aber auch auf den hohen Anteil hydrophober Aminosäurereste im N-Terminus von P1 zurückzuführen sein, die ein relativ verlangsamtes Laufverhalten des Proteins in der SDS-PAGE zur Folge haben könnten. Die weitere Analyse des P1-Homologs stimmte allerdings mit in dieser Arbeit erhaltenen Ergebnissen insoweit überein, die P1 als ein eher basisches Protein charakterisieren.

Ein Datenbankvergleich ergab signifikante Ähnlichkeiten des P1-Homologs zu anderen potentiellen Transkriptionsregulatoren ähnlicher Größe, deren Funktion in den entsprechenden Organismen bisher jedoch nicht weiter charakterisiert worden ist Abb. 4. Diese Proteine enthalten eine ein potentielles Helix-Turn-Helix-DNA-Bindemotiv in ihrem Nterminalen Bereich. Es gehört zur Gruppe der HTH 3-Bindemotive und wurde bereits in einer Vielzahl von Proteinen aus verschiedensten Organismengruppen gefunden. 
Helix-Turn-Helix (HTH 3-Familie)

$\begin{array}{llllll}\text { Re P1 } & \text { MNS---TAVPRGASEPFR LRALRRARKL QEDVARAGISREAYLRAESGQADPRMSTF } & 57 \\ \text { Se ma } & \text { MPD-ADICFMDIKEILAE VRSYRNINNL QEQLAEISGLHRTYIGSVERKERNVTLSTL } & 59 \\ \text { Rh ru } & \text { MPESDTRTIHHVDAHVGQ VRQRRTALIL QETLARRIGVSFQQIQKYERGRNRISASRI } & 60 \\ \text { Si me } & \text { MIE-NKKKPNPIDIHVGS IRLRRTMLGM QEKLGESLGITFQQIQKYEKGTNRVGASRL } & 59\end{array}$

GSTPEGHKPV-------------- 117

Abb. 4. Sequenzvergleich der abgeleiteten Aminosäuresequenz von P1 mit potentiellen Transkriptionsregulatoren aus Serratia marcescens (Se ma; Heidmann et al., 1989), Rhodospirillum rubrum (Rh ru; Falk \& Walker, 1988) und Sinorhizobium meliloti (Si me; Tiwari et al., 1996).

Identische und stark konservierte Aminosäurereste sind als schwarzer Block, schwächer konservierte Aminosäurereste als grauer Block unterlegt. Das HTH 3Motiv ist durch eine Linie oberhalb der Sequenzen gekennzeichnet.

\subsubsection{Funktionen von $P 1$ und CbbR bei der Aktivierung von $p_{c b b L}$}

Neueste Studien mit dem phototrophen Purpurbakterium $R$. sphaeroides haben erstmals belegt, daß neben CbbR noch ein weiteres Protein an der komplexen Regulation der beiden $c b b$-Operone dieses Organismus beteiligt ist. Für eine effiziente Expression des $c b b_{I}$-Operons unter photoautotrophen Wachstumsbedingungen wird neben der Bindung von CbbR auch die Bindung des übergeordneten Response-Regulators RegA benötigt. Mehrere RegABindungsstellen wurden innerhalb der promotorproximalen Operatorregion sowie in einem distal zur Promotorregion gelegenen Sequenzabschnitt mit regulatorischer Funktion detektiert. Eine schrittweise Deletion der einzelnen RegA-Bindungsstellen bewirkte eine abgestufte Aktivitätsabnahme des $c b b_{I}$-Operonpromotors (Dubbs et al., 2000). RegA ist Teil des ZweiKomponenten-Systems RegB(Sensorkinase)-RegA, das u.a. für die Regulation verschiedener Gene des Photosyntheseapparats verantwortlich ist (Eraso \& Kaplan, 1995).

Die relativ hohe Konzentrationen von P1 in $R$. eutropha H16 deuten darauf hin, daß das Protein möglicherweise einen übergeordneten Regulator darstellt. Bemerkenswerterweise waren die Konzentrationen bei unterschiedlichen Wachstumsbedingungen nahezu identisch 
(s. 3.2.). Wegen der hohen P1-Konzentrationen in den Zellextrakten bestand die Möglichkeit einer unspezifischen Bindung an die $c b b$-Kontrollregion. Die Spezifität der P1-Bindung, die auch noch bei einem 1000-fachen Überschuß an Lachs-Spermien-DNA erfolgte, wurde letztendlich durch kompetitive DNA-Bindungsstudien gezeigt. Diese führten auch zur Identifikation der P1-Bindungsregion (s. 3.5.3.3). Sie liegt unmittelbar stromaufwärts der CbbR-Bindungsregion mit der sie um 3-4 bp überlappt. Innerhalb der postulierten P1Bindungsregion wurde eine unvollständige 'inverted repeat'-Sequenz als potentielles P1Bindungsmotiv identifiziert Abb. 5. Die Spezifität der P1-Bindung innerhalb dieser Region

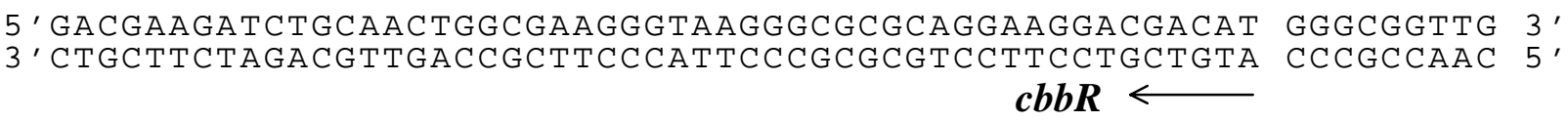
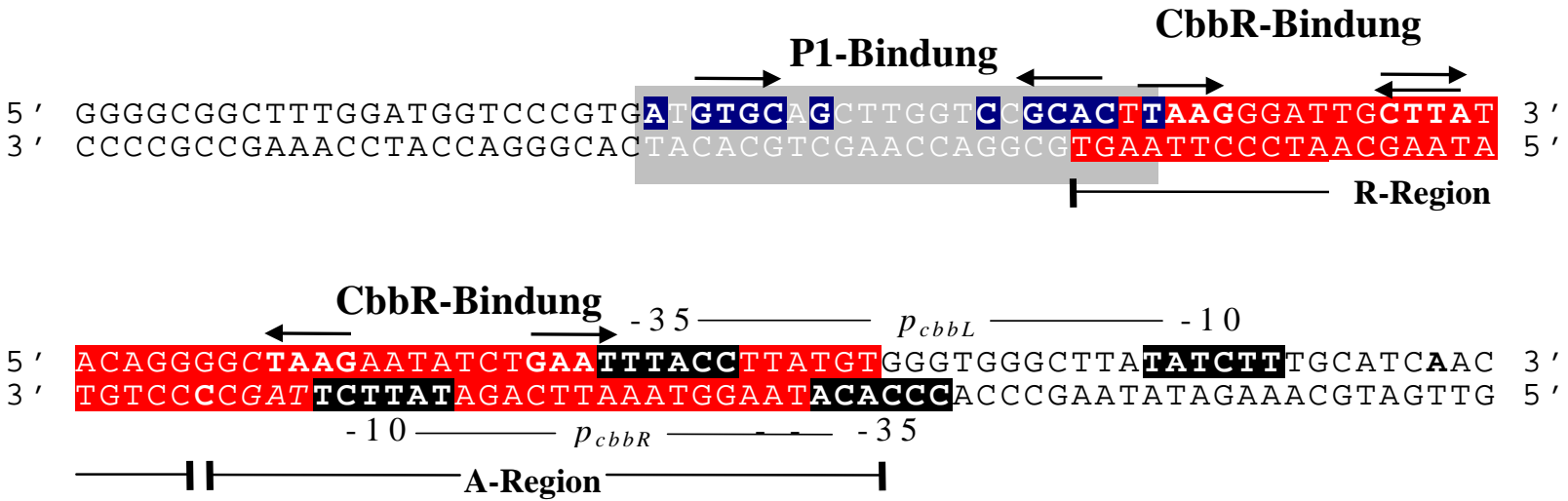

5' GCAGCAgCCAAGACGCTCAACCACGCAAgGAgACAAGC ATGAACGCACCTGATCGGTCC 3' 3' CGTCGTCGgTTCTGCAGTTGGGCGTCCTCTGTTCG TACTTGCGTGGACAgCCAGG 5 '

\section{Abb. 5. Nucleotidsequenz der zwischen $c b b R$ und $c b b L_{c}$ liegenden chromosomalen $c b b$ - Kontrollregion von R. eutropha $\mathrm{H16}$ \\ Die Pfeile oberhalb der hell unterlegten P1-Bindungsregion zeigen die Lage des potentiellen P1-Bindungsmotivs (invertierte Basen sind als dunkler Block markiert). Dunkel unterlegt ist ebenfalls die CbbR-Bindungsregion mit der R- und der A-Region. Pfeile oberhalb der CbbR-Bindungsregion zeigen die Struktur der unvollständigen Palindrome des LTTR-Bindungsmotivs von CbbR. Schwarz unterlegt sind die '-35'- und '-10'-Regionen des Operonpromotors $p_{c b b L}$ und des Regulatorgenpromotors $p_{c b b R}$.}

konnte durch gezielt eingefügte Punktmutationen innerhalb dieses Motivs bestätigt werden, die einen fast vollständigen Verlust der P1-Bindung zur Folge hatten.

Überzeugende Evidenzen für die Bedeutung von P1 bei der Aktivierung von $p_{c b b L}$ lieferten Untersuchungen mit transkriptionellen $p_{c b b L}:$ :lacZ-Fusionen (s. 3.8.4.1). Im Vergleich zur kompletten P1-Bindungsregion verursachte eine partielle Deletion der Region einen etwa 50 
$\%$ igen Aktivitätsverlust von $p_{c b b L}$, eine nahezu vollständige Deletion hatte einen Aktivitätsabfall von bis zu 90\% zur Folge. Die bei deletierter P1-Bindungsregion nach wie vor vorhandene, wenn auch stark reduzierte Aktivität von $p_{c b b L}$ belegte, daß P1 zwar nicht absolut essentiell für die Funktion von $p_{c b b L}$ ist, aber für dessen volle Aktivierung benötigt wird. Eine zusätzliche Teildeletion der R-Region der CbbR-Bindungsregion führte hingegen zur totalen Inaktivierung von $p_{c b b L}$.

Die Lokalisation der P1-Bindungsregion und die Deletionsstudien deuten auf eine wichtige Funktion von P1 als Modulator hin, der in Kooperation mit dem essentiellen Aktivator CbbR bei der Aktivierung von $p_{c b b L}$ interagiert. Diese Hypothese wird durch gleichzeitige Bindung von $\mathrm{P} 1$ und $\mathrm{CbbR}$ an die $c b b$-Kontrollregion unterstützt (s. 3.7). In DNA-Bindungsstudien war bei gleichbleibenden Konzentrationen von P1 und ansteigenden CbbR-Konzentrationen die gleichzeitige Zunahme des CbbR-DNA-Komplexes und eines stärker retardierten multimeren Komplexes zu beobachten, der mit hoher Wahrscheinlichkeit einen P1-CbbRDNA-Komplex darstellte. P1 scheint also in ähnlicher Funktion wie RegA in R. sphaeroides mit CbbR bei der Regulation der $c b b$-Operone zu interagieren.

Viele Regulatoren üben ihre aktivierende Funktion bei der Bindung an eine Zielsequenz darüber aus, daß sie innerhalb dieser Region eine Krümmung der DNA erzeugen. Die induzierte Krümmung hat meist einen direkten Einfluß auf die Promotorarchitektur und ermöglicht es der RNAP, an den modifizierten Promotor zu binden und von dort aus die Transkription einzuleiten. Neben der DNA-Krümmung spielen auch Protein-ProteinInteraktionen zwischen dem jeweiligen Regulator und der RNAP eine wichtige Rolle, die sowohl bei der Promotorerkennung als auch bei der anschließend erfolgenden Transkription durch die RNAP von entscheidender Bedeutung sein können. Die Bindung weiterer Regulatoren/Modulatoren kann ebenfalls entscheidend zur effizienten Aktivierung der Transkription beitragen. Dies wird durch zusätzliche Protein-Protein-Interaktionen, Modifikation der DNA-Konformation, verbesserte Positionierung des eigentlichen Regulators oder auch durch weitere direkte Protein-RNAP-Interaktionen, z.B. DNA-'loop'-Bildung, bewirkt (Perez-Martin et al., 1994; Perez-Martin \& de Lorenzo, 1997).

Aufgrund der leicht überlappenden Anordnung der CbbR- und P1-Bindungsregion ist davon auszugehen, daß es zu einer direkten Protein-Protein-Interaktion zwischen CbbR und P1 kommt, die durch die resultierende Veränderung der Promotorstruktur bei gleichzeitiger 
Interaktion mit der RNAP unter entsprechenden Milieubedingungen (Signalmetabolite) zu einer Aktivierung der Transkription führt. Der entscheidende Mechanismus bei der Aktivierung der Transkription ist möglicherweise in der durch CbbR und P1 induzierten Krümmung der DNA innerhalb der Operator/Promotorregion zu sehen (s. 3.6.4). Die alleinige Bindung von CbbR führt auch in Abwesenheit eines potentiellen Induktors zu einer Krümmung der DNA (Krümmungswinkel $50^{\circ}$ ). Eine zusätzliche Bindung von P1 hingegen bewirkt wahrscheinlich aufgrund einer gegenläufig induzierten Krümmung eine Abschwächung (Relaxation) der durch CbbR bewirkten Krümmung (Krümmungswinkel $30^{\circ}$ ). Die Feinregulation der $p_{c b b L}$-Aktivierung könnte daher auf einem genau abgestimmten Wechselspiel von P1 und CbbR beruhen, wobei das Ausmaß der Relaxation der DNA innerhalb der Promotor/Operatorregion den eigentlichen Aktivierungsmechanismus darstellt. Indirekt unterstützt wird diese Vorstellung durch die Studien mit dem Corepressor/Antiinduktor PEP, in dessen Gegenwart eine verstärkte Bindung von CbbR an den Operator beobachtet wurde. Eine verstärkte Bindung von CbbR könnte dem relaxierenden Effekt von P1 auf die DNA-Krümmung abschwächen. Durch die hier gemachten Befunde könnte auch die Fähigkeit von PhcA* zur Aktivierung von $p_{c b b L}$ in HB14R erklärt werden. Möglicherweise stellt die relative schwache durch $\mathrm{PhcA}^{*}$ induzierte Krümmung bereits eine annährend optimierte Promotorstruktur für eine Aktivierung von $p_{c b b L}$ dar. Da auch P1 und PhcA* gleichzeitig an die $c b b$-Kontrollregion binden, wobei es zu einer durch P1 induzierten Krümmung kommt, ist anzunehmen, daß P1 auch in der Revertante HB14R an der Aktivierung von $p_{c b b L}$ beteiligt ist.

Eine durch Relaxierung der Promotorregion eingeleitete Transkriptionsaktivierung wurde auch für die LTTR CysB und OccR gezeigt. Die Relaxation der DNA in der jeweiligen Promotor/Operatorregion wurde durch die Bindung eines Induktor an den bereits an den Operator angelagerten Regulator verursacht und führte so zu einer Aktivierung der Zielgene (Hryniewicz \& Kredich, 1991; Wang et al., 1992).

\subsubsection{Vergleich mit anderen LTTR-regulierten Systemen}

Für einzelne Genorte spezifisch fungierende Regulatoren wie CbbR liegen meist in nur sehr geringer Konzentration in der Zelle vor. Im Gegensatz dazu ist die Konzentration von $\mathrm{P} 1$ in $R$. eutropha $\mathrm{H} 16$ relativ hoch. Das Protein könnte daher wie z.B. das in die Katabolitrepression involvierte CRP (catabolite repressor protein), verschiedene Histon-ähnliche Proteine, IHF (intergration host factor), HU (heat-unstable nucleoid protein), H-NS (histone-like nucleoid 
structuring protein) oder FIS (factor for inversion stimulation) sowohl an der Stabilisierung der Chromosomenstruktur als auch genortspezifischer Regulationen beteiligt sein (PerezMartin, et al., 1994). In Bezug auf die Interaktion von LTTR und Histon-ähnlichen Proteinen bei Transkriptionsaktivierungen verschiedener Gene liegen bereits verschiedene Studien vor. So interagieren OxyR und IHF am $d p s$-Promotor von E. coli. Ähnlich wie bei P1 und CbbR überlappen die IHF- und die OxyR-Bindungsregion um 5 bp. Ebenfalls analog zu P1 und CbbR binden beide Proteine gleichzeitig innerhalb eines distinkten Sequenzbereichs, wobei davon auszugehen ist, daß die Überlappung der Bindungsregionen toleriert wird, da die Bindung von OxyR innerhalb der großen Furche der DNA-Helix erfolgt, die von IHF aber wahrscheinlich in der kleinen Furche (Altuvia et al., 1994).

Ähnlich OxyR wird in P. aeruginosa bei der Regulation von algD eine Interaktion von CysB mit IHF angenommen (Delic-Attree et al., 1997). Für R. sphaeroides liegen Hinweise vor, daß HvrA, ebenfalls ein Histon-ähnliches Protein, an der Regulation des RubisCO-Niveaus unter photoautotrophen Wachstumsbedingungen beteiligt ist (Vichivanives et al., 2000). Eine interaktive Regulation wurde auch bei NhaR und H-NS in E. coli gezeigt, der unter Salzstressbedingungen an der Regulation von $n h a A$ beteiligt ist, einem $\mathrm{Na}^{+} / \mathrm{K}^{+}$-Antiporter codierenden Gen (Dover, et al., 1996). Während H-NS meist als Repressor oder negativer Modulator fungiert, kann es scheinbar auch stabilisierendes Element in der Promotorarchitektur sein. Die Transkriptionsaktivierung ist dann abhängig von der Bindung eines Induktors an den eigentlichen Regulator der entsprechenden Gene, wobei erst durch gleichzeitige Interaktion mit H-NS eine Aktivierung des Promotors erfolgt (Ussery et al., 1994). Ein ähnliches Modell wird für die Interaktion von NhaR und H-NS am nhaA-Promotor angenommen (Dover, et al., 1996) und könnte auch für die Regulation des $c b b$ Operonpromotors von $R$. eutropha zutreffen. P1 würde dabei zunächst zusammen mit CbbR an den Operator binden, unabhängig von der Anlagerung eines Effektors an CbbR oder P1. Die Aktivierung von $p_{c b b L}$ erfolgte jedoch erst nach Bindung eines Signalmetaboliten an CbbR oder auch P1 und bewirkte so aufgrund einer Konformationsänderung innerhalb des Operator/Promotorkomplexes die Aktivierung des Promotors. Interessanterweise liegt H-NS ähnlich wie P1 in relativ hohen Konzentrationen in der Zelle vor, meist unbeeinflußt von den jeweiligen Wachstumsbedingungen und hat mit $15.4 \mathrm{kDa}$ (Atlung \& Ingmer, 1997) eine ähnliche Molekularmasse wie P1. Da H-NS bisher nur in Enterobakterien identifiziert wurde, könnte es sich bei P1 in R. eutropha um ein Analogon zu H-NS handeln. 
Im Vergleich zu IHF und H-NS findet bei der durch CRP und cAMP regulierten Katabolitrepression in E. coli eine differenziertere Genkontrolle statt. Ein für die $c b b$ Regulation entsprechendes Modell bildet die Interaktion von CRP und AraC bei der Regulation des araBAD-Operons (Lee et al., 1987; Lobell \& Schleif, 1991). Die Funktion von AraC ist in soweit mit der von CbbR vergleichbar, als AraC gleichzeitig als Aktivator und Repressor in Abhängigkeit von An- und Abwesenheit des Induktors Arabinose agiert. In Abwesenheit von Arabinose wird das Operon aufgrund einer durch AraC induzierten DNA'loop'-Bildung reprimiert. In Anwesenheit von Arabinose bewirkt die Bindung von cAMPCRP eine Auflösung des reprimierenden DNA-'loops' und initiiert in Kooperation mit dem nun aktivierenden AraC die Transkription des ara-Operons. Es erfolgt dabei eine Neupositionierung von AraC durch cAMP-CRP. Vergleichbar mit P1 bindet CRP in diesem Falle in unmittelbarer Nähe des eigentlichen Regulators. Analog hierzu wäre im $c b b$-System eine Aktivierung von P1 durch NADPH vorstellbar, wobei unter induzierenden Bedingungen bei niedrigem intrazellulären PEP-Spiegel, die aktivierende Funktion von CbbR durch NADPH-aktiviertes P1 moduliert wird. In X. flavus wurde bereits gezeigt, daß NADPH als potentielle Regelgröße aus dem Energiestoffwechsel diese Funktion scheinbar als Coaktivator von CbbR erfüllt (van Keulen et al., 1998). Für CbbR aus $R$. eutropha H16 gibt es solche Befunde nicht. Dagegen wäre es vorstellbar, daß P1 ein CRP-analoges Protein darstellt, das im Rahmen einer Katabolitrepression zusammen mit CbbR interagiert. P1 könnte in einem solchen System im Rahmen eines möglicherweise übergeordneten Regulationsnetzwerks als Sensor für den Energiehaushalt fungieren, während der Status des C-Stoffwechsels durch CbbR über den intrazellulären PEP-Spiegel erfaßt würde. Das Zusammenspiel beider Faktoren könnte für die Feinregulation der $c b b$-Operone notwendig und hinreichend sein.

\subsubsection{Modell für die $c b b$-Regulation}

Auf Grundlage der vorliegenden Ergebnisse wird folgendes hypothetisches Modell für die Regulation der cbb-Operone in R. eutropha postuliert Abb. 6:

Bei der wechselseitigen Umschaltung zwischen autotrophem und heterotrophem Wachstum stellt CbbR den zentralen Regulator bei Aktivierung und Steuerung der $c b b$-Operone dar. Unabhängig von der Anwesenheit eines Signalmetaboliten bindet CbbR an die $c b b$ Kontrollregion und fungiert als Integrator der verschiedenen regulatorischen Elemente des $c b b$-Systems. PEP kommt dabei die Rolle eines zentralen Signalmetaboliten aus dem CMetabolismus zu. Es wirkt als negativer Effektor von CbbR und verursacht bei ansteigender 
intrazellulärer Konzentration eine Repression der $c b b$-Operone durch CbbR. Bei abfallendem PEP-Spiegel, wie er beim Wechsel von Heterotrophie zu Autotrophie anzunehmen ist, tritt die Aktivatorfunktion von CbbR in den Vordergrund, die bei gleichzeitiger Bindung von P1 zur Initiation der Transkription von $p_{c b b L}$ führt. Für eine stoffwechselphysiologisch sinnvolle Aktivierung der Transkription ist neben PEP die Existenz eines Signalmetaboliten aus dem Energie- oder Baustoffwechsel naheliegend. Mit Blick auf X. flavus wäre NADPH ein plausibler Metabolit, zumal der Calvin-Cyclus der primäre Biosyntheseweg der Zelle ist. Als Sensor für diesen Metaboliten käme P1 in Betracht. Die Interaktion von P1 und CbbR am Operator scheint der wesentliche Mechanismus in der Aktivierung von $p_{c b b L} \mathrm{zu}$ sein. Zusammen induzieren sie eine DNA-Krümmung, die zu einer Konformationsänderung in der Promotorregion führt, und so die Aktivierung von $p_{c b b L}$ durch die RNA-Polymerase erlaubt. Für die exakte Positionierung von CbbR durch P1 am Operator könnte die Beteiligung eines noch nicht identifizierten Signalmetaboliten notwendig sein. 


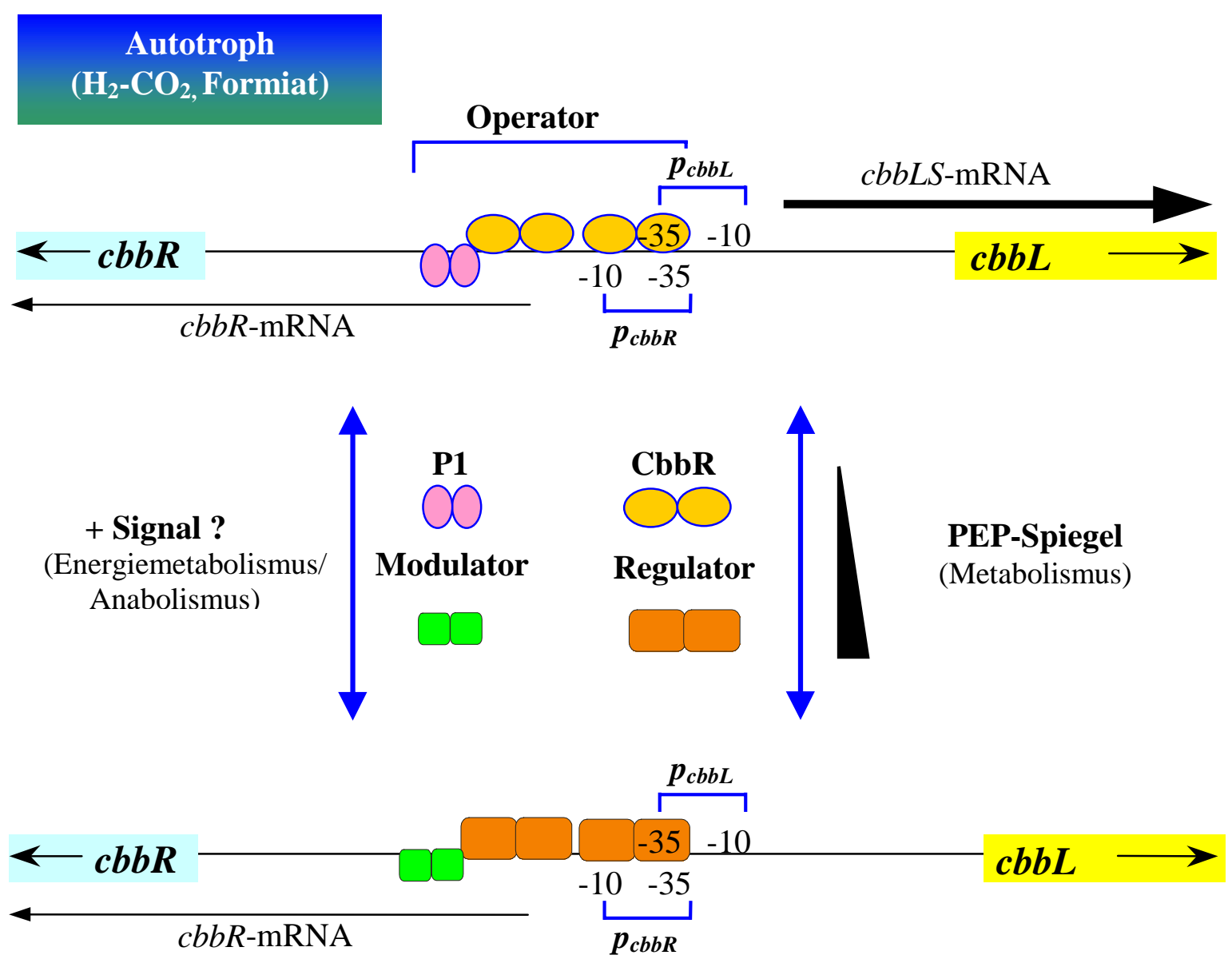

\section{Heterotroph}

(Pyruvat)

Abb. 6. Hypothetisches Modell zur Regulation der $c b b$-Operone in R. eutropha H16.

Dargestellt sind der $c b b$-Operonpromotor $p_{c b b L}$ und der Promotor des Regulatorgens $c b b R, p_{c b b R}$, mit ihren entsprechenden ' -35 '- und ' -10 '-Regionen, sowie die Aktivierungszustände des Regulators CbbR und des Modulators P1 unter autotrophen und heterotrophen Wachstumsbedingungen. Die Pfeile deuten die relativen Transkriptionsrichtungen und -stärken an.

\subsection{Ausblick}

Im Mittelpunkt zukünftiger Arbeiten sollte die weitere Aufklärung der Details bei der Kontrolle der $c b b$-Operone von $R$. eutropha stehen. Mit P1 ist nunmehr ein zusätzlicher Modulator des $c b b$-Systems bekannt, dessen exakte Funktion zu untersuchen ist. Dazu bedarf es vor allem der Klonierung und Identifizierung des P1-Gens. P1 kann im IVTS zur Identifizierung eines potentiellen weiteren Signalmetaboliten eingesetzt werden. Nicht nur im Hinblick auf die Rolle von P1 in der $c b b$-Regulation, sondern auch unter dem Aspekt einer 
Funktion dieses Proteins als potentieller übergeordneter Regulator ist die Herstellung einer Mutante anzustreben. Dabei ist vorstellbar, daß eine solche Mutation sich möglicherweise lethal auswirkt.

DNA-'footprinting'-Analysen würden weiteren Aufschluß über das individuelle und gemeinsame Bindungsverhalten von P1 und CbbR ergeben. Dabei wären die Effekte von PEP und gegebenenfalls des postulierten zusätzlichen Signalmetaboliten von besonderem Interesse. Zum Verständnis des Aktivierungsmechanismus gehört auch die genauere Untersuchung der von CbbR und P1 induzierten Krümmung innerhalb der $c b b$ Promotor/Operatorregion, die ebenfalls im direkten Zusammenhang mit der Wirkung der Signalmetabolite $\mathrm{zu}$ sehen ist. Alle diese Fragestellungen verlangen eine begleitende Mutationsanalyse des gesamten Operators.

Ein sehr interessantes neues Forschungsfeld eröffnet sich schließlich mit der Untersuchung der Funktion von PhcA als vermutlich übergeordneter Regulator in R. eutropha. Auf diesem Wege könnte ein Zugang zum Studium globaler Regulationsnetzwerke in diesem Organismus geschaffen werden. 


\section{ZUSAMMENFASSUNG}

Während des autotrophen Wachstums assimiliert Ralstonia eutropha $\mathrm{H} 16 \mathrm{CO}_{2}$ über den Calvin-Cyclus. Die genetische Kontrolle bei der wechselseitigen Umstellung des Kohlenstoffmetabolismus zwischen autotrophen und heterotrophen Bedingungen betrifft primär die Transkription der beiden hochgradig homologen $c b b$-Operone des Organismus, in denen die meisten Enzyme des Calvin-Cyclus codiert sind. Ein Operon ist auf einem der beiden Chromosome, das andere auf dem Megaplasmid pHG1 des Organismus lokalisiert. Die Expression beider Operone wird als Regulon primär über das transkriptionsaktivierende Regulatorprotein CbbR kontrolliert. Dessen Gen, cbbR, liegt 167 bp stromaufwärts und in divergenter Orientierung zum chromosomalen $c b b$-Operon, während eine plasmidcodierte Kopie des Gens, $c b b R$ ', defekt ist. Promotor- und Operatorsequenzen des $c b b$-Systems sind in überlappender Weise in der intergenen Kontrollregion zwischen $c b b R / c b b R$ ' und dem jeweils ersten Strukturgen, $c b b L$, des Operons lokalisiert. In dieser Region wurden ein Promotor $\left(p_{c b b L}\right)$ für das $c b b$-Operon und ein Regulatorgenpromotor $\left(p_{c b b R}\right)$ gefunden.

Aktivitätsmessungen mit mutierten $p_{c b b L}$ im CbbR-freien Hintergrund der $c b b R$ Deletionsmutante HB14 zeigten, daß das generelle Regulationsmuster des $c b b$-Systems auch in Abwesenheit von CbbR prinzipiell, wenn auch auf sehr niedrigem Niveau, erhalten blieb. Im Zusammenhang mit DNA-Bindungsstudien und In vitro-Transkriptionsstudien deutete dies auf die Existenz mindestens eines weiteren in der $c b b$-Regulation involvierten Regulators hin.

Im Rahmen von DNA-Bindungsstudien mit der $c b b$-Kontrollregion wurden zwei Proteine, P1 und P2, detektiert, die wie CbbR ebenfalls spezifisch an die $c b b$-Kontrollregion binden. P2 wurde in der Folge als ein Ortholog von PhcA aus Ralstonia solanacearum identifiziert, das in diesem Organismus als übergeordneter Regulator fungiert. Durch eine Spontanmutation in $p h c A$ war zuvor in einer autotroph negativen $c b b R$-Deletionsmutante die Fähigkeit zum autotrophen Wachstum wiederhergestellt worden. Das mutierte PhcA* ersetzte in der Revertante HB14R die Aktivatorfunktion von CbbR. Im Wildtyp besitzt PhcA hingegen keine Funktion bei der Regulation der $c b b$-Operone, wie eine $p h c A$-Deletionsmutante zeigte. PhcA scheint jedoch für $R$. eutropha eine wichtige Rolle für die Überlebensfähigkeit unter Stressbedingungen zu spielen. 
P1 wurde bis zur apparenten Homogenität angereichert und seine Bindungsregion eingegrenzt. Sie liegt stromaufwärts unmittelbar angrenzend an die CbbR-Bindungsregion und ist durch das symmetrische Sequenzmotiv GTGC-N $10-$ GCAC charakterisiert. DNABindungsstudien und Promotoraktivitätsmessungen mit teilweiser oder vollständig deletierter P1-Bindungsregion deuteten auf eine wichtige modulatorische Funktion dieses Protein bei der Transkriptionsaktivierung von $p_{c b b L}$ hin. Untersuchungen zu der durch P1 induzierten DNAKrümmung innerhalb der Operator/Promotorregion ergaben, daß eine durch CbbR induzierte Krümmung durch zusätzliche Bindung von P1 deutlich abgeschwächt wurde. Diese Funktion von P1 könnte einen wichtigen Mechanismus für eine effiziente Aktivierung der $c b b$-Operone darstellen.

Hinsichtlich einer strukturellen Analyse der $c b b$-Promotoren ergaben ortsspezifische Mutagenesen von $p_{c b b L}$ eine Verifizierung des Promotors als typischen $\sigma^{70}$-abhängigen Promotor, der aber auch nach vollständiger Angleichung an die Consensusstruktur von $E$. coli, trotz stark erhöhter, quasi konstitutiver Aktivität noch der Regulation des $c b b$-Systems unterlag. Frühere Befunde, die auf eine negative Autoregulation des Regulatorgenpromotor $p_{c b b R}$ hingedeutet hatten, konnten nicht bestätigt werden. Die aktuellen Studien zeigten, daß $p_{c b b R}$ nahezu konstitutiv auf sehr niedrigem Niveau aktiv ist.

Mit Hilfe von In vitro-Transkriptionsstudien war Phosphoenolpyruvat (PEP) in vorangegangenen Untersuchungen als negativer Effektor von CbbR und damit als Signalmetabolit des $c b b$-Systems von $R$. eutropha H16 identifiziert worden. Nunmehr durchgeführte DNA-Bindungsstudien und Aktivitätsmessungen von $p_{c b b L}$ in $E$. coli zeigten, daß die durch PEP verursachte Repression der $c b b$-Operone auf einer erhöhten Bindungsaffinität von CbbR an den Operator in Gegenwart des Metaboliten beruhte. Der intrazelluläre PEP-Spiegel wird daher als wichtige Regelgröße aus dem zentralen Kohlenstoffmetabolismus für die Kontrolle des $c b b$-Systems betrachtet. Im Lichte der bisherigen Befunde wäre für eine physiologisch sinnvolle Aktivierung der $c b b$-Operone ein weiterer Signalmetabolit zu fordern, der aus dem Energie- oder Baustoffwechsel stammt und möglicherweise als Effektor von P1 zur Aktivierung der $c b b$-Operone beiträgt. Die essentielle Funktion von CbbR für das System scheint in der eines zentralen Integrators zu liegen, der die verschiedenen zur Aktivierung von $p_{c b b L}$ benötigten Signale umsetzt. 


\section{LITERATURVERZEICHNIS}

Adhya S. (1999). Regulation of gene expression: Operons \& Regulons. In: Lengeler, J.W.; Drews, G.; Schlegel, H.G., Biology of the Prokaryotes, Georg Thieme Verlag, Stuttgart.

Allen C.A., Gay J., Buela S. (1997). A regulatory locus, pehSR controls polygalacturonase production and other virulence functions in $R$. solancacearum. Mol. Plant Microbe Interact. 9, 1054-1064.

Altuvia S., Almiron M., Huisman, G., Kolter R., Storz, G. (1994). The $d p s$ promoter is activated by OxyR during growth and by IHF and sigma $\mathrm{S}$ in stationary phase. Mol. Microbiol. 13, 265-272.

Atlung T., Ingmer H. (1997). H-NS: A modulator of environmentally regulated gene expression. Mol. Microbiol. 24, 7-17.

Ausubel F.M., Brent R., Kingston R.E., Moore D.D., Seidman J.G., Smith J.A., Struhl K. (1988). Current protocols in molecular biology. Greene Publishing Associates and John Wiley \& Sons, New York, NY.

Bassham J.A., Benson A.A., Kay L.D., Harris A.Z., Wilson A.T., Calvin M. (1954). The path of carbon in photosythesis XXI. The cyclic regenaration of carbon dioxide acceptor. J. Am. Chem. Soc. 76, 1760-1770.

Bednarski R. (1992). Über die Genexpression im cfx-Operon von Alcaligenes eutrophus H16. Dissertation, Georg-August-Universität zu Göttingen.

Belitsky B., Sonenshein A. (1997). Altered transcription activation specificity of a mutant form of Bacillus subtilis GltR, a LysR family member. J. Bacteriol. Feb 179, 10351043.

Berlyn M.K.B., Low K.B., Rudd K. E., Singer M. (1996). Linkage map of Eschericia coli K-12, Edition 9. In: Escherichia coli and Salmonella typhimurium: cellular and molecular biology, 2nd edition (Neidhardt F.C., Curtis III R., Ingraham J.L., Lin E.C.C., Low K.B, Magasanik B., Reznikoff W.S., Riley M., Schaechter M., Umbarger H.E.; Hrsg.), S. 1715-1902; ASM Press, Washington, D.C., USA.

Birnboim H.C., Doly J. (1979). A rapid alkaline extraction procedure for screening recombinant plasmid DNA. Nucl. Acids Res. 7, 1513-1523.

Blum H., Beier H., Gross H.J. (1987). Improved silver staining of plant proteins, RNA, and DNA in polycrylamide gels. Electrophoresis 8, 93-99. 
Bömmer D., Schäferjohann J., Bowien B. (1996). Identification of $c b b B_{\mathrm{c}}$ as a additional distal gene of the chromosomal $c b b \mathrm{CO}_{2}$ fixation operon from Ralstonia eutropha. Arch. Microbiol. 166, 245-251.

Botsford J. L., Harman J. G. (1992). Cyclic AMP in prokaryotes. Microbiol. Rev. 56, 10022.

Bowien B. (1989). Molecular biology of carbon dioxide assimilation in aerobic chemolithoautotrophs. In: Autotrophic Bacteria (Schlegel H.G., Bowien B.; Hrsg), S. 437-459; Intercept, Andover.

Bowien B., Bednarski R, Kusian B., Windhövel U., Freter A., Schäferjohann J., Yoo J.-G. (1993). Genetic regulation of $\mathrm{CO}_{2}$ assimilation in chemoautotrophs. In: Microbial growth on $\mathrm{C}_{1}$ compounds (Murrel J.C., Kelly D.P.; Hrsg.), 481-491; Intercept, Andover.

Bowien B., Friedebold J., Kusian B., Bömmer D., Schäferjohann J. (1996). Biochemistry and genetics of organoautotrophy in Alcaligenes eutrophus. In: Microbial growth on $\mathrm{C}_{1}$ compounds (Lidstrom, M.S. and Tabita F.R.; Hrsg.), 102-109; Kluwer Academic Publishers, Dordrecht.

Bowien B., Friedrich B., Friedrich C.G. (1984). Involvement of megaplasmids in heterotrophic derepression of the carbon-dioxide assimilating enzyme system in Alcaligenes spp.. Arch. Microbiol. 139, 305-310.

Bowien B., Schlegel H.G. (1981). Physiology and biochemistry of aerobic hydrogenoxidizing bacteria. Ann. Rev. Microbiol. 35, 405-452.

Bowien B., Windhövel U., Yoo J.-G., Bednarski R., Kusian B. (1990). Genetics of $\mathrm{CO}_{2}$ fixation in the chemoautotroph Alcaligenes eutrophus. FEMS Microbiol. Rev. 87, 445450.

Bradford M. (1976). A rapid and sensitive method for quantitation of microgram quantities of protein utilizing the principle of protein-dye binding. Anal. Biochem. 72, 248-254.

Brumbley S. M., Denny T. P. (1990). Cloning of wild-type Pseudomonas solanacearum $p h c A$, a gene that when mutated alters expression of multiple traits that contribute to virulence. J. Bacteriol. 172, 5677-5685.

Brumbley S. M., Carney B. F., Denny T. P. (1993). Phenotype conversion in Pseudomonas solanacearum due to spontaneous inactivation of PhcA, a putative LysR transcriptional regulator. J. Bacteriol. 175, 5477-87. 
Busby S., Kolb A. (1996). The CAP Modulon. In: Lin, E.C.C. \& Lynch, A.S (Hrsg.), Regulation of gene expression in Escherichia coli, R.G. Landes company \& Chapman \& Hall, Austin,Texas, USA.

Chester N., Marshak D. R. (1993). Dimethyl sulfoxide-mediated primer Tm reduction: a method for analyzing the role of renaturation temperature in the polymerase chain reaction. Anal. Biochem. 209, 284-90.

Clough S.J., Lee K., Schell M.A., Denny T.P. (1997a). A Two Component System in Ralstonia (Pseudomonas) solanacearum Modulates production of $\mathrm{PhcA}$ regulated virulence factors in response to 3 hydroxypalmitic acid methyl ester. J. Bacteriol. Jun 179, 3639-3648.

Clough S. J., Flavier A. B., Schell M. A., Denny, T. P. (1997b). Differential expression of virulence genes and motility in Ralstonia (Pseudomonas) solanacearum during exponential growth. Appl. Environ. Microbiol. 63, 844-850.

Dawson R.M.C., Elliott D.C., Elliott W.H., Jones K. (1986). Data for biochemical research, S. 366-367. Third Edition. Oxford University Press, Oxford.

Delic-Attree I., Toussaint B., Garin, J., Vignais P. (1997). Cloning, sequence and mutagenesis of the structural gene of Pseudomonas aeruginosa $\mathrm{CysB}$, which can activate $\operatorname{alg} D$ transcription. Mol. Microbiol. 24, 1275-1284.

Delorme C., Huisman, T., Reijnders W., Chan Y., Harms N., Stouthamer A., van Spanning R. (1997). Expression of the mau gene cluster of Paracoccus denitrificans is controlled by MauR and a second transcription regulator. Microbiology Uk. Mar 3, 793801.

Don R. H., Cox, P. T., Wainwright B. J., Baker K., Mattick J. S. (1991). 'Touchdown' PCR to circumvent spurious priming during gene amplification. Nucl. Acids Res. 19, 4008 .

Dover N., Higgins C. F., Carmel O., Rimon A., Pinner E., Padan E. (1996). Na+-induced transcription of nhaA, which encodes an $\mathrm{Na}+\mathrm{H}+$ antiporter in Escherichia coli, is positively regulated by NhaR and affected by H-NS. J. Bacteriol. 178, 6508-6517.

Dubbs J. M., Bird T. H., Bauer C. E., Tabita F. R. (2000). Interaction of CbbR and RegA* transcription regulators with the Rhodobacter sphaeroides $c b b_{I}$ Promoter-operator region. J. Biol. Chem. 275, 19224-19230. 
Eisenreich W., Strauss G., Werz U., Fuchs G., Bacher A. (1993). Retrobiosynthetic analysis of carbon fixation in the phototrophic eubacterium Chloroflexus aurantiacus. Eur. J. Biochem. 215, 619-632.

Ellis R.J. (1979). The most abundant protein in the world. Trends Biochem. Sci. 14, 241-244.

Eraso J. M., Kaplan S. (1995). Oxygen-insensitive synthesis of the photosynthetic membranes of Rhodobacter sphaeroides: a mutant histidine kinase. J. Bacteriol. 177, 2695-2706.

Falk G., Walker J. E. (1988). DNA sequence of a gene cluster coding for subunits of the F0 membrane sector of ATP synthase in Rhodospirillum rubrum. Support for modular evolution of the F1 and F0 sectors. Biochem. J. 15, 109-122.

Flavier A., Ganova-Raeva L., Schell M.A., Denny T.P. (1997). Hierarchical autoinduction in Ralstonia solanacearum: Control of acyl-homoserine lactone production by a novel autoregulatory system responsive to 3 hydroxypalmitic acid methyl ester. J. Bacteriol. 179, 7089-7097.

Flavier A., Schell M.A., Denny T.P. (1998). An RpoS (sigma(S)) homologue regulates acylhomoserine lactone-dependent autoinduction in Ralstonia solanacearum. Mol. Microbiol. 28, 475-486.

Friedebold J., Bowien B. (1993). Physiological and biochemical characterization of the soluble formate dehydrogenase, a molybdoenzyme from Alcaligenes eutrophus. J Bacteriol. 175 (15), 4719-4728.

Friedrich B., Hogrefe C., Schlegel H.G. (1981a). Natural occuring genetic transfer of hydrogen-oxidizing ability between strains of Alcaligenes eutrophus. J. Bacteriol. 147, 198-205.

Friedrich B., Schwartz E. (1993). Molecular biology of hydrogen utilization in aerobic chemolithotrophs. Ann. Rev. Microbiol. 47, 351-383.

Friedrich C.G. (1982). Depression of hydrogenase during limitation of electron donors \& derepression of ribulosebisphosphate carboxylase during carbon limitation of Alcaligenes eutrophus. J. Bacteriol. 149, 203-210.

Friedrich C.G., Friedrich B., Bowien B. (1981b). Formation of enzymes of autotrophic metabolism during heterotrophic growth of Alcaligenes eutrophus. J. Gen. Microbiol. 122, 69-78. 
Friedrich C.G., Hogrefe C., Schlegel H.G. (1979). Formate and oxalate metabolism in Alcaligenes eutrophus. J. Gen. Microbiol. 115, 185-192.

Fuchs G. (1989). Alternative pathways of autotrophic $\mathrm{CO}_{2}$ fixation. In: Autotrophic Bacteria (Schlegel H.G., Bowien B.; Hrsg.), S. 365-382; Intercept, Andover.

Fuchs G., Stupperich E., Eden G. (1980). Autotrophic $\mathrm{CO}_{2}$ fixation in Chlorobium limicola. Evidence for the operation of a reductive tricarboxylic acid cycle in growing cells. Arch. Microbiol. 128, 64-71.

Fuqua C., Winans S. C., Greenberg E. P. (1996). Census and consensus in bacterial ecosystems: the LuxR-LuxI family of quorum-sensing transcriptional regulators. Annu. Rev. Microbiol. 50, 727-751.

Garg R. P., Yindeeyoungyeon W., Gilis A., Denny T., van der Lelie D., Schell M. (2000). Evidence that Ralstonia eutropha (Alcaligenes eutrophus) contains a functional homologue of the Ralstonia solanacearum Phc cell density sensing system. Mol. Microbiol. 38, 359-367.

Gay P., Le Coq D., Steinmetz M., Berkelmann T., Kado C.I. (1985). Positive selection procedure for entrapment of insertion sequence elements in Gram-negative bacteria. J. Bacteriol. 164, 918-921.

Gibson J. L., Tabita F. R. (1996). The molecular regulation of the reductive pentose phosphate pathway in proteobacteria and cyanobacteria. Arch. Microbiol. 166, 141-150.

Grzeszik C., Jeffke T., Schäferjohann J., Kusian B., Bowien B. (2000). Phosphoenolpyruvat is a signal metabolite in transcriptional control of the $c b b \mathrm{CO}_{2}$ fixation operons in Ralstonia eutropha. J. Mol. Microbiol. Biotechnol. 2 (3), 311-320.

Hanahan D. (1985). Frozen storage of competent cells, protocol 3. In: DNA cloning: a practical approach Vol. 1 (Glover D.M; Hrsg.), S. 121, IRL Press, Oxford.

Harrison S.C. (1990). A structural taxonomy of DNA-binding domains. Nature 353, 715719.

Harrison S.C., Aggarwal A.K. (1990). DNA recognition by proteins with the helix-turnhelix motif. Ann. Rev. Biochem. 59, 933-936.

Heidmann S., Seifert W., Kessler C., Domdey H. (1989). Cloning, characterization and heterologous expression of the SmaI restriction-modification system. Nucl. Acids Res. 17, 9783-9796. 
Hengge Aronis, R. (1996). Back to log phase: sigma S as a global regulator in the osmotic control of gene expression in Escherichia coli. Mol. Microbiol. 21, 887-893.

Henikoff S., Haughn G.W., Calvo J.M., Wallace C.J. (1988). A large family of bacterial activator proteins. Proc. Natl. Acad. Sci. USA 85, 6602-6606.

Hernandez J., Baker S., Lorbach S., Shively J., Tabita F. (1996). Deduced amino acid sequence, functional expression, and unique enzymatic properties of the form I and form II ribulose bisphosphate carboxylase/oxygenase from the chemoautotrophic bacterium Thiobacillus denitrificans. J. Bacteriol. 178, 347-356.

Holmes D.S., Quigley M. (1981). A rapid boiling method for the preparation of bacterial plasmids. Anal. Biochem. 114, 193-197.

Holo M. (1989). Chloroflexus aurantiacus secretes 3-hydroxy-propionate, a possible intermediate in the assimilation of $\mathrm{CO}_{2}$ and acetate. Arch. Microbiol. 151, 252-256.

Hryniewicz M. M., Kredich N. M. (1991). The cysP promoter of Salmonella typhimurium: characterization of two binding sites for CysB protein, studies of in vivo transcription initiation, and demonstration of the anti-inducer effects of thiosulfate. J. Bacteriol. 173, 5876-5886.

Huang J., Carney B. F., Denny T. P., Weissinger A. K., Schell M. A. (1995). A complex network regulates expression of eps and other virulence genes of Pseudomonas solanacearum. J. Bacteriol. 177, 1259-1267.

Huang, J., Denny T. P., Schell M. A. (1993). VsrB, a regulator of virulence genes of Pseudomonas solanacearum, is homologous to sensors of the two-component regulator family. J. Bacteriol. 175, 6169-6178.

Huang J., Yindeeyoungyeon W., Garg R. P., Denny T. P., Schell M. A. (1998). Joint transcriptional control of $x p s R$, the unusual signal integrator of the Ralstonia solanacearum virulence gene regulatory network, by a response regulator and a LysRtype transcriptional activator. J. Bacteriol. 180, 2736-2743.

Im D.S., Friedrich C.G. (1983). Fluoride, hydrogen, and formate activate ribulosebisphosphate carboxylase formation in Alcaligenes eutrophus. J. Bacteriol. 154, 803808.

Jeffke T., Gropp N. H., Kaiser C., Grzeszik C., Kusian B., Bowien B. (1999). Mutational analysis of the $c b b$ operon $\left(\mathrm{CO}_{2}\right.$ assimilation) promoter of Ralstonia eutropha. J. Bacteriol. 181, 4374-4380. 
Kolter R., Siegele D. A., Tormo A. (1993). The stationary phase of the bacterial life cycle. Annu. Rev. Microbiol. 47, 855-874.

Kossman J., Klintworth R., Bowien B. (1989). Sequence analysis of the chromosomal and plasmid genes encoding phosphoribulokinase from Alcaligenes eutrophus. Gene 85, 247-252.

\section{Kovach M.E., Elzer P.H., Hill D.S., Robertson G.T., Farris M.A., Roop R.M.,}

Peterson K.M. (1995) Four new broad-host-range cloning vector pBBR1MCS, carrying different antibioticresistance cassettes. Gene. 166, 175-176.

Kusano T., Sugawara K. (1993). Specific binding of Thiobacillus ferrooxidans RbcR to the intergenic sequence between the $r b c$ operon and the $r b c R$ gene. J. Bacteriol. 175, 10191025 .

Kusian B. (1994). $\mathrm{CO}_{2}$-Assimilation in Alcaligenes eutrophus: Genetische Charakterisierung der $c b b$-Kontrollregion. Dissertation, Georg-August-Universität zu Göttingen.

Kusian B., Yoo J.-G., Bednarski R., Bowien B. (1992). The Calvin cycle enzyme pentose5-phosphate 3-epimerase is encoded within the $c f x$ operons of the chemoautotroph Alcaligenes eutrophus. J. Bacteriol. 174, 7337-7344.

Kusian B., Bowien B. (1995). Operator binding of the CbbR protein, which activates the duplicate $c b b \mathrm{CO}_{2}$ assimilation operons of Alcaligenes eutrophus. J. Bacteriol. 177, 6568-6574.

Kusian B., Bowien B. (1997). Organization and regulation of $c b b \mathrm{CO}_{2}$ assimilation genes in autotrophic bacteria. FEMS Microbiol. Rev. 21, 135-155.

Laemmli U.K. (1970). Cleavage of structural proteins during the assembly of the head of bacteriophage T4. Nature 227, 680-685.

Lane D., Prentki P., Chandler M. (1993). Use of gel retardation to analyze protein-nucleic acid interactions. Microbiol. Rev. 56, 509-528.

Lee N., Francklyn C., Hamilton E. P. (1987). Arabinose-induced binding of AraC protein to araI2 activates the $\operatorname{araBAD}$ operon promoter. Proc. Natl. Acad. Sci. U S A 84, 88148828 .

Lenz O., Schwartz E., Dernedde J., Eitinger M., Friedrich B. (1994). The Alcaligenes eutrophus H16 hoxX gene participates in hydrogenase regulation. J. Bacteriol. 176, 4385-4393. 
Lobell R. B., Schleif R. F. (1991). AraC-DNA looping: orientation and distance-dependent loop breaking by the cyclic AMP receptor protein. J. Mol. Biol. 218, 45-54.

Loewen P. C., Hengge Aronis R. (1994). The role of the sigma factor sigma S (KatF) in bacterial global regulation. Annu. Rev. Microbiol. 48, 53-80.

Lottspeich F., Sorbas S. (1998). Bioanalytik. Spektrum akademischer Verlag, Heidelberg.

Lowry O. H., Carter J., Ward J. B., Glaser L. (1971). The effect of carbon and nitrogen sources on the level of metabolic intermediates in Escherichia coli. J. Biol. Chem. 246, 6511-6521.

Marshall D. G., Sheehan B. J., Dorman C. J. (1999). A role for the leucine-responsive regulatory protein and integration host factor in the regulation of the Salmonella plasmid virulence (spv) locus in Salmonella typhimurium. Mol. Microbiol. 34, 134-145.

McFall S., Abraham B., Narsolis C., Chakrabarty A. (1997). A tricarboxylic acid cycle intermediate regulating transcription of a chloroaromatic biodegradative pathway: fumarate mediated repression of the $c l c A B D$ Operon. J. Bacteriol. Nov 179, 6729-6735.

Miller J.H. (1972). Assay of $\beta$-galactosidase. In: Experiments in molecular genetics (Platt T., Miller-Hill B., Miller J.H.; Hrsg.), S. 319-353; Cold Spring Harbor Laboratory, Cold Spring Harbor, NY, USA.

Mukherjee A., Cui Y., Ma W., Liu Y., Chatterjee A. (2000). HexA of Erwinia carotovora ssp carotovora strain Ecc71 negatively regulates production of RpoS and $r s m B$ RNA, a global regulator of extracellular proteins, plant virulence and the quorum-sensing signal, N-(3-oxohexanoyl)-L-homoserine lactone. Environment. Microbiol. 2, 203-215.

Mullis K. B., Faloona F. A. (1987). Specific synthesis of DNA in vitro via a polymerasecatalyzed chain reaction. Methods Enzymol. 155, 335-50.

Paoli G., Soyer F., Shively J., Tabita F. (1998a). Rhodobacter capsulatus genes encoding form I ribulose-1,5-bisphosphate carboxylase/oxygenase ( $c b b L S)$ and neighbouring genes were acquired by a horizontal gene transfer. Microbiology Uk. 1, 219-227.

Paoli G., Vichivanives P., Tabita F. (1998b). Physiological control and regulation of the Rhodobacter capsulatus cbb operons. J. Bacteriol. 180, 4258-4269.

Perez-Martin J., de Lorenzo V. (1997). Clues and consequences of DNA bending in transcription. Annu. Rev. Microbiol. 51, 593-628. 
Perez-Martin J., Rojo F., de Lorenzo V. (1994). Promoters responsive to DNA bending: a common theme in prokaryotic gene expression. Microbiol. Rev. 58, 268-90.

Pfennig N., Trüper H.G. (1981). Isolation of members of the families Chromatiaceae and Chlorobiaceae. In: The Prokaryotes (M.P. Starr, H.G. Trüper, A. Bellows, H.G. Schlegel; Hrsg.), S. 279-289; Springer Verlag, Berlin.

Postma P. W., Lengeler J. W., Jacobson G. R. (1993). Phosphoenolpyruvate:carbohydrate phosphotransferase systems of bacteria. Microbiol. Rev. 57, 543-594.

Puskas A., Greenberg E. P., Kaplan S., Schaefer A. L. (1997). A quorum-sensing system in the free-living photosynthetic bacterium Rhodobacter sphaeroides. J. Bacteriol. 179, 7530-7537.

Quandt J., Hynes M.F. (1993). Versatile suicide vectors which allow direct selection for gene replacement in Gram-negative bacteria. Gene 127, 15-21.

Renault P., Gaillardin C., Heslot H. (1989). Product of the Lactococcus lactis gene required for malolactic fermentation is homologous to a family of positive regulators. $\mathrm{J}$. Bacteriol. 171, 3108-3114.

Renna M. C., Najimudin N., Winik L. R., Zahler S. A. (1993). Regulation of the Bacillus subtilis als $S$, alsD, and alsR genes involved in post-exponential-phase production of acetoin. J. Bacteriol. 175, 3863-3875.

Rhee K., Opel M., Ito E., Hung S., Arfin S., Hatfield G. (1999). Transcriptional coupling between the divergent promoters of a prototypic LysR-type regulatory system, the ilvYC operon of Escherichia coli. Proc. Natl. Acad. Sci. 96, 14294-14299.

Riggs M.G., McLachlan A. (1986). A simplified screening procedure for large numbers of plasmid mini-preparation. Bio Techniques 4, 310-311.

Salmond G. P., Bycroft B. W., Stewart G. S., Williams P. (1995). The bacterial 'enigma': cracking the code of cell-cell communication. Mol. .Microbiol. 16, 615-624.

Sambrook J., Fritsch E.F., Maniatis T. (1989). Molecular cloning: a laboratory manual.

Sanger F., Coulsen A.R., Hong G.F., Hill D.F., Petersen G.B. (1982). Nucleotide sequence of bacteriophage $\lambda$ DNA. J. Mol. Biol. 162, 729-773.

Sanger F., Micklen S., Coulson A.R. (1977). DNA sequencing with chain-terminating inhibitors. Proc. Natl Acad. Sci.USA 74, 5463-5467. 
Schäferjohann J. (1996). Autotrophie in Alcaligenes eutrophus: Zur Funktion und Regulation von $c b b$-Genen. Dissertation, Georg-August-Universität zu Göttingen.

Schäferjohann J., Yoo J.-G., Kusian B., Bowien B. (1993). The $c b b$ operons of the facultative chemoautotroph Alcaligenes eutrophus encode phosphoglycolate phosphatase. J. Bacteriol. 175, 7329-7340.

Schäferjohann J., Bednarski R., Bowien B. (1996). Regulation of $\mathrm{CO}_{2}$ assimilation in Alcaligenes eutrophus: premature transcription termination within the $c b b$ operon. J. Bacteriol. 178 (23), 6714-6719.

Schell M. A. (1993). Molecular biology of the LysR family of transcriptional regulators. Annu. Rev. Microbiol. 47, 597-626.

Schink B., Schlegel H.G. (1978). Mutants of Alcaligenes eutrophus defective in autotrophic metabolism. Arch. Microbiol. 117, 123-129.

Schlegel H.G., Kaltwasser H., Gottschalk G. (1961). Ein Submersverfahren zur Kultur wasserstoffoxidierender Bakterien: Wachstumsphysiologische Untersuchungen. Arch. Microbiol. 38, 209-222.

Schneider K., Schlegel H.G. (1976). Purification and properties of soluble hydrogenase from Alcaligenes eutrophus. Biochim. Biophys. Acta 452, 66-80.

Shively J. M., van Keulen G., Meijer W. G. (1998). Something from almost nothing: carbon dioxide fixation in chemoautotrophs. Annu. Rev. Microbiol. 52, 191-230

Siegele D. A., Kolter R. (1992). Life after log. J. Bacteriol. 174, 345-368.

Stackebrandt E., Murray R.G.E., Trüper H.G. (1988). Proteobacteria classis nov., a name for the phylogenetic taxon that includes the "purple bacteria and their relatives". Int. J. Syst. Bacteriol. 38, 321-325.

Strauss G., Fuchs G. (1993). Enzymes of a novel autotrophic $\mathrm{CO}_{2}$ fixation pathway in the phototrophic bacterium Chloroflexus aurantiacus, the 3-hydroxypropionate cycle. Eur. J. Biochem. 215 , 633-643.

Swift S., Throup J. P., Williams P., Salmond G. P., Stewart, G. S. (1996). Quorum sensing: a population-density component in the determination of bacterial phenotype. Trends Biochem. Sci. 21, 214-219.

Tiwari R. P., Reeve W. G., Dilworth M. J., Glenn A. R. (1996). An essential role for actA in acid tolerance of Rhizobium meliloti. Microbiology 142, 601-610. 
Towbin H., Staehelin T., Gordan J. (1979). Elektrophoretic transfer of proteins from polyarcylamide gels to nitrocellulose sheets: procedure and some application. Proc. Natl Acad. Sci. USA 76, 4350-4354.

Ussery D. W., Hinton J. C. D., Jordi B. J. A. M., Granum P. E., Seirafi A., Stephen R. J., Tupper A. E., Berridge G., Sidebotham J. M., Higgins C. H. (1994). The chromatinassociated protein H-NS. Biochimie 76, 968-980.

van Keulen G., Girbal L., van den Bergh E. R., Dijkhuizen L., Meijer W. G. (1998). The LysR-type transcriptional regulator $\mathrm{CbbR}$ controlling autotrophic $\mathrm{CO}_{2}$ fixation by Xanthobacter flavus is an NADPH sensor. J. Bacteriol. 180, 1411-1417.

van Spanning R.J.M., Wansell C.W., Reijnders W.N., Harms N., Ras J., Oltman F., Stouthamer A.H. (1991). A method for introduction of unmarked mutations in the genome of Paracoccus denitrificans: Construction of strains with multiple mutations in the genes encoding periplasmic cytochromes $c_{550}, c_{551}, c_{553}$. J. Bacteriol. 173, 6962-6970.

Vichivanives P., Bird T. H., Bauer C. E., Tabita, F. (2000). Multiple regulators and their interactions in vivo and in vitro with the $c b b$ regulons of Rhodobacter capsulatus. J. Mol. Biol. 300, 1079-1099.

Vieira J., Messing J. (1982). The pUC plasmids, an M13mp7-derived system for insertion mutagenesis and sequencing with synthetic universal primers. Gene 19, 259-268.

Wang L., Helmann J. D., Winans S. C. (1992). The A. tumefaciens transcriptional activator OccR causes a bend at a target promoter, which is partially relaxed by a plant tumor metabolite. Cell 69, 659-667.

Weber K., Osborn N. (1969). The reliability of the molecular weight determination by dodecylsulfate-polyacrylamide gel electrophoresis. J. Biol. Chem. 244, 4006-4012.

Windhövel U., Bowien B. (1990a). Cloning and expression of chromosomally and plasmidencoded glyceraldehyde-3-phosphate dehydrogenase genes from the chemoautotroph Alcaligenes eutrophus. FEMS Microbiol. Lett. 66, 29-34

Windhövel U., Bowien B. (1990b). On the operon structure of the $c f x$ gene clusters in Alcaligenes eutrophus. Arch. Microbiol. 154, 85-91.

Windhövel U., Bowien B. (1991). Identification of $c f x R$, an activator gene of autotrophic $\mathrm{CO}_{2}$ fixation in Alcaligenes eutrophus. Mol. Microbiol. 5, 2695-2705. 
Wood H.G., Ragsdale S.W., Pezacka E. (1986). The acetyl-CoA pathway: a newly discovered pathway for autotrophic growth. Trends Biochem. Sci. 11, 14-18.

Yabuuchi E., Kosako Y., Yano I., Hotta H., Nishiuchi Y. (1995). Transfer of two Burkholderia and an Alcaligenes species to Ralstonia gen. Nov.: Proposal of Ralstonia pickettii (Ralston, Palleroni and Doudoroff 1973) comb. Nov., Ralstonia solanacearum (Smith 1896) comb. Nov. and Ralstonia eutropha (Davis 1969) comb. Nov. Microbiol. Immunol. 39, 897-904.

Yanisch-Perron C., Vieira J., Messing J. (1985). Improved M13 phage cloning vectors and host strains: nucleotide sequences of M13mp18 and pUC19 vectors. Gene 33, 103-119.

Yoo J.-G. (1993). Struktur und Funktionsanalyse von Genen der $c b b$-Operone von Alcaligenes eutrophus. Dissertation, Georg-August-Universität zu Göttingen.

Zwieb C., Adhya S. (1994). Improved plasmid vectors for the analysis of protein-induced DNA bending. Methods Mol. Biol. 30, 281-294. 


\section{Danksagungen}

Mein besonderer Dank gilt Herrn Prof. Dr. B. Bowien für die Überlassung des Themas, sein großes Interesse am Fortgang dieser Arbeit und die mir stets gewährte Unterstützung. Ebenfalls bedanken möchte ich mich für die zahlreichen anregenden Diskussionen, die wesentlich zum Gelingen dieser Arbeit beigetragen haben und für das sorgfältige Korrekturlesen des Manuskripts.

Herrn Dr. Bernhard Kusian möchte ich vielmals für die grundlegenden Vorarbeiten zur Thematik, seiner steten Hilfsbereitschaft in jedweder Situation und für die vielen fruchtbaren Diskussionen und Anregungen danken.

Für die intensive Einführung in die Wunderwelt der Molekularbiologie danke ich Frau Dr. Claudia Grzeszik herzlich.

Den ehemaligen und jetzigen Mitarbeitern der Labore 45 und 51 Tanja Burgdorf, Plamena Encheva, Niels-Holger Gropp, Lubo Grozdanov, Semin Kheradmand, Daniela Oed, Gertrud Stahlhut, Mladen Tzvetkov, Franz von Götz, Tanja Wendt und Silke Wahlburg danke ich für die immer gute Zusammenarbeit, das angenehme Arbeitsklima und vor allem für die spaßigen außeruniversitären Unternehmungen.

Vielmals danken möchte ich Herrn Prof. Dr. K. Weber und Herrn U. Plessmann für die Ansequenzierung des P1-Proteins.

Den Mitarbeitern der Werkstatt Charlie Bertram, Gerd Birke und Jürgen Steckel danke ich für die immer gewährte und meist umgehend erfolgte Unterstützung bei allen technischen Problemen.

Bei Herrn Hellwig und Frau Hick möchte ich mich für die freundliche und stete Hilfsbereitschaft bei allen Be- und Entsorgungen bedanken.

Besonders möchte ich mich auch nochmal für die Unterstützung aus der Arbeitsgruppe von Prof. Dr. Liebl bedanken.

Allen weiteren Institutsangehörigen danke ich ebenfalls für die immer vorhandene Hilfsbereitschaft und das gute Arbeitsklima im Haus. 
Ein ganz großes Dankeschön geht an meine Freundin Elke, die mich sowohl fachlich durch kritisches Korrekturlesen dieses Manuskripts als auch mental mit viel Liebe und Geduld sehr unterstützt hat.

Schließlich möchte ich meiner Mutter noch vielmals für ihre immerwährende Unterstützung während meines gesamten Studiums und der Promotionszeit danken, ohne die diese Arbeit nicht zustande gekommen wäre. 


\section{LEBENSLAUF}

Name:

Geburtsdatum:

Geburtsort:

\section{Schulausbildung:}

1973-1977

1977-1979

1979-1983

1983-1987

1987

\section{Wehrdienst:}

Oktober 1987 - Oktober 1988

\section{Wissenschaftlicher Werdegang:}

Oktober 1988 - September 1991

Oktober 1991 - Juni 1996

August 1994 - Dezember1995

Mai 1995 - April 1996

03.06 .96

Januar 1997
Thomas Jeffke

15.02 .67

Bremen

Grundschule in Bremen

Orientierungsstufe: Landskronastraße, Bremen

Gerhard-Rohlfs-Gymnasium, Bremen

Gymnasiale Oberstufe: Alwin-Lonke-Schulzentrum, Bremen

Abitur

Grundwehrdienst in Schwanewede, Niedersachsen

Immatrikulation an der Universität Bremen für das Fach Biologie (Diplom)

Vordiplom in Biologie

Immatrikulation an der Carl-von-Ossietzky Universität zu Oldenburg

Wissenschaftliche Hilfskraft:

Institut für Phytopathologie, Abt. Biotechnologie, Christian-Albrechts-Universität zu Kiel:

Isolierung, Screening und Fermentation von mit Nematoden in Symbiose lebenden Bakterienstämmen

Experimentelle Diplomarbeit unter Anleitung von Dr. R.U. Ehlers am Institut für Phytopathologie, Abt. Biotechnologie, Christian-Albrechts-Universität zu Kiel mit dem Titel: Untersuchungen zum Einfluß einer semikontinuierlichen Zufütterung auf Wachstum und Entwicklung des Antagonisten-Komplexes Photorhabdus luminescens (Enterobacteriaceae) und Heterorhabditis bacteriophora (Nematoda) im Bioreaktorprozeß

Diplom in Biologie

Beginn der experimentellen Arbeiten zur vorliegenden Dissertation 